\title{
WestVirginiaUniversity
}

THE RESEARCH REPOSITORY @ WVU

Graduate Theses, Dissertations, and Problem Reports

2007

\section{Analysis of a 2007 EPA compliant diesel particulate matter sampling system}

Robin W. Ames

West Virginia University

Follow this and additional works at: https://researchrepository.wvu.edu/etd

\section{Recommended Citation}

Ames, Robin W., "Analysis of a 2007 EPA compliant diesel particulate matter sampling system" (2007). Graduate Theses, Dissertations, and Problem Reports. 4287.

https://researchrepository.wvu.edu/etd/4287

This Thesis is protected by copyright and/or related rights. It has been brought to you by the The Research Repository @ WVU with permission from the rights-holder(s). You are free to use this Thesis in any way that is permitted by the copyright and related rights legislation that applies to your use. For other uses you must obtain permission from the rights-holder(s) directly, unless additional rights are indicated by a Creative Commons license in the record and/ or on the work itself. This Thesis has been accepted for inclusion in WVU Graduate Theses, Dissertations, and Problem Reports collection by an authorized administrator of The Research Repository @ WVU. For more information, please contact researchrepository@mail.wvu.edu. 
Analysis of a 2007 EPA Compliant Diesel Particulate Matter Sampling System

\author{
Robin W. Ames
}

Thesis Submitted to the

College of Engineering and Mineral Resources

at West Virginia University

in partial fulfillment of the requirements

for the degree of

\author{
Master of Science \\ in \\ Mechanical Engineering \\ Mridul Gautam, Ph.D., Chair \\ Benjamin C. Shade, Ph.D. \\ Mohan Krishnamurthy, Ph.D.
}

Department of Mechanical and Aerospace Engineering

Morgantown, West Virginia

2007

Keywords: Particulate Matter, Filter Face Velocity, Dilution Ratio, Filter Media 


\begin{abstract}
Analysis of a 2007 EPA Compliant Diesel Particulate Matter Sampling System
\end{abstract}

\title{
Robin W. Ames
}

A study was conducted for the West Virginia University (WVU) particulate matter (PM) sampling system designed to comply with the updated 2007 Code of Federal Regulations (CFR) Title $40 \mathrm{Pt} 86$ Subpart N, issued by the United States (US) Environmental Protection Agency (EPA) which includes a new set of requirements regarding the PM emissions from heavy duty diesel engines (HDDEs). The 2007 compliant PM system was installed within WVU's Engine and Emissions Research Laboratory (EERL) and an analysis was performed to determine which operating system conditions produced the most repeatable system results. The data from the 2007 PM system were compared with the pre-2007 PM system to provide a system comparison.

The three test conditions, secondary dilution ratio (SDR), filter face velocity (FFV), and filter media, had a major effect on the resulting PM deposition. Both PM systems showed similar trends across tests with like testing conditions. It was determined that the 2007 CFR compliant PM system was capable of producing repeatable results with a common coefficient of variation $(\mathrm{CV})$ of less then $2 \%$, across a range of moderate SDRs, FFVs, and certain filter medias. Both Teflo and Tx40 filters produced efficient and repeatable results and are recommended with SDRs of 1/1 to 2/1 with FFVs between 1.0 and $1.5 \mathrm{cfm}$ for future work with the WVU 2007 compliant PM collection system. 


\section{Acknowledgments}

I would first like to thank Dr. Mridul Gautam for giving me the opportunity to receive a graduate education. You have allowed me to work on numerous projects, allowing me to gain valuable experience for my future. Not only were you my advisor, but also a good friend.

The other members of my committee, Dr. Ben Shade and Dr. Mohan Krishnamurthy, also deserve my gratitude. Without their good natured criticism, completing the editing of this thesis would have felt more like a chore. I consider you both my friends and appreciate everything you've done for me.

The rest of WVU's faculty and staff, especially those at the Westover and ERC labs have always been there to provided guidance and direction. Dan Carder has also provided constant support. No matter how busy he actually may be he makes himself available to answer calls.

All of my fellow graduate students and friends have been a pleasure to work with. Josh, Tom, Petr, Victor, Michelangelo, Raffaello, and everyone else, I'll miss you all. Always remember what we learned in Bluefield, Big Bubbles - No Troubles.

My family has been the best possible influence on my life. My parents have instilled the values of hard work and the drive with which to pursue educational goals. You have supported every move I've made and I thank you for it. Emily and Morgan, thanks for always being there to talk to or even just watch movies with.

Karrah, you have always been there for me. Spending my time with you has been not only a great time, but also a good influence. You have always helped me deal with any stressful situations and tend to overlook my fallbacks. You make me a better person, thank you.

I've mentioned a number of the most important influences in my life, and I'm sure that I've overlooked plenty. To all of you, thanks as well. 


\section{Table of Contents}

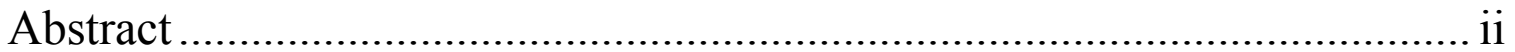

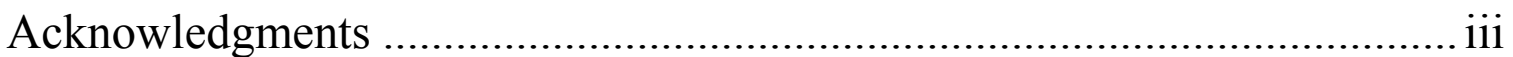

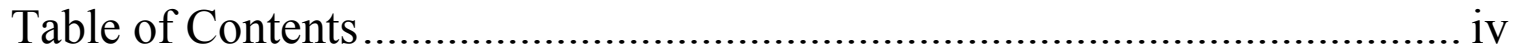

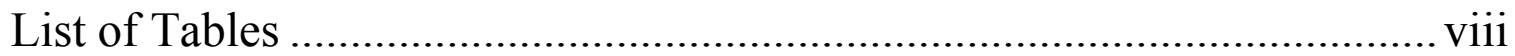

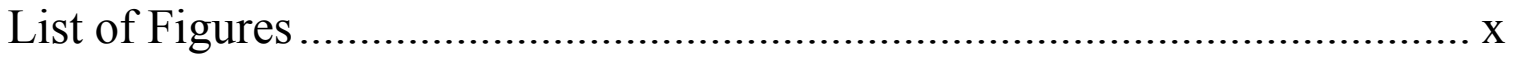

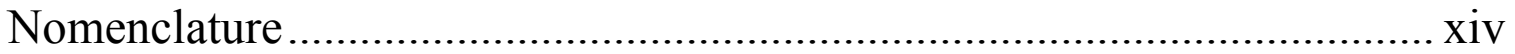

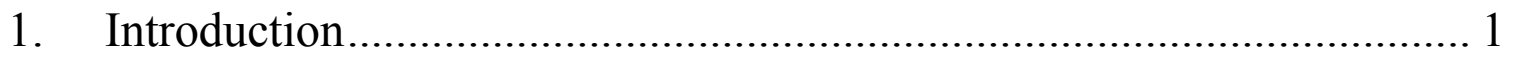

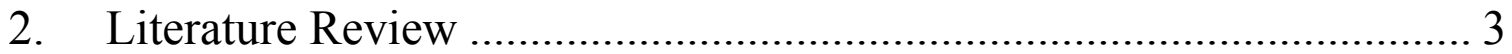

2.1 What is Particulate Matter? .................................................................. 3

2.1.1 Why is Particulate Matter Important? .......................................... 4

2.1.1.1 Environmental Effects ..................................................... 4

2.1.1.2 Health Effects .................................................................... 5

2.1.2 Particulate Matter Constituents ................................................ 6

2.1.2.1 Solid Particulates ................................................................. 7

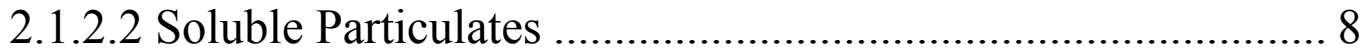

2.1.2.3 Particulate Formation and Morphology................................. 9

2.2 How is Particulate Matter Measured? ............................................... 11

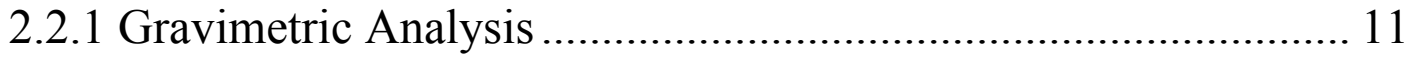

2.2.2 Real Time Particulate Measurement.......................................... 11

2.2.2.1 Mobility PM Sizing ............................................................ 12

2.2.2.1.1 Scanning Mobility Particle Sizer with Condensation

Particle Counter ............................................................................... 12

2.2.2.1.2 Scanning Electrical Mobility Spectrometer................... 14

2.2.2.1.3 Differential Mobility Particle Sizer ............................... 14

2.2.2.2 Non-gravimetric PM Mass Estimations .............................. 15

2.2.2.2.1 Tapered Element Oscillating Microbalance .................. 15

2.2.2.2.2 Quartz Crystal Microbalance....................................... 15

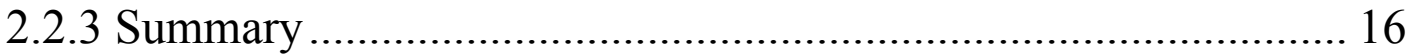

2.3 Particulate Matter Legislation....................................................... 17

2.3.1 History of EPA Heavy Duty Engine PM Emissions Standards .. 17

2.3.2 PM Size Regulations................................................................. 19

2.3.3 2007 Legislation Modifications ................................................... 20

2.3.3.1 Dilution Tunnel Specifications ............................................ 20

2.3.3.2 Filter Collection Specifications ............................................ 21

2.3.3.3 Filter Weighing Techniques and Clean Room Specifications

2.4 Previous 2007 PM Studies........................................................ 22 
2.4.1 Southwest Research Institute - Imad A Khalek, Ph.D............... 22

2.4.2 University of Minnesota - David B. Kittelson, Ph.D................. 24

2.4.3 Ford Motor Company - Matti Maricq, Ph.D.............................. 25

2.4.4 Cummins Inc. - Shirish A. Shimpi, Ph.D.................................. 26

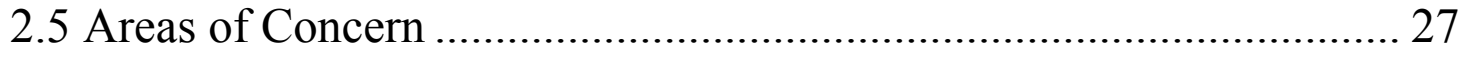

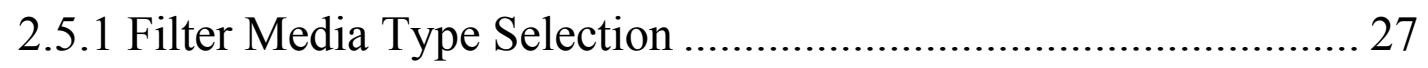

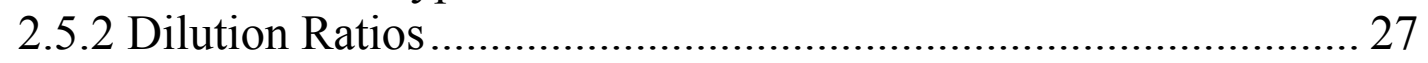

2.5.3 Filter Face Velocities ............................................................... 27

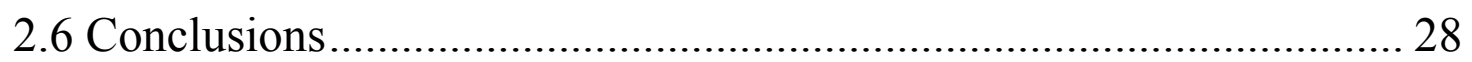

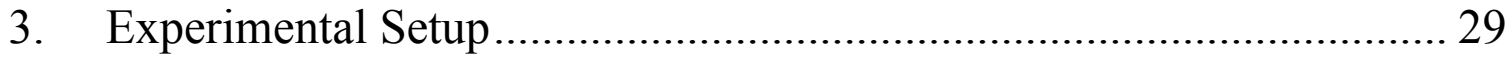

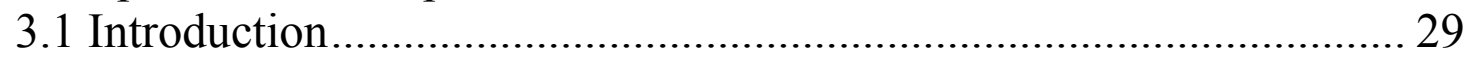

3.2 WVU 2007 EPA Compliant PM System........................................ 29

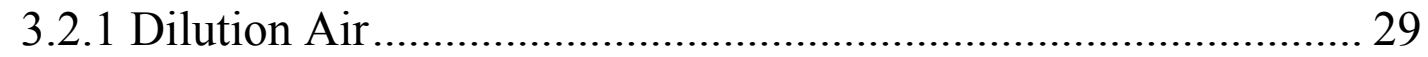

3.2.2 Dilution Tunnel........................................................................... 30

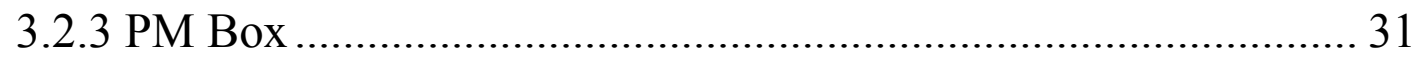

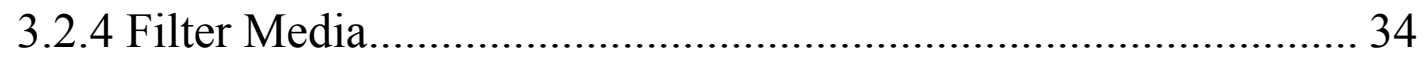

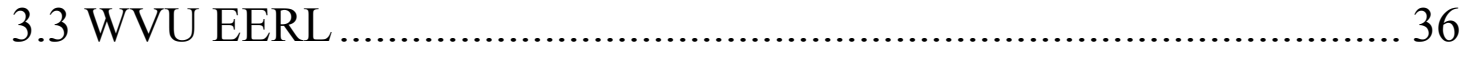

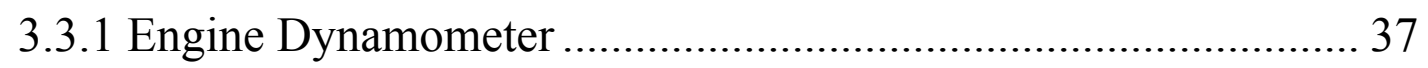

3.3.2 Full Flow Primary Exhaust Dilution Tunnel .............................. 38

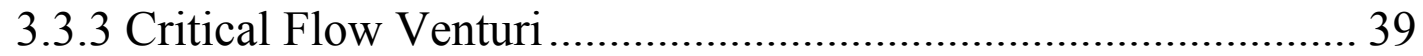

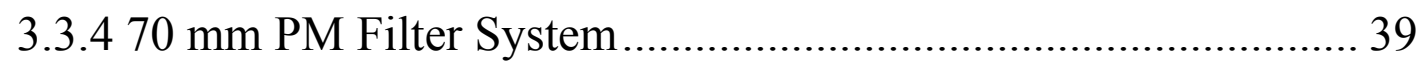

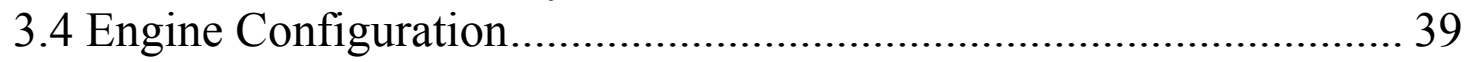

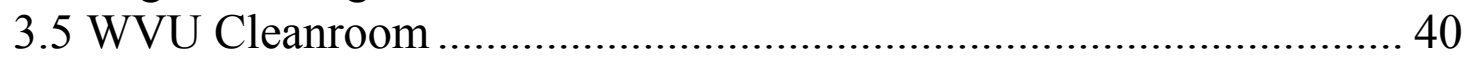

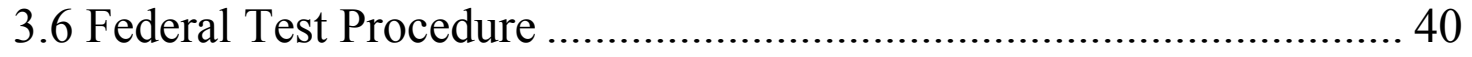

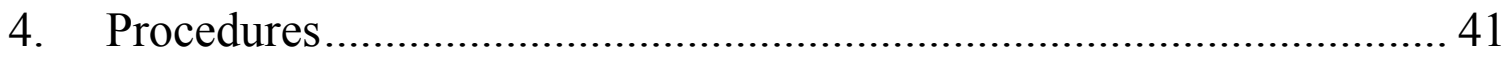

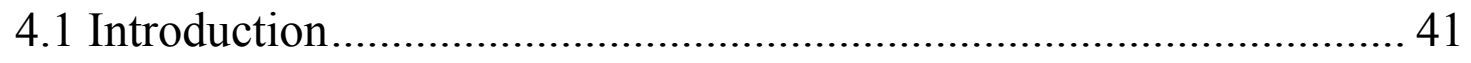

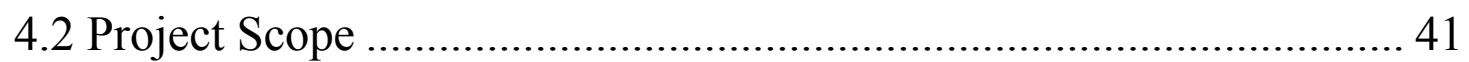

4.3 Post Test Filter Maintenance …........................................................ 43

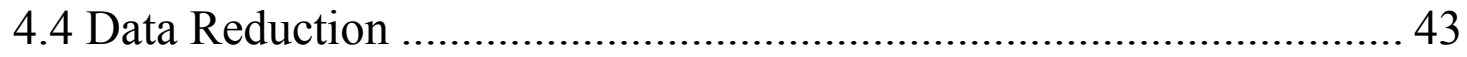

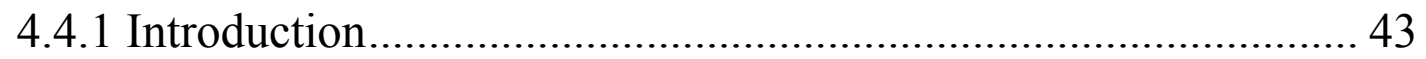

4.4.2 System Flow and PM Mass Calculations .................................. 44

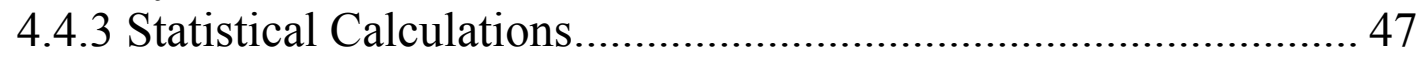

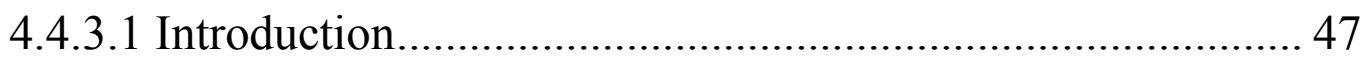

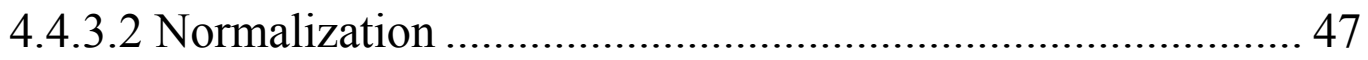

4.4.3.3 Difference from Mean ....................................................... 47

4.4.3.4 Coefficient of Variation ....................................................... 48

4.4.3.4 Percent Difference .............................................................. 48

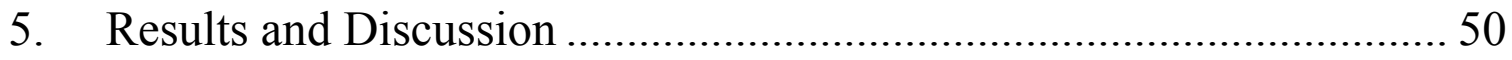

5.1 Averaged Mass of PM Deposition...................................................... 50

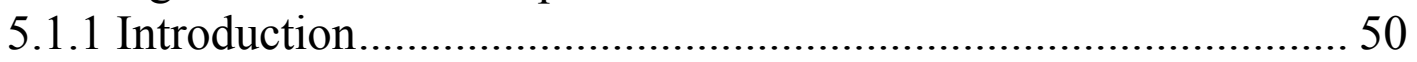




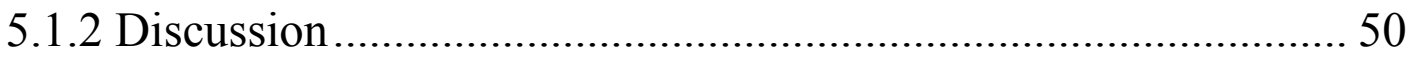

5.1.2.1 1992 Detroit Diesel Corporation S60 …........................... 50

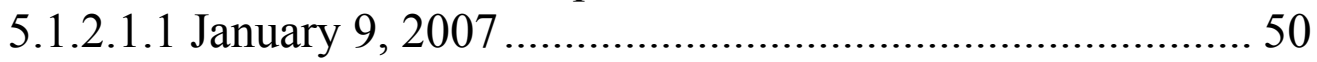

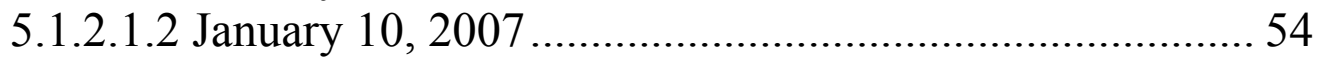

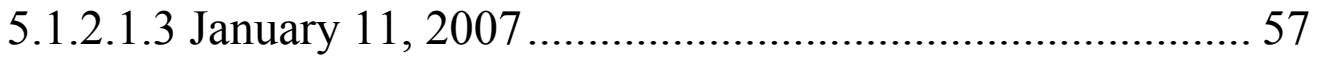

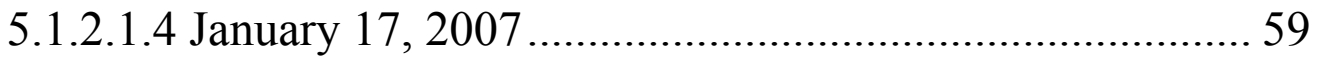

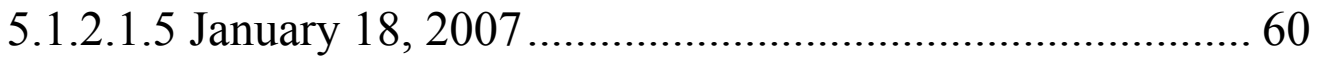

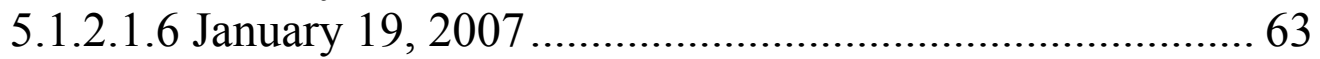

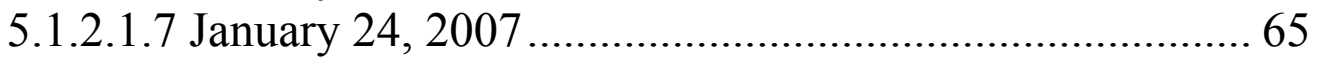

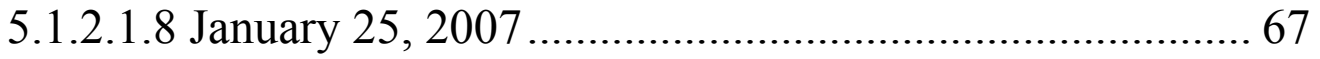

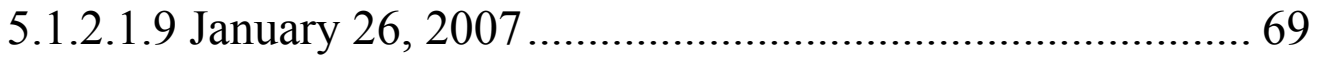

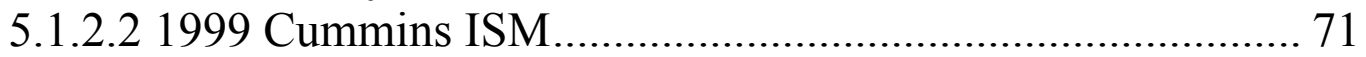

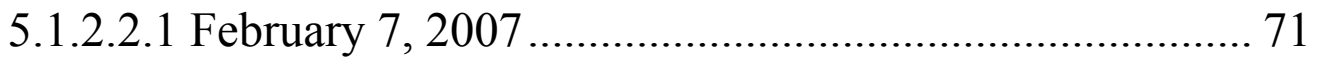

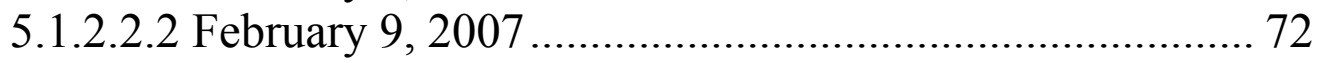

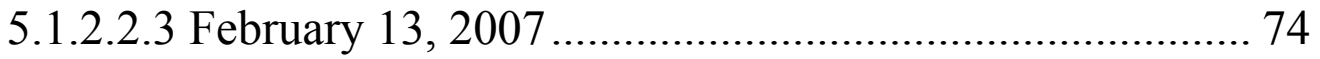

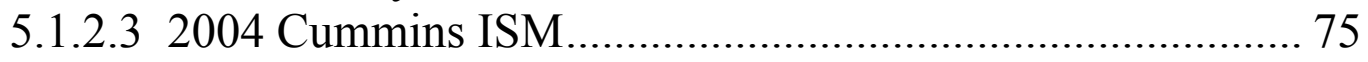

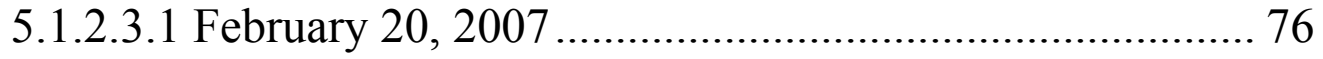

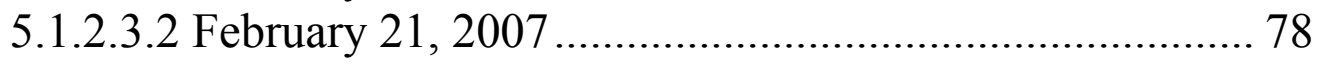

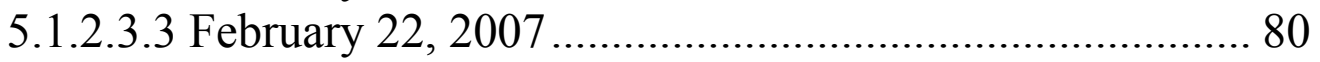

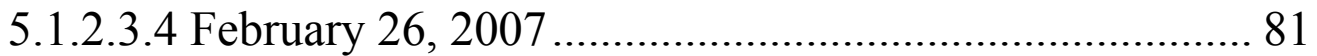

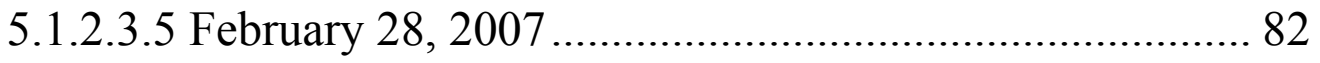

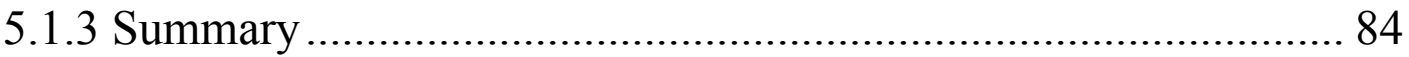

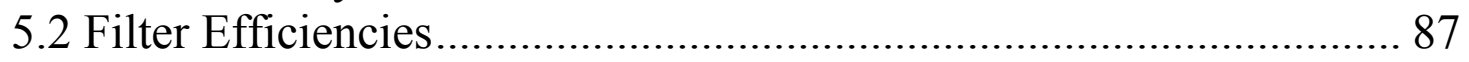

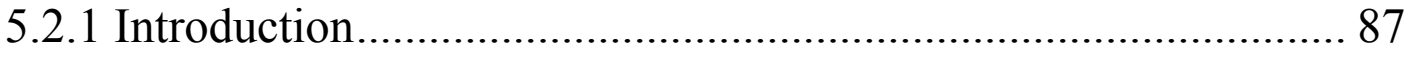

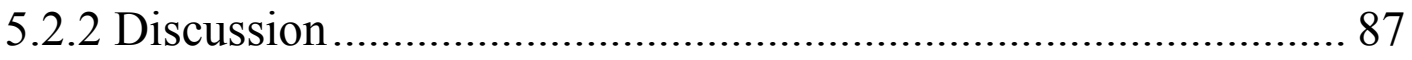

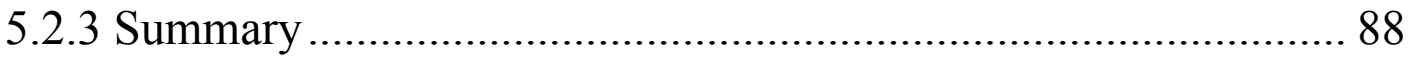

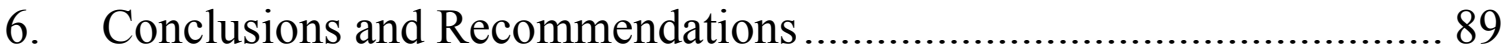

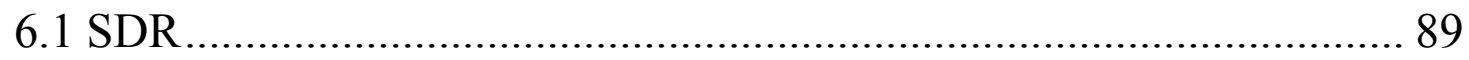

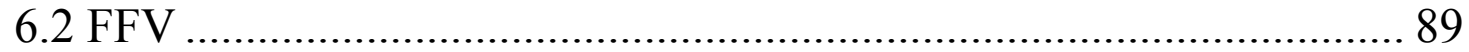

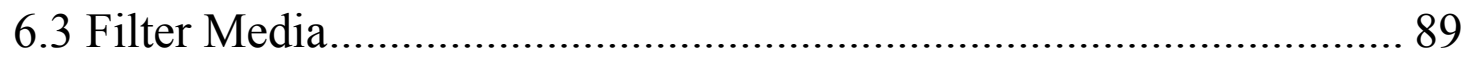

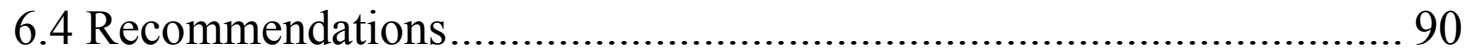

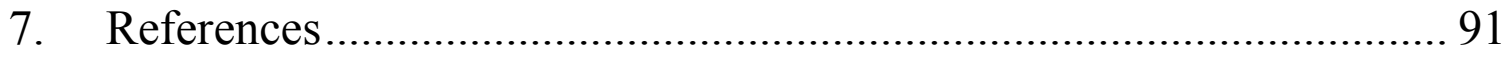

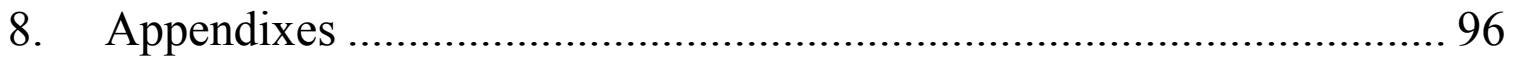

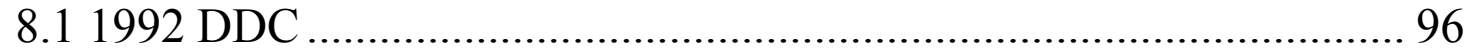

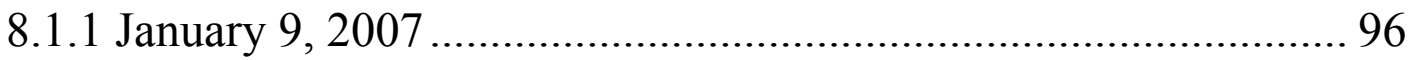

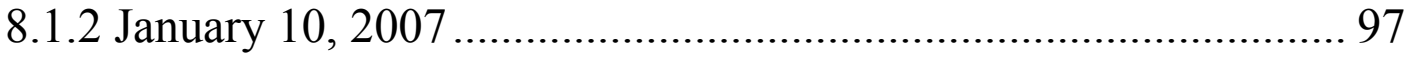

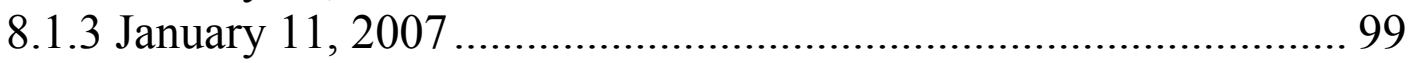

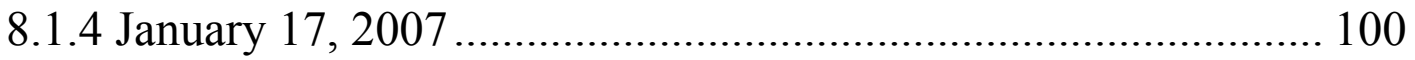

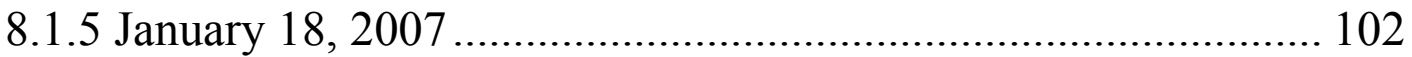

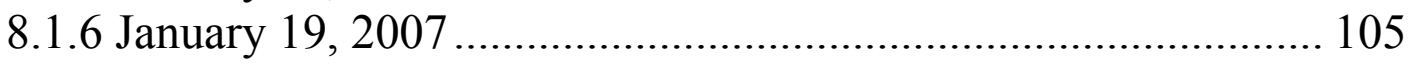




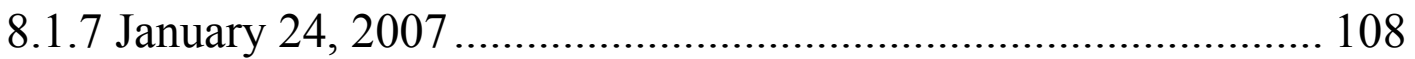

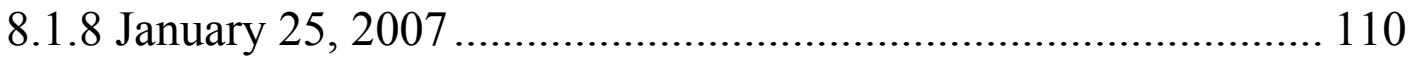

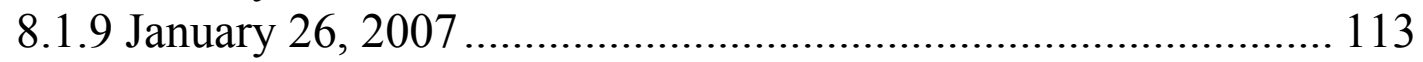

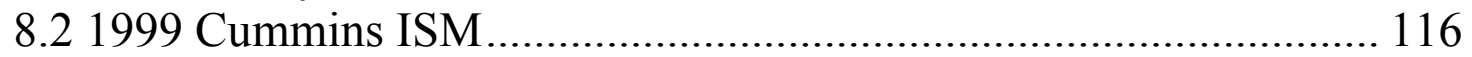

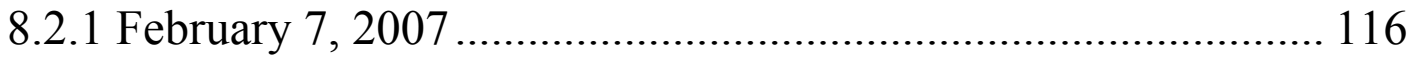

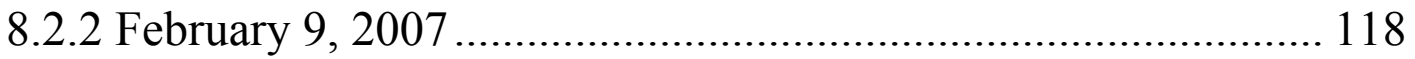

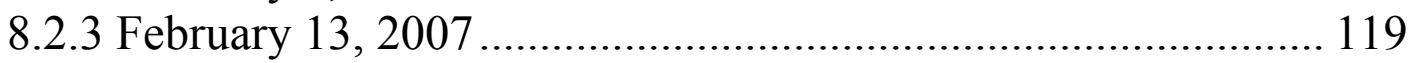

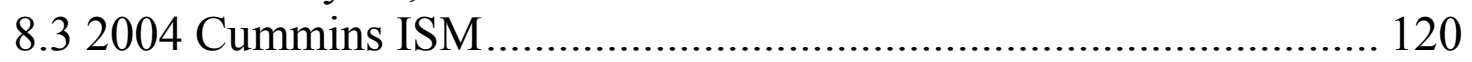

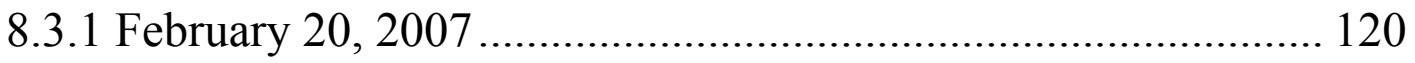

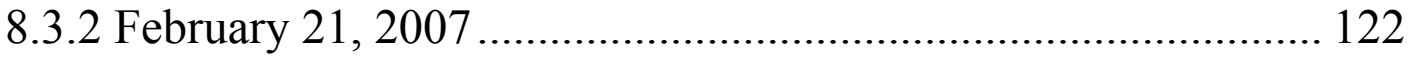

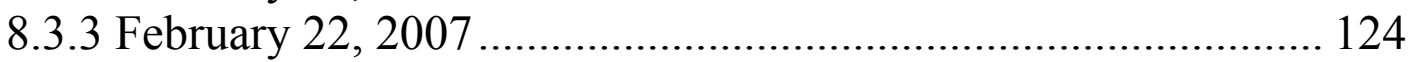

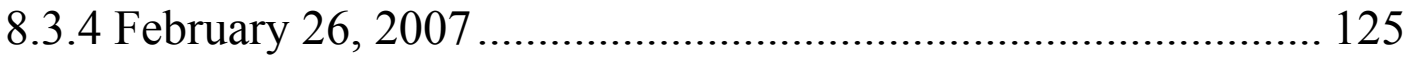

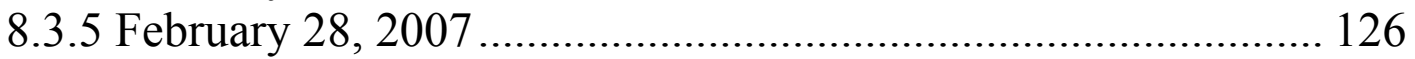

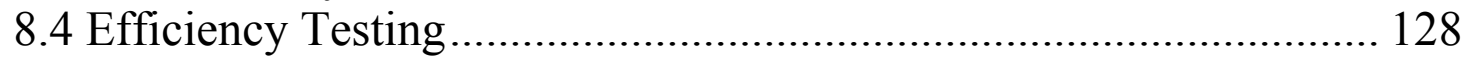

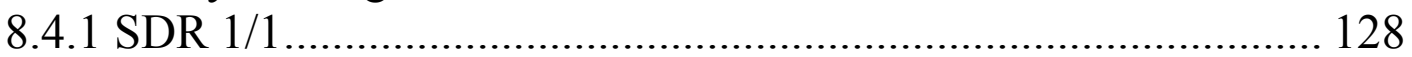

8.4.2 SDR 2/1 ..................................................................... 129

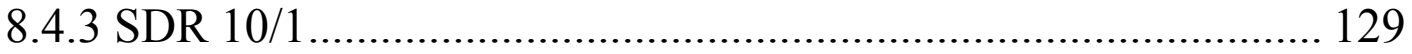

8.5 WVU EERL Clean Room Procedures............................................. 130 


\section{List of Tables}

Table 2.1 Federal emission standards for NOx and PM for vehicles powered

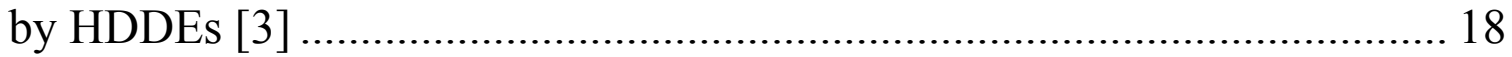

Table 2.2 Changes in Diesel Engine Technology [3] ................................ 19

Table 2.3 PM Size Regulation Trends [3] .................................................. 20

Table 3.1 List of Components Used for WVU Secondary Dilution

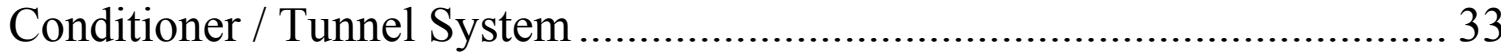

Table 3.2 List of Components Used for WVU PM System ........................ 33

Table 3.3 Characteristics of Different Filter Media [33] ............................. 34

Table 4.1 Test Matrix of SDR vs. FFV for Each Filter Media..................... 43

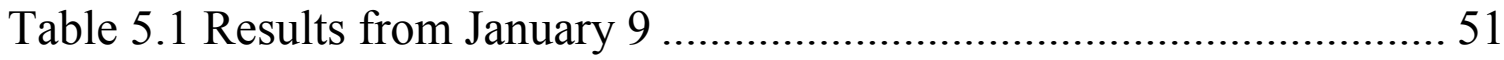

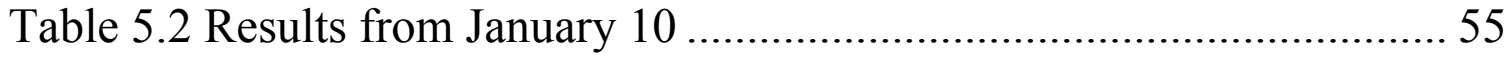

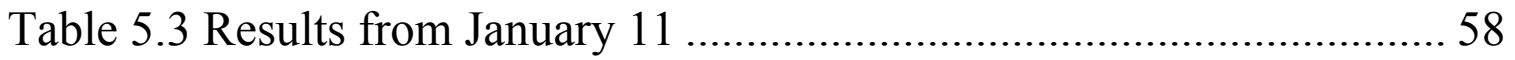

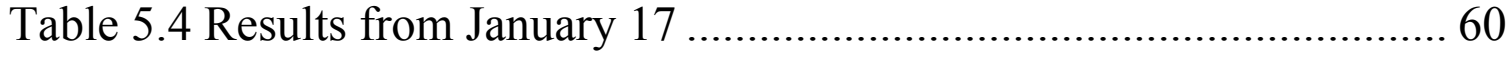

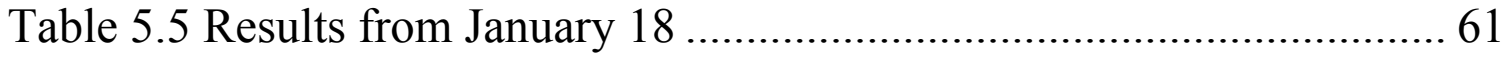

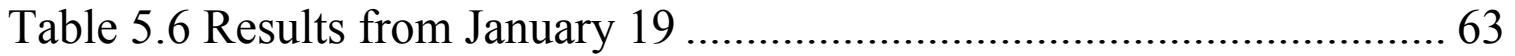

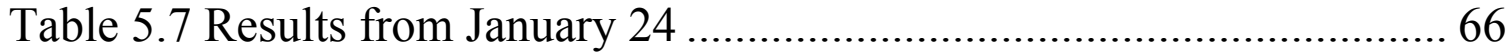

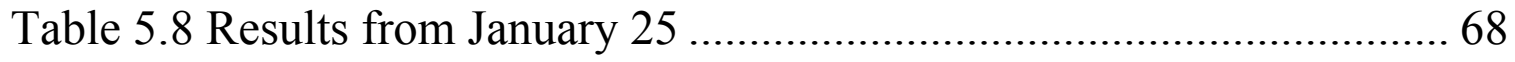

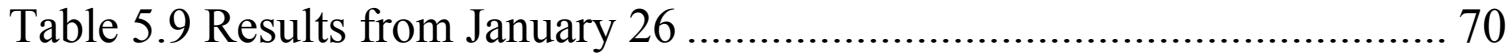

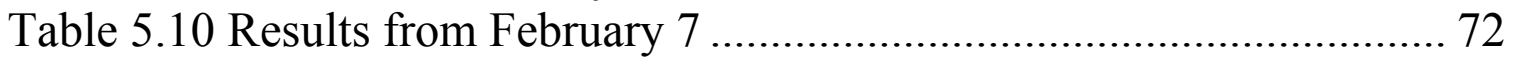

Table 5.11 Results from February 9 .......................................................... 73

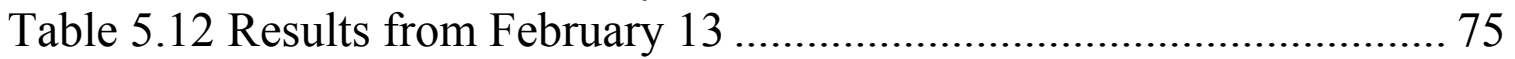

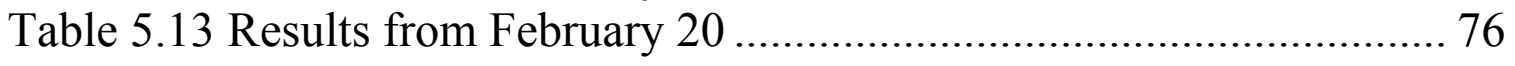

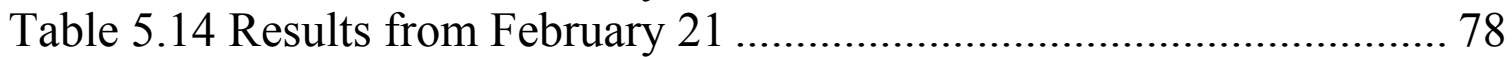

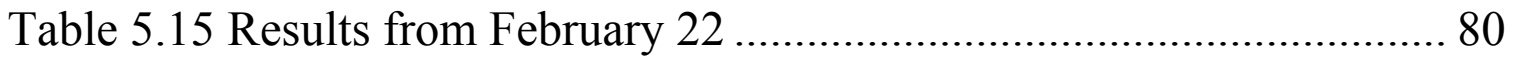

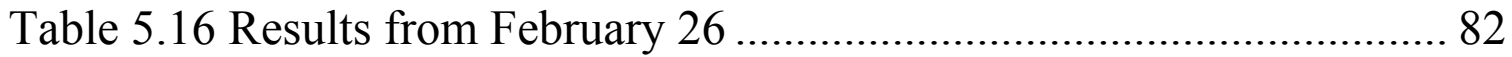

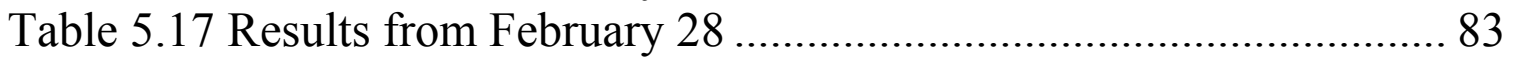

Table 5.18 Results for Tx40 $47 \mathrm{~mm}$ Filters .............................................. 85

Table 5.19 Difference (\%) Between $70 \mathrm{~mm}$ T60A20 and $47 \mathrm{~mm}$ Tx40 Filters

Table 5.20 Tabulated Results for Teflo $47 \mathrm{~mm}$ Filters................................ 86

Table 5.21 Difference (\%) Between $70 \mathrm{~mm}$ T60A20 and $47 \mathrm{~mm}$ Teflo

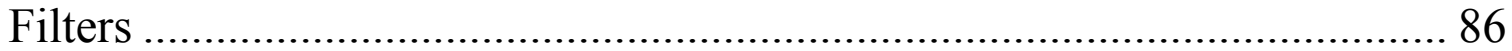

Table 5.22 Tabulated Results for T60A20 47 mm Filters.......................... 86

Table 5.23 Difference (\%) Between $70 \mathrm{~mm}$ T60A20 and $47 \mathrm{~mm}$ T60A20

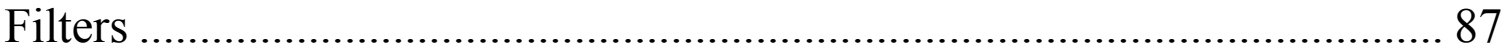

Table 8.1 January 9, PM Filter Mass Data ................................................. 96

Table 8.2 January 10, PM Filter Mass Data ................................................ 97 
Table 8.3 January 11, PM Filter Mass Data .................................................. 99

Table 8.4 January 17, PM Filter Mass Data ........................................... 100

Table 8.5 January 18, PM Filter Mass Data ............................................ 102

Table 8.6 January 19, PM Filter Mass Data ............................................ 105

Table 8.7 January 24, PM Filter Mass Data ............................................... 108

Table 8.8 January 25, PM Filter Mass Data ........................................... 110

Table 8.9 January 26, PM Filter Mass Data .............................................. 113

Table 8.10 February 7, PM Filter Mass Data .......................................... 116

Table 8.11 February 9, PM Filter Mass Data ........................................... 118

Table 8.12 February 13, PM Filter Mass Data ......................................... 119

Table 8.13 February 20, PM Filter Mass Data ......................................... 120

Table 8.14 February 21, PM Filter Mass Data …....................................... 122

Table 8.15 February 22, PM Filter Mass Data ........................................ 124

Table 8.16 February 26, PM Filter Mass Data .......................................... 125

Table 8.17 February 28, PM Filter Mass Data .......................................... 126 


\section{List of Figures}

Figure 2.1 Particulate Matter Constituent Scale Estimation [6].................... 7 Figure 2.2 Example Particle Concentrations from HDDE Transient Test [11]

Figure 2.3 Atmospheric Dilution and Cooling of Hot Diesel Exhaust [6].... 9 Figure 2.4 Soot Formation in Homogeneous Systems or Premixed Flames [13]

Figure 2.5 Schematic for TSI Scanning Mobility Particle Sizer [5] ........... 13 Figure 2.6 Schematic for TSI Condensation Particle Counter Model 3007 [19]

Figure 2.7 Schematic for TSI Scanning Electronic Particle Mobility

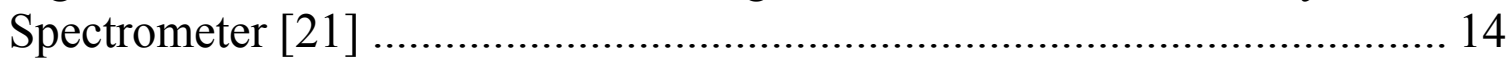

Figure 2.8 Quartz Crystal Microbalance QCM [5] ................................... 16

Figure 2.9 U.S. Diesel Engine Particle Emission Regulation Trends [6] .... 18 Figure 3.1 WVU 2007 Temperature Controlled Secondary Dilution Air

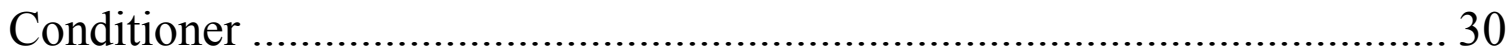

Figure 3.2 Secondary Dilution Tunnel from Old Tunnel Sample Port ........ 30 Figure 3.3 PM Sampling System, Sec Dilution Tunnel and PM Box for 2007

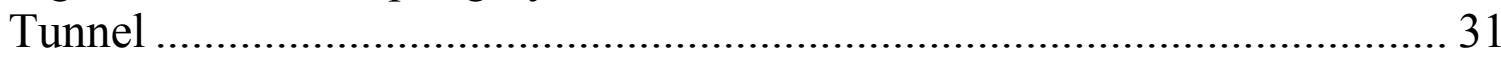

Figure 3.4 WVU Temperature Controlled 2007 Compliant PM Sampling

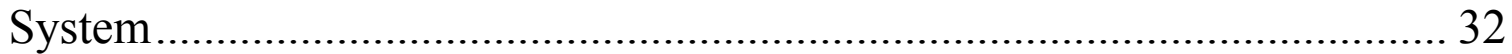

Figure 3.5 Photograph of WVU 2007 Compliant PM Sampling System .... 32

Figure 3.6 URG 47 mm Filter Holder .................................................... 34

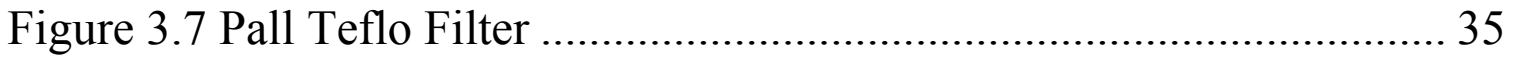

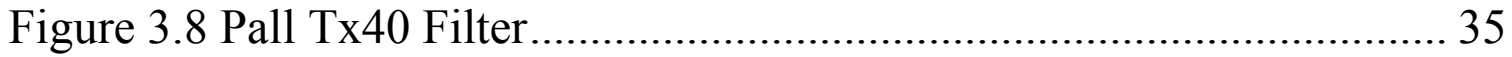

Figure 3.9 Pall T60A20 Filter................................................................. 36

Figure 3.10 Schematic of WVU EERC Emission Measurement System [34]

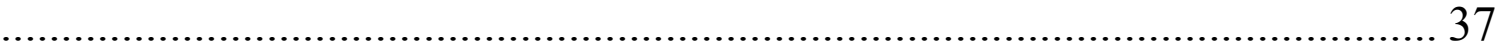

Figure 3.11 WVU EERL Test Bed with HDDE and GE Dynamometer .... 38

Figure 5.1 January 9, Average PM Mass of 1 Warm Start and 3 Hot Start

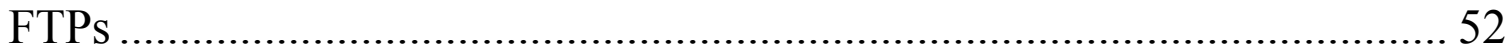

Figure 5.2 January 9, Average PM Mass of 3 Hot Start FTPs ................... 52

Figure 5.3 Example of Test Proportionality ............................................... 53

Figure 5.4 Filter Face Temperature ……................................................... 54

Figure 5.5 January 10, Average PM Mass of 3 Hot Start FTPs ................... 56

Figure 5.6 January $9 \&$ 10, Average PM Mass of 3 Hot Start FTPs ............ 57

Figure 5.7 January 11, Average PM Mass of 3 Hot Start FTPs ................... 58

Figure 5.8 Example of Lack of Flow Proportionality ................................. 59

Figure 5.9 January 17, Average PM Mass of 3 Hot Start FTPs .................. 60 
Figure 5.10 January 18, Average PM Mass Hot Start FTPs ....................... 62

Figure 5.11 January 19, Average PM Mass of 3 Hot Start FTPs ................. 65

Figure 5.12 January 24, Average PM Mass of Hot Start FTPs ................... 67

Figure 5.13 January 25, Average PM Mass of Hot Start FTPs .................... 69

Figure 5.14 January 26, Average PM Mass of 3 Hot Start FTPs ................. 71

Figure 5.15 February 7, Average PM Mass of 3 Hot Start FTPs ................. 72

Figure 5.16 February 9, Average PM Mass of 3 Hot Start FTPs ................. 73

Figure 5.17 February $7 \&$ 9, Average PM Mass of 3 Hot Start FTPs .......... 74

Figure 5.18 February 13, Average PM Mass of 3 Hot Start FTPs .............. 75

Figure 5.19 February 20, Average PM Mass of 3 Hot Start FTPs .............. 77

Figure 5.20 February 21, Average PM Mass of 3 Hot Start FTPs .............. 79

Figure 5.21 February 22, Average PM Mass of 3 Hot Start FTPs ............... 80

Figure 5.22 February $21 \&$ 22, Average PM Mass of 3 Hot Start FTPs ..... 81

Figure 5.23 February 26, Average PM Mass of 3 Hot Start FTPs .............. 82

Figure 5.24 February 28, Average PM Mass of 3 Hot Start FTPs .............. 84

Figure 5.25 Secondary Dilution Ratio's Effect on Filter Efficiency ........... 88

Figure 8.1 January 9, Filter Face Temperature.......................................... 97

Figure 8.2 January 10, Proportionality for Teflo media at 0 SDR and 0.705

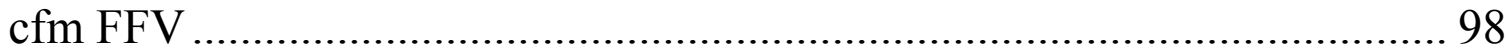

Figure 8.3 January 10, Proportionality for Tx40 media at 0 SDR and 0.705

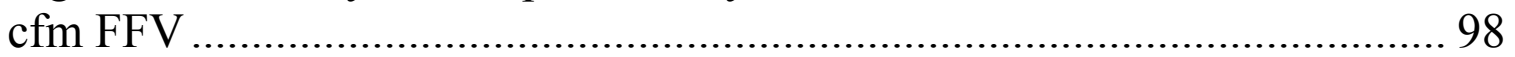

Figure 8.4 January 10, Filter Face Temperature......................................... 99

Figure 8.5 January 11, Filter Face Temperature....................................... 100

Figure 8.6 January 17, Proportionality for Tx40 Media at 0 SDR and $1 \mathrm{cfm}$

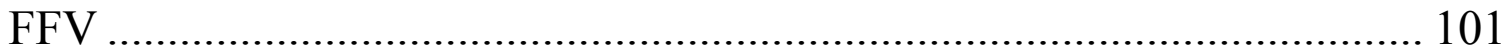

Figure 8.7 January 17, Filter Face Temperature....................................... 101

Figure 8.8 January 18, Proportionality for Tx40 Media at 0 SDR and $1.5 \mathrm{cfm}$

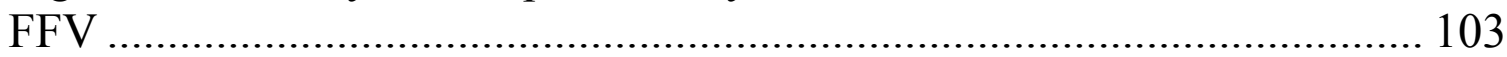

Figure 8.9 January 18, Proportionality for Tx40 Media at 0 SDR and $2 \mathrm{cfm}$

FFV 103

Figure 8.10 January 18, Proportionality for Tx40 Media at 1/1 SDR and $0.705 \mathrm{cfm}$ FFV

Figure 8.11 January 18, Proportionality for Tx40 Media at 1/1 SDR and 1.5 cfm FFV

Figure 8.12 January 19, Proportionality for Tx40 Media at 1/1 SDR and 2.0 cfm FFV

Figure 8.13 January 19, Proportionality for Tx40 Media at 10/1 SDR and 1.5 cfm FFV

Figure 8.14 January 19, Proportionality for Tx40 Media at 10/1 SDR and 2.4 cfm FFV 
Figure 8.15 January 19, Proportionality for Tx40 Media at 10/1 SDR and $0.705 \mathrm{cfm}$ FFV.

Figure 8.16 January 24, Proportionality for T60A20 Media at 1/1 SDR and $1.5 \mathrm{cfm}$ FFV 109

Figure 8.17 January 24, Proportionality for T60A20 Media at 1/1 SDR and $2.0 \mathrm{cfm}$ FFV

Figure 8.18 January 24, Proportionality for T60A20 Media at 1/1 SDR and

$2.4 \mathrm{cfm}$ FFV

Figure 8.19 January 25, Proportionality for T60A20 Media at 10/1 SDR and $2.4 \mathrm{cfm}$ FFV

Figure 8.20 January 25, Proportionality for T60A20 Media at 2/1 SDR and $1.0 \mathrm{cfm}$ FFV

Figure 8.21 January 25, Proportionality for T60A20 Media at 10/1 SDR and $1.5 \mathrm{cfm}$ FFV

Figure 8.22 January 25, Proportionality for T60A20 Media at 2/1 SDR and $1.5 \mathrm{cfm}$ FFV

Figure 8.23 January 26, Proportionality for T60A20 Media at 1/1 SDR and $1.0 \mathrm{cfm}$ FFV

Figure 8.24 January 26, Proportionality for Teflo Media at 0 SDR and 1.0 cfm FFV

Figure 8.25 January 26, Proportionality for T60A20 Media at 0 SDR and 1.5 cfm FFV

Figure 8.26 February 7, Proportionality for Teflo Media at 0 SDR and 1.5 cfm FFV

Figure 8.27 February 7, Proportionality for Teflo Media at 1/1 SDR and 1.5

cfm FFV

Figure 8.28 February 9, Proportionality for Teflo Media at 2/1 SDR and 1.5 cfm FFV

Figure 8.29 February 13, Proportionality for Teflo Media at 2/1 SDR and 1.5 cfm FFV

Figure 8.30 February 20, Proportionality for Tx40 Media at 10/1 SDR and

$1.0 \mathrm{cfm}$ FFV

Figure 8.31 February 20, Proportionality for Tx40 Media at 1/1 SDR and 1.0 cfm FFV

Figure 8.32 February 20, Proportionality for Tx40 Media at 1/1 SDR and 2.4 cfm FFV

Figure 8.33 February 21, Proportionality for Tx40 Media at 2/1 SDR and $1.5 \mathrm{~m} \mathrm{cfm} \mathrm{FFV}$

Figure 8.34 February 21, Proportionality for Tx40 Media at 2/1 SDR and 1.0 cfm FFV 
Figure 8.35 February 21, Proportionality for Tx40 Media at 2/1 SDR and $0.705 \mathrm{cfm}$ FFV.

Figure 8.36 February 26, Proportionality for Tx40 Media at 2/1 SDR and 2.0 cfm FFV 125

Figure 8.37 February 26, Proportionality for Tx40 Media at 10/1 SDR and

$2.4 \mathrm{cfm}$ FFV 126

Figure 8.38 February 28, Proportionality for Teflo Media at 1/1 SDR and

$0.705 \mathrm{cfm}$ FFV 127

Figure 8.39 February 28, Proportionality for Teflo Media at 2/1 SDR and

$0.705 \mathrm{cfm}$ FFV 127

Figure 8.40 Particle Counts across Pall Filters at 1/1 SDR and $1.5 \mathrm{cfm}$ FFV

Figure 8.41 Particle Counts across Pall Filters at 2/1 SDR and $1.5 \mathrm{cfm}$ FFV

Figure 8.42 Particle Counts across Pall Filters at 10/1 SDR and $1.5 \mathrm{cfm}$ FFV 


\section{Nomenclature}

CARB California Air Resources Board

CFR Code of Federal Regulations

$\mathrm{CO}_{2} \quad$ Carbon Dioxide

CPC Condensation Particle Counter

CRC Coordinating Research Council

$\mathrm{CV} \quad$ Coefficient of Variation

CVS Constant Volume Sampling

DOE/NREL Department of Energy National Renewable Energy Laboratory

DMS Differential Mobility Particle Sizer

DPF Diesel Particulate Filter

DPM Diesel Particulate Matter

EERL Engine and Emissions Research Laboratory

EMA Engine Manufacturers Association

EPA Environmental Protection Agency

FFV Filter Face Velocity

FTP Federal Test Procedure

GE General Electric

HDDEs Heavy Duty Diesel Engines

HEI Health Effects Institute

HEPA High Efficiency Particle Air Filter

$\mathrm{K}_{v} \quad$ Flow Calibration Coefficient

$\mathrm{NO}_{\mathrm{x}} \quad$ Oxides of nitrogen

P Venture Inlet Pressure

PAH Polycyclic aromatic hydrocarbon

PM Particulate Matter

$\mathrm{PM}_{2.5} \quad$ Aerodynamic diameter of $2.5 \mu \mathrm{m}$, largest size for "fine" particle

$\mathrm{PM}_{10} \quad$ Aerodynamic diameter of $10 \mu \mathrm{m}$, largest size for "coarse" particle

PMP Polymethylpentene

PTFE Polytetrafluoroethylene 
QCM Quartz Crystal Microbalance

SDR Secondary Dilution Ratio

SEMS Scanning Electrical Mobility Spectrometer

SMPS Scanning Mobility Particle Sizer

SOF Soluble Organic Fraction

SwRI Southwest Research Institute

T Venturi Inlet Temperature

TEOM Tapered Element Oscillating Microbalance

TFE Fluorocarbon

TSP Total Suspended Particles

US United States

VOC Volatile organic compounds

WVU West Virginia University 


\section{Introduction}

In the updated 2007 Code of Federal Regulations (CFR) Title 40 Pt 86 Subpart N, the United States (US) Environmental Protection Agency (EPA) has issued a new set of requirements regarding the particulate matter (PM) emissions from heavy duty diesel engines (HDDEs). These stringent new standards have also led to a required adjustment in laboratory PM measurement techniques.

The new legislation specifically requires specifications including a temperature controlled PM collection chamber, as well as secondary dilution transfer tunnel. The secondary dilution of the exhaust from the primary flow tunnel is required, with temperature controlled filtered dilution air. The flow rate through the system must be maintained at a level proportional to the flow rate of the primary tunnel. The geometry of the system is established, with room for engineering interpretation, with the diluted exhaust flowing across a required $47 \mathrm{~mm}$ filter of restricted media type. These specifications are discussed in detail in the Literature Review.

In order to comply with the new certification standards, West Virginia University (WVU) designed, fabricated and qualified a 2007 CFR Title 40 Pt 86 Subpart N compliant PM collection system.

While the certification standard within the 2007 CFR Title 40 Pt 86 Subpart N has regulated the testing environment for the PM collection system, there is still a variation allowance for several of the important system conditions. The three variables considered to be the most important for the PM collection system are secondary dilution ratios (SDRs), filter face velocities (FFVs), and filter media types.

In order to accurately assess the performance of WVU's 2007 PM system, a wide test matrix was designed to determine the behavior of PM deposition with these varying SDRs, FFVs, and filter media types. The observed relationships were compared to previous PM studies, yet the most important aspect of this research was obtaining the ideal testing conditions for the new 2007 compliant system. In other words, which combination of these media types, SDRs, and FFVs produced the most repeatable and reliable results. 
A number of experiments were performed at these varying critical conditions, comparing the PM data from the new 2007 compliant system with the older collection method which used larger $70 \mathrm{~mm}$ filters, which met a different set of specifications as defined in the 1990 CFR regulations [1]. The repeatability of both systems was calculated with data collected over the Federal Test Procedures (FTP) for a HDDE, which was run for a research study other than the one reported herein, and consisted of a number of varying test conditions. 


\section{Literature Review}

This section provides a brief overview of total PM measurement importance and the related adverse health and environmental effects. As an increased number of studies claim that the smallest particulates are the most responsible for PM associated health risks, the regulations regarding particulate emissions are becoming more rigid. Particulate constituents and formations affect PM collection and the accuracy required to comply with the 2007 PM standards make it essential to understand these complex issues. The lowered PM emission requirements have forced the EPA to impose stringent requirements on the gravimetric PM collection process as well as weighing procedures. These new requirements were recorded in the most recent additions to the CFR Title 40 Pt 86 Subpart N and will be reviewed and compared to the previous EPA regulations.

\subsection{What is Particulate Matter?}

From a regulatory point of view, diesel particulate matter (DPM) is not a specifically defined substance; instead Burtscher [2] describes PM as "a complex mixture characterized by widely changing chemical composition and physical properties." This complex mixture of solid particles and liquid droplets is dependent on many variables including fuel, engine technology, engine operating conditions, exhaust aftertreatment, and the atmospheric exposure time [2]. These particulates range in size and origination from visible dirt, dust, and soot to microscopic organic materials resulting from combustion.

Particulate matter has been divided into categories based on the approximate particulate diameter. Those with diameters between $2.5\left(\mathrm{PM}_{2.5}\right)$ and $10\left(\mathrm{PM}_{10}\right)$ micrometers are categorized as "inhalable coarse materials," while any particle with a diameter smaller that 2.5 micrometers fall into the "fine particle" category. A common analogy used to consider this minute measurement is to consider that the thickness of a human hair is approximately 70 micrometers, 30 times the diameter of the largest fine particle [3]. A more precise definition for this PM sizing technique is described by the mean aerodynamic diameter or 50 percent diameter. "This is the diameter for which the efficiency of particle collection is 50 percent. Larger particles are not excluded 
altogether, but are collected with substantially decreasing efficiency and smaller particles are collected with increasing efficiency [4]."

Because of the difficulty in classifying PM, the EPA defines PM as material collected on a filter in a diluted exhaust stream maintained at a temperature of $47 \pm 5^{\circ} \mathrm{C}$. This definition can include carbon agglomerates bonded with sulfates, metallic ash or evaporate engine oil. In an attempt to remove the largest diameter particles, the EPA also requires a cyclone, a pre-classifier removing particles with diameters greater than $2.5 \mu \mathrm{m}$, to be placed upstream of the filter face in order to specify the PM size being collected [5].

\subsubsection{Why is Particulate Matter Important?}

For the past ten years diesel engine technology has seen tremendous advances. At the same time, concerns about diesel engine emissions have also grown, particularly in the areas of oxides of nitrogen $\left(\mathrm{NO}_{\mathrm{x}}\right)$ and $\mathrm{PM}$. The large numbers of diesel engines in current operation have a huge effect on the current world wide air pollution problems. PM contributes to aesthetic and environmental concerns such as when particles are emitted in high concentrations as smoke or soot and also their association with a number of health problems resulting from inhalation [6]. More and more studies have been showing a direct correlation between particulates, in general diesel particulates, and thousands of premature deaths worldwide [7]. The effects of diesel PM on the environment and human health will be further discussed in the following sections.

\subsubsection{Environmental Effects}

While diesel engines are more fuel efficient and emit less carbon dioxide $\left(\mathrm{CO}_{2}\right)$ on a work basis than their gasoline counterparts, they emit significantly high mass rates of $\mathrm{NO}_{\mathrm{x}}$ and PM. $\mathrm{NO}_{\mathrm{x}}$ and additional volatile organic compounds (VOCs) emitted from petroleum-based fuel burning engines are precursors to ozone and other greenhouse gases, all considered to be air pollution problems [8]. The lower $\mathrm{CO}_{2}$ emissions and higher fuel efficiencies associated with diesel engines are not as strong contributors to the environmental and global warming issues as the emitted $\mathrm{NO}_{\mathrm{x}}$, and PM. It is also important to consider the indications that diesel exhaust is responsible for a substantial 
percentage of the rising amount of atmospheric particles which are reducing rainfall and cloud cover, a serious variable in the global warming equation which overshadows the lower amount of emitted $\mathrm{CO}_{2}$ [7].

\subsubsection{Health Effects}

To date, the main focus of the diesel emissions debate has centered primarily on the contribution of long-term diesel exhaust exposure to cancer incidence, particularly lung cancer. Recently, a number of epidemiologic and experimental studies have suggested that the effects of short-term exposure to diesel exhaust particles on the respiratory and immune systems, particularly in individuals with asthma and other allergic diseases, may also be a concern [8]. Since PM contains a number of constituents, numerous studies have evaluated the individual associated risks as well as the toxicity variance for organic compound reactions within ambient air. Particle size and formation also governs deposition within human lung tissue. Understanding which particles and particle components cause the greatest risk to health will contribute to the debate about future ambient PM standards and pollution control strategies.

After reviewing a number of scientific studies concerned with the effects of diesel exhaust on lung cancer rates in rats and hamsters, the Health Effects Institute (HEI) suggested that lung cancer is most likely related to high exposure levels of the particulates rather than the gases and organic compounds [8].

A number of national and international agencies have designated diesel exhaust, more specifically diesel PM, as a "probable" human carcinogen [9]. The State of California included diesel exhaust as a cancer causing chemical in 1990 and in 1998, after an extensive study, listed diesel exhaust as a "toxic air contaminant" [7]. Even more recently diesel PM was included to a list of substances which are thought to be human carcinogens during the $9^{\text {th }}$ National Toxicology Report on Carcinogens by the US National Institute for Environmental Health Sciences (NIEHS) [7].

The EPA has published evidence supporting a relationship between pre-existing pulmonary disorders and increased PM deposition on lung tissue, or "hot spots." They also support the claim that some groups are more susceptible to the health affects of PM, yet more conclusive evidence must be performed to evaluate the individual variable 
governing the groups' susceptibility: age, disease, etc. [3]. The EPA has also released results supporting epidemiologic studies concerning fine particle deposition when they were able to produce a strong comparison between ambient $\mathrm{PM}_{2.5}$ and personal exposure to $\mathrm{PM}_{2.5}$. When comparing particle size to "lung toxicity" in a test group of mice, pulmonary inflammation was shown to have a stronger relationship with ultra-fine and fine particles than with coarse particles. Mice also showed a change in cardiac tissue comparing air-exposed and PM-exposed results. Similar results of pulmonary inflammation and cardiac rhythm and tissue changes have also been observed in humans [3].

Polycyclic aromatic hydrocarbons (PAHs) are present within the soluble organic fraction (SOF) of PM. The possible carcinogenic character of $\mathrm{PAH}$, along with the propensity to penetrate deep into lung tissue, is a major cause for the major health risk fears of the high level nano-particle emissions from diesel engines. Most of the SOF in PM is absorbed onto the surface of the primary particles, where it resides as a thin outer shell [10]. Therefore, the surface constituents of PM are a viable source for health related issues.

\subsubsection{Particulate Matter Constituents}

Diesel exhaust particles are composed of a carbon core onto which sulfate, nitrate, metals, and organic compounds are adsorbed [8]. Figure 2.1 depicts an estimated scale of several particulate constituents. This portrayal is merely a general characterization of diesel exhaust particle size and composition whereas the actual composition is a complex combination of hundreds of species [6]. 
- Chain Agglomerate of Soot Particles $(40 \mathrm{~nm}$ to $500 \mathrm{~nm}$ )

- Metallic Ash Particles Formed from Lube Oil (10 $\mathrm{nm}$ to $20 \mathrm{~nm}$ )

- Hydrocarbon Particles (10 nm to $30 \mathrm{~nm}$ After Growth)

- Sulfate Particles (10 $\mathrm{nm}$ to $30 \mathrm{~nm}$ After Growth)

- Chain Agglomerate of Soot Particles with

Adsorbed/Condensed Layers of Hydrocarbon and

Sulfate and Metallic Ash ( $40 \mathrm{~nm}$ to $500 \mathrm{~nm}$ )

Figure 2.1 Particulate Matter Constituent Scale Estimation [6]

The particles vary in size, composition, solubility and therefore their toxic properties vary as well [2]. One specific example, Figure 2.2, shows the particle composition from HDDEs over a transient test.

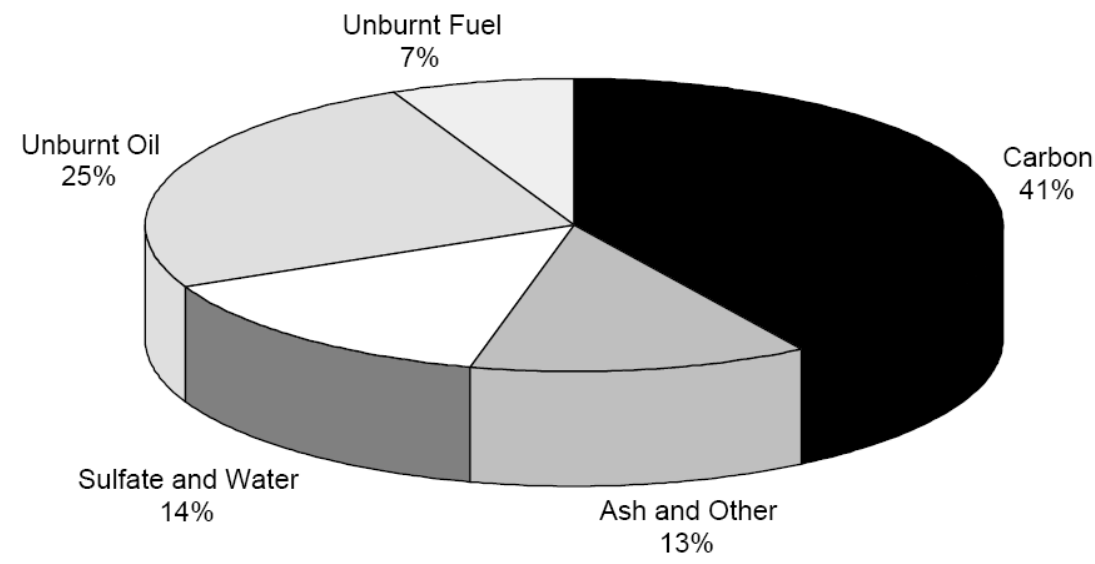

Figure 2.2 Example Particle Concentrations from HDDE Transient Test [11]

\subsubsection{Solid Particulates}

The solid elemental carbon, or soot, particles present in diesel PM are formed within the combustion chamber of the engine. These particles are formed as chain agglomerates with diameters within the range of $40-500 \mathrm{~nm}$. The agglomerates are 
actually formed by a collection of individual particles of $10-30 \mathrm{~nm}$ in diameter that undergo coagulation and form larger particles during the combustion process [6]. Other solid particles present within diesel exhaust may be metallic ash, unburned lubricating oil, unburned fuel and additives, and a combination of these species attached to the elemental carbon [11].

\subsubsection{Soluble Particulates}

The tiny fraction of the atomized and evaporated oil and fuel that was able to escape oxidation within the combustion chamber will appear as either volatile/semivolatile organic compounds or soluble organic fraction [11]. The dilution process, when exhaust is expelled into the atmosphere, may also trigger the nucleation of new nanoparticles such as PAHs, sulfuric acid, or a combination of sulfuric acid nuclei with adsorbed layers of hydrocarbon coating. The new species formed during dilution and cooling can also adsorb and condense onto the carbon chain agglomerates as well as forming their own "stand alone" nano-particles [6]. Figure 2.3, shown below, depicts an example of the diesel particulate reaction during the natural dilution with ambient air. 


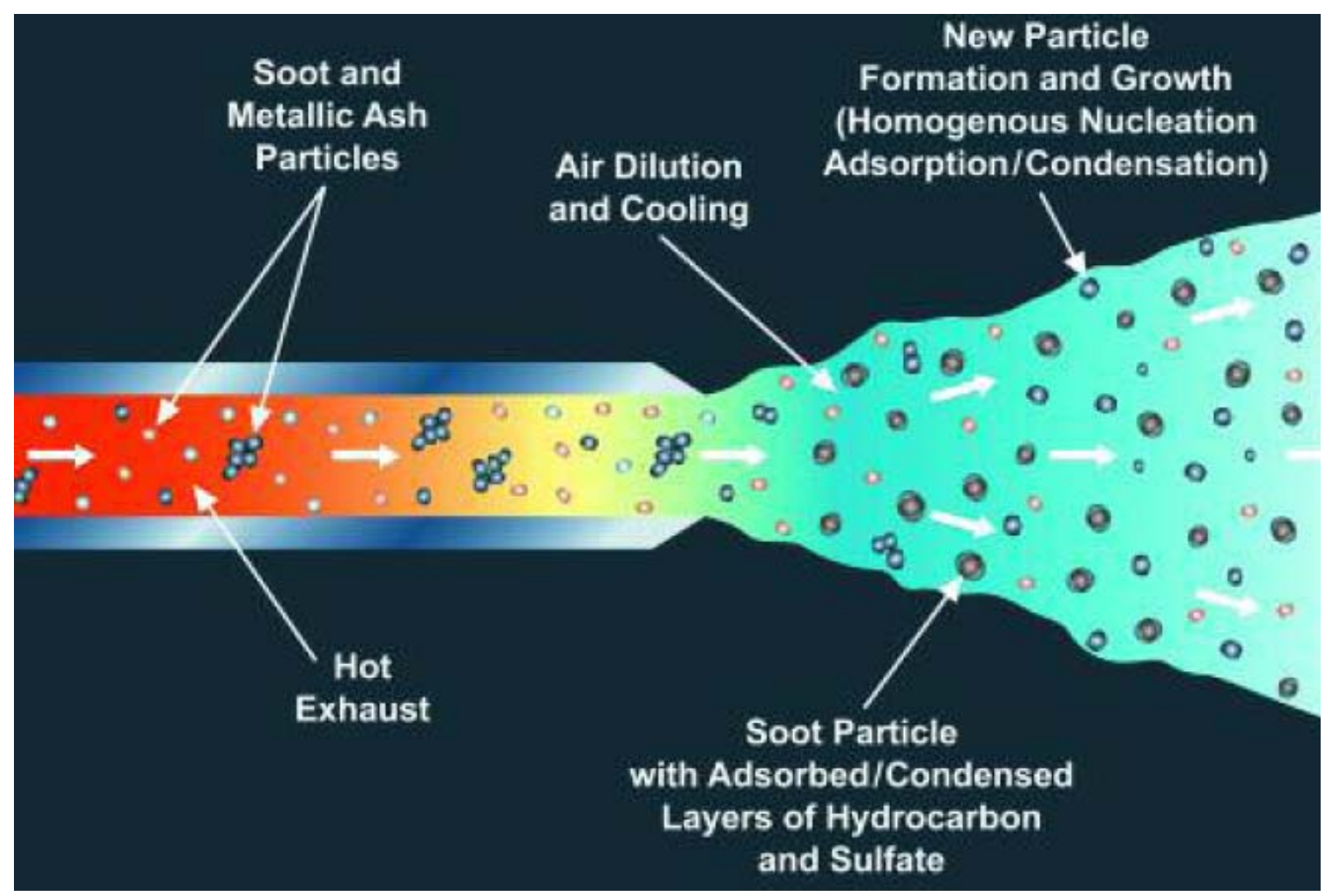

Figure 2.3 Atmospheric Dilution and Cooling of Hot Diesel Exhaust [6]

\subsubsection{Particulate Formation and Morphology}

The actual formation process, that is, morphology, from a hydrocarbon fuel with a few carbon atoms into carbon based agglomerate chains consisting of millions of carbon atoms in mere milliseconds is extremely complex [12]. This section discusses the formation and growth of different particulate constituents. Figure 2.4 describes the conversion of hydrocarbon fuels to PAHs and soot during combustion. 


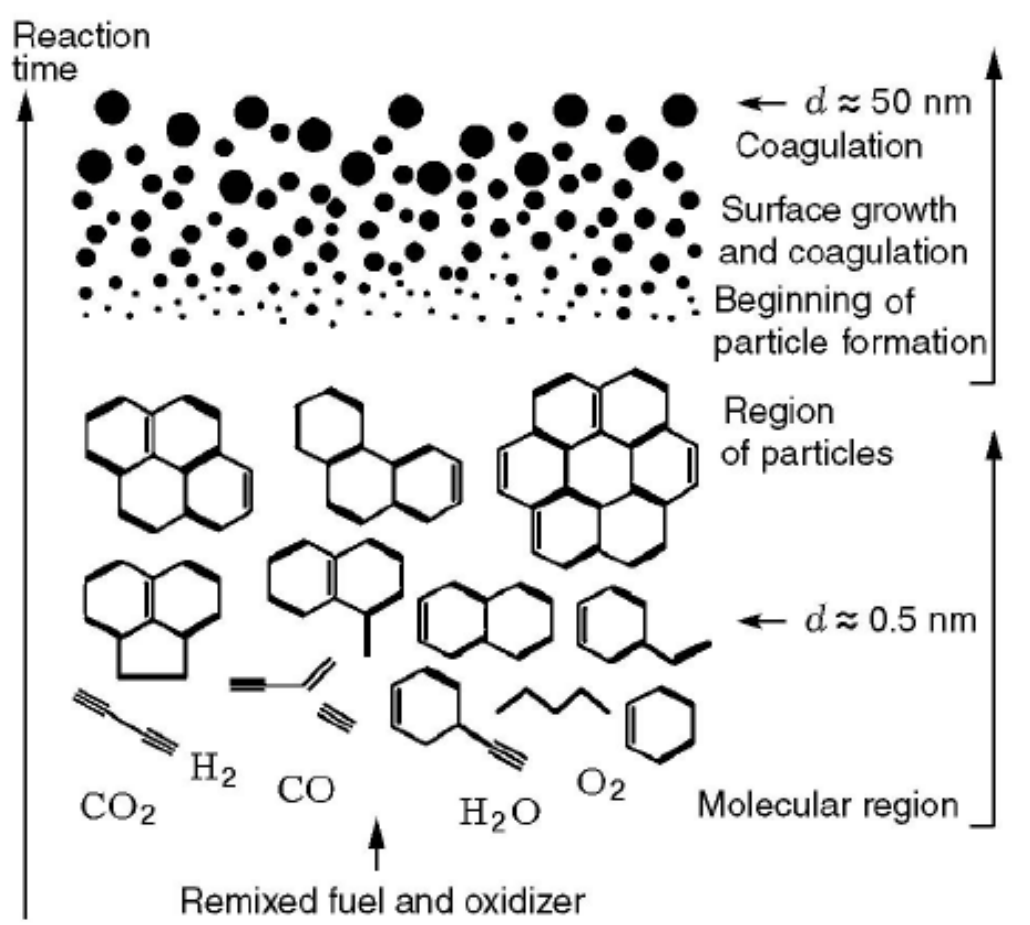

Figure 2.4 Soot Formation in Homogeneous Systems or Premixed Flames [13]

Polycyclic aromatic hydrocarbons usually form under conditions of rich mixtures and are generally considered as important precursors to soot nano-particle formation [14]. This soot formation process can be regarded as a transition from gas hydrocarbon fuel molecules to solid phase carbonaceous agglomerates [15]. This reaction strongly depends on the temperature and time of conversion of the particles in the oxidizing medium.

The PM soot concentration increases due to the adsorption of PAHs and as a result of particle surface reactions, which also causes the surface size to increase [14]. This process involves the detachment of hydrogen and attachment of carbon [16]. The sulfate present in PM is usually sulfuric acid derived from the fuel's sulfur. Sulfur dioxide and a trace amount of sulfur trioxide are components of combustion. Upon coming into the presence of water, these elements will form sulfuric acid. The propensity of hydrated sulfuric acid to nucleate is believed to be the main source of the nano-particle formation during dilution [10]. 
The soot emissions from diesel engines contribute to a considerable portion of the atmospheric aerosol and are highly dependent on engine performance. Soot emissions from diesel engines are influenced by the atomization and configuration of the spray, the method of air supply, turbulence level, injection pressure, injection time, and ignition delay [17].

\subsection{How is Particulate Matter Measured?}

\subsubsection{Gravimetric Analysis}

The current certification method for analyzing PM involves a work-specific massbasis (g/bhp-hr) measurement. Gravimetric filtration, removing a diluted exhaust sample from the dilution tunnel and passing the flow across a primary and secondary filter, or a single filter, must be designed to efficiently collect at least $99 \%$ of the available PM. While the specifics about gravimetric filtration will be further discussed within the PM legislation section, there are several concerns about this measuring technique.

\subsubsection{Real Time Particulate Measurement}

With the realization that the smallest particles are of the greatest importance, there are concerns that the current mass based particulate standards may not be appropriate [2].

There are a range of other methods used for PM measurement, especially when gravitationally collected PM mass is not the critical metric. If PM size distribution or number measurements are sought, real time measurement is often employed. PM measurement is currently a challenge for ongoing in-use emissions programs. Systems must be able to adapt to the multiple variables associated with in-use testing; vibrations, highly transient testing, non-controllable conditions, etc. However the most important metric for in-use testing is the opportunity to obtain continuous, real time PM information. Therefore, a number of the following measurement devices have been chosen, or even specifically designed, for use in-use emissions research. 
Several of these measurement techniques which are used by WVU or other PM studies are briefly discussed in this section. The following real time methods are divided into two sections: Mobility PM sizing and PM mass estimations.

\subsubsection{Mobility PM Sizing}

\subsection{Scanning Mobility Particle Sizer with Condensation Particle Counter}

The scanning mobility particle sizer (SMPS) is capable of measuring PM size distributions and concentrations. The particles moving through a diluted exhaust stream first enter a neutralizer in order to reduce the particle charge distribution to a known minimum level. The charged particles then enter near the outside wall of a transfer tube with clean air flowing through the middle of the tube where a central charged rod is positioned. Individual particles will then move inward or outward radially, depending on the particles individual polarity. The particles with the correct polarity and mobility than leave the transfer tube through the exit holes which lead to the condensation particle counter (CPC) [18]. It should be noted that if an analysis for a different size particle is desired, one merely has to adjust the voltage scan level across the central rod.

The CPC consists of a saturator, condenser, particles sensor, flowmeter, and pump. The particle sample is first saturated with alcohol than cooled in the condenser tube. This cooling process allows the alcohol to condense onto the particles, forming droplets with diameters of approximately $5-10 \mu \mathrm{m}$. These droplets then enter the particle sensing region of the apparatus. The particle sensing region emits a laser light through a very small region. The individual particles are measured by counting the pulses caused by particles passing through the established view volume. CPCs are known to be able to have a detection efficiency of $50 \%$ for particles with diameters as small as $7 \mathrm{~nm}$ and, by adjusting the condenser tubes temperature, can even detect $5 \mathrm{~nm}$ particles with an equal efficiency [18].

The CPC can also run in a photometric mode. This mode consists of a photodetector measuring the intensity of the light instantaneously scattered by the entire particulate flow field. Since all the particles grow to essentially equal size droplets after condensation, the light scattered is correlated to particle number concentration independent of size [18]. The following Figure 2.5 and Figure 2.6 illustrate the mechanisms of the SMPS and CPC, respectively. 


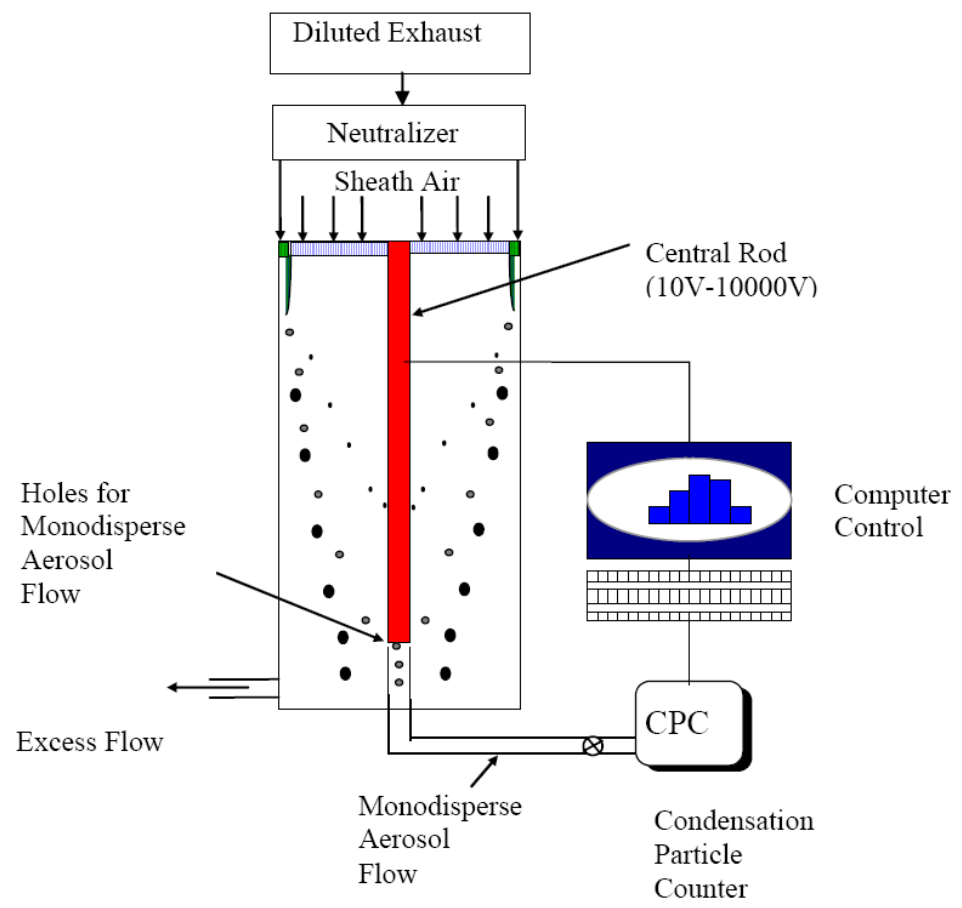

Figure 2.5 Schematic for TSI Scanning Mobility Particle Sizer [5]

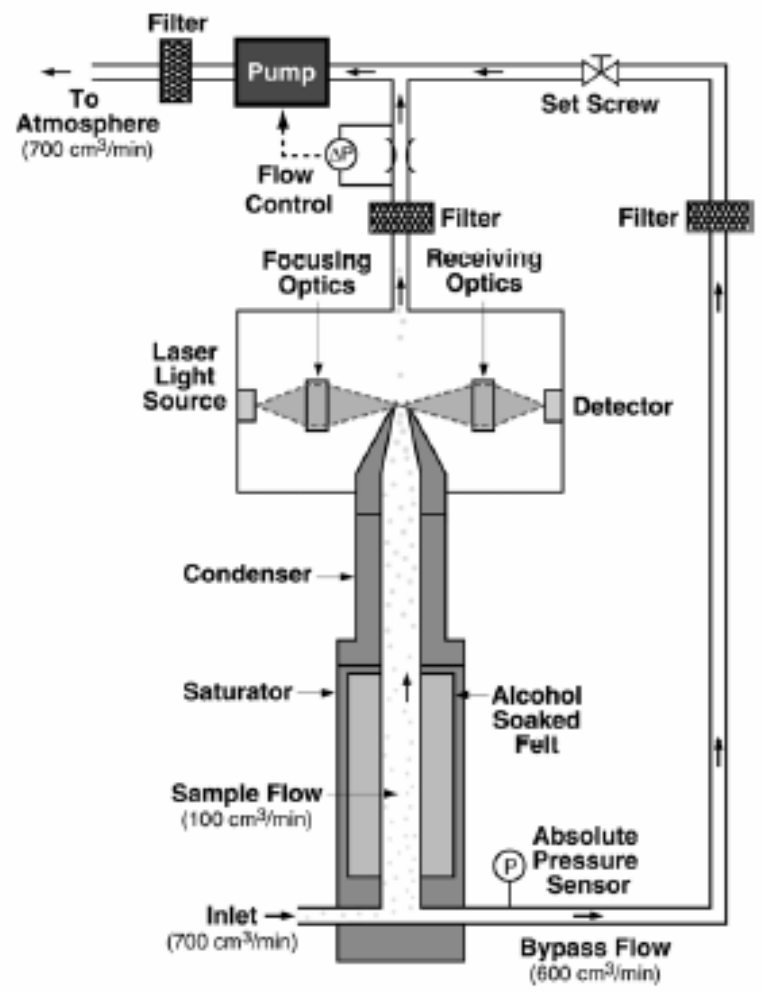

Figure 2.6 Schematic for TSI Condensation Particle Counter Model 3007 [19] 


\subsection{Scanning Electrical Mobility Spectrometer}

The scanning electrical mobility spectrometer (SEMS) operates similarly using the electrical mobility methods previously discussed. However, it allows for a dramatically reduced measurement time without losses in resolution [0]. Specifically the SEMS is very similar to the EAA with the major differences being in the voltage stepping procedure. Instead of a time based voltage stepping, the voltage of the central rod is allowed to vary continuously. By using a very fast response detector, one is able to analyze a complete range of particle sizes much faster than when using the voltage stepping mode [20]. Refer to the following Figure 2.7 for a schematic of this method.

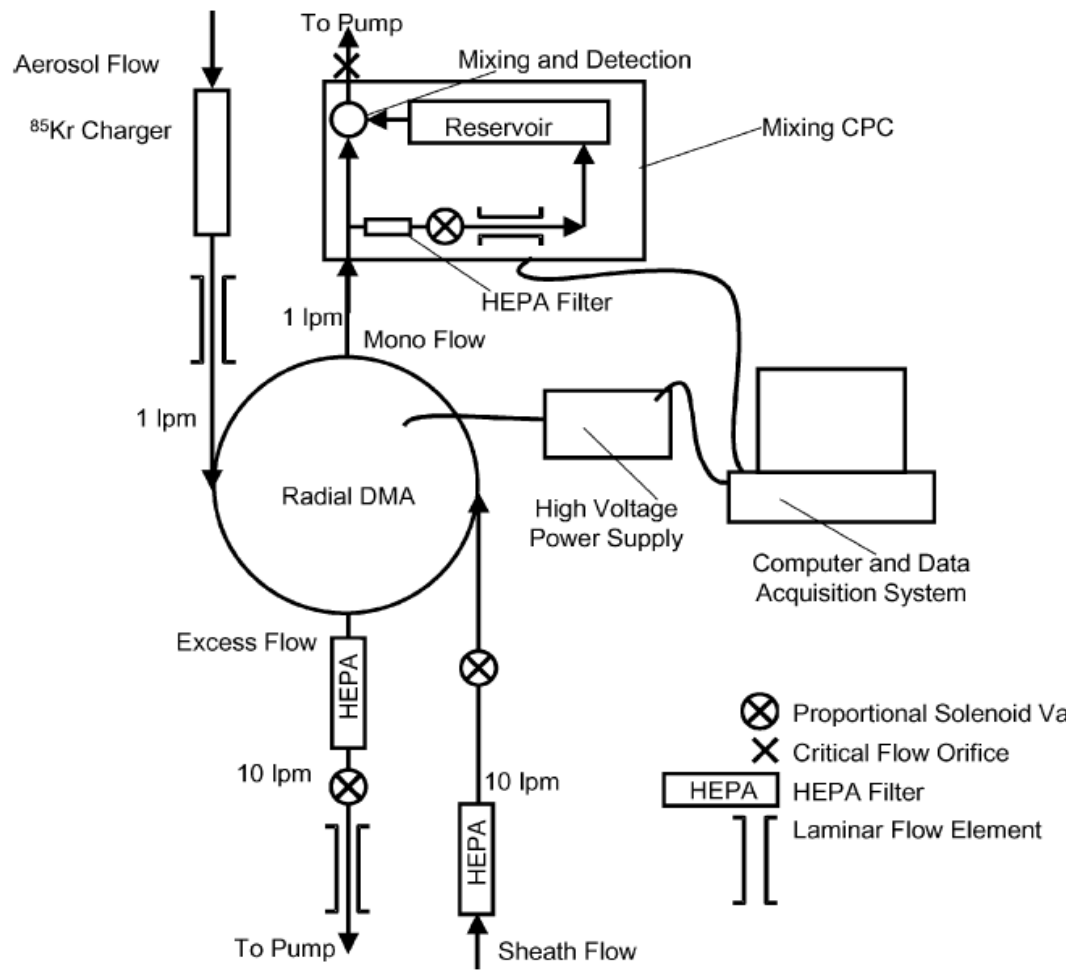

Figure 2.7 Schematic for TSI Scanning Electronic Particle Mobility Spectrometer [21]

\subsection{Differential Mobility Particle Sizer}

The differential mobility particle sizer (DMS) is very similar to the previously described SMPS. The system measures electrically charged aerosols with a mobility analyzer that only allows particles of specified charge, or electric mobility, to pass through a port to be measured downstream. Unlike the SMPS however, the DMS must 
make discrete changes in voltage controlling the interval of particle charge passing through the system. This required voltage change slows the measurement process of the entire particulate size scan. The DMS uses a condensation nucleus counter to count the range of electric mobility passing by at each given step [22]. Because the DMS is so similar to the SMPS, refer to Figure 2.5 for a basic schematic of this system.

\subsubsection{Non-gravimetric PM Mass Estimations}

\subsection{Tapered Element Oscillating Microbalance}

The tapered element oscillating microbalance (TEOM) measures particle mass continuously deposited on a small filter positioned on an oscillating element. This method of PM mass analysis has been compared to the gravimetric analysis is a number of previous studies. Podsiadlik et al. [23] showed that a phase-by-phase operation with careful equilibration of the TEOM gave similar results to the filter methods but with an offset between $9 \%$ and $14 \%$. This trend continued with a number of studies. For example, an Australian report found the TEOM to report 16\% less PM mass on average [24]. Kelly and Morgan found that the TEOM reported even less, between 20 to 25\%, than the previously mentioned studies [25]. After a large number of studies showed these disagreements, filter manufacturers improved their filter design so as to capture more of the PM mass than in previous designs [26]. In a 2005 comparison using the new filter design, WVU found improved TEOM comparison results with an average of $6 \%$ lower than the filter based method. The comparison represents a much closer agreement between the TEOM and gravimetric filter methods of PM collection than previous studies [26].

\subsection{Quartz Crystal Microbalance}

The quartz crystal microbalance (QCM), manufactured by Sensors Inc., utilizes electrostatic precipitation to collect aerosol particles and deposits them onto an oscillating piezoelectric crystal. The known natural oscillation frequency of the crystal reduces in proportion to the amount of deposition onto its surface. The frequency shifts lead to a calculation of the mass of PM with a resolution approaching on nanogram. According to 
Sensors, the instrument offers fast response times and its small and light weight structure allows for transient PM mass measurements [27].

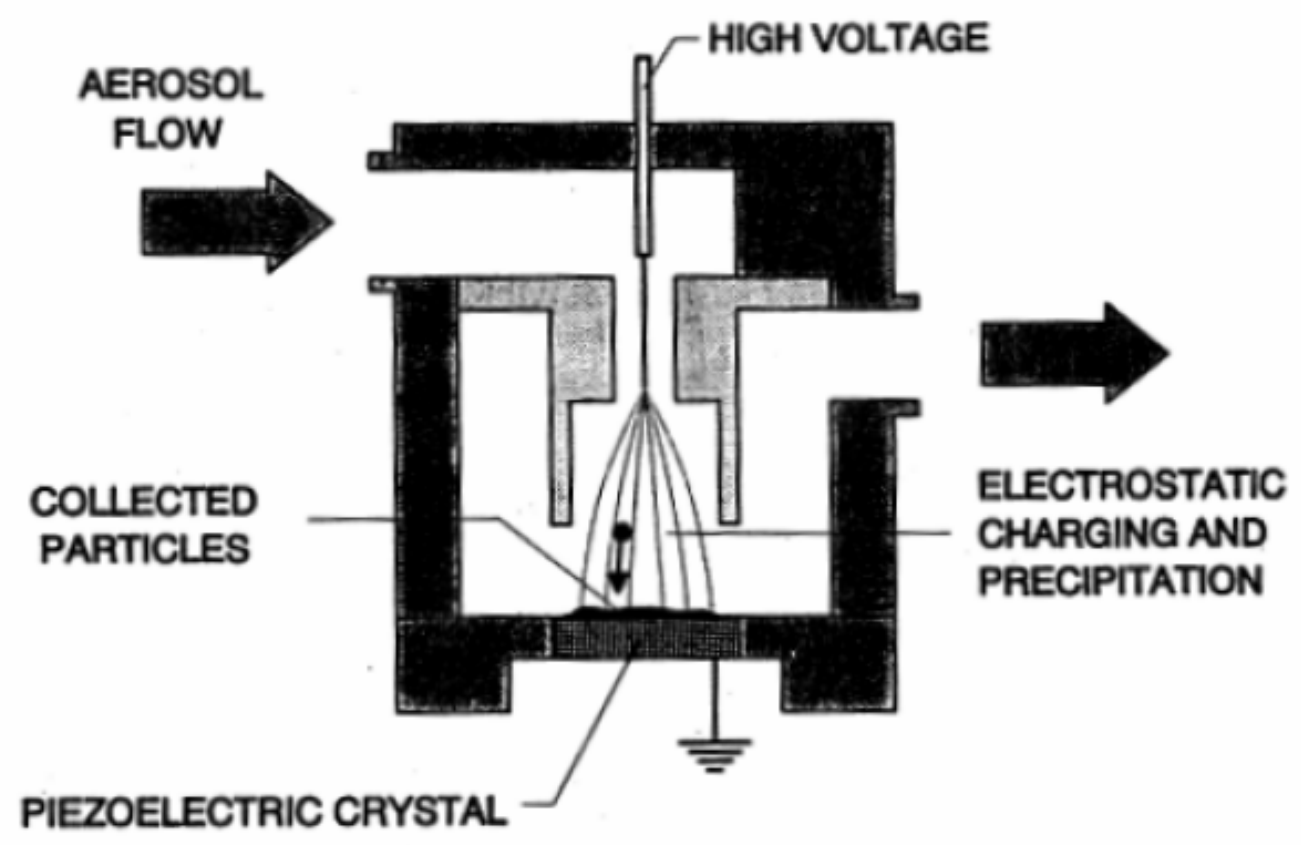

Figure 2.8 Quartz Crystal Microbalance QCM [5]

\subsubsection{Summary}

While electronic mobility methods are used for the analysis of particle sizing, the only PM analysis required by the EPA is the use of gravimetric filters. Considering the increased concern with the smallest particles emitted from HDDEs, future PM measurement techniques may be adjusted.

It should also be noted that every one of the previously discussed systems has a number of issues that can lead to errors in data collection or misrepresentation of particulate measurements [28]. Several of these issues common for the majority of the systems are listed below.

1. Prediction of particle charging efficiencies

2. Ability to zero and span system

3. NIST traceable accuracy

4. Effect of solid particle deposition on the relationship between electronic frequencies and other methods used for analyzing PM concentration and/or mass 
5. Influence of water vapor on measurement instruments

6. Influence of volatile species adsorption onto measurement instruments.

These factors represent some of the possible areas for error. Therefore it is important to consider that while these real time measurements provide more insight on PM studies than gravimetric analysis, the data collected cannot be considered as completely accurate.

\subsection{Particulate Matter Legislation}

\subsubsection{History of EPA Heavy Duty Engine PM Emissions Standards}

The first diesel exhaust emissions standards were established by the EPA in 1971 as a result of 1970's Clean Air Act [8]. These guidelines were then periodically modified in accordance with reviews of the appropriate research and literature. The EPA first included standards on PM emitted from HDDEs when a mass based level of $0.6 \mathrm{~g} / \mathrm{bhp}-\mathrm{hr}$ was imposed in 1988. This restriction continued to decrease in 1991 when $0.25 \mathrm{~g} / \mathrm{bhp}-\mathrm{hr}$ was implemented as the regulated level. In 1994 the valid level of PM was reduced to $0.1 \mathrm{~g} / \mathrm{bhp}-\mathrm{hr}$ [29]. The more stringent requirements led the development of diesel engines with significantly reduced emissions, yet these engines also displayed an increase in number and volume of very small nuclei mode particles, $\mathrm{PM}_{2.5}$ [3]. As more studies supported evidence concerning $\mathrm{PM}_{2.5}$ the EPA began concentrating on regulating the acceptable levels of fine PM while leaving the $\mathrm{PM}_{10}$ policies untouched [8]. These policies have lead to the implication of the 2007 PM standards which limit HDDEs' exhaust PM to a level of merely $0.01 \mathrm{~g} / \mathrm{bhp}-\mathrm{hr}$ [29]. This new modification has decreased the acceptable PM level by a complete order of magnitude from the previous legislation, and is $1 / 60^{\text {th }}$ of the original 1988 levels.

While the early diesel engines were designed to emphasize maximum fuel economy and performance, emissions regulations forced engine manufacturers to meet these standards without sacrificing their performance levels. These goals were typically achieved by modifying and tightening engine controls, injection systems, and the combustion chamber. In an attempt to reduce the high $\mathrm{NO}_{\mathrm{x}}$ levels emitted from diesel engines, adsorber catalysts were implemented. These catalysts adsorb $\mathrm{NO}_{\mathrm{x}}$ during lean 
engine operation and release and convert the $\mathrm{NO}_{\mathrm{x}}$ to nitrogen during the rich conditions. However, sulfur in the fuel is a poison for the $\mathrm{NO}_{\mathrm{x}}$ adsorber catalyst. The sulfur collects in the active sites for $\mathrm{NO}_{\mathrm{x}}$ adsorption, rendering them useless for $\mathrm{NO}_{\mathrm{x}}$ reduction [30]. In turn, the EPA has established a maximum on-road use fuel sulfur level of 15 ppm, which also leads to a further decrease in DPM [3].

The EPA has also implemented a different range of emissions requirements for diesel transit buses. Table 2.1 presents a year by year certified level of allowable emissions, included $\mathrm{NO}_{\mathrm{x}}$ requirements. Figure 2.9 depicts the same allowable diesel engine on-road particulate emissions for HDDEs trucks.

Table 2.1 Federal emission standards for NOx and PM for vehicles powered by HDDEs [3]

\begin{tabular}{|c|c|c|}
\hline \multirow{2}{*}{ Engine Year } & $\begin{array}{r}\text { Oxides of Nitrogen } \\
\text { g/bhp-hr }\end{array}$ & $\begin{array}{c}\text { Particulate Matter } \\
\text { g/bhp-hr }\end{array}$ \\
\cline { 2 - 3 } & Truck and Bus & Truck \\
\hline 1985 & 10.7 & None \\
\hline 1988 & 10.7 & 0.6 \\
\hline 1990 & 6.0 & 0.6 \\
\hline 1991 & 5.0 & 0.25 \\
\hline 1993 & 5.0 & 0.25 \\
\hline 1994 & 5.0 & 0.10 \\
\hline 1996 & 5.0 & 0.10 \\
\hline 1998 & 4.0 & 0.10 \\
\hline 2002 & 2.5 & 0.10 \\
\hline 2007 & 1.2 & 0.01 \\
\hline
\end{tabular}

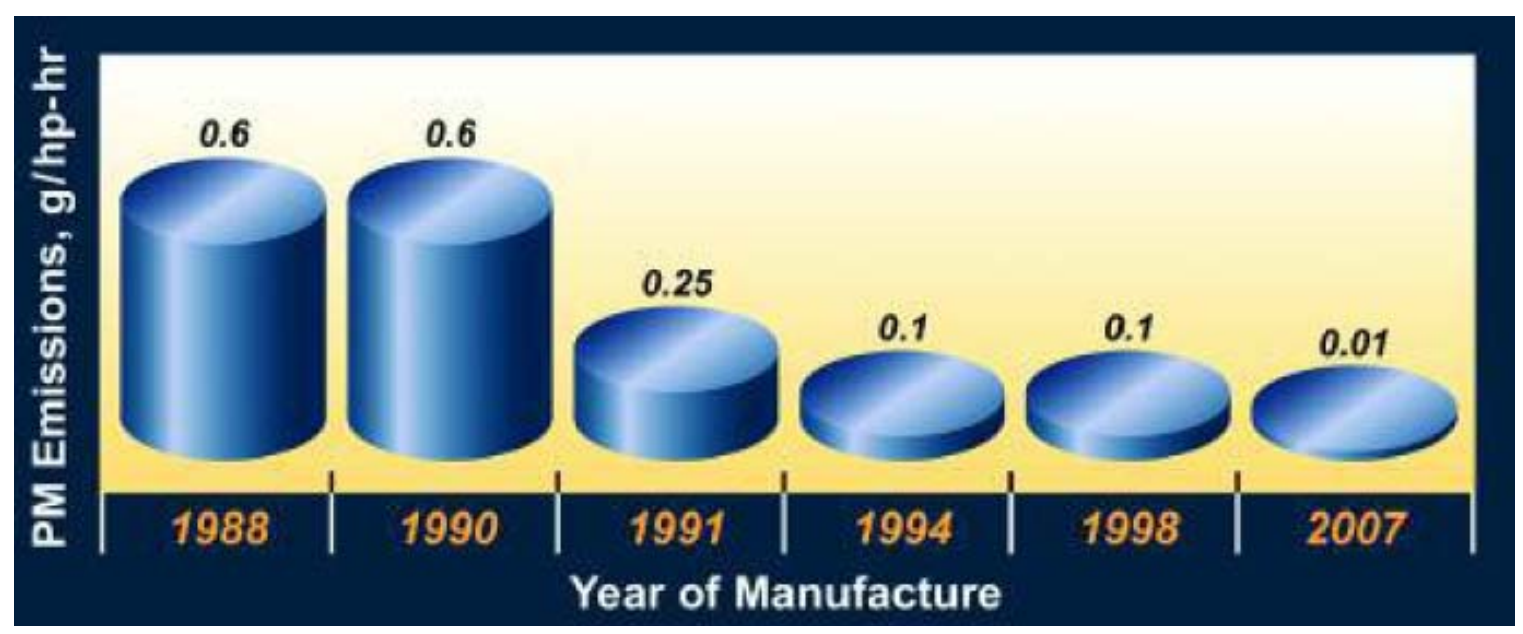

Figure 2.9 U.S. Diesel Engine Particle Emission Regulation Trends [6] 
Table 2.2 briefly reviews the common techniques employed by the engine manufacturers in order to meet the EPA's implemented goals.

Table 2.2 Changes in Diesel Engine Technology [3]

\begin{tabular}{|c|c|c|c|}
\hline Technology & $1970 \mathrm{~s}$ & $1980 \mathrm{~s}$ & $1990 \mathrm{~s}$ \\
\hline HDDEs & $\begin{array}{l}\text { Mostly naturally } \\
\text { aspirated. } \\
\text { Some turbo } \\
\text { charged/aftercooling. } \\
4 \text { and } 2 \text { stroke } \\
\text { cycles. Direct } \\
\text { injection } \\
\text { predominates. }\end{array}$ & $\begin{array}{l}\text { Mostly turbo- } \\
\text { charged/water to air } \\
\text { aftercooling. } \\
4 \text { stroke cycle. } \\
\text { Direct injection. }\end{array}$ & $\begin{array}{l}\text { Mostly turbo- } \\
\text { charged/air to air } \\
\text { aftercooling. } \\
4 \text { stroke cycle. } \\
\text { Direct injection. }\end{array}$ \\
\hline LDDEs & Indirect injection & Indirect injection & $\begin{array}{l}\text { Indirect injection, } \\
\text { small direct } \\
\text { injection } \\
\text { introduced. }\end{array}$ \\
\hline Fuel sulfur content & $\geq 0.3 \mathrm{wt} \%$ & $\geq 0.3 \mathrm{wt} \%$ & $\leq 0.05 \mathrm{wt} \%$ \\
\hline
\end{tabular}

\subsubsection{PM Size Regulations}

While the total PM allowances are described above, it is also important to consider the regulation trends for the specification of PM sizing. When the EPA first established national ambient air quality standards for PM in 1971, the reference method used was a high-volume sampler. This method collects PM up to a nominal size of 25 to $45 \mu \mathrm{m}$, referred to as total suspended particles (TSP). The original standards were modified in 1987, highlighted by a significant revision changing the indicator for particles from TSP to $\mathrm{PM}_{10}$, or particles with a mean aerodynamic diameter less than or equal to $10 \mu \mathrm{m}$. These provisions remained intact until 1997 when the EPA determined that the focus should remain on particles less than or equal to $10 \mu \mathrm{m}$, while also considering coarse and fine particles separately. PM with a diameter less than or equal to $2.5 \mu \mathrm{m}$ were chosen to represent "fine" particles, while PM standards represented the "coarse" particles. Finally, in the 2007 regulations, the coarse particle standards were removed with the $\mathrm{PM}$ focus remaining on $\mathrm{PM}_{2.5}$ [4]. Refer to Table 2.3 for tabulated reference to these PM size regulation trends. 
Table 2.3 PM Size Regulation Trends [3].

\begin{tabular}{|l|l|l|}
\hline Legislation Year & PM Indication Method & Description \\
\hline 1971 & TSP & Total Suspended Particles \\
\hline 1987 & $\mathrm{PM}_{10}$ & Coarse Particles \\
\hline 1997 & $\mathrm{PM}_{10}$ and $\mathrm{PM}_{2.5}$ & $\begin{array}{l}\text { Separate Coarse and Fine } \\
\text { Particles }\end{array}$ \\
\hline 2007 & $\mathrm{PM}_{2.5}$ & Fine Particles \\
\hline
\end{tabular}

\subsubsection{Legislation Modifications}

The 2007 EPA requirements have established a PM allowable level of $0.01 \mathrm{~g} / \mathrm{bhp}-$ $\mathrm{hr}$ over the FTP. This significant reduction in regulation leads to a much more strict method of PM measurement. The resulting modifications for the gravimetric PM sampling and other standards were published in the CFR Title $40 \mathrm{Pt} 86$ and are explained in the following sections. The new standards are divided into the Gravimetric Sampling System, Allowable Filter Specifications, and Filter Weighing Techniques and Clean Room Specifications. A brief review is included, highlighting the most recent EPA recommendations and significant changes.

\subsubsection{Dilution Tunnel Specifications}

The EPA has established a new PM compliance level of 0.01g/bhp-hr within the 2007 regulations, decreasing the allowable level by an entire order of magnitude. This drastic change has influenced not only the regulations concerning the filter measurement systems but also the weighing procedures and even the filters themselves. The following section concentrates on the 2007 modifications regarding PM collection [31].

The mass of PM from the exhaust is to be determined via filtration. The particulate sampling system requires dilution of the exhaust to a temperature of $47 \pm 5^{\circ} \mathrm{C}$, $125 \pm 7^{\circ} \mathrm{F}$, measured upstream of a single or double, high-efficiency sample filter. The constant volume sampling (CVS) is to meet the required specifications of the gas sampling system, satisfactorily maintain the primary dilution air below $191^{\circ} \mathrm{C}$, in order for the cooling of the exhaust to be the result of dilution and mixing rather than heat transfer through the surfaces of the sampling systems [31]. The secondary dilution 
system must be sampled proportionally to the primary system, meaning the mass flow ratio must remain $\pm 5 \%$.

The secondary dilution system must be able to appropriately supply the secondary dilution air to maintain the exhaust stream at the required $47 \pm 5^{\circ} \mathrm{C}$. This measurement must be checked between the filter face and $16 \mathrm{~cm}$ upstream of the filter face [31]. The air used for both primary and secondary dilution must be maintained at a temperature of $\geq 15{ }^{\circ} \mathrm{C}$. The secondary dilution air must be filtered using a high efficiency particle airfilter (HEPA) with an advertised efficiency of $99.97 \%$. The primary dilution air must be filtered using a filter providing an efficiency rate of $98 \%$ or higher, but a HEPA filter similar to that used for the secondary air is recommended [31]. The primary air must be sampled for the background PM. The sampling position needs to be positioned between the particulate filter and the engine exhaust tube.

The PM filter is to be placed no more than 12 inches from the secondary dilution tunnel exit with the flow not to exceed a face velocity of $100 \mathrm{~cm} / \mathrm{sec}$ [31].

\subsubsection{Filter Collection Specifications}

Once the exhaust stream enters the PM filtration system it must pass through a particle preclassifier, upstream of the filter holder assembly. This preclassifier will remove the coarse undesired mechanically caused solid particulates from the stream and allowing only the carbon chain agglomerates caused during the combustion process to pass through to the filter [31].

The particulate filters in use must have a diameter of $46.50 \pm 0.6 \mathrm{~mm}, 38 \mathrm{~mm}$ minimum stain diameter. The allowable media types include: Polytetrafluoroethylene (PTFE or Teflon) coated borosilicate glass fiber high-efficiency filters or PTFE, or Teflon, high-efficiency membrane filters with an integral support ring of polymethylpentene (PMP) or equivalent inert material. The filter efficiency must have a minimum value of $99 \%$ as specified by the manufacturer [31].

The filter holder assembly shall be made of 302,303 , or 304 stainless steel. The holder shall comply with all other specifications established in 40 CFR Part 50, Appendix L 7.3.5. Variations to the holder can be used so long as there is an even flow distribution across the filter media and a leak-free seal with the filter cartridge assembly [31]. 


\subsubsection{Filter Weighing Techniques and Clean Room Specifications}

A number of filter weight measurement processes have been standardized in order to reduce possible fluctuations. The precision of the filter microbalance has been reduced from $20 \mu \mathrm{g}$ to $2.5 \mu \mathrm{g}$. The allowable drift of reference filter weights has also been reduced from $\pm 40 \mu \mathrm{g}$ to $\pm 10 \mu \mathrm{g}$. The allowance for the use of the average of multiple filter weights has been included [29,31].

A preconditioning period is now required for the entire sampling system of 30 minutes instead of the previous 60 minutes. The use of static neutralizers and grounded tweezers has also become a required procedure $[29,31]$.

The tolerances of the weight room have become tighter. A Class 1000 Clean Room has been recommended, a controlled area where no more than 1000 particles of diameter greater than $0.5 \mu \mathrm{g}$ exist within any given cubic foot of air. The conditions of the area must be able to be controlled to $22 \pm 1{ }^{\circ} \mathrm{C}$ temperature, $9.5 \pm 1{ }^{\circ} \mathrm{C}$ dewpoint temperature, and a $45 \pm 8 \%$ relative humidity $[29,31]$.

\subsection{Previous 2007 PM Studies}

\subsubsection{Southwest Research Institute - Imad A Khalek, Ph.D.}

Dr. Imad A. Khalek led the 2007 Diesel Particulate Measurement Research Project, funded by the Coordinating Research Council (CRC), Department of Energy National Renewable Energy Laboratory (DOE/NREL), EPA, Engine Manufacturers Association (EMA), and California Air Resources Board (CARB) [5]. There were several objectives considered as a part of Project E-66 by the Southwest Research Institute (SwRI) Phase 1.

The first goal was to minimize the volatile and semi-volatile gas adsorption onto the PM collecting filters by installing a carbon denuder. Denuders are designed to separate the carbonates from these gases in order to allow the undesired volatiles to pass through the filter. However, due to inconsistencies in the performance of the carbon denuder, the analysis of volatile and semi-volatile gas adsorption was abandoned in the early stages of the program. 
The second goal was to investigate the relationship between filter media types and the corresponding PM emissions. After comparing a wide range of filter media and manufacturers, Khalek recommended the use of the Teflo filter media. The Teflon membrane contains a PMP ring and led to the lowest average positive artifact mass. This filter type also had the lowest coefficient of variation when compared to the TX-40 and other Teflon membrane filters. Recommendations concerning pre-baking of the filter media and the necessity of a secondary PM filter were also made. After exploring the weight fluctuations between pre-baked and unbaked filters, Khalek determined that there was no significant difference between the performance of baked and unbaked filters. Use of a secondary filter, at least for the Teflo media, also appeared to be unnecessary since the average weight gain of the filter was very near that of the clean filter weight variability and therefore within the filter weighing uncertainty.

Next the effect of filter face velocity on collected PM emissions was explored. The filter face velocity proved to have a significant effect on PM deposition. For example, when running federal test procedure transient test cycles, increasing the filter face velocity from $24 \mathrm{~cm} / \mathrm{s}$ to $120 \mathrm{~cm} / \mathrm{s}$ led to a $25 \%$ decrease in PM deposition. This relationship also held steady for a light load cycle with results showing a $60 \%$ decrease in PM when adjusting the filter face velocity from $120 \mathrm{~cm} / \mathrm{s}$ to $60 \mathrm{~cm} / \mathrm{s}$. It should also be noted that the PM sampling time was also a significant contributor to PM deposition. Tests were performed in 40 and 20 minute intervals with the shorter sample time consistently produced a lower PM emission level. Khalek suggests that gas phase adsorption on the filter and filter saturation may be responsible for these observed changes. The resulting recommendation is to increase the protocol on allowable filter face velocities. Khalek includes a possible range of $90 \mathrm{~cm} / \mathrm{s} \pm 10 \mathrm{~cm} / \mathrm{s}$ instead of the allowable range of less than $100 \mathrm{~cm} / \mathrm{s}$. Narrowing this velocity window could minimize the obvious variations in PM deposition. This effect of velocity on PM measurement may be filter media dependent. More in depth studies could explore this relationship on a number of common filter media types.

Finally the fourth, and last, objective was to explore the performance of several other methods of PM measurement including instruments such as the SMPS, DMM-230, which is a particle impactor system, and the QCM. These systems were compared to the 
gravimetric methods complying with the 2007 PM protocol. It should first be noted that the QCM was inconsistent and results were not included within the determined conclusions of Khalek's publication. However, a good correlation was obtained between the DMM-230, SMPS and the filter-based method. When the DMM-230 was used for the filter face velocity experiments, the emissions measurements were shown to be much more repeatable. This difference may be due to the flow concentration affecting the real time system instead of sensitivity to the filter face velocity.

These tools have different applications; the DMM-230 explores real time particle mass, the EEPS also includes particle number and size, and the SMPS can only operate within steady-state mode testing. These real time measurement systems give a much broader information spectrum than obtainable using gravimetric PM measurement. While the real time systems were similar to the filter weighing method concerning PM mass, the SMPS and EEPS actually were inconsistent with each other concerning concentration and particle size number. This discrepancy may have been due to particle charging and system response time differences.

\subsubsection{University of Minnesota - David B. Kittelson, Ph.D.}

In 1999 Kittelson published the University of Minnesota's review of diesel PM sampling methods, a project sponsored by the EPA [11]. A critical section of this extensive review concerned the dilution ratio and residence transfer time of exhaust PM. By comparing a critical saturation ratio, the ratio at which the desired behavior of organic adsorption produces the formation of nanoparticles, to the corresponding dilution ratios, Kittleson recommends a critical dilution ratio range of between 5 and 50:1. Many atmospheric measurements over roadways show large numbers of these nanoparticles. This suggests that roadway dilution conditions may lead to nanoparticle formation, validating the recommended critical dilution ratio.

While some gas-to-particle mass transfer occurs during dilution, SOF collection depends on dilution ratio, and this effect does not change total collected mass significantly. However, even small amounts of mass transfer have enormous effects on the number concentration and weighted size distribution of particles. Therefore if any changes were made to the current mass based emission standards to include size or 
number concentration measurements, measurement and sampling challenges would be significant [11].

One should note that the $90 \%$ decrease in allowable PM mass legislation has been adopted since Kittelson's study. This leads to the importance of the discussed gas-toparticle mass transfer during the dilution process. While the previous higher mass levels of PM were not affected by the SOF collection, the newer levels will see a significant contribution.

\subsubsection{Ford Motor Company - Matti Maricq, Ph.D.}

Maricq presented the 2007 Exhaust Composition and Sampling Artifacts research at the 2003 ACES Workshop [32]. The scope of this research was to answer a set range of questions concerning the sampling of exhaust PM. By exploring the problems encountered in PM filtration, an appropriate test plan was formed. A vapor artifact relative to filter media analysis was first performed by using multiple filters in series with the exhaust stream. Next several filter media and real time aerosol instruments were evaluated in parallel. Finally a comparison between SOF and PM fractions deposited on a filter were evaluated using a thermal analysis.

- Expected positive and negative artifacts in filter samples and their effect on PM sample characterization.

Downstream of a diesel particulate filter (DPF) a positive artifact is expected since particles' levels can be low enough that filter collected mass is dominated by adsorbed gaseous species. The gaseous species give an artificially high PM level for the filter based mass. Maricq recommends the use of a denuder system, an apparatus which separates gases and aerosols depending upon the difference in their diffusion velocity, to remove gaseous artifacts and an aerosol instrument for consistency checks.

- How sampling should be conducted in order for properly determining nitrate composition during long-term filter sampling.

Once again the use of a denuder will remove the positive artifact, however Maricq also recommends the use of a secondary nylon backup filter to reduce negative artifact. 
- Appropriate exhaust residence time and dilution/concentrations.

Because of the need to reduce water content and exhaust temperature in order to remove chemical and physical aerosol processes, dilution is necessary. The dilution drawback is that a reduced exhaust concentration reduces exposure and PM characterization. Therefore, at anticipated low levels of emissions, dilution ratios will need to be kept minimal.

- Techniques to be used for sampling total exhaust.

In order to receive an accurate total PM measurement, Maricq recommends the use of Teflon filters for PM mass, due to minimal artifact collection, and a particle mass spectrometer for chemical characterization. For the sake of measurement accuracy, the transfer hose/dilution tunnel must be kept clean and the dilution air must be filtered.

\subsubsection{Cummins Inc. - Shirish A. Shimpi, Ph.D.}

After reviewing the EPA legislation changes for the 2007 standards, Shimpi established a wide array of complications that the lowered allowable levels will present [29]. The first area of concern deals with the percentage of background PM to the total collected PM concentration. At the minute allowable level of $0.01 \mathrm{~g} / \mathrm{bhp}$-hr over a standard FTP cycle, Shimpi estimates the background PM concentration to make up 11$31 \%$ and $0.3-0.9 \%$ of the total PM concentration for unfiltered and filtered dilution air respectively. Shimpi also noted that the fluctuations in the required $2.5 \mu \mathrm{g}$ balance precision could allow for $1.9-4.9 \%$ of the filter loading.

Because of the low 2007 levels, a number of factors are expected to lead to a high variability. The results are expected to be especially different between one test location to another, therefore understanding measurement issues needs to be improved to help reduce this variability. 


\subsection{Areas of Concern}

There are several parameters related to gravimetric mass based PM collection which need further research. These parameters include: filter media selection, dilution ratio, and filter face velocities.

\subsubsection{Filter Media Type Selection}

At the 2007 levels, artifact formation is a main concern. Filter media has been identified as an important factor in artifact formation [29]. The 2007 regulations have recommended a number of allowable filter media types. The efficiencies and validity of PM mass collected still vary between filter media type and filter manufacturer. Therefore it is critical to test the multiple filter types with several SDRs and FFVs.

\subsubsection{Dilution Ratios}

At the 2007 levels, the PM collected on the filter will be nearly all semi-volatile aerosols with very little carbon. The formation of these aerosols is highly path dependent, therefore the process of exhaust cooling and dilution is a very critical component to the resulting PM [29]. The new regulation changes have eliminated dilution problems caused by fluctuating dilution air temperature and residence times. These changes will lead to further research and analysis on direct effect of dilution ratio to collected PM as well as the validity of PM mass data.

\subsubsection{Filter Face Velocities}

The filter face velocity has also been identified as a critical variable that effects the formation of aerosols and therefore leads to fluctuations in PM filter deposition. After showing a direct relationship between decreasing the FFV and an increase in PM deposition, Khalek concluded that a range of $90 \mathrm{~cm} / \mathrm{s} \pm 10 \mathrm{~cm} / \mathrm{s}$ produced the most consistent PM results [5]. However this study only represented one filter media type and dilution ratio, and therefore the acceptable range of FFVs should receive a more in depth study. 


\subsection{Conclusions}

This chapter introduced and discussed many issues concerning PM. PM constituents and their effects on human health and the environment were briefly reviewed. Many methods of PM measurement from mass based, particle size, and particle size number methods, and their specific systems were also assessed. Most importantly however, the 2007 standards, set forth by the 40 CFR 86, were reviewed in order to assure compliance by the $47 \mathrm{~mm}$ PM collection system designed at West Virginia University. By investigating previous PM literature, a scope of system validation, as well as research, experiments were planned and implemented. 


\section{Experimental Setup}

\subsection{Introduction}

As a result of the EPA's 2007 PM Regulations, WVU researched commercially available secondary dilution PM measurement systems, and chose to design and fabricate a system in-house. The specific components are discussed in the following sections and are categorized into three areas; dilution air conditioning, secondary dilution tunnel, and temperature controlled PM sampling unit.

\subsection{WVU 2007 EPA Compliant PM System}

\subsubsection{Dilution Air}

The ambient air used for the secondary dilution of the 2007 compliant system has to undergo strict conditioning requirements. The air must be filtered using a HEPA filter, with $99.97 \%$ efficiency, for $0.3 \mu \mathrm{m}$ particles, and maintained at a temperature greater then or equal to $15^{\circ} \mathrm{C}$ [31]. In order to comply with regulations, WVU assembled their own secondary dilution air conditioning unit. Initially, air is drawn from an ambient source and passed through a primary HEPA filter. The air flows through a refrigerator dryer; condensing moisture from the air stream. The physical principle consists of cooling the air down to a few degrees above $0{ }^{\circ} \mathrm{C}$, then separating the condensate from the compressed air flow rate and disposing of it externally [36].

The air then enters a refrigeration unit designed to maintain a secondary air temperature of at least $15^{\circ} \mathrm{C}$. The flow travels through several coils within the refrigerator in order to reach the appropriate temperature. Next the air travels through another HEPA filter, with the required $99.97 \%$ efficiency, before flowing through a condensation chamber where any remaining moisture will be separated and drained from the sample. Finally the filtered, dried, and appropriately heated/cooled sample air is distributed to the secondary dilution tunnel. The flow rate for this system is continuously metered using digital mass flow controllers with instantaneous feedback. A schematic of this design can be seen below in Figure 3.1. 


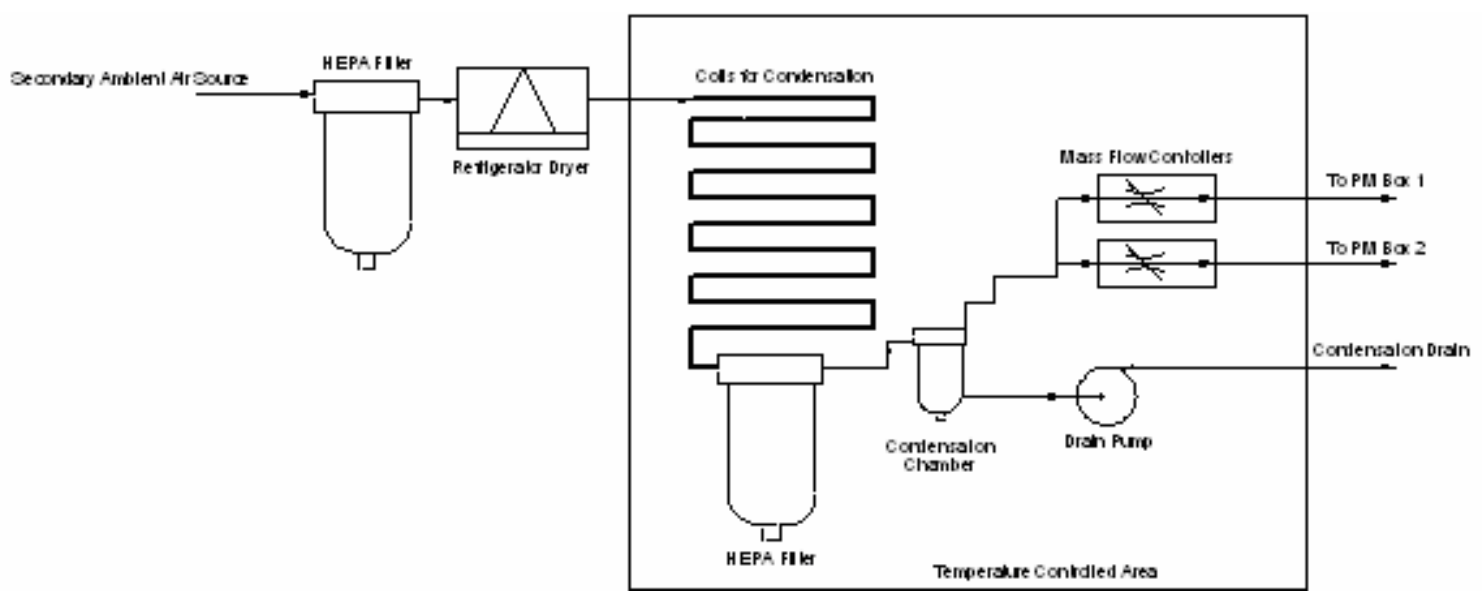

Figure 3.1 WVU 2007 Temperature Controlled Secondary Dilution Air Conditioner

\subsubsection{Dilution Tunnel}

The secondary dilution tunnel, shown in Figure 3.2 and Figure 3.3, is a mixing region for the sampled exhaust from the primary tunnel and the secondary dilution air. The system was designed to maintain flow proportional to within $\pm 5 \%$ of the main tunnel flow rate. This mixing region was controlled at a uniform temperature of $47 \pm 5$ ${ }^{\circ} \mathrm{C}$ and the exhaust was less than 12 inches from the filter face. It should be noted that because the pre-2007 primary exhaust tunnel was used with this research, the secondary dilution tunnel was longer then desired. Laboratory positioning forced the design to be less efficient then required, however, the system was designed to eliminate excessive transport distances and flow obstructions.

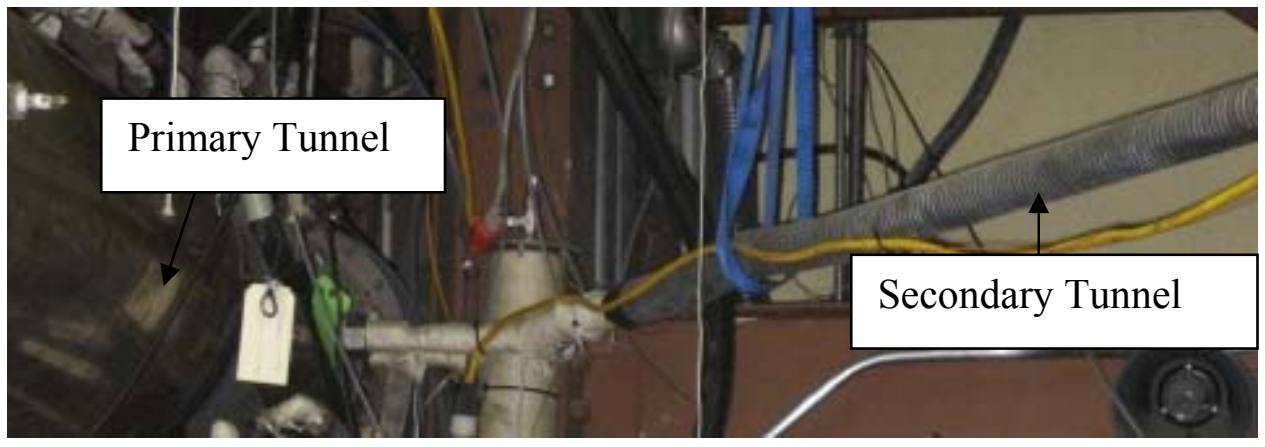

Figure 3.2 Secondary Dilution Tunnel from Old Tunnel Sample Port 


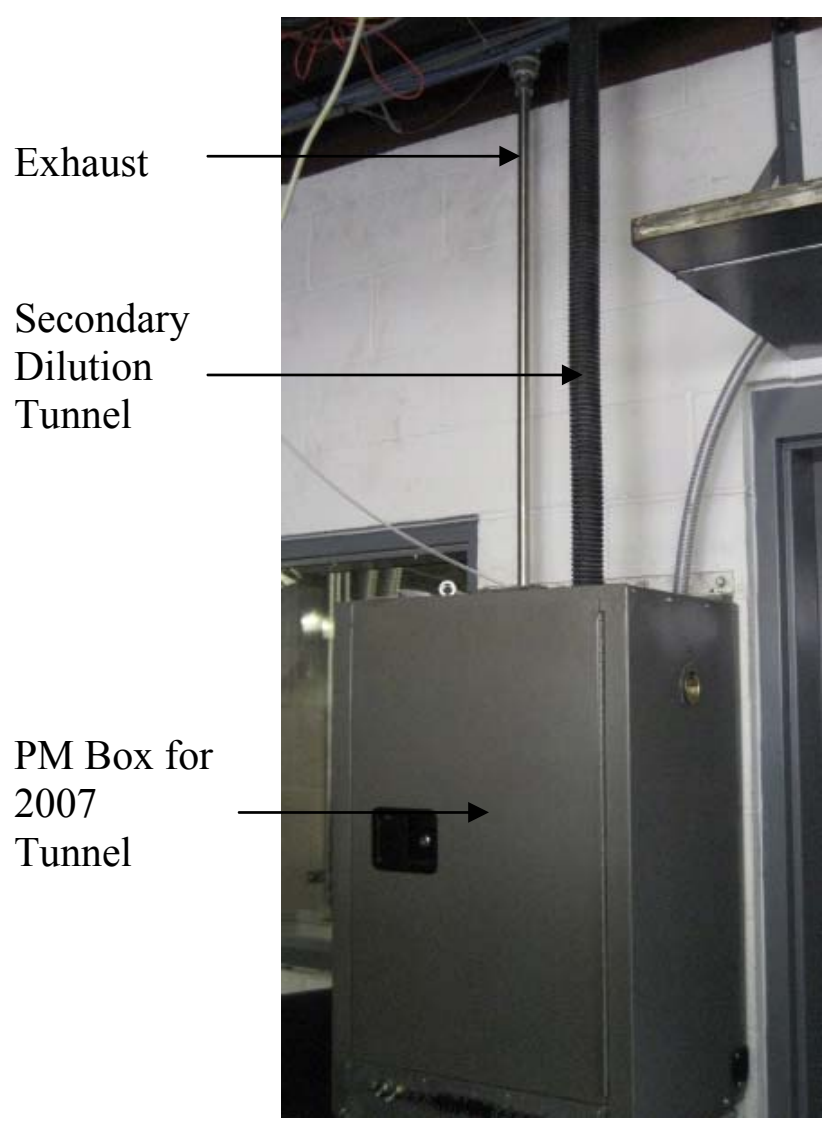

Figure 3.3 PM Sampling System, Sec Dilution Tunnel and PM Box for 2007 Tunnel

\subsubsection{PM Box}

The actual gravimetric, temperature controlled, filter housing container design implements a size-selective impactor placed immediately prior to a T-connection, wherein sample flow is diverted to the sample filter holder or to a bypass leg. The flow rate through these two sample legs is continuously metered with digital mass flow controllers to provide for accurate sample proportionality, while not affecting cyclone cut-size. Additional filters are mounted in both of these sample streams in order to protect the mass flow meters and pumps in the event of a sample filter omission. Rotary vane vacuum pumps are in line to minimize possible pressure pulsations. Figures showing the temperature controlled PM sampling system can be viewed in Figures 3.4 and 3.5 . 


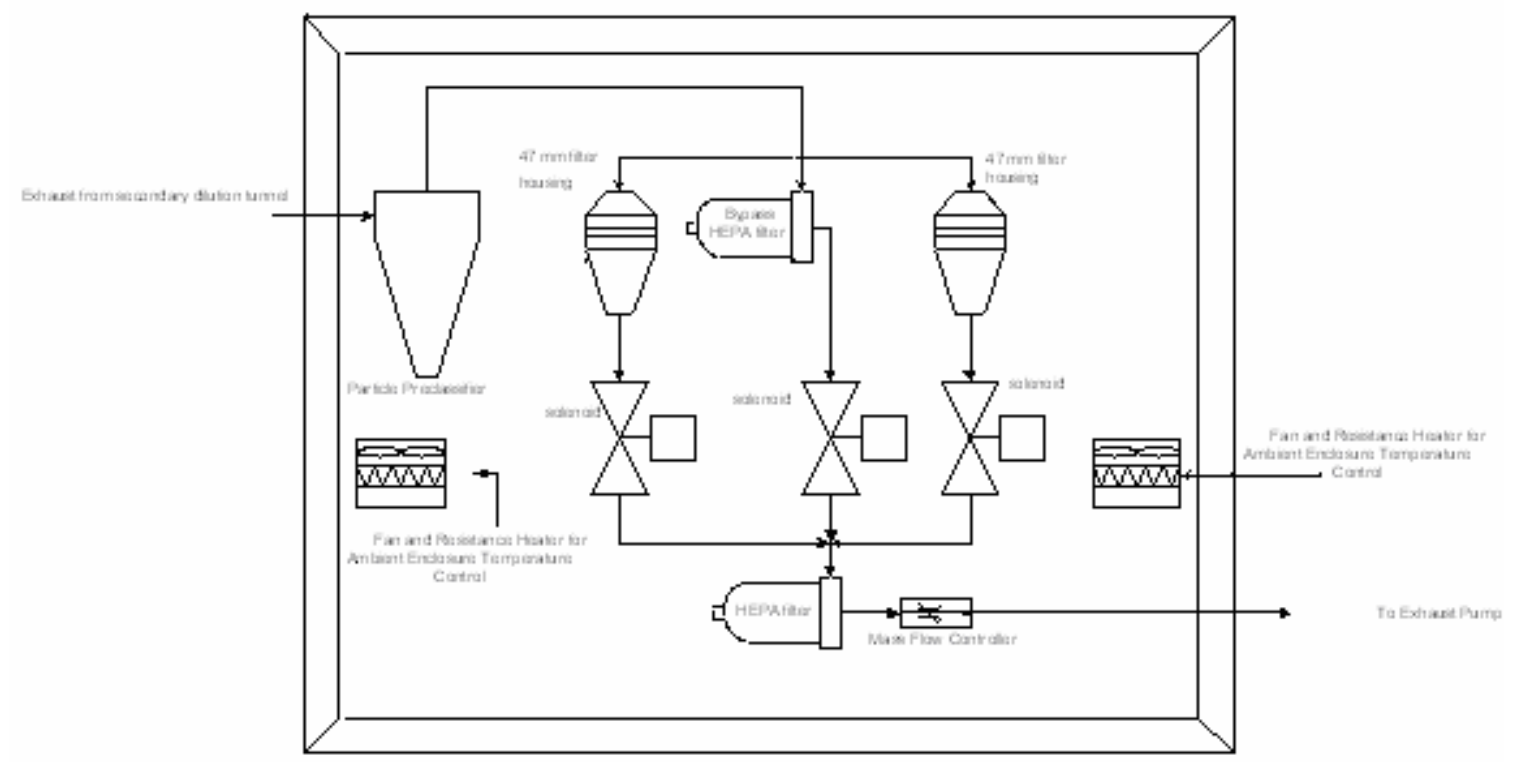

Figure 3.4 WVU Temperature Controlled 2007 Compliant PM Sampling System

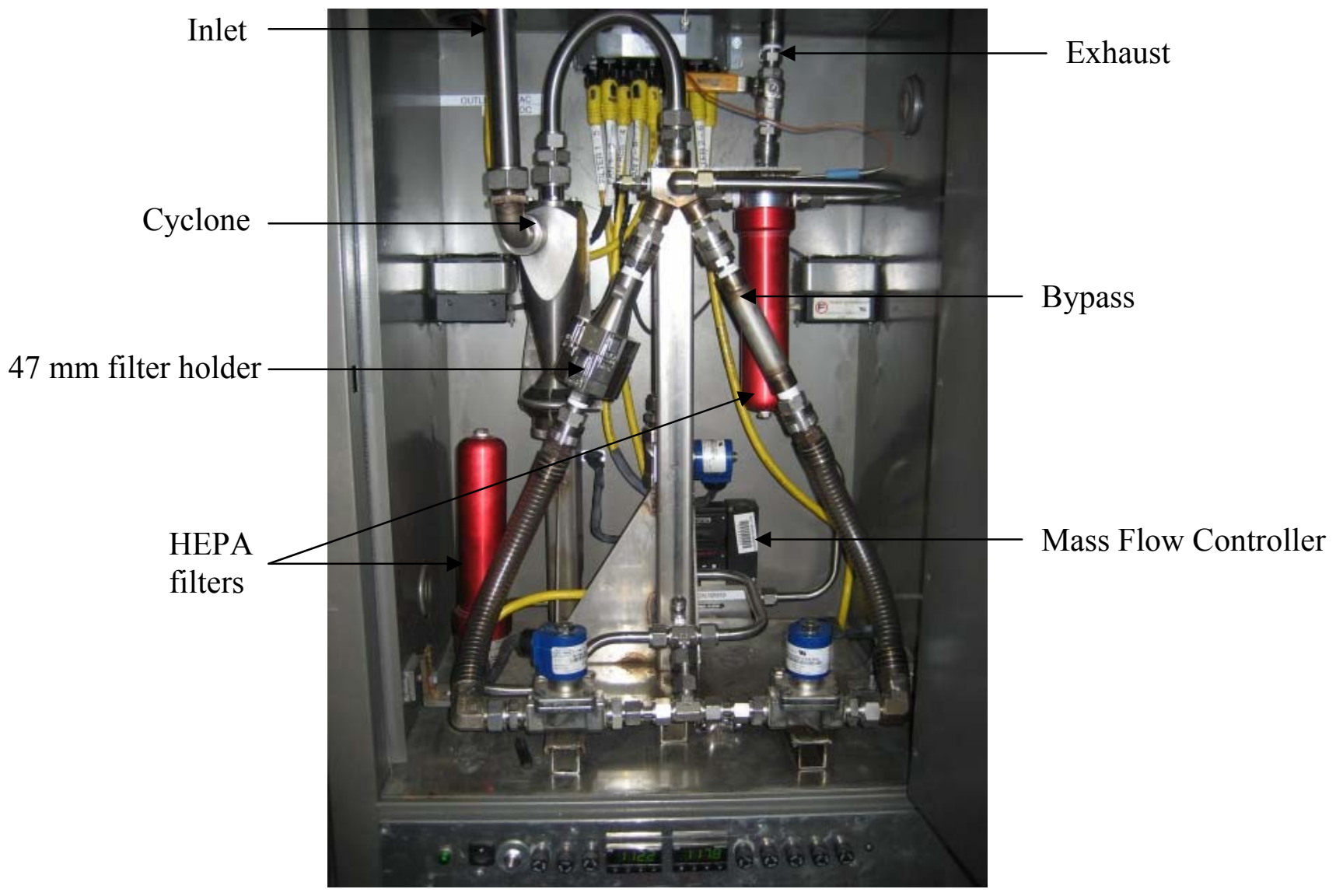

Figure 3.5 Photograph of WVU 2007 Compliant PM Sampling System 
The specific manufacturers of the components used are listed in Table 3.1 and Table 3.2.

Table 3.1 List of Components Used for WVU Secondary Dilution Conditioner / Tunnel System

\begin{tabular}{|c|c|c|}
\hline Description & Manufacturer & Quantity \\
$\begin{array}{c}\text { Air } \\
\text { Conditioning } \\
\text { Unit }\end{array}$ & Domnick Hunter & 1 \\
\hline $\begin{array}{c}\text { Primary HEPA } \\
\text { Filter }\end{array}$ & $\begin{array}{c}\text { United Filtration } \\
\text { Systems }\end{array}$ & 1 \\
\hline $\begin{array}{c}\text { Final HEPA } \\
\text { Filter }\end{array}$ & PALL & 1 \\
\hline $\begin{array}{c}\text { Mass Flow } \\
\text { Controller }\end{array}$ & Sierra \\
\hline $\begin{array}{c}\text { Solenoid } \\
\text { Valves }\end{array}$ & $\begin{array}{c}\text { B/C Valve } \\
\text { Company }\end{array}$ & 1 \\
\hline Drain Pump & - & 1 \\
\hline $\begin{array}{c}\text { Condensation } \\
\text { Chamber }\end{array}$ & - & 1 \\
\hline
\end{tabular}

Table 3.2 List of Components Used for WVU PM System

\begin{tabular}{|c|c|c|}
\hline Description & Manufacturer & Quantity \\
\hline $\begin{array}{c}2.5 \mu \mathrm{m}-10 \mu \mathrm{m} \\
\text { cut Cyclone }\end{array}$ & URG & 1 \\
\hline $\begin{array}{c}47 \mathrm{~mm} \text { Filter } \\
\text { Holder }\end{array}$ & URG & 2 \\
\hline HEPA Filter & $\begin{array}{c}\text { United Filtration } \\
\text { Systems }\end{array}$ & 2 \\
\hline $\begin{array}{c}\text { Mass Flow } \\
\text { Controller }\end{array}$ & $\begin{array}{c}\text { Sierra } \\
\text { Instruments Inc. }\end{array}$ & 3 \\
\hline $\begin{array}{c}\text { Solenoid } \\
\text { Valves }\end{array}$ & $\begin{array}{c}\text { B/C Valve } \\
\text { Company }\end{array}$ & 2 \\
\hline $\begin{array}{c}\text { Axial Fan } \\
\text { Heater }\end{array}$ & $\begin{array}{c}\text { Farnam Custom } \\
\text { Products }\end{array}$ & \\
\hline
\end{tabular}




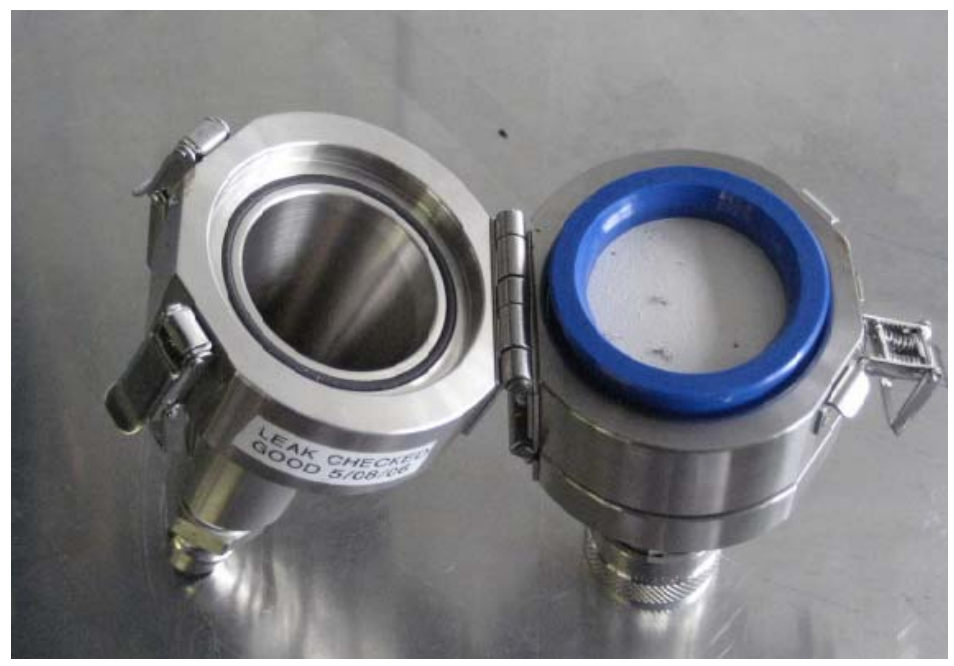

Figure 3.6 URG 47 mm Filter Holder

\subsubsection{Filter Media}

Three filter media types, and specifications, chosen for this research are shown in Table 3.3. These particular filters were chosen in accordance with regulations established within CFR 40, Part 86, Subpart N and were selected in order to identify which type should be used for the optimal results. The Teflo and Tx40 filters were also used within Khalek's E-66 project, while the T60A20 was used as it was the pre-2007 media of choice. All three media types were used within the URG $47 \mathrm{~mm}$ filter holder shown in Figure 3.6.

Table 3.3 Characteristics of Different Filter Media [33].

\begin{tabular}{|l|l|l|l|l|}
\hline $\begin{array}{l}\text { Filter } \\
\text { Media }\end{array}$ & Manufacturer & $\begin{array}{l}\text { Initial Single } \\
\text { Filter Weight } \\
\text { (approx.) }\end{array}$ & Material & $\begin{array}{l}\text { Efficiency \% } \\
\text { (manufacturer } \\
\text { rating). }\end{array}$ \\
\hline Teflo & Pall & 180 & $\begin{array}{l}\text { PTFE Membrane with } \\
\text { PMP ring }\end{array}$ & 99.99 \\
\hline Tx40 & Pall & 90 & $\begin{array}{l}\text { PTFE Coated } \\
\text { Borosilicate Glass } \\
\text { Fiber }\end{array}$ & 99.90 \\
\hline T60A20 & Pall & 70 & $\begin{array}{l}\text { Borosilicate Glass fiber } \\
\text { coated with TFE }\end{array}$ & 96.4 \\
\hline $\begin{array}{l}\text { PTFE - Polytetrafluroethylene } \\
\text { PMP - Polymethylpentene } \\
\text { TFE - Fluorocarbon }\end{array}$
\end{tabular}




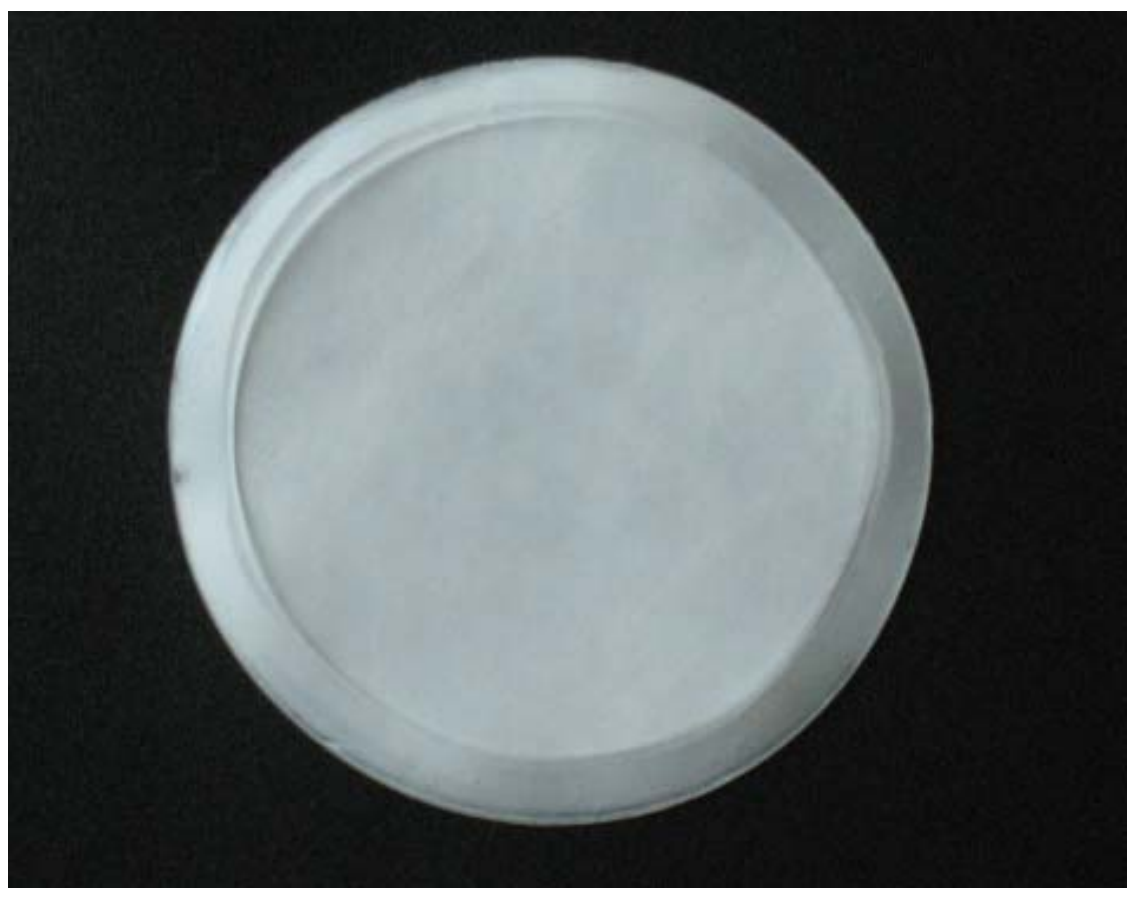

Figure 3.7 Pall Teflo Filter

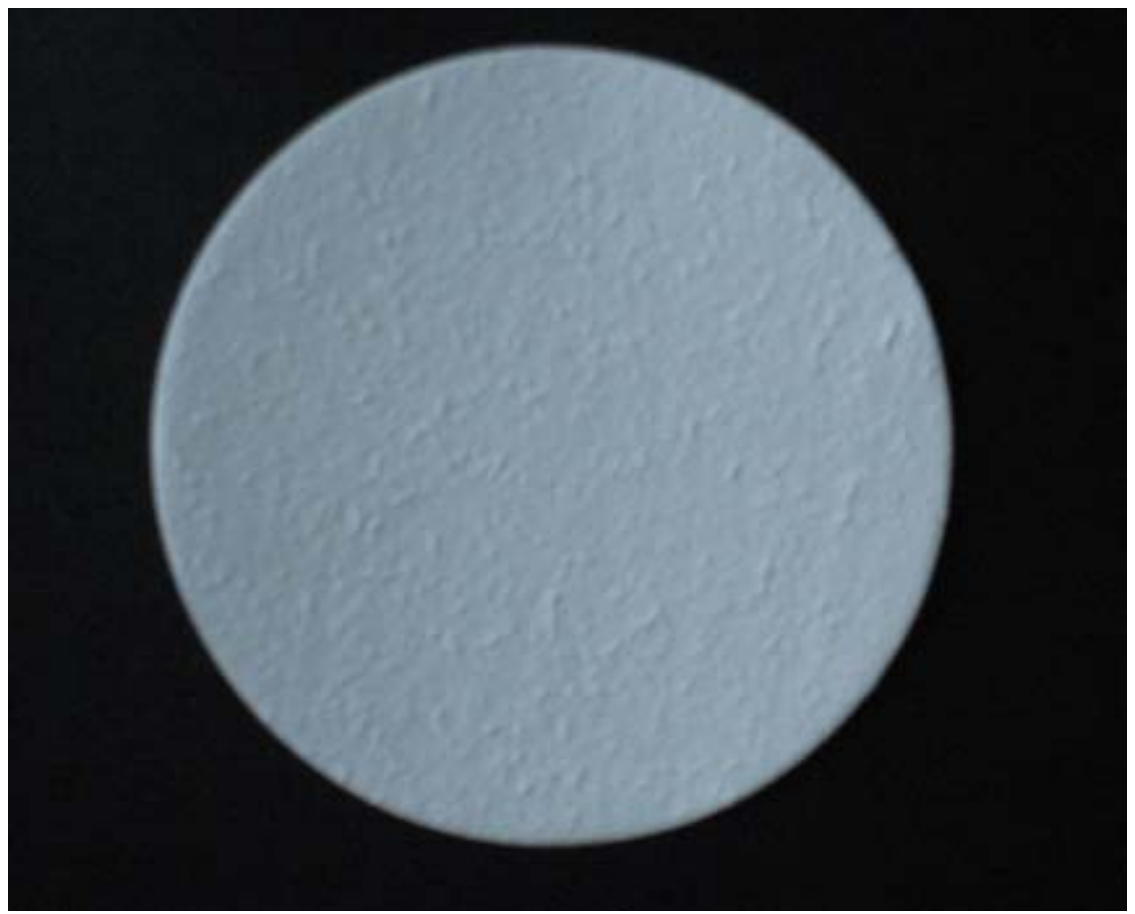

Figure 3.8 Pall Tx40 Filter 


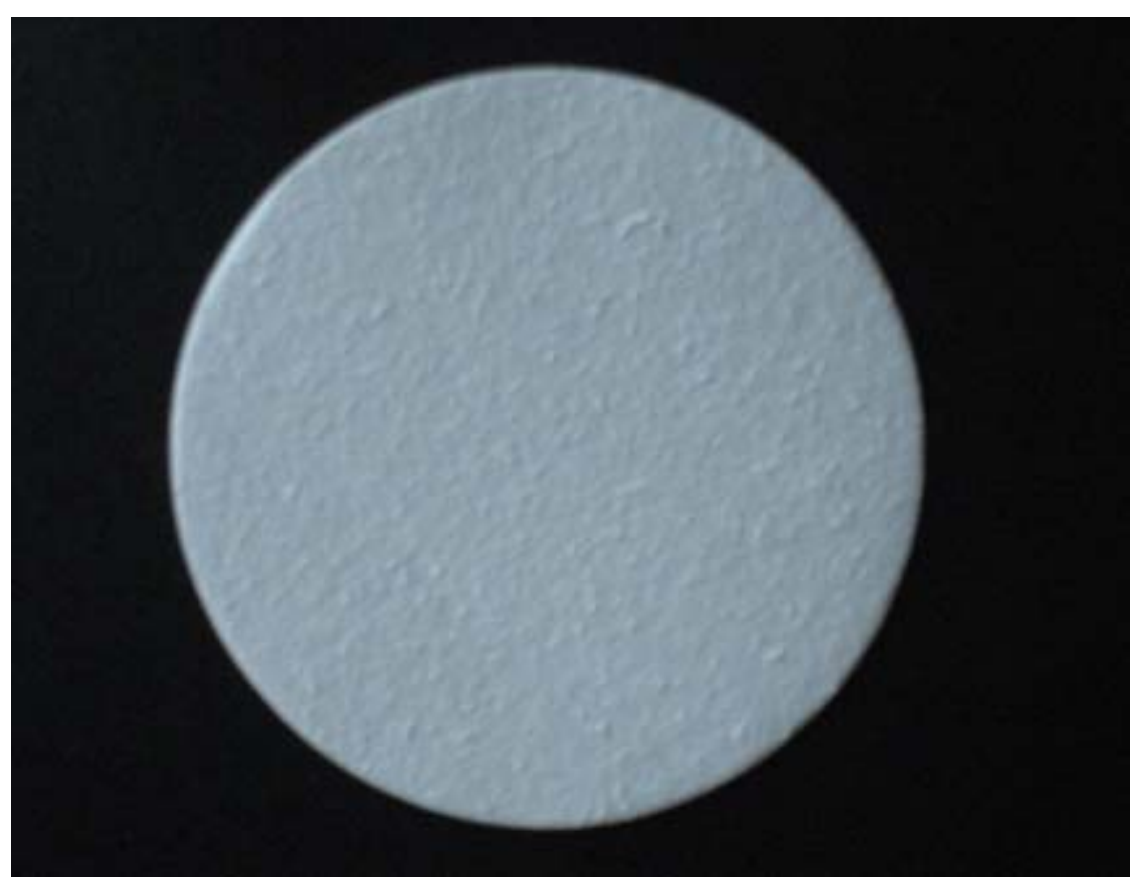

Figure 3.9 Pall T60A20 Filter

\subsection{WVU EERL}

All the testing for this research was conducted using the engine dynamometer in WVU's EERL in Morgantown, West Virginia. The laboratory was built to meet the specifications as required in CFR 40, Part 86 Subpart N, and has been fully operational since 1993. A brief description of the main flow tunnel components used during the testing is included in this section. Figure 3.10 shows the schematic of WVU EERL emission measurement system. 


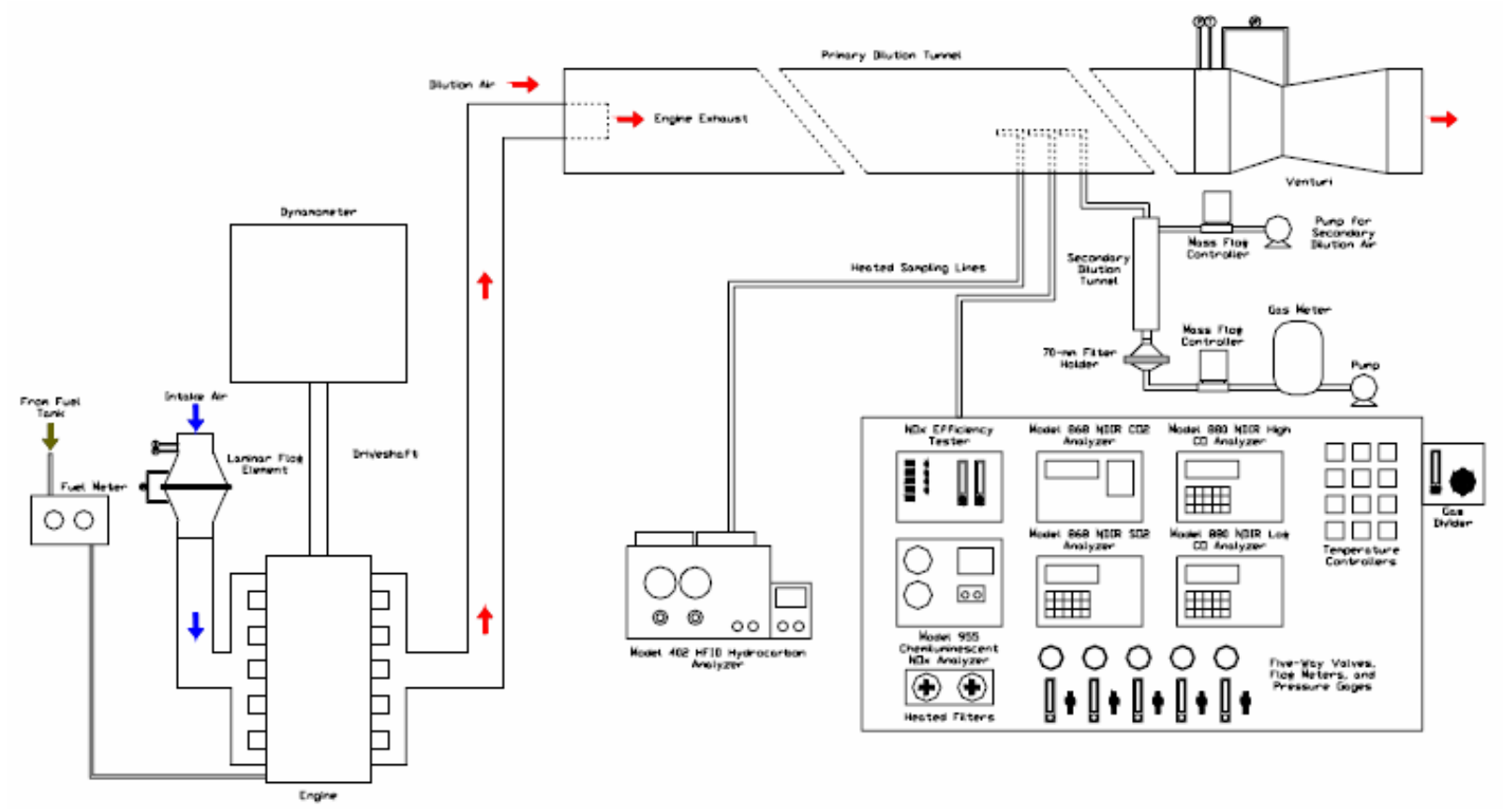

Figure 3.10 Schematic of WVU EERC Emission Measurement System [34]

\subsubsection{Engine Dynamometer}

In a laboratory environment, a load must be applied to the engine to simulate the real world vehicle load that an engine receives. This is the purpose of an engine dynamometer. The engine dynamometer at WVU EERL that was used for this testing was a General Electric (GE) model DYC 243 air-cooled, direct current (DC) dynamometer. It has the capabilities to absorb up to $550 \mathrm{hp}$ and providing $500 \mathrm{hp}$ to motor the engine. Torque is measured using a load cell, which is attached to an arm of known length to measure force. Engine speed is determined via a digital encoder mounted inside of the dynamometer. A driveshaft and a coupling link the dynamometer directly to the flywheel of the engine. The GE dynamometer is shown in Figure 3.11. 


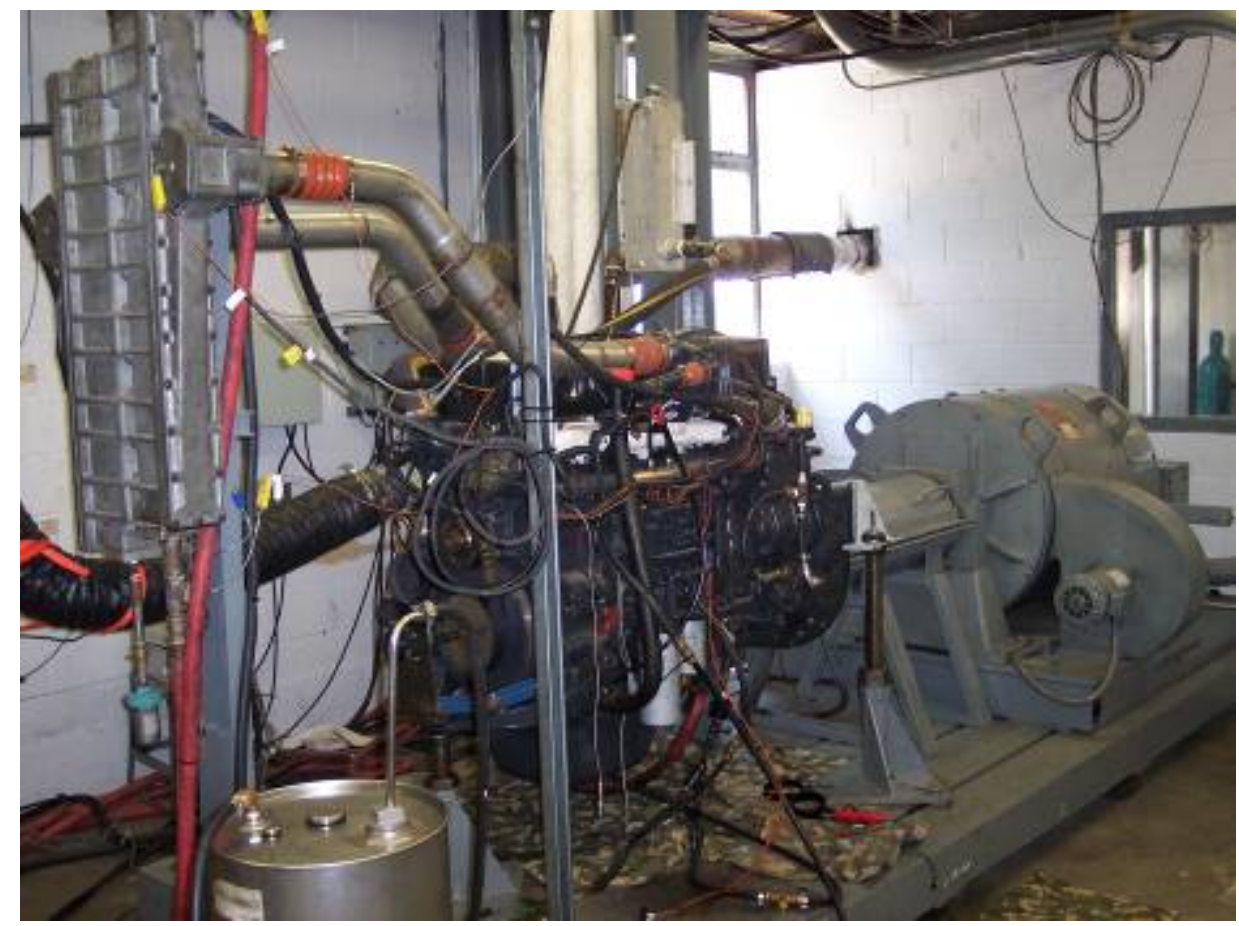

Figure 3.11 WVU EERL Test Bed with HDDE and GE Dynamometer

\subsubsection{Full Flow Primary Exhaust Dilution Tunnel}

The main purpose of a dilution tunnel is to dilute the exhaust gas sample in order to simulate natural ambient air dilution of vehicle exhaust. By simulating this real-world condition, it is possible to measure accurately the exhaust emissions as found in the atmosphere. The dilution tunnel can also lower dewpoint temperature of the exhaust gas to prevent condensation in the sampling line, remove harmful moisture from the analyzers, and prevent post cylinder combustion reactions. The dilution tunnel is an 18 inch diameter, 40 feet in length duct made out of stainless steel. A 75 hp blower pulls a temperature controlled air mixture through the tunnel where a combination of four venturis provides a constant flow rate of $400 \mathrm{scfm}$ to $3400 \mathrm{scfm}$. An orifice is placed 3 feet from the entrance to aide the mixing of exhaust gas with dilution gas. Sample probes are placed 15 feet downstream from the inlet to direct a portion of the mixture into the analyzers. The whole configuration satisfies the requirements as set forth in CFR 40, Part 86 , Subpart N. 


\subsubsection{Critical Flow Venturi}

A constant volume sampling (CVS) system as described in CFR 40, Part 86, Subpart $\mathrm{N}$ is used for the regulation of the diluted exhaust flow. The WVU EERL employs three venturis designed for a $1000 \mathrm{scfm}$ flow rate and one venturi designed for $400 \mathrm{scfm}$ flow rate. The purpose of this system is to maintain constant total flow rate, which is expressed as a relationship between a calibration coefficient $\left(\mathrm{K}_{\mathrm{v}}\right)$, absolute venture inlet pressure $(\mathrm{P})$, and the absolute venture inlet gas temperature $(\mathrm{T})$. The corresponding standardized flow rate can then be computed with the following expression.

\section{Equation 3.1}

$$
\dot{Q}=K_{v} \frac{P}{\sqrt{T}}
$$

Although the tunnel has a flow rate rating of $3400 \mathrm{scfm}$, the conditioned air cannot be supplied sufficiently to maintain this rating continuously. The tunnel can be maintained at $3000 \mathrm{scfm}$.

\subsubsection{0 mm PM Filter System}

A PM sampling system compliant with pre-2007 CFR 40, Part 86, Subpart N regulations was used for comparison with the new $47 \mathrm{~mm}$ system. The PM is collected onto primary and secondary $70 \mathrm{~mm}$ T60A20 filters at nominal FFV of $100 \mathrm{~cm} / \mathrm{s}$, yet tunnel flow proportionality is maintained. The T60A20 filter manufacturer rated efficiency is only $96.4 \%$, which is to low for the most recent CFR standards.

\subsection{Engine Configuration}

The data were obtained in conjunction with a number of fuel studies as well as other graduate research projects. These different projects implemented the use of four different heavy duty diesel engines. The engines used within the scope of this research include: (A) 1992 Detroit Diesel Series 60 (rebuilt), (B) 1992 Detroit Diesel Series 60, (C) 2004 Cummins ISM 370, and (D) 1999 Cummins ISM 370. 


\subsection{WVU Cleanroom}

The WVU Cleanroom was designed and built by the specifications laid out by CFR 40, Part 86 Subpart N. The equipment includes a precision microbalance, with readability of $0.1 \mu \mathrm{g}$ and a precision of $0.25 \mu \mathrm{g}$ used to measure the filter weights. Environment, calibration and weighing information is recorded by software on WVU's cleanroom computer. Weighing procedures are outlined in order to reduce unwanted variation in filter weight measurements.

The room undergoes strict maintenance to ensure that particles are minimized and class 1000 status, where the particle count cannot exceed 1000 particles of size $0.5 \mu \mathrm{m}$ per square foot, can be maintained.

\subsection{Federal Test Procedure}

It is necessary to certify HDDEs over a pre-determined dynamometer test cycle. The FTP is a representative transient cycle using setpoints based on engine speed and torque on an engine dynamometer. The duration of the test is 20 minutes, or 1200 seconds, and is divided into 4 equal 300 second long segments. Each of these segments is modeled after a freeway or non-freeway traffic data from either New York or Los Angeles and developed by the US EPA in the 1970s [34]. The FTP can be either a cold start, warm start, or hot start depending on critical engine temperatures at the beginning of the test. Continuously collected data is averaged to determine a brake-specific result [35]. 


\section{4. $\quad$ Procedures}

\subsection{Introduction}

This section discusses the preliminary goals for this project as well as the expected outcomes. The procedures used to derive the statistical results are also explained.

\subsection{Project Scope}

Perhaps the most important aspect of the following research tasks is a determination of optimal sampling conditions, FFVs, SDRs, media type, and which produce the most repeatable results. The collected PM mass was sampled in conjunction with WVU's previous $70 \mathrm{~mm}$ PM filters, allowing for a comparison between the pre2007 method and the 2007 compliant system. The most consistent resulting sampling conditions are to be used as recommendations to WVU for the use of the WVU 2007 compliant engine testing laboratory. The results were also evaluated to determine the relationships between the PM mass and the dilution ratios, filter face velocities, and filter media types.

It was important to evaluate the efficiency of the $47 \mathrm{~mm}$ filter system by recording real time particle counts both pre and post-filter. The particle counter selected for this task was the TSI 3007, a hand held CPC. The specific instrument was chosen for it's small size and wide particulate detection range. The difference between the upstream and downstream particle counts led to an efficiency calculation. Three filter media types, Tx40, T60A20, and Teflo, were examined in order to determine the most efficient situation.

Khalek has published results from an extensive 2007 compliance PM study. Therefore, the results obtained from the WVU 2007 compliant system will be compared and contrasted to this work. There are several critical components presented by Khalek that will be specifically studied.

In his 2005 paper with SwRI, Khalek states that the majority of the particle sizes in counted over a transient test were larger sized particles. He used this observation to conclude that it is the mass emissions that are dominated by elemental carbon levels [5]. His work can be supported in this WVU PM study which used an earlier engine, which 
exhausts more PM, to show that mass emissions experience similar levels of the repeatability, whereas if there was a variation improvement, it would be acceptable to assume that organics cause higher fluctuation at lower PM levels.

Several of the important relationships under concern are SDR, FFV, and filter media to PM collection. In his previous work Khalek observed an increase in PM deposition with an increasing SDR. The associated rational would mean that the presence of more filtered dilution air would lead to the formation of more nanoparticles, thus more PM mass [5]. He also included an observation of more PM deposition at lower FFVs. This can be explained by slower transport through the secondary dilution tunnel allowing more time for particle growth. These specific relationships are of particular interest to this study.

Engine testing was performed within the months of January through March 2007. These tests were all 20 minute FTPs run in conjunction with fuel studies and other graduate student research performed within WVU's EERL. The four engines outlined earlier, as well as a number of fuels, fuel treatment scenarios, and throttle approaches, were used throughout the testing period. If separate fuels/treatments and throttle approaches were used across a single test day, they were given a nomenclature with the first number indicating the test day and the second number indicating their daily occurrence. For example, if two fuels were used on the third day of testing, the fuels were referred to as Fuel 3.1 and Fuel 3.2.

The analysis of the 2007 PM system was designed to implement a number of SDR and FFV across the $47 \mathrm{~mm}$ filter and compare them to the $70 \mathrm{~mm}$ filter associated with the same test. The following test matrix, as shown in Table 4.1, was designed in order to obtain well rounded results in order to identify the relationship between SDR, FFV, filter media type, and PM collection. The goal was to obtain average PM mass depositions from at least 3 Hot Start FTPs for a wide array of SDRs, FFVs, and filter media. The 3 Hot Start FTPs are referred to as a Test Set. The FFV velocity will be defined in units of cfm from this point forward, the conversion between exhaust velocity and exhaust flow rate can be seen in Equation 4.6. 
Table 4.1 Test Matrix of SDR vs. FFV for Each Filter Media

\begin{tabular}{|l|l|l|l|l|}
\hline & \multicolumn{5}{|c|}{ SDR } \\
\hline FFV $(\mathrm{cfm})$ & 0 & $1 / 1$ & $2 / 1$ & $10 / 1$ \\
\hline 2.4 & & & & \\
\hline 2.0 & & & & \\
\hline 1.5 & & & & \\
\hline 1.0 & & & & \\
\hline 0.705 & & & & \\
\hline
\end{tabular}

As mentioned earlier, during March 2007 a handheld CPC was introduced to the PM collection system and another group of 20 minute FTPs were collected. The CPC was installed both before and after the filter in order to obtain a complete particle count which leads to a calculation of filer media efficiency. The efficiency tests were performed across the three filter types at a constant FFV of $1.5 \mathrm{cfm}$ with the SDR varying from $1 / 1,2 / 1$, and $10 / 1$.

\subsection{Post Test Filter Maintenance}

Following engine testing, the appropriate filters were weighed within WVU's certified class 1000 clean room and the resulting weights were reduced for comparison with the $70 \mathrm{~mm}$ results. Each filter, or set of filters, was appropriately conditioned within the clean room for at least four hours. All of the satisfactorily conditioned filters were weighed at the end of each days testing, with the uncompleted conditioning filters being weighed the following mornings. This routine was taken in an attempt to reduce any possible randomness associated with different lengths of conditioning time within the WVU clean room. Upon weighing the filters, values were recorded within the WVU filter database and the results were standardized for comparison.

\subsection{Data Reduction}

\subsubsection{Introduction}

In order to compare the results between systems, it is necessary to compute both systems' flow values in standard conditions, as well as obtaining the appropriate background flow and PM measurements. This section includes the necessary steps and 
equations for reducing the PM data, as well as an explanation of the statistical analysis which leads to comparable data.

\subsubsection{System Flow and PM Mass Calculations}

Upon collecting the mass of PM collected onto the filter, the value must be standardized in order to account for flow, background, and other conditions. Equation 4.1 shows the calculation for the standardized PM mass in grams and was applied to both the $47 \mathrm{~mm}$ and $70 \mathrm{~mm}$ measurements.

\section{Equation 4.1 [1]}

$$
P_{\text {mass }}=\left(V_{\text {mix }}+V_{s f}\right) \times\left[\left(\frac{P_{f}}{V_{s f}}\right)-\left(\frac{P_{b f}}{V_{b f}}\right) \times\left(1-\frac{1}{D F}\right)\right] \times \frac{1}{1000}
$$

Where:

$\mathrm{P}_{\text {mass }}=$ Mass of particulate emitted per test phase, grams per test phase.

$\mathrm{V}_{\text {mix }}=$ Total dilute exhaust volume corrected to standard conditions, cubic feet and is a value computed by WVU EERL.

$\mathrm{V}_{\mathrm{sf}}=$ Total volume of sample removed from the primary dilution tunnel at standard conditions, cubic feet. This value can be found as the summation of the instantaneous sample flow rate recorded by WVU's EERL, shown in the following Equation 4.2. Or if a secondary dilution is used for the $47 \mathrm{~mm}$ system, this value is the difference between the total sample flow rate and the secondary dilution air flow rate which can be seen in Equation 4.3. 


\section{Equation 4.2}

$$
V_{s f}=\left[\frac{\sum_{i}^{n} V}{t_{n}-t_{i}}\right] \times\left(\frac{t_{n}}{60}\right)
$$

\section{Equation 4.3}

$$
V_{s f}=\left(\left[\begin{array}{c}
\sum_{i}^{n} V \\
t_{n}-t_{i}
\end{array}\right] \times\left(\frac{t_{n}}{60}\right)\right)_{\text {total }}-\left(\left[\begin{array}{c}
\sum_{i}^{n} V \\
t_{n}-t_{i}
\end{array}\right] \times\left(\frac{t_{n}}{60}\right)\right)_{\text {sda }}
$$

$\mathrm{P}_{\mathrm{f}}=$ Mass of particulate on the sample filter, measured within WVU's class 1000 clean room in milligrams per test phase.

$\mathrm{P}_{\mathrm{bf}}=$ Net weight of particulate on the background particulate filter, measured within WVU's class 1000 clean room in milligrams per background test phase.

$\mathrm{V}_{\mathrm{bf}}=$ Total volume of sampled background air at standard conditions, computed by WVU's EERL in cubic feet.

Note: It should be considered that the values taken for $\mathrm{P}_{\mathrm{bf}}$ and $\mathrm{V}_{\mathrm{bf}}$ used for both system calculations were taken for a 20 minute background test over a $70 \mathrm{~mm}$ filter.

$\mathrm{DF}=$ Dilution Factor, standardized calculation established within the CFR 40, Part 86 Subpart N and shown in the following Equation 4.4. 


\section{Equation $4.4[1]$}

$$
D F=\frac{13.4}{\left(C O_{2}+H C_{e}+C O_{e}\right) 10^{-4}}
$$

Where,

$\mathrm{CO}_{2}=$ Amount of Carbon Dioxide recorded by gas analyzers in ppm.

$\mathrm{HC}_{\mathrm{e}}=$ Amount of Hydrocarbons recorded by gas analyzers in ppm.

$\mathrm{CO}_{\mathrm{e}}=$ Amount of Carbon Monoxide recorded by gas analyzers in ppm.

Note: 13.4 is the assumed Stoichiometric ratio for all diesel fuels.

It should also be noted that the secondary dilution ratio is simply a ratio between the total sample flow rate and the difference between the total and secondary dilution flow. This expression is seen in the following Equation 4.5.

\section{Equation 4.5}

$$
S D R=\frac{\left[\frac{\sum_{i}^{n} V}{t_{n}-t_{i}}\right]_{s f}}{\left(\left[\frac{\sum_{i}^{n} V}{t_{n}-t_{i}}\right]_{s f}-\left[\frac{\sum_{i}^{n} V}{t_{n}-t_{i}}\right]_{s d a}\right.}
$$

The CFR defines filter face velocity in units of $\mathrm{cm} / \mathrm{s}$. The mass flow controllers used for this study used cfm for the description of the velocity of exhaust over the filter 
face area. The conversion between these flow rate definitions can be seen in Equation 4.6.

\section{Equation 4.6}

$$
\dot{V}=\left(\frac{1}{47194.7445}\right) * V *\left(\frac{\pi^{*} d_{s}^{2}}{4}\right)
$$

Where,

$\dot{\mathrm{V}}=$ Exhaust flow rate over filter face, FFV $(\mathrm{cfm})$

$\mathrm{V}=$ Velocity of exhaust stream $(\mathrm{cm} / \mathrm{s})$

$\mathrm{d}_{\mathrm{s}}=$ Filter stain diameter, diameter of filter which is exposed to the exhaust stream $(\mathrm{mm})$

\subsubsection{Statistical Calculations}

\subsubsection{Introduction}

It is necessary to compute a number of statistical values after each filter mass has been taken and tabulated. Values for flow proportionality, coefficient of variation, and percent difference are important for analyzing the data set.

\subsubsection{Normalization}

The CFR requires that the sample across the PM filter face be extracted proportionally to the primary tunnel exhaust flow, within $\pm 5 \%$. Therefore it is necessary to normalize the resulting flow values for the main tunnel, $70 \mathrm{~mm}$ filter flow, and $47 \mathrm{~mm}$ filter flow. Equation 4.7 expresses the proportionality between the desired flow rate and the actual measured value.

\section{Equation 4.7}

$$
\text { proportionality }=\frac{V_{\text {actual }}}{V_{\text {nominal }}}
$$

\subsubsection{Difference from Mean}

The error bars shown in the Results section when plotting averaged PM mass include the maximum and minimum difference from this average. The equations used for maximum and minimum difference are shown below in Equation 4.8 and Equation 4.9. 


\section{Equation 4.8}

$$
P M_{\text {high }}=\max \left(P M_{\mathrm{i}}: P M_{\mathrm{n}}\right)-P M_{\text {avg }}
$$

\section{Equation 4.9}

$$
P M_{\text {low }}=P M_{\text {avg }}-\min \left(P M_{\mathrm{i}}: P M_{\mathrm{n}}\right)
$$

\subsubsection{Coefficient of Variation}

The CV is a very valuable representation of the repeatability of a data set. This value allows one to compare how wide a range of data is from the mean. In this case the $\mathrm{CV}$ will enable a comparison for the repeatability of both the 47 and $70 \mathrm{~mm}$ PM collection systems. The expression for CV can be seen in Equation 4.10.

\section{Equation 4.10}

$$
C V=\frac{\left(\sigma_{i}^{n}\left(P M_{\text {mass }}\right)\right.}{\left(A v g_{i}^{n}\left(P M_{\text {mass }}\right)\right.} \times 100
$$

\subsubsection{Percent Difference}

When calculating a difference percentage between the $70 \mathrm{~mm}$ and $47 \mathrm{~mm}$ systems, the $70 \mathrm{~mm}$ PM value is labeled as "known" and the $47 \mathrm{~mm}$ value as "experimental." This computation format is because the previously accepted value for PM has been established using the $70 \mathrm{~mm}$ system. The percent difference can be seen below in Equation 4.11.

\section{Equation 4.11}

$$
\% \text { Diff }=\frac{\left|P M_{\text {known }}-P M_{\text {experiment al }}\right|}{P M_{\text {known }}} \times 100
$$




\subsubsection{Efficiency}

The filter efficiency is calculated using the ratio of total post-filter particles to total pre-filter particles.

\section{Equation 4.12}

$$
\text { Efficiency }=\left[1-\left(\frac{\text { Particles }_{\text {post }}}{\text { Particles }_{\text {pre }}}\right)\right] \times 100
$$




\section{Results and Discussion}

\subsection{Averaged Mass of PM Deposition}

\subsubsection{Introduction}

The following section will review and discuss the daily procedures and observations, and also allow for a visual representation of the resulting data. The tests performed are all 20 minute FTPs run by WVU's EERL. The critical results include the ability to obtain tunnel flow proportionality over the duration of a 20 minute FTP, the coefficients of variation for both $47 \mathrm{~mm}$ and $70 \mathrm{~mm}$ systems, as well as the relationship between the PM collected on each system, which is to be expressed as a percent difference. These results have also been tabulated and are shown along with the plotted PM mass averages.

It is important to introduce an acceptable level of data variation. From common engineering standards, a level of $\leq 5 \%$ should be used to determine acceptable results for the testing conditions.

\subsubsection{Discussion}

\subsubsection{1992 Detroit Diesel Corporation S60}

The following section discusses the PM results from two WVU owned 1992 Detroit Diesel Corporation (DDC) Series 60 engines. The engines are labeled in the tabulated results as DDC 1 and DDC 2. A number of different testing conditions were examined for both the engine test cell as well as the $47 \mathrm{~mm}$ PM collection system.

\subsection{January 9, 2007}

This first day of testing included WVU's 1992 DDC Series 60, used conjunctively for fuel testing. A $0.705 \mathrm{scfm}$ flow, equal to the flow over the $70 \mathrm{~mm}$ filter face, was used with no secondary dilution air for the $47 \mathrm{~mm}$ system. Both $47 \mathrm{~mm}$ and $70 \mathrm{~mm}$ systems were sampled with T60A20 media. The test cell parameters included one fuel and one throttle setting, which will be referred to as Fuel 1.1 and Throttle 1.1. 
A total of four FTPs, one warm start and three hot starts, were collected in order to determine the variation effect of combining warm and hot start PM averages. As can be seen in the following

Table 5.1, including the warm start average almost triples the coefficient of variation for both the $70 \mathrm{~mm}$ and $47 \mathrm{~mm}$ systems. Therefore none of the averaged PM masses will include warm start data.

Table 5.1 Results from January 9

\begin{tabular}{|c|c|c|c|c|}
\hline Description & \multicolumn{2}{|c|}{ WS } & \multicolumn{2}{|c|}{ w/o WS } \\
\hline Engine & \multicolumn{2}{|c|}{ DDC 1} & \multicolumn{2}{|c|}{ DDC 1} \\
\hline Fuel & \multicolumn{2}{|c|}{ Fuel 1.1} & \multicolumn{2}{|c|}{ Fuel 1.1} \\
\hline Throttle & \multicolumn{2}{|c|}{ Throttle 1.1} & \multicolumn{2}{|c|}{ Throttle 1.1} \\
\hline \# FTPs in Avg & \multicolumn{2}{|c|}{4} & \multicolumn{2}{|c|}{3} \\
\hline PM System & $47 \mathrm{~mm}$ & $70 \mathrm{~mm}$ & $47 \mathrm{~mm}$ & $70 \mathrm{~mm}$ \\
\hline Filter Media & T60A20 & T60A20 & T60A20 & T60A20 \\
\hline SDR & 0 & - & 0 & - \\
\hline FFV $(\mathrm{cfm})$ & 0.705 & 0.705 & 0.705 & 0.705 \\
\hline $\begin{array}{l}\text { Avg Mass / test } \\
\text { cycle }(\mathrm{g})\end{array}$ & 5.5406 & 5.9090 & 5.4731 & 5.8245 \\
\hline $\begin{array}{l}\text { Variation } \\
\text { Coefficient (\%) }\end{array}$ & 2.55 & 2.87 & 0.93 & 0.34 \\
\hline Difference $(\%)$ & -6.24 & - & -6.03 & - \\
\hline Proportionality & Yes & - & Yes & - \\
\hline
\end{tabular}

One can observe how the inclusion of warm start FTP PM data will increase the average PM mass, as well as variation of the sample set, in the following Figure 5.1 and Figure 5.2. The negative percent difference refers to less mass deposition on the $47 \mathrm{~mm}$ filter than on the $70 \mathrm{~mm}$ filter. 


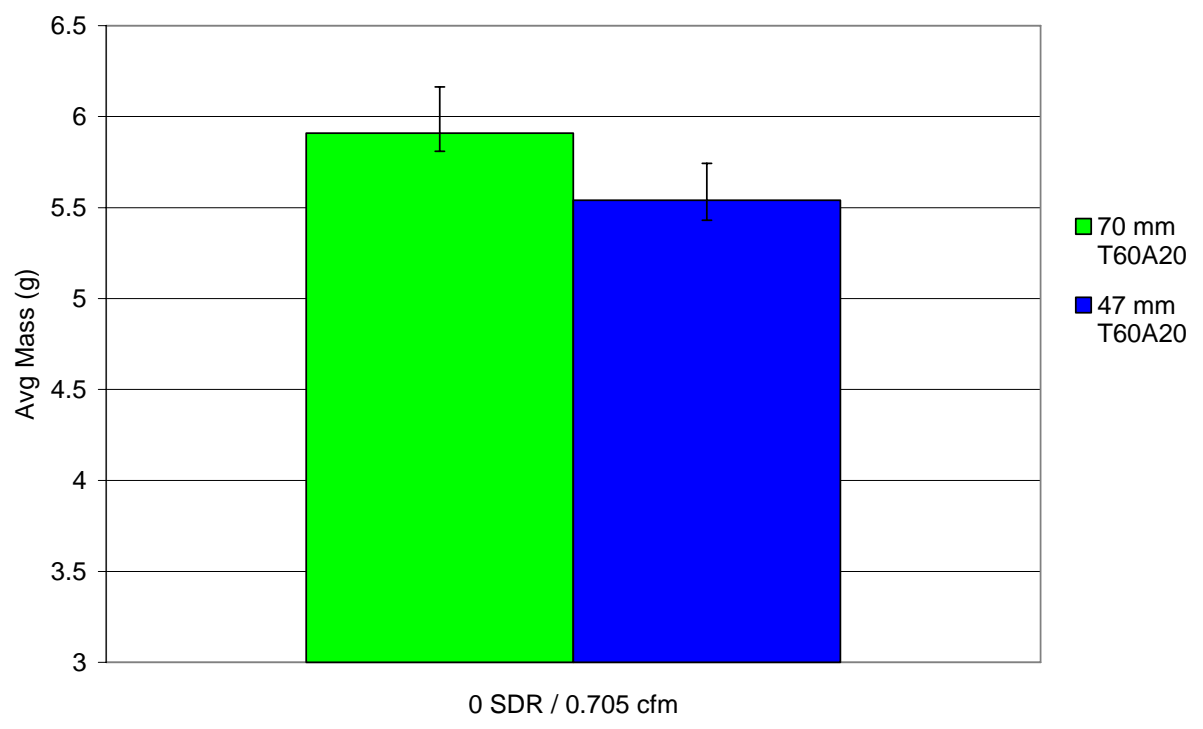

Figure 5.1 January 9, Average PM Mass of 1 Warm Start and 3 Hot Start FTPs

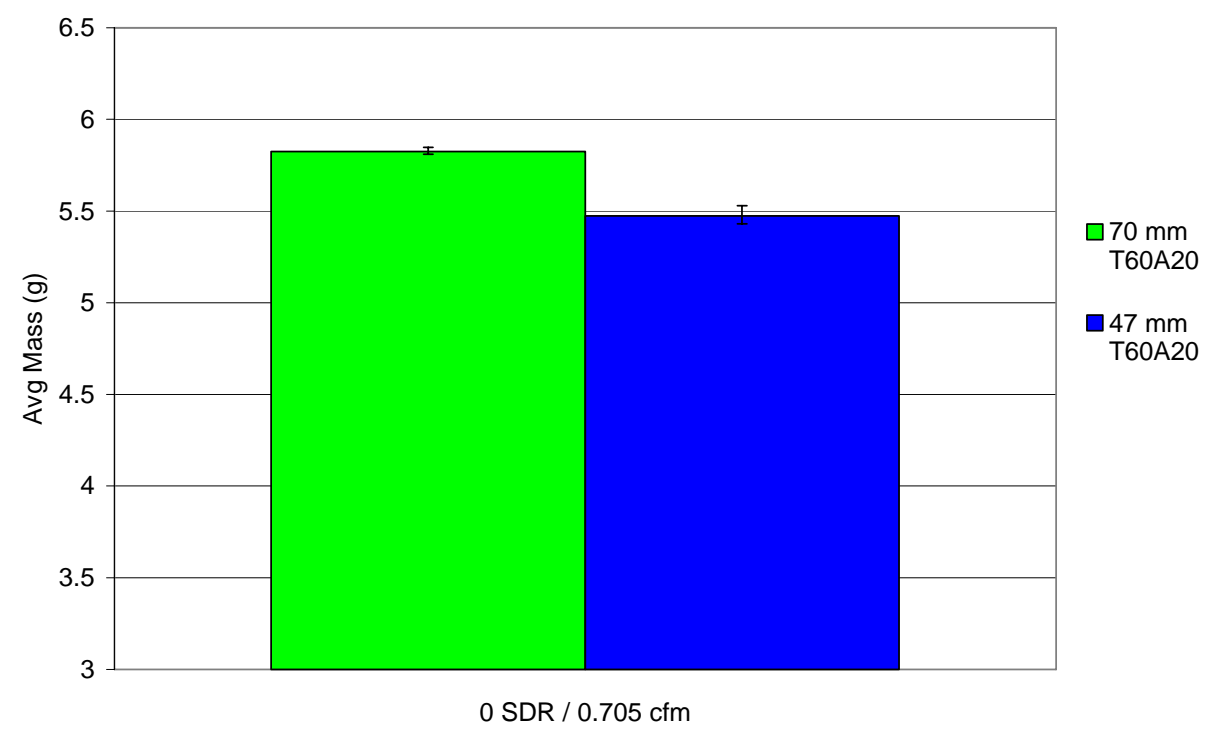

Figure 5.2 January 9, Average PM Mass of 3 Hot Start FTPs

By further examining the results from this day of testing, one can note a $6.03 \%$ lower PM mass collection by the $47 \mathrm{~mm}$ system. Both PM systems showed very low, 
less than $1 \%$, coefficients of variation when only the hot start FTP data were averaged. Therefore at these specific conditions it appears that the 2007 PM compliant system produced acceptable results.

Figure 5.3 shows the sample flow rate proportionality during the test. If proportionality was achieved, the $47 \mathrm{~mm}$ normalized data will almost fall identically in line with the main tunnel and $70 \mathrm{~mm}$ trendlines. Proportionality was maintained across the $47 \mathrm{~mm}$ T60A20 filters at 0 SDR and a $0.705 \mathrm{cfm}$ flow rate.

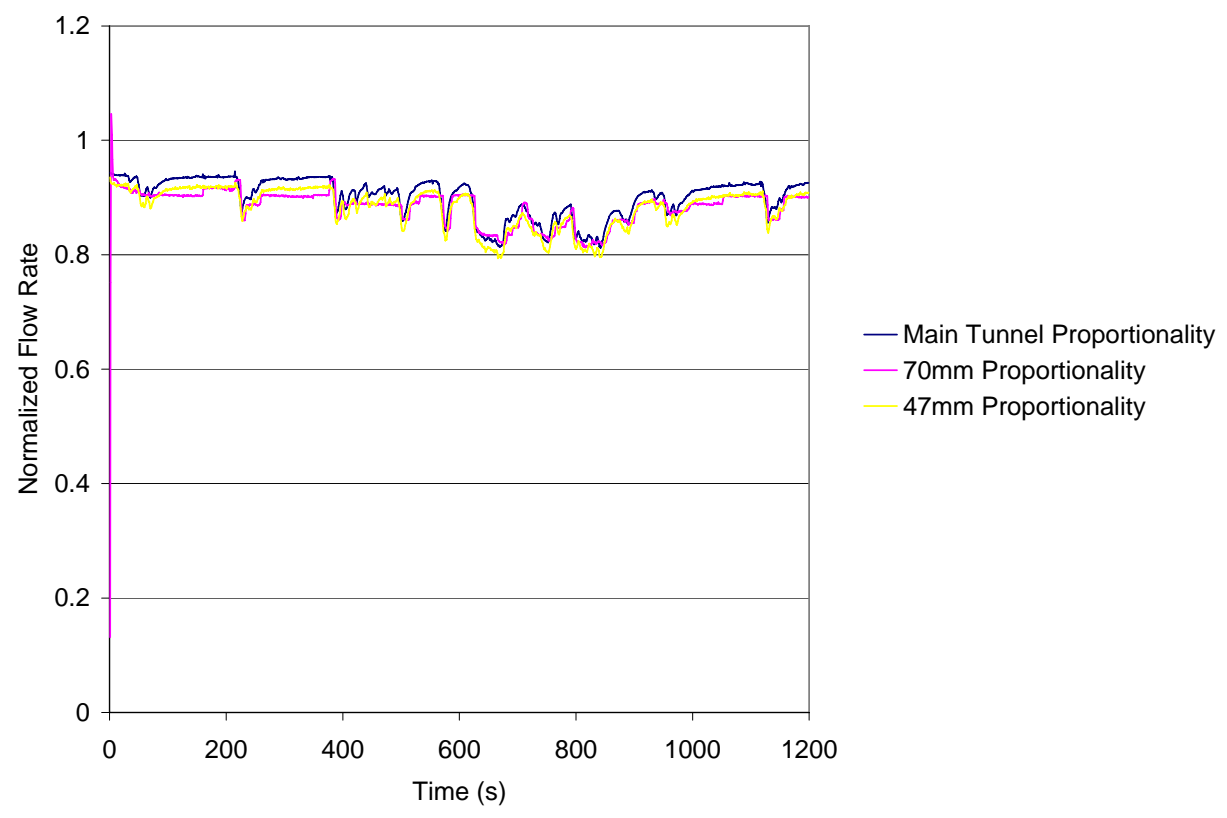

Figure 5.3 Example of Test Proportionality

Figure 5.4 represents the filter face temperature (FFT) for both the $47 \mathrm{~mm}$ and 70 $\mathrm{mm}$ systems. The graph clearly shows that the new $47 \mathrm{~mm}$ system was able to maintain the $125 \pm 7^{\circ} \mathrm{C}$ temperature required within the new CFR regulations. The existing $70 \mathrm{~mm}$ system has only a set maximum temperature of $51.7{ }^{\circ} \mathrm{C}$. Therefore the apparent temperature fluctuations are acceptable by regulation. Figure 5.4 is representative of the temperature graphs for the entirety of the testing. Therefore, the remainder of the FFT plots can be found in the Appendix. 


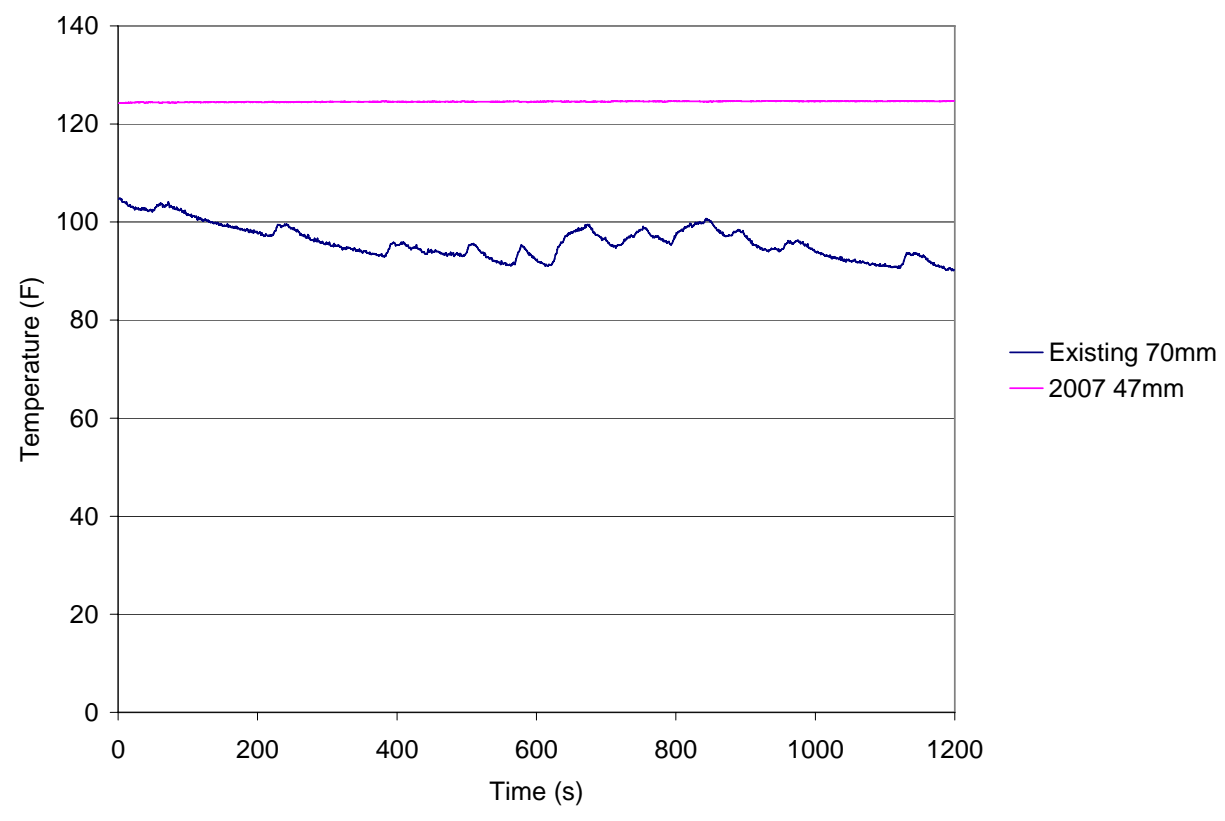

Figure 5.4 Filter Face Temperature

\subsection{January 10, 2007}

Day two of testing with the 1992 DDC Series 60 incorporated two fuels, which will be referenced to as Fuel 2.1 and Fuel 2.2, and one throttle approach, Throttle 2.1. A $0.705 \mathrm{cfm} F F V$, equal to the flow over the $70 \mathrm{~mm}$ filter face, was used with no secondary dilution air for the $47 \mathrm{~mm}$ system. All six hot start FTPs were sampled with T60A20 70 mm filters. Fuel 2.1 was sampled with $47 \mathrm{~mm}$ Teflo filters and Fuel 2.2 with $47 \mathrm{~mm}$ Tx40 filters.

Small coefficients of variation were observed once again, with all values falling below $1.5 \%$. An available point of interest was to evaluate the percent difference between the two PM collection system changes with different filter media types. For the results for each condition refer to Table 5.2. 
Table 5.2 Results from January 10

\begin{tabular}{|c|c|c|c|c|}
\hline Test Set & \multicolumn{2}{|c|}{2.1} & \multicolumn{2}{|c|}{2.2} \\
\hline Engine & \multicolumn{2}{|c|}{ DDC 1} & \multicolumn{2}{|c|}{ DDC 1} \\
\hline Fuel & \multicolumn{2}{|c|}{ Fuel 2.1} & \multicolumn{2}{|c|}{ Fuel 2.2} \\
\hline Throttle & \multicolumn{2}{|c|}{ Throttle 2.1} & \multicolumn{2}{|c|}{ Throttle 2.1} \\
\hline \# FTPs in Avg & \multicolumn{2}{|c|}{3} & \multicolumn{2}{|c|}{3} \\
\hline PM System & $47 \mathrm{~mm}$ & $70 \mathrm{~mm}$ & $47 \mathrm{~mm}$ & $70 \mathrm{~mm}$ \\
\hline Filter Media & Teflo & T60A20 & Tx40 & T60A20 \\
\hline SDR & 0 & - & 0 & - \\
\hline FFV (cfm) & 0.705 & 0.705 & 0.705 & 0.705 \\
\hline $\begin{array}{l}\text { Avg Mass / test } \\
\text { cycle }(\mathrm{g})\end{array}$ & 5.2565 & 5.7719 & 5.4555 & 5.7040 \\
\hline $\begin{array}{l}\text { Variation } \\
\text { Coefficient (\%) }\end{array}$ & 1.36 & 1.21 & 0.17 & 0.73 \\
\hline Difference (\%) & -8.93 & - & -4.36 & - \\
\hline Proportionality & Yes & - & Yes & \\
\hline
\end{tabular}

Figure 5.5 shows the average PM mass, in grams, for each fuel and filter condition. When comparing the PM deposition across the $70 \mathrm{~mm}$ filters, one can see the change in fuel had only a small effect on $70 \mathrm{~mm}$ PM deposition. In fact the difference between the two mass averages is only $0.0679 \mathrm{~g}$, about $1 \%$ of the total mass deposition.

There was a noticeable difference for the $47 \mathrm{~mm}$ PM deposition. The difference of average mass of PM deposition across the fuel and filter change was $0.159 \mathrm{~g}$, about $4 \%$ of the total mass deposition.

While the change from Fuel 2.1 to Fuel 2.2 may have had a more adverse effect on the $47 \mathrm{~mm}$ system than the $70 \mathrm{~mm}$ system, it seems likely that the increase in $47 \mathrm{~mm}$ PM deposition is associated with changing the filter from Teflo to Tx40 media. 


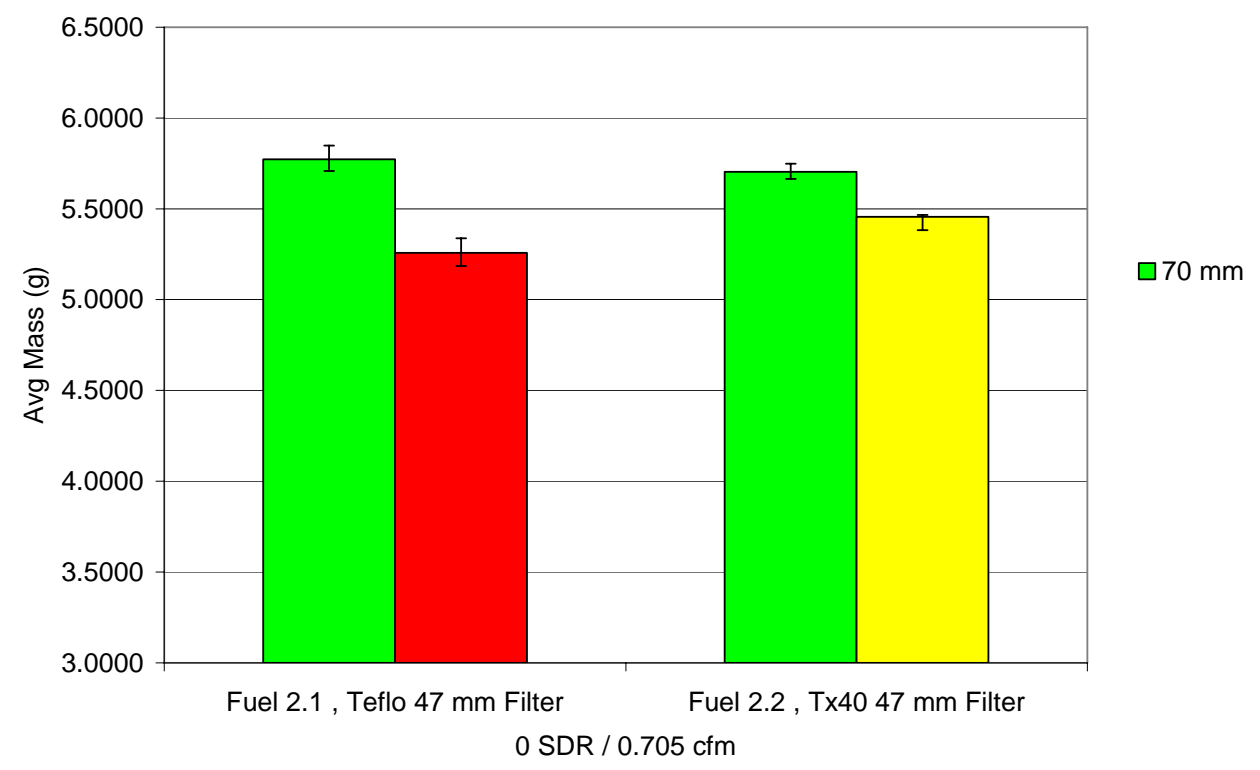

Figure 5.5 January 10, Average PM Mass of 3 Hot Start FTPs

The results from Day 1 and Day 2 were then combined to determine if the T60A20 $47 \mathrm{~mm}$ filters also affected PM deposition. Although fuels and days were changed, the $70 \mathrm{~mm}$ collection was once again consistent, with about a $2 \%$ difference between the maximum and minimum collected masses. This difference for the $47 \mathrm{~mm}$ filters between Day 1 and Day 2 was found to be around 4\%. While these are not drastic differences, the trends do show that for zero secondary dilution and $0.705 \mathrm{cfm}$ flow rate, the $47 \mathrm{~mm}$ filter media does indeed have an effect on the mass of PM deposition. The plot of Day 1 and Day 2 can be seen in Figure 5.6. The data thus far seems to represent an increase in PM deposition when changing from Teflo, Tx40, and T60A20.

It should also be noted that up to this point the $47 \mathrm{~mm}$ filters have always resulted in less PM accumulation than that on the $70 \mathrm{~mm}$ filters. 


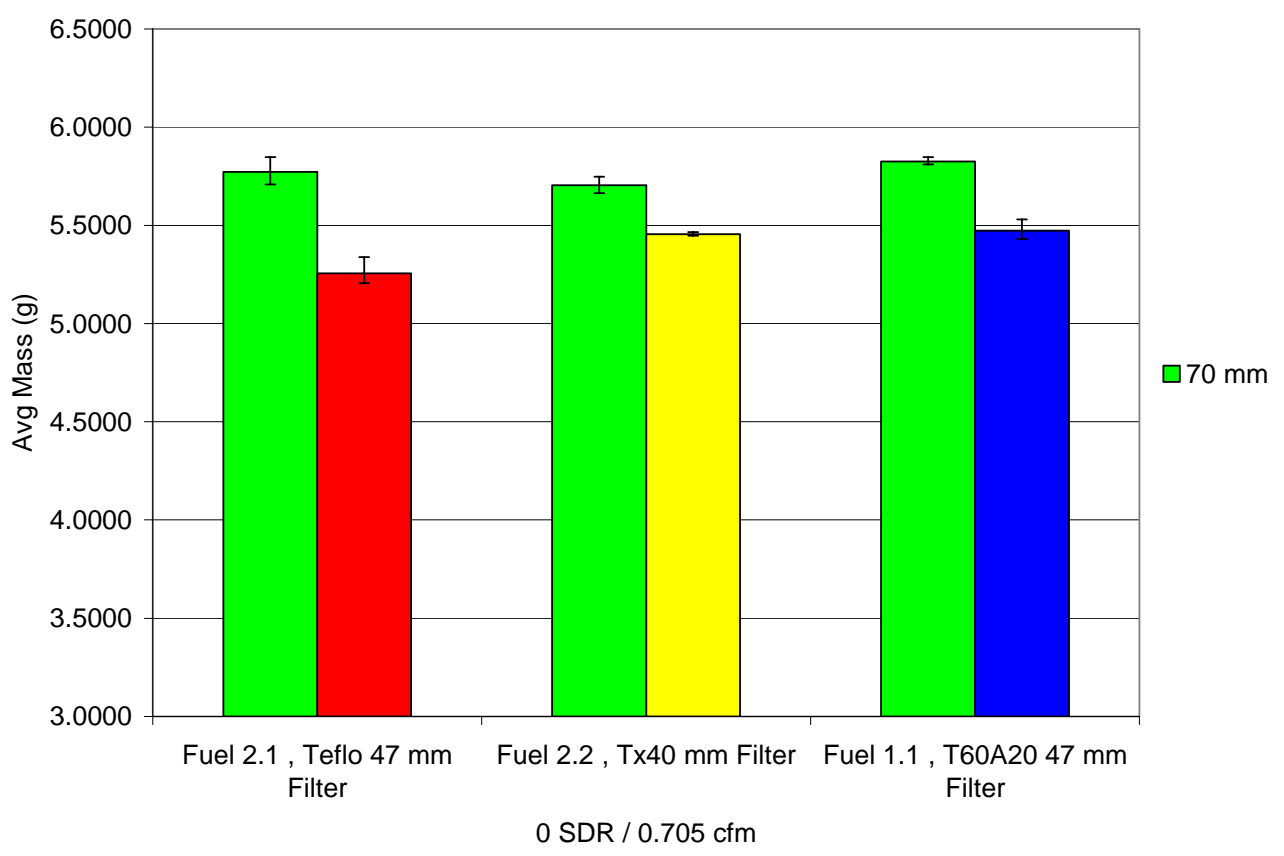

Figure 5.6 January 9 \& 10, Average PM Mass of 3 Hot Start FTPs

\subsection{January 11, 2007}

Three FTPs were sampled over T60A20 $47 \mathrm{~mm}$ filters. The $70 \mathrm{~mm}$ system also used the T60A20 filters, as it did for the extent of the testing. The different systems produced almost identical PM mass deposition with a percent difference of $0.69 \%$. Coefficients of variation were also very low and can be seen in Table 5.3. 
Table 5.3 Results from January 11

\begin{tabular}{|c|c|c|}
\hline Test Set & \multicolumn{2}{|c|}{3} \\
\hline Engine & \multicolumn{2}{|c|}{ DDC 1} \\
\hline Fuel & \multicolumn{2}{|c|}{ Fuel 3.1} \\
\hline Throttle & \multicolumn{2}{|c|}{ Throttle 3.1} \\
\hline \# FTPs in Avg & \multicolumn{2}{|c|}{3} \\
\hline PM System & $47 \mathrm{~mm}$ & $70 \mathrm{~mm}$ \\
\hline Filter Media & T60A20 & T60A20 \\
\hline SDR & 0 & - \\
\hline FFV (cfm) & 2.0 & 0.705 \\
\hline $\begin{array}{l}\text { Avg Mass / test } \\
\text { cycle (g) }\end{array}$ & 5.9724 & 6.0138 \\
\hline $\begin{array}{l}\text { Variation } \\
\text { Coefficient (\%) }\end{array}$ & 0.36 & 0.69 \\
\hline Difference (\%) & -0.69 & - \\
\hline Proportionality & No & - \\
\hline
\end{tabular}

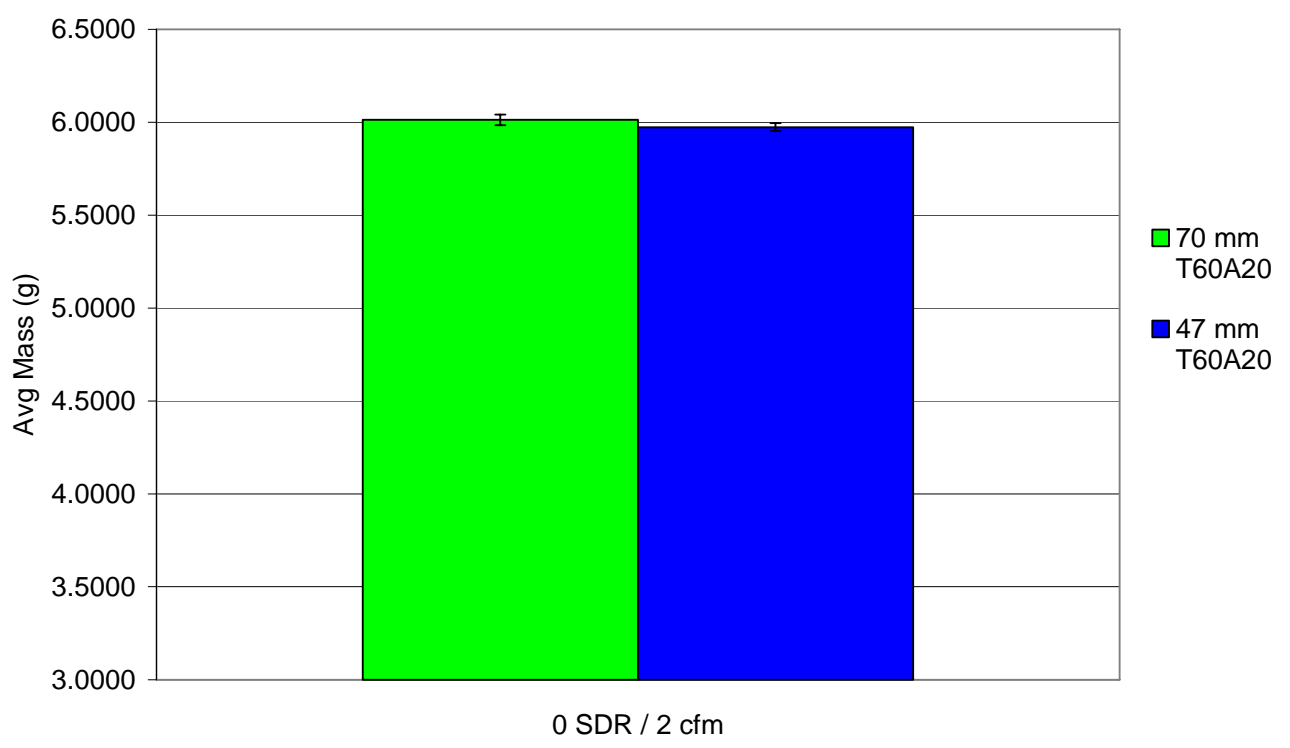

Figure 5.7 January 11, Average PM Mass of 3 Hot Start FTPs

Despite these seemingly acceptable results, flow proportionality was unable to be maintained over the duration of the FTP. As can be seen in Figure 5.8, the flow decreased during the last several minutes of the test. This characteristic is thought to be due to a pressure drop over the filter face as the result of PM buildup. 


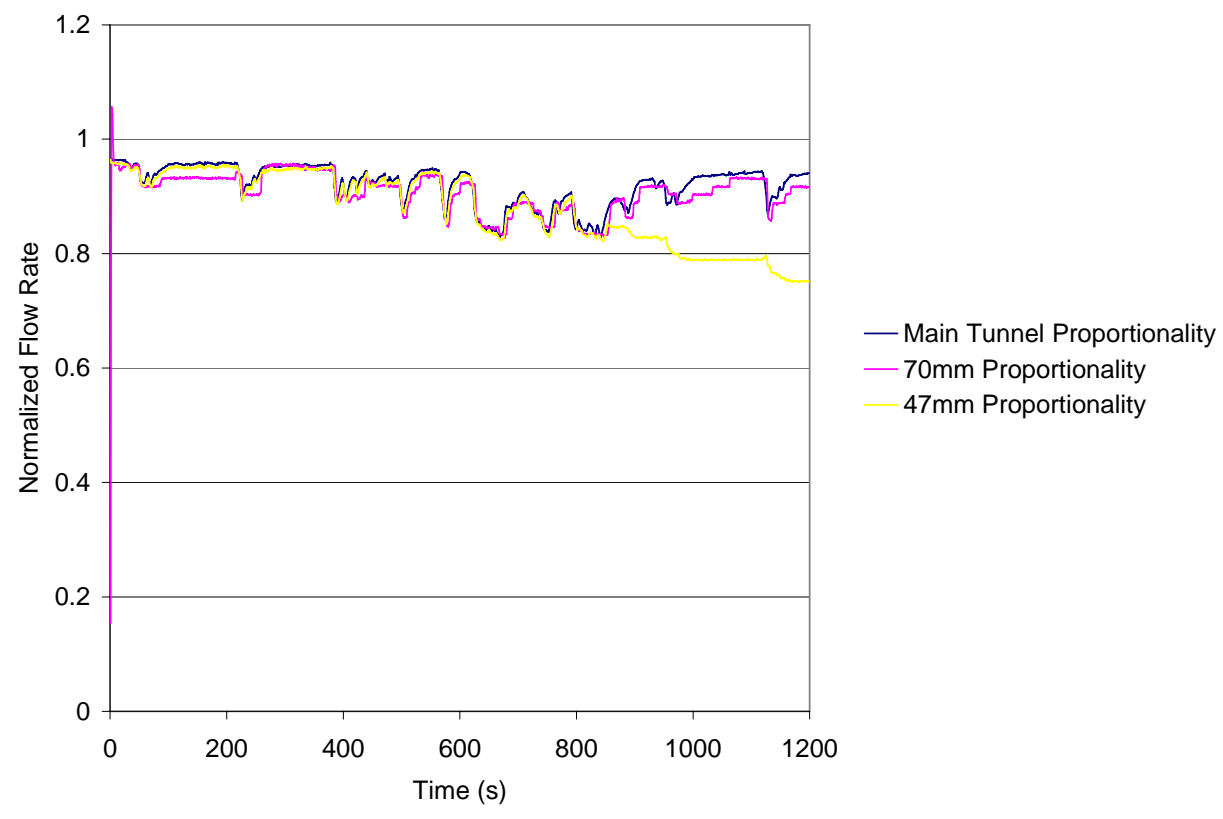

Figure 5.8 Example of Lack of Flow Proportionality

From this point on, if a series of tests is accurately proportional or fails to maintain this desired tunnel flow proportionality, it will simply be stated in the results table. The remainder of the proportionality plots can be found in the Appendixes.

\subsection{January 17, 2007}

The following three days of testing were performed using a second 1992 DDC Series 60 engine owned by WVU. The concurrent ongoing research involved exploring emissions effects by adjusting the aggressiveness of the engines throttle control.

The first day of this experimental setup involved three hot start FTPs using one fuel and throttle approach. The $47 \mathrm{~mm}$ system was sampled on Tx40 filter with 0 SDR and $1 \mathrm{cfm}$ flow rate. The resulting CVs seen below are acceptably low and the system was able to maintain a proportional sample.

There were several points of interest for this specific set of conditions. While the difference between the two systems was very small, the $47 \mathrm{~mm}$ system actually recorded more PM deposition than the $70 \mathrm{~mm}$ system, unlike the previous observed relationships. The results also showed very similar PM deposition, a difference of only 0.0222 grams, 
less then $1 \%$ of the total PM deposition. The results are shown in Figure 5.9 and Table 5.4 .

Table 5.4 Results from January 17

\begin{tabular}{|c|c|c|}
\hline Test Set & \multicolumn{2}{|c|}{4} \\
\hline Engine & \multicolumn{2}{|c|}{ DDC 2} \\
\hline Fuel & \multicolumn{2}{|c|}{ Fuel 4.1} \\
\hline Throttle & \multicolumn{2}{|c|}{ Throttle 4.1} \\
\hline \# FTPs in Avg & \multicolumn{2}{|c|}{3} \\
\hline PM System & $47 \mathrm{~mm}$ & $70 \mathrm{~mm}$ \\
\hline Filter Media & Tx40 & T60A20 \\
\hline SDR & 0 & - \\
\hline FFV (cfm) & 1.0 & 0.705 \\
\hline $\begin{array}{l}\text { Avg Mass / test } \\
\text { cycle }(\mathrm{g})\end{array}$ & 2.9400 & 2.9178 \\
\hline $\begin{array}{l}\text { Variation } \\
\text { Coefficient (\%) }\end{array}$ & 0.61 & 1.12 \\
\hline Difference (\%) & 0.76 & - \\
\hline Proportionality & Yes & - \\
\hline
\end{tabular}

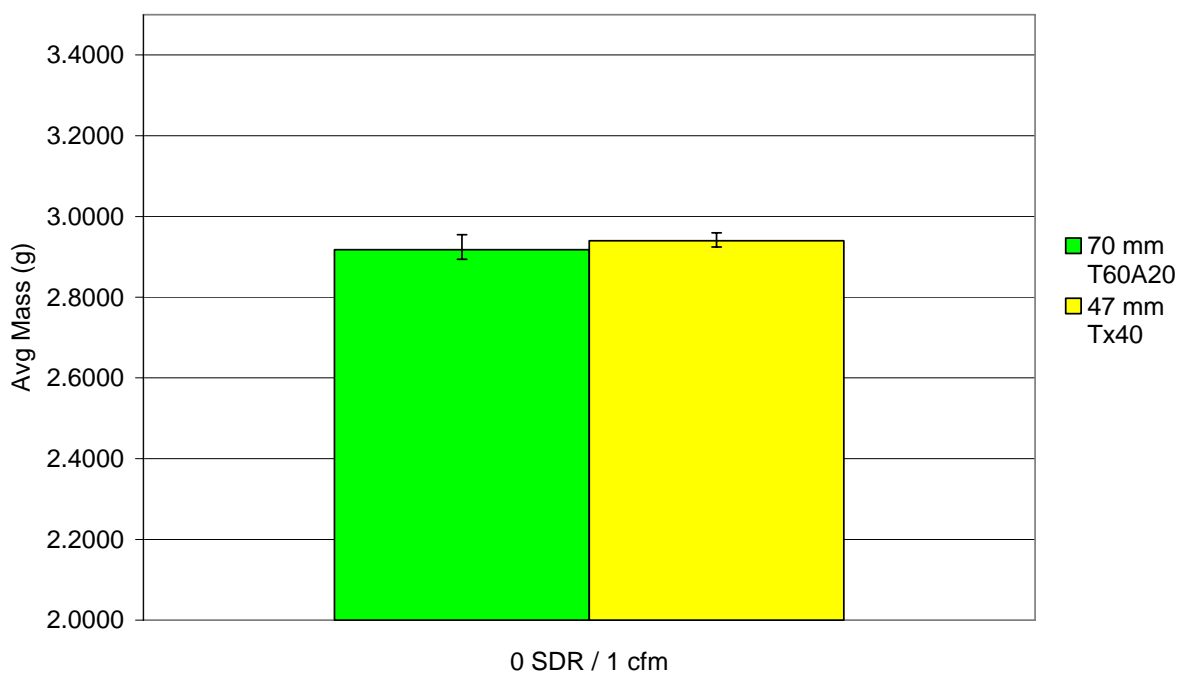

Figure 5.9 January 17, Average PM Mass of 3 Hot Start FTPs

\subsection{January 18, 2007}

Four different flow conditions were used throughout this test day. It should be noted that two of the data conditions only consist of two hot start FTPs. As was shown 
on a previous day of testing, the adjustment from Fuel 5.1 to 5.2 had little effect on the 70 $\mathrm{mm}$ PM deposition. The change in the $47 \mathrm{~mm}$ deposition may be due to the change in flow rate parameters. In this case, increasing the SDR and decreasing the FFV led to less PM collection on the Tx40 filter media. This trend can be observed for both Throttles 5.1 and 5.2 .

As the throttle was changed from 5.1 to 5.2 , an obvious increase in mass deposition was observed for the corresponding PM systems. This increase in PM for the $47 \mathrm{~mm}$ was much higher than the $70 \mathrm{~mm}$. The increase in $47 \mathrm{~mm}$ PM mass deposition may therefore be associated with increasing the FFV over the $47 \mathrm{~mm}$ filter face at a constant SDR. The associated results and relationships can be seen below in the following Table 5 and Figure 9.

The $47 \mathrm{~mm}$ system was unable to maintain proportionality over the Tx40 filters for the conditions of 0 SDR and $2 \mathrm{cfm}$. This is similar to the results for the T60A20 47 mm filters shown in Table 5.5 and Figure 5.10.

Table 5.5 Results from January 18

\begin{tabular}{|c|c|c|c|c|}
\hline Test Set & \multicolumn{2}{|c|}{5.1} & \multicolumn{2}{|c|}{5.2} \\
\hline Engine & \multicolumn{2}{|c|}{ DDC 2} & \multicolumn{2}{|c|}{ DDC 2} \\
\hline Fuel & \multicolumn{2}{|c|}{ Fuel 5.1} & \multicolumn{2}{|c|}{ Fuel 5.2} \\
\hline Throttle & \multicolumn{2}{|c|}{ Throttle 5.1} & \multicolumn{2}{|c|}{ Throttle 5.1} \\
\hline \# FTPs in Avg & \multicolumn{2}{|c|}{2} & \multicolumn{2}{|c|}{3} \\
\hline PM System & $47 \mathrm{~mm}$ & $70 \mathrm{~mm}$ & $47 \mathrm{~mm}$ & $70 \mathrm{~mm}$ \\
\hline Filter Media & $\mathrm{Tx} 40$ & T60A20 & $\mathrm{Tx} 40$ & T60A20 \\
\hline SDR & 0 & - & $1 / 1$ & - \\
\hline FFV (cfm) & 1.5 & 0.705 & 0.705 & 0.705 \\
\hline $\begin{array}{l}\text { Avg Mass / test } \\
\text { cycle (g) }\end{array}$ & 3.0354 & 2.9676 & 2.6436 & 2.9780 \\
\hline $\begin{array}{l}\text { Variation } \\
\text { Coefficient (\%) }\end{array}$ & 0.01 & 0.01 & 0.88 & 1.12 \\
\hline Difference (\%) & $2.29 \%$ & - & -11.23 & - \\
\hline Proportionality & Yes & - & Yes & - \\
\hline
\end{tabular}


Table 5.5 cont.

\begin{tabular}{|c|c|c|c|c|}
\hline Test Set & \multicolumn{2}{|c|}{5.3} & \multicolumn{2}{|c|}{5.4} \\
\hline Engine & \multicolumn{2}{|c|}{ DDC 2} & \multicolumn{2}{|c|}{ DDC 2} \\
\hline Fuel & \multicolumn{2}{|c|}{ Fuel 5.1} & \multicolumn{2}{|c|}{ Fuel 5.2} \\
\hline Throttle & \multicolumn{2}{|c|}{ Throttle 5.1} & \multicolumn{2}{|c|}{ Throttle 5.1} \\
\hline \# FTPs in Avg & \multicolumn{2}{|c|}{2} & \multicolumn{2}{|c|}{3} \\
\hline PM System & $47 \mathrm{~mm}$ & $70 \mathrm{~mm}$ & $47 \mathrm{~mm}$ & $70 \mathrm{~mm}$ \\
\hline Filter Media & $\mathrm{Tx} 40$ & T60A20 & $\mathrm{Tx} 40$ & T60A20 \\
\hline SDR & 0 & - & $1 / 1$ & - \\
\hline FFV (cfm) & 2.0 & 0.705 & 1.5 & 0.705 \\
\hline $\begin{array}{l}\text { Avg Mass / test } \\
\text { cycle (g) }\end{array}$ & 3.9829 & 3.7510 & 3.6211 & 3.6299 \\
\hline $\begin{array}{l}\text { Variation } \\
\text { Coefficient (\%) }\end{array}$ & 0.88 & 1.08 & 0.71 & 0.46 \\
\hline Difference (\%) & 6.18 & - & -0.24 & - \\
\hline Proportionality & No & - & Yes & - \\
\hline
\end{tabular}

An interesting relationship between the two systems can be seen for the tests using Fuel 5.1. The $47 \mathrm{~mm}$ PM deposition exceeded that of the $70 \mathrm{~mm}$ system for both cases.

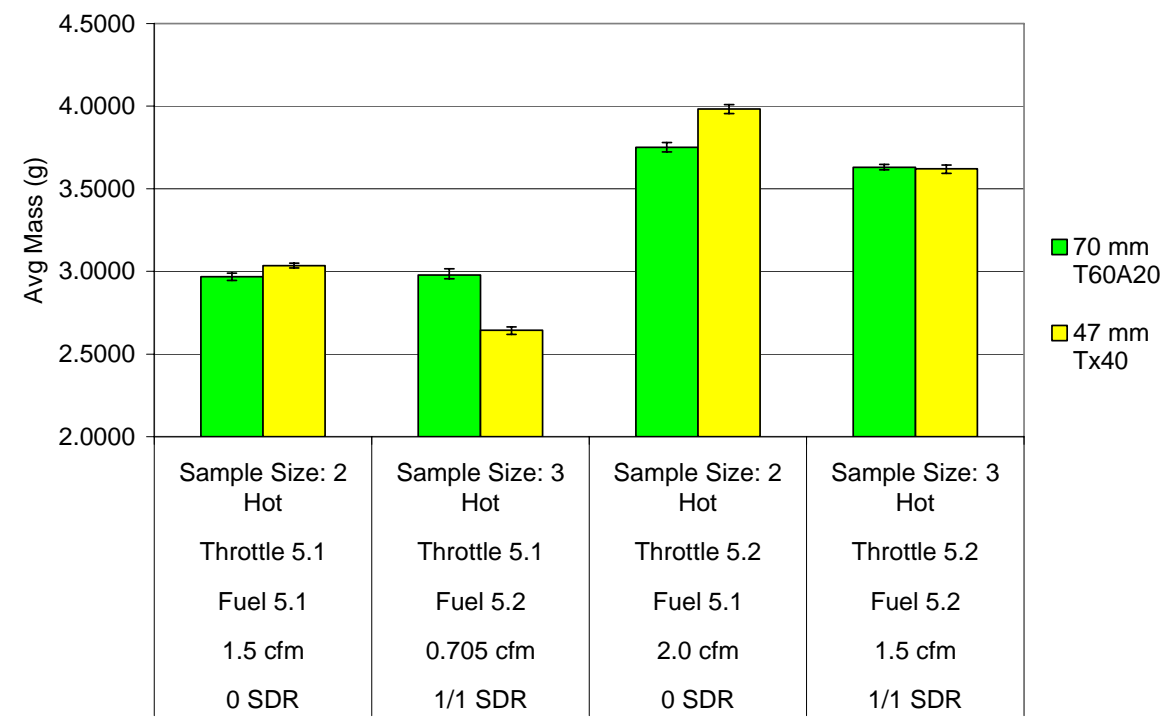

Figure 5.10 January 18, Average PM Mass Hot Start FTPs 


\subsection{January 19, 2007}

Four varying flow conditions were collected on this day of testing; each with three hot start FTPs. Once again the adjustment from Fuel 6.1 to 6.2 had little effect on the $70 \mathrm{~mm}$ PM deposition. The change in the $47 \mathrm{~mm}$ deposition is most likely due to the change in the flow rate parameters. Increasing the SDR and/or decreasing the FFV led to less PM collection on the Tx40 filter media. This trend can be observed for both throttles 6.1 and 6.2. Similarly, as the throttle was changed from 6.1 to 6.2 , an obvious increase in mass deposition was observed for the corresponding PM systems.

The $47 \mathrm{~mm}$ system was unable to maintain proportionality over the Tx40 filters for the conditions of $1 / 1 \mathrm{SDR}$ and $2 \mathrm{cfm}$. This condition also resulted in more mass accumulated on the $47 \mathrm{~mm}$ filter than on the $70 \mathrm{~mm}$ filter. The only instances thus far where the $47 \mathrm{~mm}$ filter reported a higher PM mass is at low SDR and high FFV. These results can be seen Table 5.6 and Figure 5.11.

Table 5.6 Results from January 19

\begin{tabular}{|c|c|c|c|c|}
\hline Test Set & \multicolumn{2}{|c|}{6.1} & \multicolumn{2}{|c|}{6.2} \\
\hline Engine & \multicolumn{2}{|c|}{ DDC 2} & \multicolumn{2}{|c|}{ DDC 2} \\
\hline Fuel & \multicolumn{2}{|c|}{ Fuel 6.1} & \multicolumn{2}{|c|}{ Fuel 6.2} \\
\hline Throttle & \multicolumn{2}{|c|}{ Throttle 6.1} & \multicolumn{2}{|c|}{ Throttle 6.1} \\
\hline \# FTPs in Avg & \multicolumn{2}{|c|}{3} & \multicolumn{2}{|c|}{3} \\
\hline PM System & $47 \mathrm{~mm}$ & $70 \mathrm{~mm}$ & $47 \mathrm{~mm}$ & $70 \mathrm{~mm}$ \\
\hline Filter Media & $\mathrm{Tx} 40$ & T60A20 & $\mathrm{Tx} 40$ & T60A20 \\
\hline SDR & $1 / 1$ & - & $10 / 1$ & - \\
\hline FFV (cfm) & 2.0 & 0.705 & 1.5 & 0.705 \\
\hline $\begin{array}{l}\text { Avg Mass / test } \\
\text { cycle (g) }\end{array}$ & 2.9350 & 2.9066 & 2.2708 & 2.8403 \\
\hline $\begin{array}{l}\text { Variation } \\
\text { Coefficient (\%) }\end{array}$ & 1.19 & 0.80 & 2.28 & 1.45 \\
\hline Difference (\%) & 0.98 & - & -20.05 & - \\
\hline Proportionality & Yes & - & No & - \\
\hline
\end{tabular}


Table 5.6 cont.

\begin{tabular}{|c|c|c|c|c|}
\hline Test Set & \multicolumn{2}{|c|}{6.3} & \multicolumn{2}{|c|}{6.4} \\
\hline Engine & \multicolumn{2}{|c|}{ DDC 2} & \multicolumn{2}{|c|}{ DDC 2} \\
\hline Fuel & \multicolumn{2}{|c|}{ Fuel 6.1} & \multicolumn{2}{|c|}{ Fuel 6.2} \\
\hline Throttle & \multicolumn{2}{|c|}{ Throttle 6.2} & \multicolumn{2}{|c|}{ Throttle 6.2} \\
\hline \# FTPs in Avg & \multicolumn{2}{|c|}{3} & \multicolumn{2}{|c|}{3} \\
\hline PM System & $47 \mathrm{~mm}$ & $70 \mathrm{~mm}$ & $47 \mathrm{~mm}$ & $70 \mathrm{~mm}$ \\
\hline Filter Media & $\mathrm{Tx} 40$ & T60A20 & $\mathrm{Tx} 40$ & T60A20 \\
\hline SDR & $10 / 1$ & - & $10 / 1$ & - \\
\hline FFV (cfm) & 2.4 & 0.705 & 0.705 & 0.705 \\
\hline $\begin{array}{l}\text { Avg Mass / test } \\
\text { cycle (g) }\end{array}$ & 3.3128 & 3.5248 & 1.0369 & 3.4457 \\
\hline $\begin{array}{l}\text { Variation } \\
\text { Coefficient (\%) }\end{array}$ & 2.78 & 0.74 & 28.74 & 0.38 \\
\hline Difference $(\%)$ & -6.02 & - & -69.91 & - \\
\hline Proportionality & No & - & Yes & - \\
\hline
\end{tabular}

By examining the averaged PM mass, a very interesting result is exposed. At a high SDR of 10/1, the percent difference between PM deposited on Tx40 $47 \mathrm{~mm}$ and the T60A20 $70 \mathrm{~mm}$ filters increases as the FFV decreases. By comparing the values between the two systems for $2.4 \mathrm{cfm}, 1.5 \mathrm{cfm}$, and $0.705 \mathrm{cfm}$ one can see increasing differences of $6.02 \%, 20.05 \%$, and $69.91 \%$ respectfully. The CV for the $47 \mathrm{~mm}$ Tx40 filter for the low FFV and high SDR reaches $28.74 \%$. Using low FFV at high SDR leads to unacceptably inaccurate results. This appears to be a key indication to use higher FFV when a high SDR is selected. 


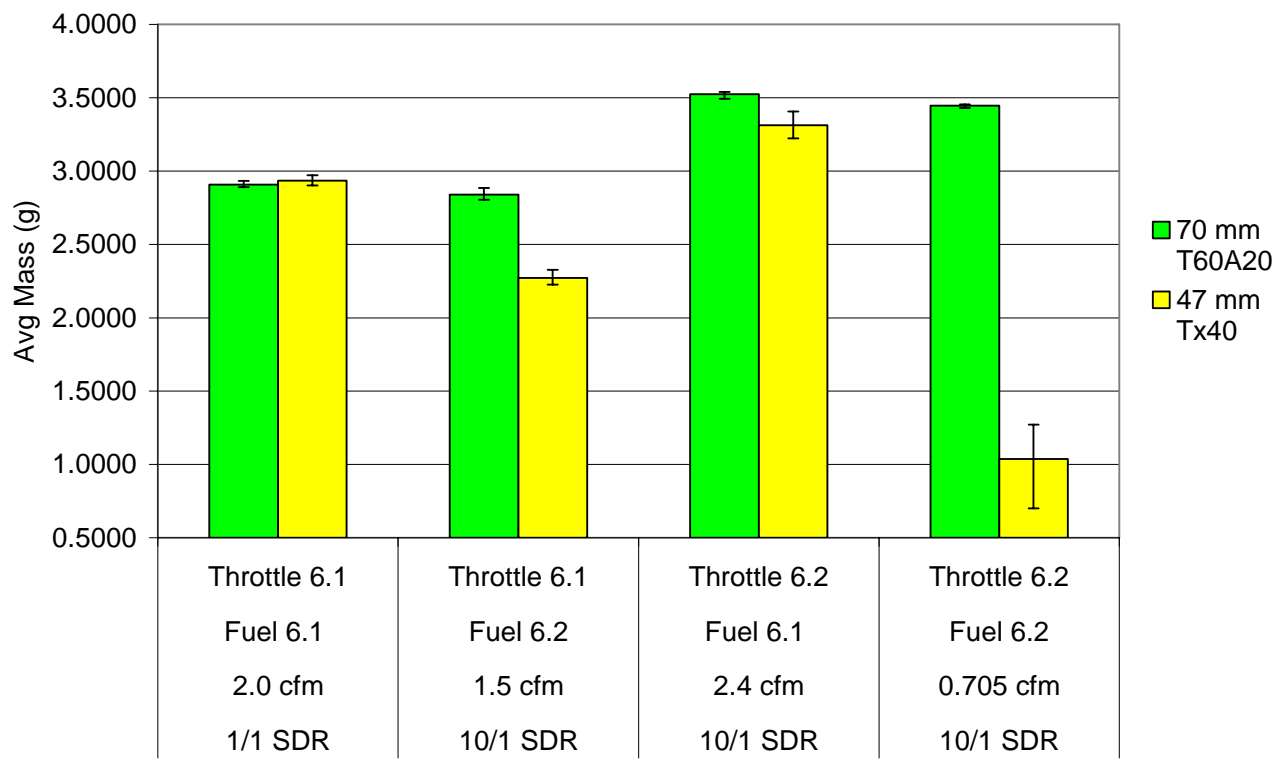

Figure 5.11 January 19, Average PM Mass of 3 Hot Start FTPs

\subsection{January 24, 2007}

The next three days of testing were performed using the first 1992 DDC Series 60 engine owned by WVU. The $24^{\text {th }}$ of January involved Fuel 7.1 with two throttle approaches, 7.1 and 7.2. Both systems used T60A20 media and the sample was conditioned at a constant SDR of 1/1. The FFV for the $47 \mathrm{~mm}$ system was increased for each set of FTPs.

The first two conditions, 1.5 and $2 \mathrm{cfm}$, produced similar differences between the 70 and $47 \mathrm{~mm}$ systems. T60A20 filters showed repeatability and low percent differences between both systems at these moderate conditions. The T60A20 filters for both systems led to extremely percent differences. This observation suggests that the filter media has a strong effect on the mass of PM deposition.

Increasing the FFV to 2.4 led to failure in maintaining flow proportionality as well as a higher accumulation by the $47 \mathrm{~mm}$ than the $70 \mathrm{~mm}$ system. However, the percent difference between the systems was $0.77 \%$. While the $\mathrm{CV}$ and percent difference were below the acceptable levels, the results for the proportionality suggest that at modest 
levels of SDR, high FFVs should be avoided. The specific results can be seen in Figure 5.12 and Table 5.7.

Table 5.7 Results from January 24

\begin{tabular}{|c|c|c|c|c|}
\hline Test Set & \multicolumn{2}{|c|}{7.1} & \multicolumn{2}{|c|}{7.2} \\
\hline Engine & \multicolumn{2}{|c|}{ DDC 1} & \multicolumn{2}{|c|}{ DDC 1} \\
\hline Fuel & \multicolumn{2}{|c|}{ Fuel 7.1} & \multicolumn{2}{|c|}{ Fuel 7.1} \\
\hline Throttle & \multicolumn{2}{|c|}{ Throttle 7.1} & \multicolumn{2}{|c|}{ Throttle 7.2} \\
\hline \# FTPs in Avg & \multicolumn{2}{|c|}{3} & \multicolumn{2}{|c|}{4} \\
\hline PM System & $47 \mathrm{~mm}$ & $70 \mathrm{~mm}$ & $47 \mathrm{~mm}$ & $70 \mathrm{~mm}$ \\
\hline Filter Media & T60A20 & T60A20 & T60A20 & T60A20 \\
\hline SDR & $1 / 1$ & - & $1 / 1$ & - \\
\hline FFV (cfm) & 1.5 & 0.705 & 2.0 & 0.705 \\
\hline $\begin{array}{l}\text { Avg Mass / test } \\
\text { cycle (g) }\end{array}$ & 6.6538 & 6.8825 & 6.1828 & 6.3721 \\
\hline $\begin{array}{l}\text { Variation } \\
\text { Coefficient (\%) }\end{array}$ & 0.45 & 0.63 & 1.82 & 2.68 \\
\hline Difference $(\%)$ & -3.32 & - & -2.97 & - \\
\hline Proportionality & Yes & - & Yes & - \\
\hline
\end{tabular}

Table 5.7 cont.

\begin{tabular}{|c|c|c|}
\hline Test Set & \multicolumn{2}{|c|}{7.3} \\
\hline Engine & \multicolumn{2}{|c|}{ DDC 1} \\
\hline Fuel & \multicolumn{2}{|c|}{ Fuel 7.1} \\
\hline Throttle & \multicolumn{2}{|c|}{ Throttle 7.2} \\
\hline \# FTPs in Avg & \multicolumn{2}{|c|}{2} \\
\hline PM System & $47 \mathrm{~mm}$ & $70 \mathrm{~mm}$ \\
\hline Filter Media & T60A20 & T60A20 \\
\hline SDR & $1 / 1$ & - \\
\hline FFV (cfm) & 2.4 & 0.705 \\
\hline $\begin{array}{l}\text { Avg Mass / test } \\
\text { cycle (g) }\end{array}$ & 6.3511 & 6.3027 \\
\hline $\begin{array}{l}\text { Variation } \\
\text { Coefficient (\%) }\end{array}$ & 2.19 & 2.32 \\
\hline Difference $(\%)$ & 0.77 & - \\
\hline Proportionality & No & - \\
\hline
\end{tabular}




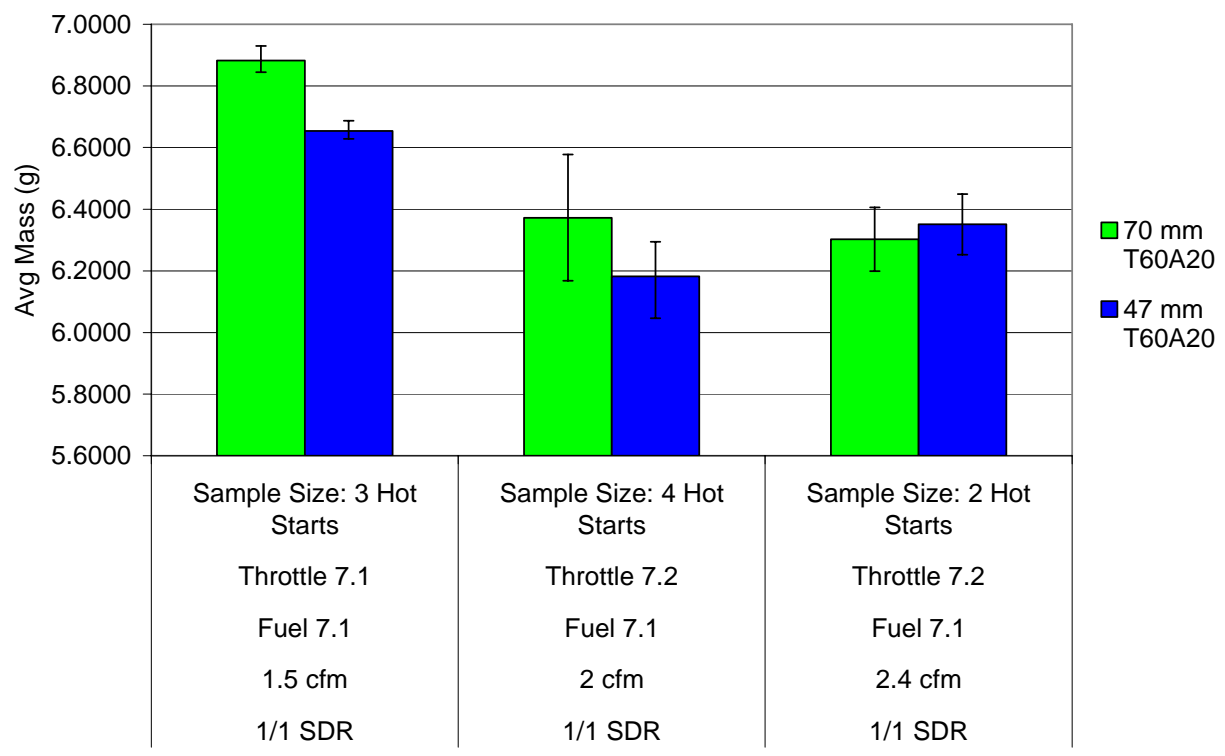

Figure 5.12 January 24, Average PM Mass of Hot Start FTPs

\subsection{January 25, 2007}

Two fuels and throttle settings were incorporated for this day of testing. The typical relationship between these settings were again observed for the $70 \mathrm{~mm}$ system, i.e. small effect from fuel on PM mass and a large effect by throttle on PM mass.

The $47 \mathrm{~mm}$ system also displayed results which matched previously observed relationships. For conditions with constant FFVs, more mass was collected at low SDRs. Results from high SDRs and FFVs were almost identical to those at moderate SDR and FFV levels. For example, the CVs and percent differences between systems are very similar when considering the 10/1 SDR and $2.4 \mathrm{cfm}$ data to those from the 2/1 SDR and 1 cfm conditions. Both displayed CVs around $2 \%$ and a $15 \%$ system difference for each of the respectful settings.

Once again these results seem to be typical of the observed trend between FFV and SDR. Refer to Table 5.8 and Figure 5.13 for a better representation of this data. 
Table 5.8 Results from January 25

\begin{tabular}{|c|c|c|c|c|}
\hline Test Set & \multicolumn{2}{|c|}{8.1} & \multicolumn{2}{|c|}{8.2} \\
\hline Engine & \multicolumn{2}{|c|}{ DDC 1} & \multicolumn{2}{|c|}{ DDC 1} \\
\hline Fuel & \multirow{2}{*}{\multicolumn{2}{|c|}{ Fuel 8.1}} & \multicolumn{2}{|c|}{ Fuel 8.2} \\
\hline Throttle & \multirow{2}{*}{\multicolumn{2}{|c|}{ Throttle 8.1}} & \multicolumn{2}{|c|}{ Throttle 8.1} \\
\hline \# FTPs in Avg & & & \multicolumn{2}{|c|}{3} \\
\hline PM System & $47 \mathrm{~mm}$ & $70 \mathrm{~mm}$ & $47 \mathrm{~mm}$ & $70 \mathrm{~mm}$ \\
\hline Filter Media & T60A20 & T60A20 & T60A20 & T60A20 \\
\hline SDR & $10 / 1$ & - & $2 / 1$ & - \\
\hline FFV (cfm) & 2.4 & 0.705 & 1.0 & 0.705 \\
\hline $\begin{array}{l}\text { Avg Mass / test } \\
\text { cycle (g) }\end{array}$ & 5.0529 & 5.9093 & 4.8690 & 5.7384 \\
\hline $\begin{array}{l}\text { Variation } \\
\text { Coefficient (\%) }\end{array}$ & 1.21 & 2.00 & 0.84 & 2.58 \\
\hline Difference (\%) & -14.49 & - & -15.15 & - \\
\hline Proportionality & Yes & - & Yes & - \\
\hline
\end{tabular}

Table 5.8 cont.

\begin{tabular}{|c|c|c|c|c|}
\hline Test Set & \multicolumn{2}{|c|}{8.3} & \multicolumn{2}{|c|}{8.4} \\
\hline Engine & \multicolumn{2}{|c|}{ DDC 1} & \multicolumn{2}{|c|}{ DDC 1} \\
\hline Fuel & \multicolumn{2}{|c|}{ Fuel 8.1} & \multicolumn{2}{|c|}{ Fuel 8.2} \\
\hline Throttle & \multicolumn{2}{|c|}{ Throttle 8.2} & \multicolumn{2}{|c|}{ Throttle 8.2} \\
\hline \# FTPs in Avg & \multicolumn{2}{|c|}{2} & \multicolumn{2}{|c|}{3} \\
\hline PM System & $47 \mathrm{~mm}$ & $70 \mathrm{~mm}$ & $47 \mathrm{~mm}$ & $70 \mathrm{~mm}$ \\
\hline Filter Media & T60A20 & T60A20 & T60A20 & T60A20 \\
\hline SDR & $10 / 1$ & - & $2 / 1$ & - \\
\hline FFV (cfm) & 1.5 & 0.705 & 1.5 & 0.705 \\
\hline $\begin{array}{l}\text { Avg Mass / test } \\
\text { cycle (g) }\end{array}$ & 3.8566 & 6.8480 & 5.7367 & 6.2876 \\
\hline $\begin{array}{l}\text { Variation } \\
\text { Coefficient (\%) }\end{array}$ & 0.84 & 2.58 & 0.70 & 0.58 \\
\hline Difference (\%) & -43.68 & - & -8.76 & - \\
\hline Proportionality & Yes & - & Yes & - \\
\hline
\end{tabular}




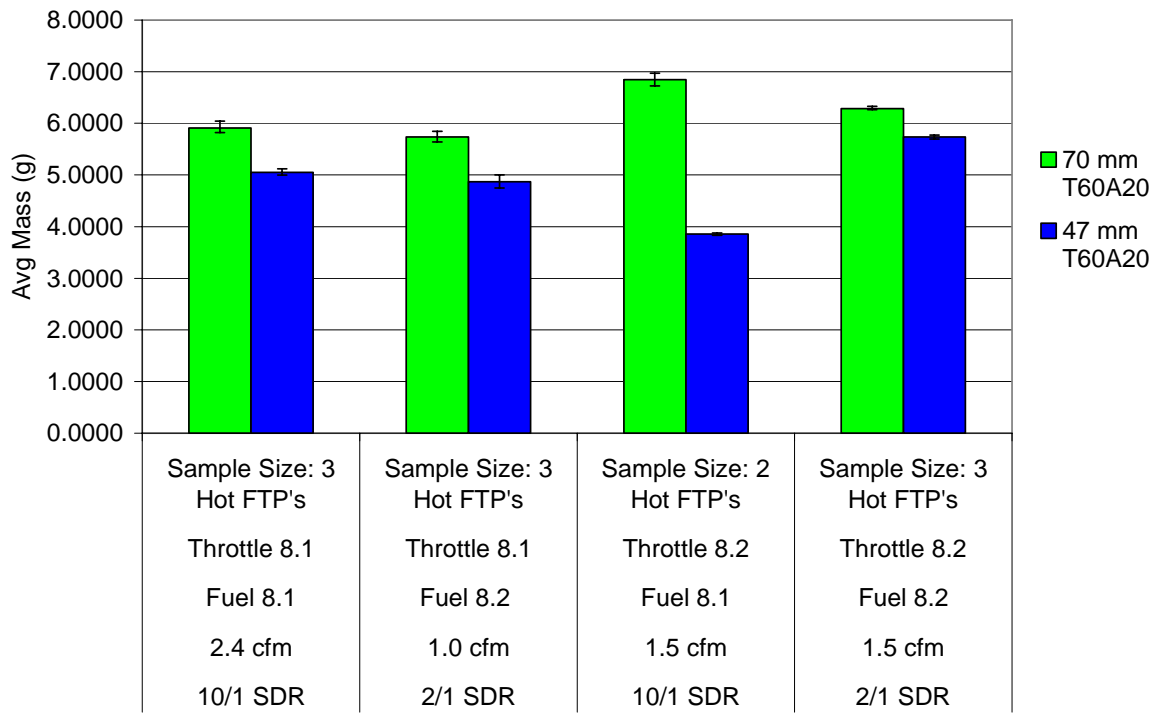

Figure 5.13 January 25, Average PM Mass of Hot Start FTPs

\subsection{January 26, 2007}

The last day of testing with WVU's 1992 DDC Series 60 employed two fuels and two throttle settings, 9.1 and 9.2. The typical relationship between the $70 \mathrm{~mm}$ system and the changing parameters was observed, a small effect from fuel on PM mass and a large effect by throttle on mass.

Two of the sets of FTPs were collected on T60A20 $47 \mathrm{~mm}$ filters at 1/1 SDR, 1 cfm flow and $0 \mathrm{SDR}, 1.5 \mathrm{cfm}$ flow, respectfully. An increase in $47 \mathrm{~mm}$ PM collection was observed for the situation with a lower SDR and higher FFV. However, the throttle approaches for the tests were different. This parameter makes it difficult to determine the exact cause of higher PM deposition.

The last set of FTPs was collected on Teflo $47 \mathrm{~mm}$ filters with 0 SDR and a $1 \mathrm{cfm}$ flow rate. The resulting averaged PM mass replicated that collected by the $70 \mathrm{~mm}$ system and was in fact only lower by $0.52 \%$. Both the $70 \mathrm{~mm}$ and $47 \mathrm{~mm}$ systems showed acceptable variations, 3.28\% and 1.24\% respectfully, leading one to believe that the Teflo media can reproduce respectful results at these testing conditions. Refer to Table 5.9 and Figure 5.14 for a visual representation of this data. 
Table 5.9 Results from January 26

\begin{tabular}{|c|c|c|c|c|}
\hline Test Set & \multicolumn{2}{|c|}{9.1} & \multicolumn{2}{|c|}{9.2} \\
\hline Engine & \multicolumn{2}{|c|}{ DDC 1} & \multicolumn{2}{|c|}{ DDC 1} \\
\hline Fuel & \multirow{2}{*}{\multicolumn{2}{|c|}{ Fuel 9.1}} & \multicolumn{2}{|c|}{ Fuel 9.2} \\
\hline Throttle & \multirow{2}{*}{\multicolumn{2}{|c|}{ Throttle 9.1}} & \multicolumn{2}{|c|}{ Throttle 9.1} \\
\hline \# FTPs in Avg & & & \multicolumn{2}{|c|}{3} \\
\hline PM System & $47 \mathrm{~mm}$ & $70 \mathrm{~mm}$ & $47 \mathrm{~mm}$ & $70 \mathrm{~mm}$ \\
\hline Filter Media & T60A20 & T60A20 & Teflo & T60A20 \\
\hline SDR & $1 / 1$ & - & 0 & - \\
\hline FFV (cfm) & 1.0 & 0.705 & 1.0 & 0.705 \\
\hline $\begin{array}{l}\text { Avg Mass / test } \\
\text { cycle (g) }\end{array}$ & 5.3623 & 5.7344 & 5.7805 & 6.3639 \\
\hline $\begin{array}{l}\text { Variation } \\
\text { Coefficient (\%) }\end{array}$ & 0.56 & 0.78 & 1.24 & 3.28 \\
\hline Difference (\%) & -6.49 & - & -0.52 & - \\
\hline Proportionality & Yes & - & Yes & - \\
\hline
\end{tabular}

Table 5.9 cont.

\begin{tabular}{|c|c|c|}
\hline Test Set & \multicolumn{2}{|c|}{9.3} \\
\hline Engine & \multicolumn{2}{|c|}{ DDC 1} \\
\hline Fuel & \multicolumn{2}{|c|}{ Fuel 9.1} \\
\hline Throttle & \multicolumn{2}{|c|}{ Throttle 9.2} \\
\hline \# FTPs in Avg & \multicolumn{2}{|c|}{2} \\
\hline PM System & $47 \mathrm{~mm}$ & $70 \mathrm{~mm}$ \\
\hline Filter Media & T60A20 & T60A20 \\
\hline SDR & 0 & - \\
\hline FFV (cfm) & 1.5 & 0.705 \\
\hline $\begin{array}{l}\text { Avg Mass / test } \\
\text { cycle (g) }\end{array}$ & 6.5517 & 6.3639 \\
\hline $\begin{array}{l}\text { Variation } \\
\text { Coefficient (\%) }\end{array}$ & 1.11 & 2.33 \\
\hline Difference (\%) & 2.95 & - \\
\hline Proportionality & Yes & - \\
\hline
\end{tabular}




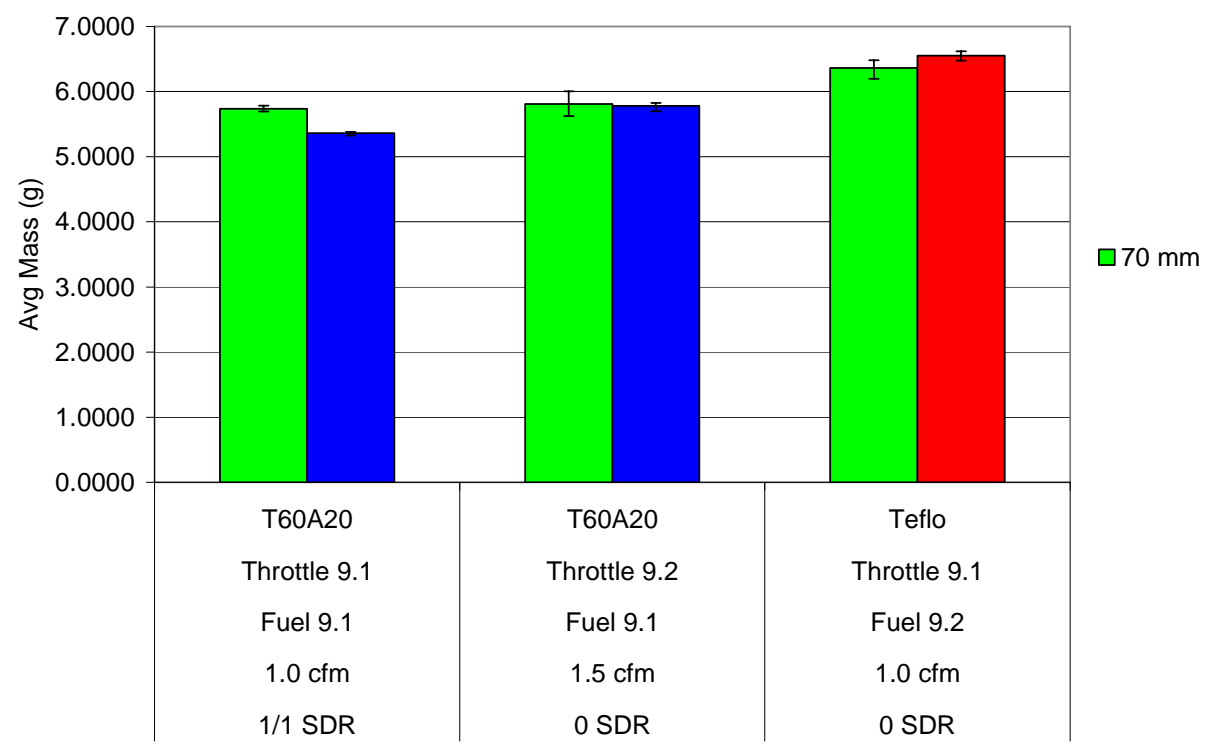

Figure 5.14 January 26, Average PM Mass of 3 Hot Start FTPs

\subsubsection{1999 Cummins ISM}

The following three days of PM testing used a WVU owned 1999 Cummins ISM engine. One fuel was used with one or two throttle approaches on each day. The $47 \mathrm{~mm}$ system also incorporated the usual changing SDRs, FFVs, and filter medias. As usual, the $70 \mathrm{~mm}$ PM system was used with T60A20 media type and the normal sample specifications.

\subsection{February 7, 2007}

Two different $47 \mathrm{~mm}$ SDRs, 0 and 1/1, were used across two tests with different throttle approaches. The FFV was held constant at $1.5 \mathrm{cfm}$ across $47 \mathrm{~mm}$ Teflo filters. The different approaches had the same effect on both systems with the percent difference across Throttle 10.1 and 10.2 observed as $38.95 \%$ and $33.44 \%$ respectively. While the 70 $\mathrm{mm}$ showed a decreasing variation across the throttle change, $1.31 \%$ to $3.49 \%$, the $\mathrm{CV}$ for the $47 \mathrm{~mm}$ Teflo filters improved from $13.46 \%$ to $2.32 \%$ when the SDR was increased from 0 to $1 / 1$. The tabulated results and visual representations for this test day can be seen in Table 5.10 and Figure 5.15. 
Table 5.10 Results from February 7

\begin{tabular}{|c|c|c|c|c|}
\hline Test Set & \multicolumn{2}{|c|}{10.1} & \multicolumn{2}{|c|}{10.2} \\
\hline Engine & \multicolumn{2}{|c|}{1999 ISM } & \multicolumn{2}{|c|}{1999 ISM } \\
\hline Fuel & \multicolumn{2}{|c|}{ Fuel 10.1} & \multicolumn{2}{|c|}{ Fuel 10.1} \\
\hline Throttle & \multicolumn{2}{|c|}{ Throttle 10.1} & \multicolumn{2}{|c|}{ Throttle 10.2} \\
\hline \# FTPs in Avg & \multicolumn{2}{|c|}{3} & \multicolumn{2}{|c|}{3} \\
\hline PM System & $47 \mathrm{~mm}$ & $70 \mathrm{~mm}$ & $47 \mathrm{~mm}$ & $70 \mathrm{~mm}$ \\
\hline Filter Media & Teflo & T60A20 & Teflo & T60A20 \\
\hline SDR & 0 & - & $1 / 1$ & - \\
\hline FFV (cfm) & 1.5 & 0.705 & 1.5 & 0.705 \\
\hline $\begin{array}{l}\text { Avg Mass / test } \\
\text { cycle (g) }\end{array}$ & 1.8719 & 3.0662 & 2.3211 & 3.4875 \\
\hline $\begin{array}{l}\text { Variation } \\
\text { Coefficient (\%) }\end{array}$ & 13.46 & 1.31 & 2.32 & 3.49 \\
\hline Difference $(\%)$ & -38.95 & - & -33.44 & - \\
\hline Proportionality & No & - & No & - \\
\hline
\end{tabular}

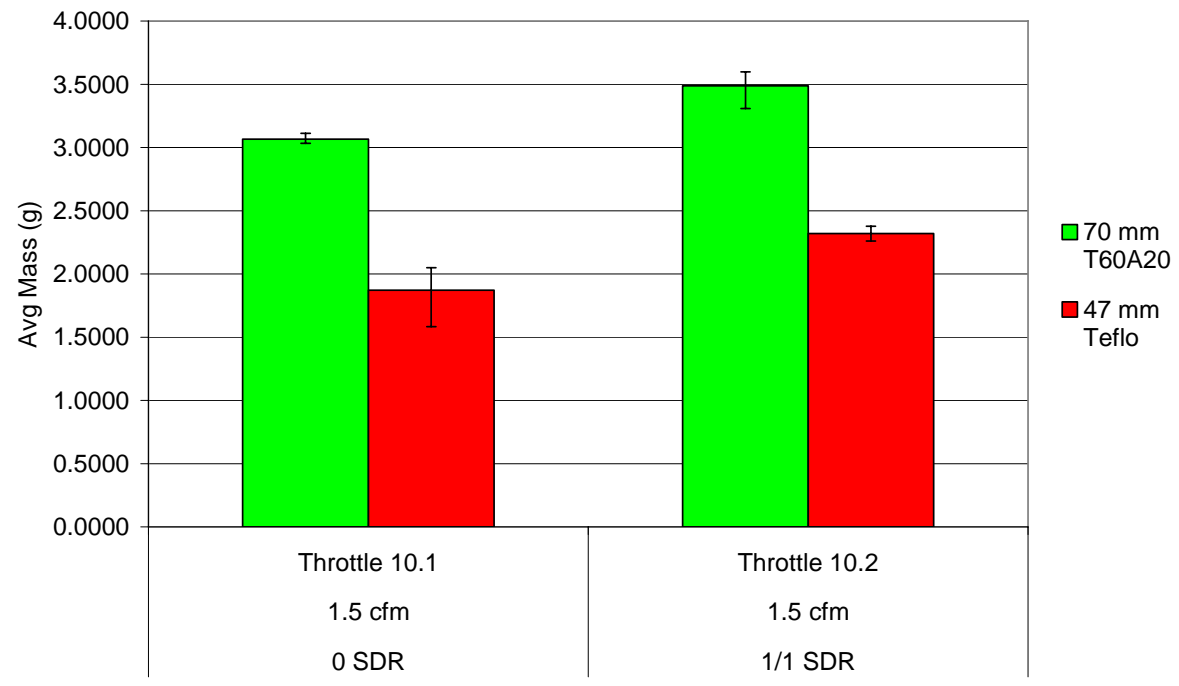

Figure 5.15 February 7, Average PM Mass of 3 Hot Start FTPs

\subsection{February 9, 2007}

$47 \mathrm{~mm}$ Teflo filters were sampled at $1.5 \mathrm{cfm}$ with an increased SDR of 2/1. The percent difference between the systems was observed at approximately $30 \%$, and is likely to be attributed to the differences in PM accumulation across the media types. The 
results from these test conditions were acceptable, with the $47 \mathrm{~mm}$ system producing a CV of $2.19 \%$.

Table 5.11 Results from February 9

\begin{tabular}{|c|c|c|}
\hline Test Set & \multicolumn{2}{|c|}{11} \\
\hline Engine & \multicolumn{2}{|c|}{1999 ISM } \\
\hline Fuel & \multicolumn{2}{|c|}{ Fuel 11.1} \\
\hline Throttle & \multicolumn{2}{|c|}{ Throttle 11.1} \\
\hline \# FTPs in Avg & \multicolumn{2}{|c|}{3} \\
\hline PM System & $47 \mathrm{~mm}$ & $70 \mathrm{~mm}$ \\
\hline Filter Media & Teflo & T60A20 \\
\hline SDR & $2 / 1$ & - \\
\hline FFV (cfm) & 1.5 & 0.705 \\
\hline $\begin{array}{l}\text { Avg Mass / test } \\
\text { cycle (g) }\end{array}$ & 1.8130 & 2.5651 \\
\hline $\begin{array}{l}\text { Variation } \\
\text { Coefficient (\%) }\end{array}$ & 2.19 & 4.21 \\
\hline Difference $(\%)$ & -29.32 & - \\
\hline Proportionality & Yes & - \\
\hline
\end{tabular}

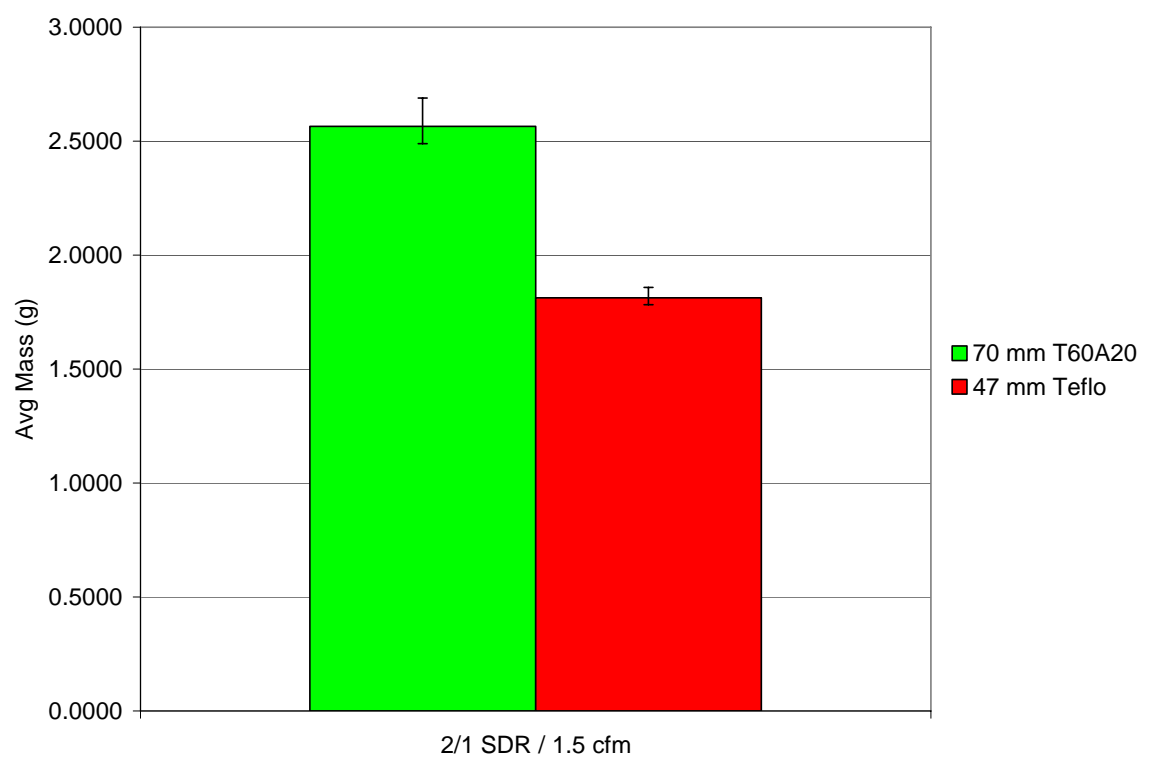

Figure 5.16 February 9, Average PM Mass of 3 Hot Start FTPs 
The relationship between $47 \mathrm{~mm}$ Teflo filters and SDR at a constant FFV can be seen by plotting results from both February $7^{\text {th }}$ and February $9^{\text {th }}$. Increasing the SDR at this medium level of FFV produces results which show decreasing system percent differences.

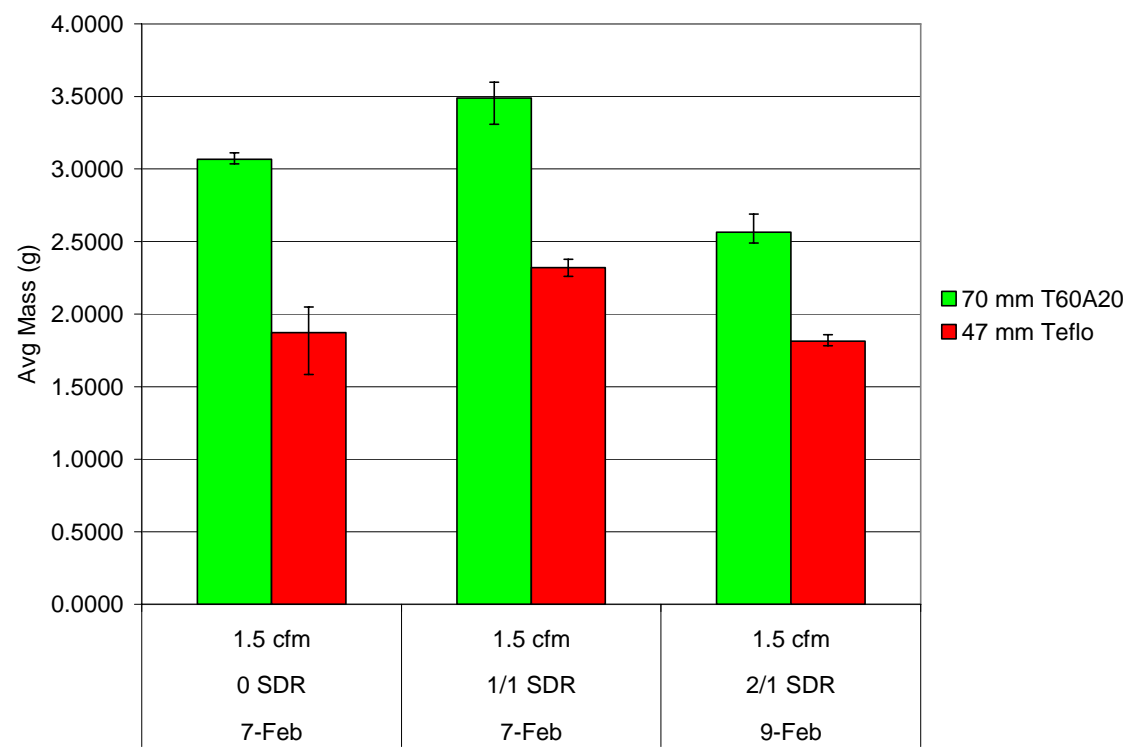

Figure 5.17 February 7 \& 9, Average PM Mass of 3 Hot Start FTPs

\subsection{February 13, 2007}

Three FTPs were collected at 10/1 SDR and $2 \mathrm{cfm}$ flow rate across Tx40 $47 \mathrm{~mm}$ filters. While both systems portrayed CVs below 3\%, the Tx40 filters accumulated $10.42 \%$ less PM than that shown by the $70 \mathrm{~mm}$ T60A20. While the $47 \mathrm{~mm}$ filters typically show less mass, this large percent difference is likely caused by the high SDR. Even though the FFV has increased as well, the excessive SDR seems to inhibit the amount of PM deposition on the $47 \mathrm{~mm}$ filters. 
Table 5.12 Results from February 13

\begin{tabular}{|c|c|c|}
\hline Test Set & \multicolumn{2}{|c|}{12} \\
\hline Engine & \multicolumn{2}{|c|}{1999 ISM } \\
\hline Fuel & \multicolumn{2}{|c|}{ Fuel 12.1} \\
\hline Throttle & \multicolumn{2}{|c|}{ Throttle 12.1} \\
\hline \# FTPs in Avg & \multicolumn{2}{|c|}{3} \\
\hline PM System & $47 \mathrm{~mm}$ & $70 \mathrm{~mm}$ \\
\hline Filter Media & Tx40 & T60A20 \\
\hline SDR & $10 / 1$ & - \\
\hline FFV (cfm) & 2.0 & 0.705 \\
\hline $\begin{array}{l}\text { Avg Mass / test } \\
\text { cycle (g) }\end{array}$ & 1.9749 & 2.2046 \\
\hline $\begin{array}{l}\text { Variation } \\
\text { Coefficient (\%) }\end{array}$ & 2.67 & 1.33 \\
\hline Difference $(\%)$ & -10.42 & - \\
\hline Proportionality & Yes & - \\
\hline
\end{tabular}

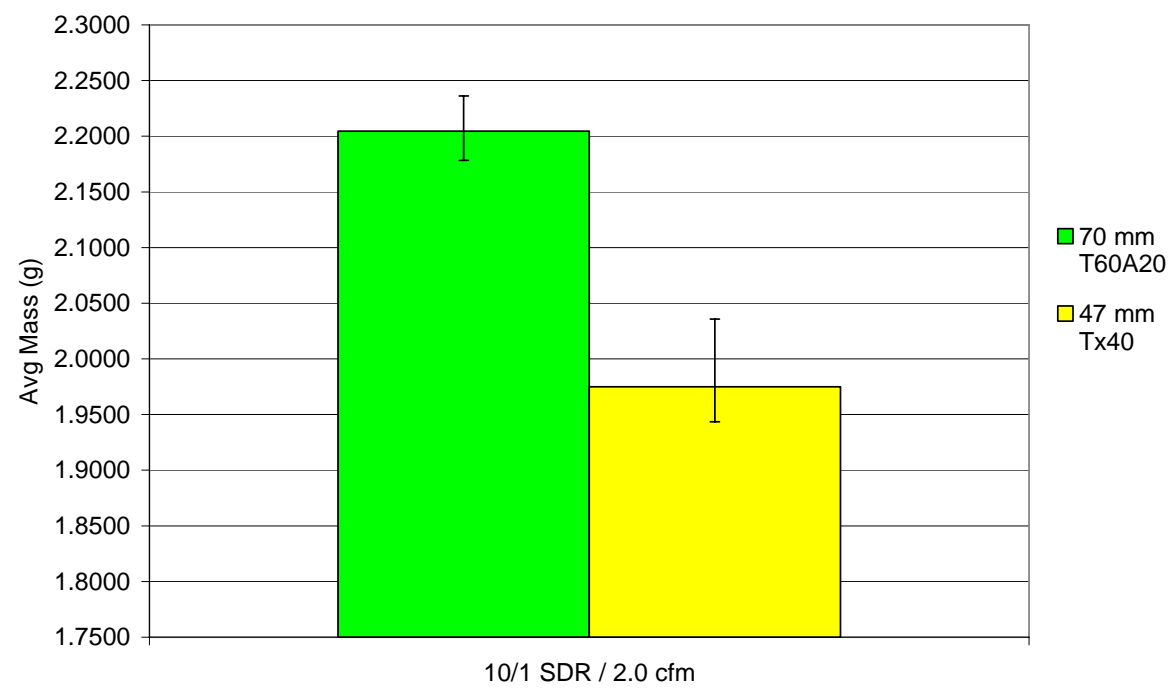

Figure 5.18 February 13, Average PM Mass of 3 Hot Start FTPs

\subsubsection{2004 Cummins ISM}

The following five test days used a WVU owned 2004 Cummins ISM engine. Five fuels and six throttle approaches were used along with the changing parameters implemented for the $47 \mathrm{~mm}$ system. The $70 \mathrm{~mm}$ PM system was used with T60A20 media type and the normal sample specifications. 
It should be noted that this 2004 Cummins engine, by certification standard, emits PM at a much lower level than the 1992 DDC. The resulting variability and system differences will be valuable for evaluating the new systems validity when measuring ultra low PM emitting vehicles.

\subsection{February 20, 2007}

The first test day with the 2004 Cummins ISM incorporated Tx40 $47 \mathrm{~mm}$ filters at two SDRs and three FFVs. Previous observations were replicated at the lower PM levels. The $47 \mathrm{~mm}$ system failed to maintain sample proportionality with the main tunnel at moderate levels of SDR and high FFV. Although proportionality was not established, the difference between $47 \mathrm{~mm}$ and $70 \mathrm{~mm}$ masses was less than $5 \%$.

At a very high SDR and low FFV, 10/1 and $1 \mathrm{cfm}$, the average mass of PM accumulated on the $47 \mathrm{~mm}$ filter was much smaller than the $70 \mathrm{~mm}$ system. Similar results were observed on January $19^{\text {th }}$ with the higher PM emitting DDC. The CV for the $47 \mathrm{~mm}$ system was found to be $122.68 \%$ at these extreme conditions.

The system percent difference and CV, at $1.0 \mathrm{FFV}$, improved by decreasing the SDR. For complete results for each of the three testing conditions, refer to the following Table 5.13 and Figure 5.19.

Table 5.13 Results from February 20

\begin{tabular}{|l|l|l|l|l|}
\hline Test Set & \multicolumn{2}{c|}{13.1} & \multicolumn{2}{c|}{13.2} \\
\hline Engine & \multicolumn{2}{|c|}{ 2004 ISM } & \multicolumn{2}{c|}{ Fuel 13M } \\
\hline Fuel & \multicolumn{2}{|c|}{ Fuel 13.1 } & \multicolumn{2}{c|}{ Throttle 13.1 } \\
\hline Throttle & \multicolumn{2}{|c|}{ Throttle 13.1 } & \multicolumn{2}{c|}{3} \\
\hline \# FTPs in Avg & \multicolumn{2}{|c|}{$20 \mathrm{~mm}$} & $\mathrm{~m}$ & $70 \mathrm{~mm}$ \\
\hline PM System & \multicolumn{2}{|c|}{$47 \mathrm{~mm}$} & \multicolumn{1}{c|}{$70 \mathrm{~m}$} & T60A20 \\
\hline Filter Media & Tx40 & T60A20 & - \\
\hline SDR & $10 / 1$ & - & 1.0 & 0.705 \\
\hline FFV (cfm) & 1.0 & 0.705 & 1.8048 & 2.0195 \\
\hline $\begin{array}{l}\text { Avg Mass / test } \\
\text { cycle (g) }\end{array}$ & 0.7440 & 1.5280 & 8.70 & 7.23 \\
\hline $\begin{array}{l}\text { Variation } \\
\text { Coefficient (\%) }\end{array}$ & 122.68 & 2.25 & -10.63 & - \\
\hline Difference (\%) & -51.34 & - & Yes & - \\
\hline Proportionality & Yes & - & \multicolumn{2}{|c|}{} \\
\hline
\end{tabular}


Table 5.13 cont.

\begin{tabular}{|c|c|c|}
\hline Test Set & \multicolumn{2}{|c|}{13.3} \\
\hline Engine & \multicolumn{2}{|c|}{2004 ISM } \\
\hline Fuel & \multicolumn{2}{|c|}{ Fuel 13.2} \\
\hline Throttle & \multicolumn{2}{|c|}{ Throttle 13.2} \\
\hline \# FTPs in Avg & \multicolumn{2}{|c|}{3} \\
\hline PM System & $47 \mathrm{~mm}$ & $70 \mathrm{~mm}$ \\
\hline Filter Media & $\mathrm{Tx} 40$ & T60A20 \\
\hline SDR & $1 / 1$ & - \\
\hline FFV (cfm) & 2.4 & 0.705 \\
\hline $\begin{array}{l}\text { Avg Mass / test } \\
\text { cycle (g) }\end{array}$ & 1.7929 & 1.8764 \\
\hline $\begin{array}{l}\text { Variation } \\
\text { Coefficient (\%) }\end{array}$ & 3.12 & 0.75 \\
\hline Difference $(\%)$ & -4.45 & - \\
\hline Proportionality & No & - \\
\hline
\end{tabular}

It should be noted that for this instance, it appears that the PM level is most affected by changing between fuels 13.1 and 13.2 other than adjusting the throttle approach.

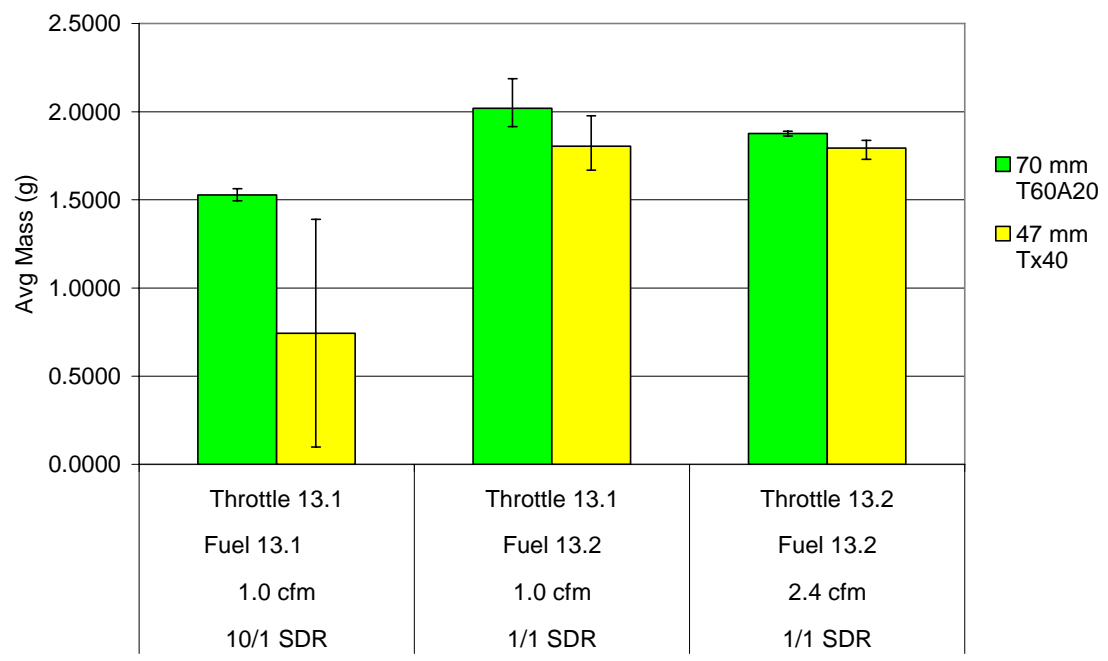

Figure 5.19 February 20, Average PM Mass of 3 Hot Start FTPs 


\subsection{February 21, 2007}

Two sets of test conditions for the $47 \mathrm{~mm}$ PM collection system were run in conjunction with two throttle approaches, 14.1 and 14.2. Both sets of FTPs were conducted using Tx40 $47 \mathrm{~mm}$ filters at a 2/1 SDR. While the throttle approach change led to less PM deposition, the decrease was observed equally across both systems. For the flow rates of $1.5 \mathrm{cfm}$ and $1.0 \mathrm{cfm}$ both filter sizes displayed similar results. The systems were approximately $6 \%$ different for the throttle approach 14.1 and $8 \%$ for approach 14.2. The CV of the $47 \mathrm{~mm}$ system was lower than that of the $70 \mathrm{~mm}$ system for the case with a 2/1 SDR and $1.0 \mathrm{cfm}$ FFV. The complete results are shown in Table 5.13.

Table 5.14 Results from February 21

\begin{tabular}{|c|c|c|c|c|}
\hline Test Set & \multicolumn{2}{|c|}{14.1} & \multicolumn{2}{|c|}{14.2} \\
\hline Engine & \multicolumn{2}{|c|}{2004 ISM } & \multicolumn{2}{|c|}{2004 ISM } \\
\hline Fuel & \multirow{2}{*}{\multicolumn{2}{|c|}{ Fuel 14.1}} & \multicolumn{2}{|c|}{ Fuel 14.1} \\
\hline Throttle & & & \multicolumn{2}{|c|}{ Throttle 14.2} \\
\hline \# FTPs in Avg & 3 & Throttle 14.1 & \multicolumn{2}{|c|}{3} \\
\hline PM System & $47 \mathrm{~mm}$ & $70 \mathrm{~mm}$ & $47 \mathrm{~mm}$ & $70 \mathrm{~mm}$ \\
\hline Filter Media & Tx40 & T60A20 & Tx40 & T60A20 \\
\hline SDR & $2 / 1$ & - & $2 / 1$ & - \\
\hline FFV (cfm) & 1.5 & 0.705 & 1.0 & 0.705 \\
\hline $\begin{array}{l}\text { Avg Mass / test } \\
\text { cycle (g) }\end{array}$ & 1.8942 & 2.0148 & 1.6953 & 1.8502 \\
\hline $\begin{array}{l}\text { Variation } \\
\text { Coefficient (\%) }\end{array}$ & 6.78 & 6.69 & 2.50 & 5.58 \\
\hline Difference (\%) & -5.99 & - & -8.37 & - \\
\hline Proportionality & Yes & - & Yes & - \\
\hline
\end{tabular}

By examining the corresponding results, one can see that these moderate levels of SDR and FFV lead to reasonable CVs and percent differences across the two systems. 


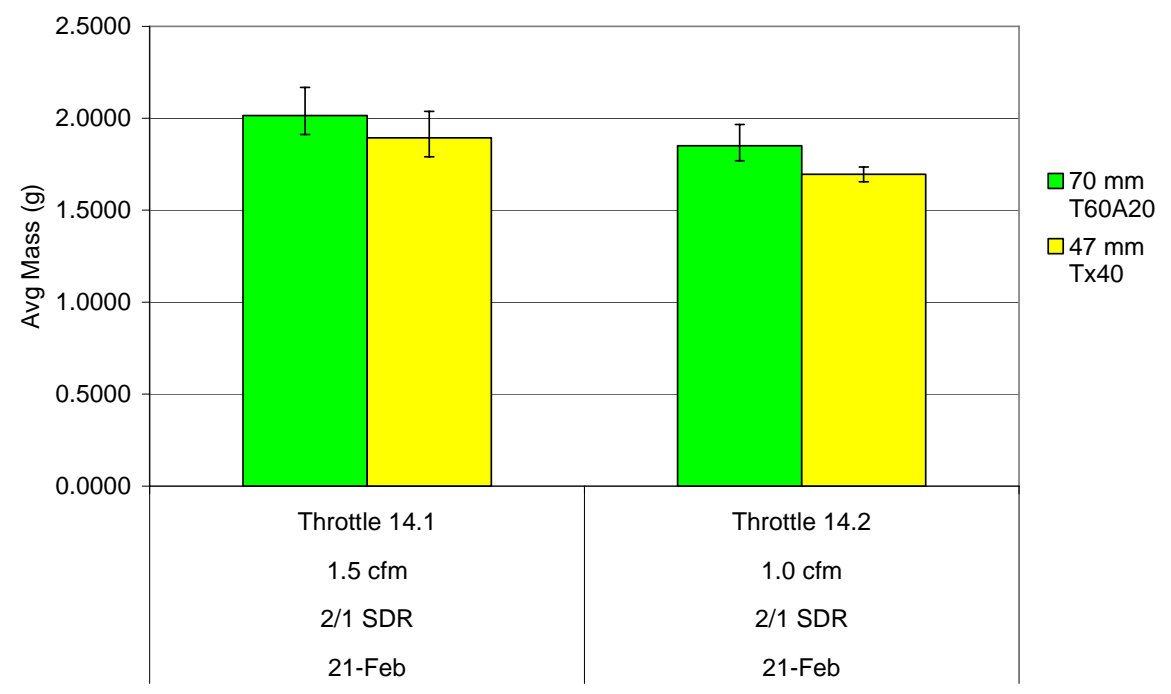

Figure 5.20 February 21, Average PM Mass of 3 Hot Start FTPs 


\subsection{February 22, 2007}

This test day consisted of a set of 3 FTPs across Tx40 $47 \mathrm{~mm}$ filters at a 2/1 SDR and $0.705 \mathrm{cfm}$. Although the $70 \mathrm{~mm}$ system has an acceptable CV, the $47 \mathrm{~mm}$ system's $\mathrm{CV}$ is almost $8 \%$ and the difference between the two is approaching $15 \%$.

Table 5.15 Results from February 22

\begin{tabular}{|c|c|c|}
\hline Test Set & \multicolumn{2}{|c|}{15} \\
\hline Engine & \multicolumn{2}{|c|}{2004 ISM } \\
\hline Fuel & \multicolumn{2}{|c|}{ Fuel 15.1} \\
\hline Throttle & \multicolumn{2}{|c|}{ Throttle 15.1} \\
\hline \# FTPs in Avg & \multicolumn{2}{|c|}{3} \\
\hline PM System & $47 \mathrm{~mm}$ & $70 \mathrm{~mm}$ \\
\hline Filter Media & Tx40 & T60A20 \\
\hline SDR & $2 / 1$ & - \\
\hline FFV (cfm) & 0.705 & 0.705 \\
\hline $\begin{array}{l}\text { Avg Mass / test } \\
\text { cycle (g) }\end{array}$ & 1.6117 & 1.8842 \\
\hline $\begin{array}{l}\text { Variation } \\
\text { Coefficient (\%) }\end{array}$ & 7.67 & 1.08 \\
\hline Difference (\%) & -14.46 & - \\
\hline Proportionality & Yes & - \\
\hline
\end{tabular}

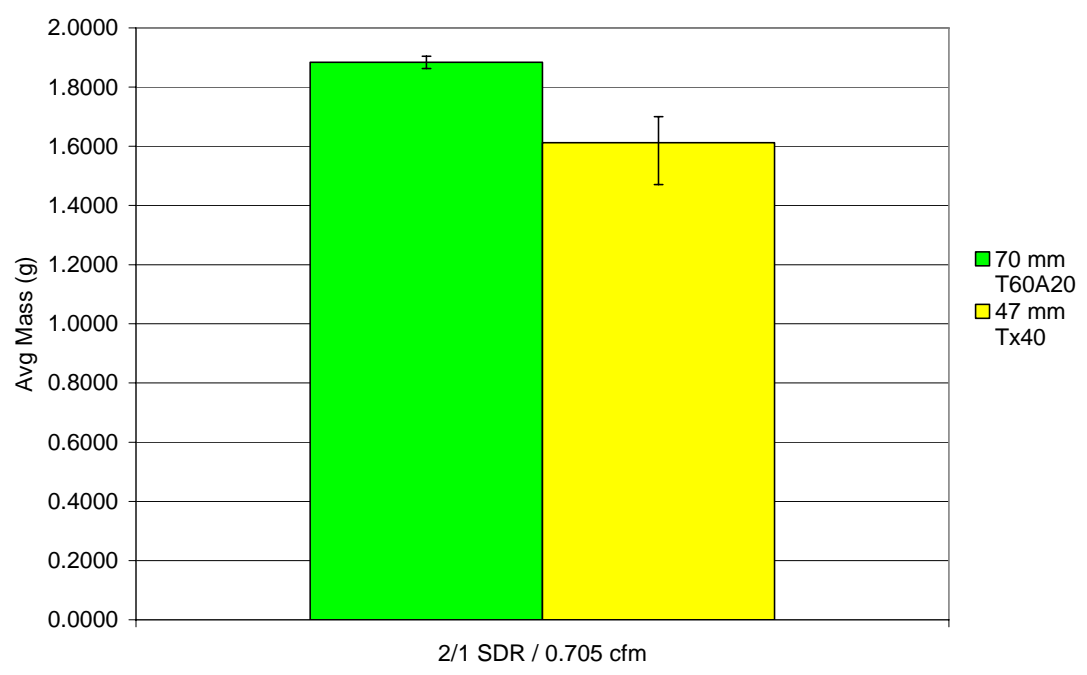

Figure 5.21 February 22, Average PM Mass of 3 Hot Start FTPs 
When comparing these results to the previous day, it can be seen that at a $2 / 1$ SDR the percent difference between the two PM collection systems increases with a decreasing velocity. However, the $47 \mathrm{~mm}$ system did produce an acceptable CV, $2.50 \%$, at a $1 \mathrm{cfm}$ FFV.

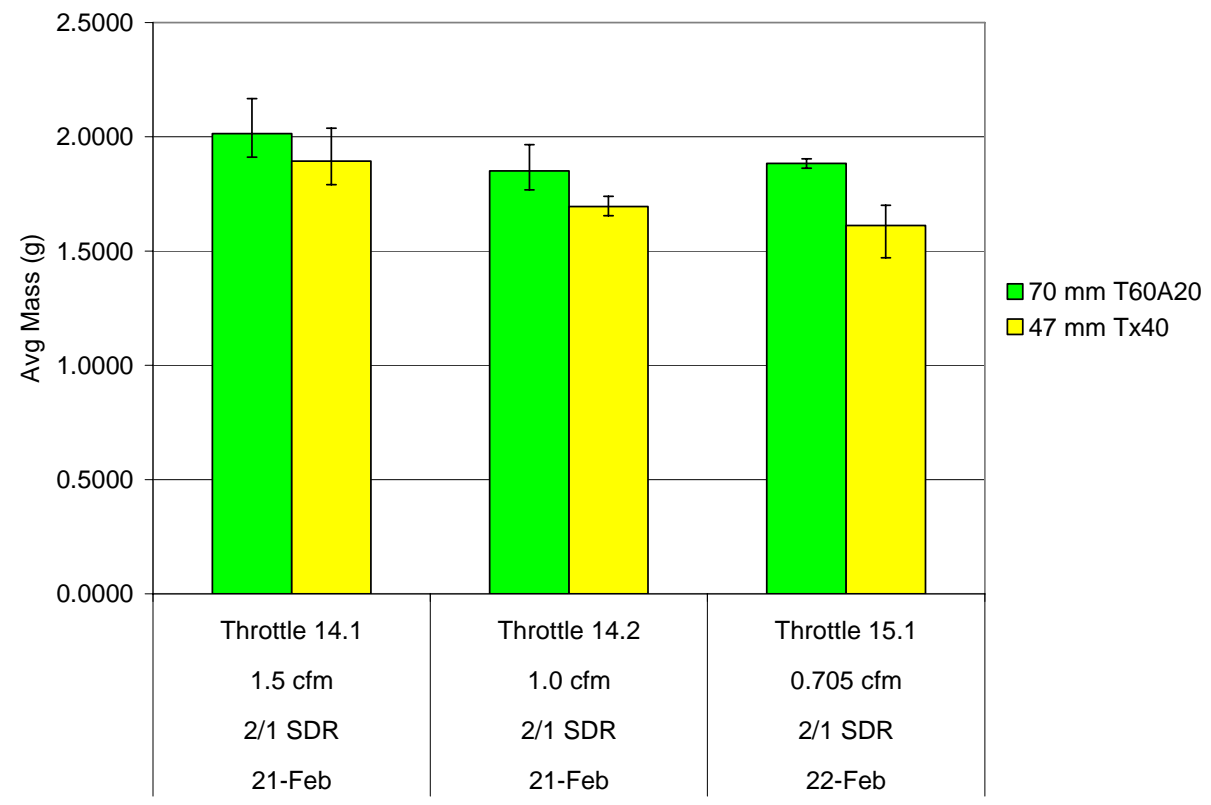

Figure 5.22 February 21 \& 22, Average PM Mass of 3 Hot Start FTPs

\subsection{February 26, 2007}

The Tx40 2/1 SDR comparison continued with 2 sets of FTPs at $2 \mathrm{cfm}$ and 2.4 cfm FFVs. The results were better than seen on the previous days with both systems portraying very low CVs, never above 3\%, and percent differences less than $5 \%$. While not always the case, both of these conditions portray the $47 \mathrm{~mm} \mathrm{Tx} 40 \mathrm{~s}$ as a more repeatable system than the $70 \mathrm{~mm}$ T60A20. 
Table 5.16 Results from February 26

\begin{tabular}{|c|c|c|c|c|}
\hline Test Set & \multicolumn{2}{|c|}{16.1} & \multicolumn{2}{|c|}{16.2} \\
\hline Engine & \multicolumn{2}{|c|}{2004 ISM } & \multicolumn{2}{|c|}{2004 ISM } \\
\hline Fuel & \multicolumn{2}{|c|}{ Fuel 16.1} & \multicolumn{2}{|c|}{ Fuel 16.1} \\
\hline Throttle & \multicolumn{2}{|c|}{ Throttle 16.1} & \multicolumn{2}{|c|}{ Throttle 16.2} \\
\hline \# FTPs in Avg & \multicolumn{2}{|c|}{3} & \multicolumn{2}{|c|}{3} \\
\hline PM System & $47 \mathrm{~mm}$ & $70 \mathrm{~mm}$ & $47 \mathrm{~mm}$ & $70 \mathrm{~mm}$ \\
\hline Filter Media & Tx40 & T60A20 & Tx40 & T60A20 \\
\hline SDR & $2 / 1$ & - & $10 / 1$ & - \\
\hline FFV (cfm) & 2.0 & 0.705 & 2.4 & 0.705 \\
\hline $\begin{array}{l}\text { Avg Mass / test } \\
\text { cycle }(\mathrm{g})\end{array}$ & 1.7718 & 1.8488 & 1.7742 & 1.8607 \\
\hline $\begin{array}{l}\text { Variation } \\
\text { Coefficient (\%) }\end{array}$ & 0.69 & 1.65 & 1.17 & 2.95 \\
\hline Difference (\%) & -4.16 & - & -4.65 & - \\
\hline Proportionality & Yes & - & Yes & - \\
\hline
\end{tabular}

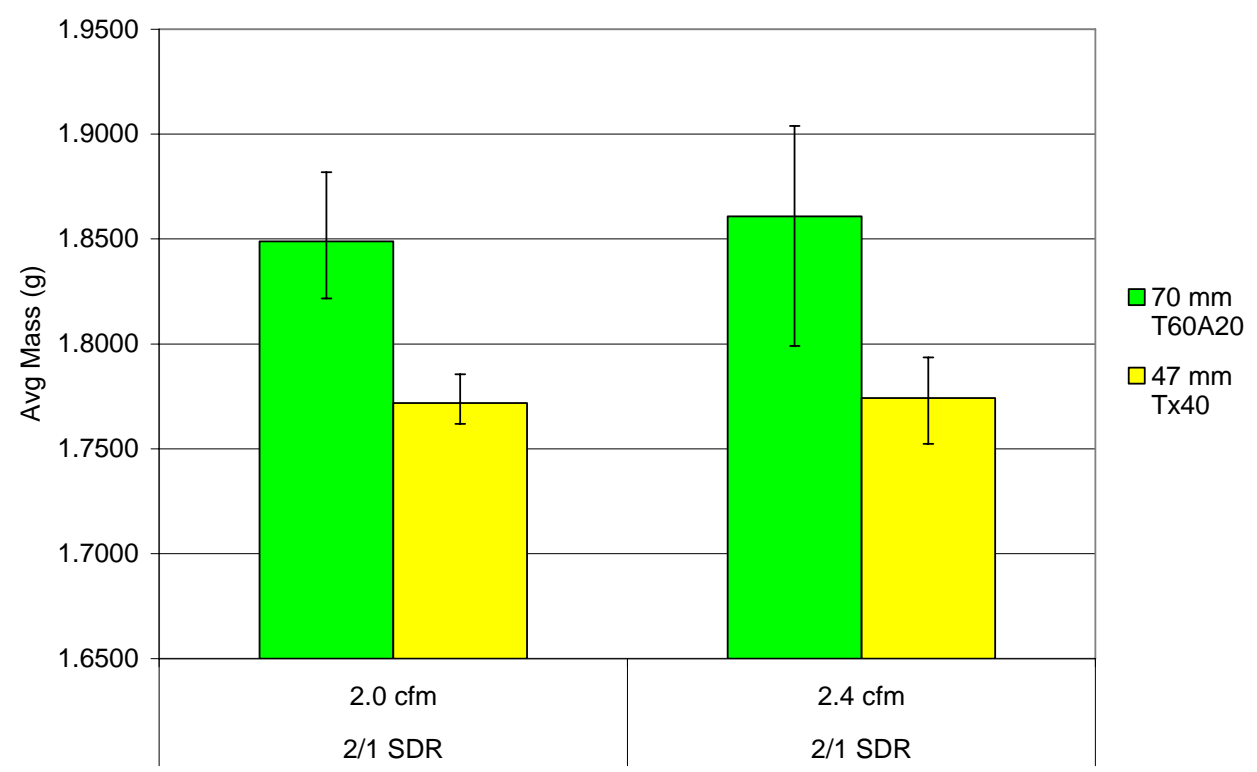

Figure 5.23 February 26, Average PM Mass of 3 Hot Start FTPs

\subsection{February 28, 2007}

Two SDRs, 1/1 and 2/1, were used with a $0.705 \mathrm{cfm}$ FFV over Teflo $47 \mathrm{~mm}$ filters. WVU's EERL also varied the test conditions by running the ISM with and without the exhaust gas recirculation (EGR) option, a common $\mathrm{NO}_{\mathrm{x}}$ reduction technique. 
The EGR's effect on PM deposition is obviously seen for the $70 \mathrm{~mm}$ filters yet the 47 $\mathrm{mm}$ Teflo filters seemed to be completely unaffected by the change in testing approach.

The moderate SDR variation across the Teflo filters produced little change, with resulting CVs of $3.02 \%$ and $4.64 \%$, both smaller than the $70 \mathrm{~mm}$ values of $3.43 \%$ and $5.49 \%$. The two systems portrayed large differences, likely attributed to not only the EGR use, but filter media as well. In fact, the percent difference between the Teflo and T60A20 filters was around 30\%, very similar to observations seen for the 1999 ISM.

Table 5.17 Results from February 28

\begin{tabular}{|c|c|c|c|c|}
\hline Test Set & \multicolumn{2}{|c|}{17.1} & \multicolumn{2}{|c|}{17.2} \\
\hline Description & \multicolumn{2}{|c|}{ with EGR } & \multicolumn{2}{|c|}{ w/o EGR } \\
\hline Engine & \multicolumn{2}{|c|}{2004 ISM } & \multicolumn{2}{|c|}{2004 ISM } \\
\hline Fuel & \multicolumn{2}{|c|}{ Fuel 17.1} & \multicolumn{2}{|c|}{ Fuel 17.1} \\
\hline Throttle & \multicolumn{2}{|c|}{ Throttle 17.1} & \multicolumn{2}{|c|}{ Throttle 17.1} \\
\hline \# FTPs in Avg & \multicolumn{2}{|c|}{3} & \multicolumn{2}{|c|}{3} \\
\hline PM System & $47 \mathrm{~mm}$ & $70 \mathrm{~mm}$ & $47 \mathrm{~mm}$ & $70 \mathrm{~mm}$ \\
\hline Filter Media & Teflo & T60A20 & Teflo & T60A20 \\
\hline SDR & $1 / 1$ & - & $2 / 1$ & - \\
\hline FFV (cfm) & 0.705 & 0.705 & 0.705 & 0.705 \\
\hline $\begin{array}{l}\text { Avg Mass / test } \\
\text { cycle (g) }\end{array}$ & 1.0220 & 1.4413 & 1.0045 & 1.6429 \\
\hline $\begin{array}{l}\text { Variation } \\
\text { Coefficient (\%) }\end{array}$ & 3.02 & 3.43 & 4.64 & 5.49 \\
\hline Difference $(\%)$ & -29.09 & - & -38.86 & - \\
\hline Proportionality & Yes & - & Yes & - \\
\hline
\end{tabular}




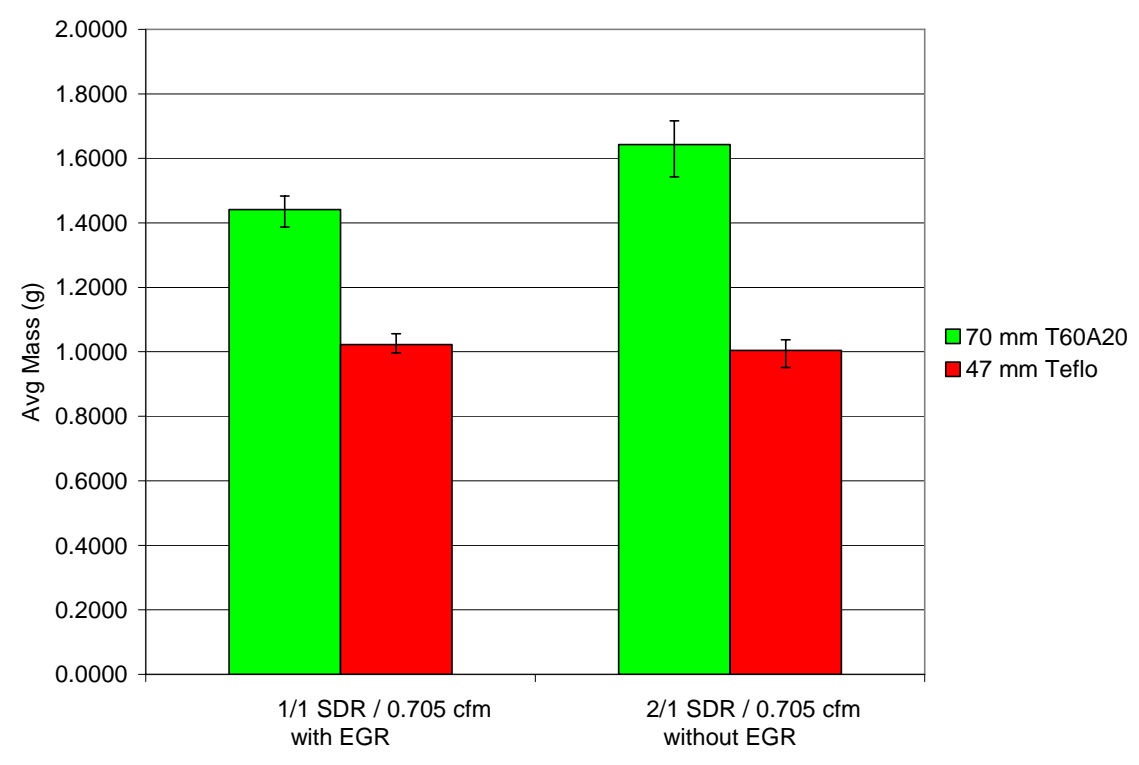

Figure 5.24 February 28, Average PM Mass of 3 Hot Start FTPs

\subsubsection{Summary}

After compiling the tables of results for each specific test condition, SDR and FFV, it becomes obvious that there are certain conditions which yield more repeatable results than others. In fact the relationship, as mentioned earlier, between repeatable results and an increasing SDR is found with increasing the FFV. While the test matrix was only completed for the Tx40 filter media, leaving several testing conditions unfilled for the T60A20 and Teflo medias, the relationship was clear for all three types.

Using both primary and secondary Teflo filters with a medium to high level FFV usually led to a high pressure drop across the filter towards the end of the 20 minute FTP and in turn a failure to maintain tunnel flow proportionality. Proportionality was only maintained at FFV levels of $1.5 \mathrm{cfm}$ or lower with a minimum SDR of 1/1. However it should be noted that a SDR of 10/1 appeared to lead to higher variations as well as percent differences between the two systems for all media types.

There appears to be a range of testing parameters most optimal for all three media types. For example, when employing a $1.5 \mathrm{cfm}$ flow rate with a $1 / 1 \mathrm{SDR}$, the results often varied less than $2 \%$ between systems, with minimal CVs of less than $1 \%$. A test matrix of results was compiled in order to visually represent this "best results" trend 
which is observed at low SDR, low FFV increasing to high SDR, high FFV levels. The completed matrix for Tx40 filter media can be seen below in Table 2.1e 5.18. Cells with normal black font are concluded to be "acceptable" testing conditions, while cells with red font "unacceptable." While the values for CV were tabulated for situations with failed proportionality, they are not considered for the recommended testing conditions.

One important observation in this research was showing that WVU's PM system is indeed capable of producing very repeatable results, and for several PM level engines. While the previous $70 \mathrm{~mm}$ PM system also produced repeatable results, and typically higher PM levels, which system is the most effective? The percent difference between the two systems should probably not determine the precision of the new 2007 compliant setup. The new requirements were established in order to remove a number of PM constituents, particles greater than $\mathrm{PM}_{2.5}$ and the SOF, which still make up a part of the $70 \mathrm{~mm}$ mass deposition. These system differences can be seen in Table 5.19.

Table 5.18 Results for Tx40 47 mm Filters

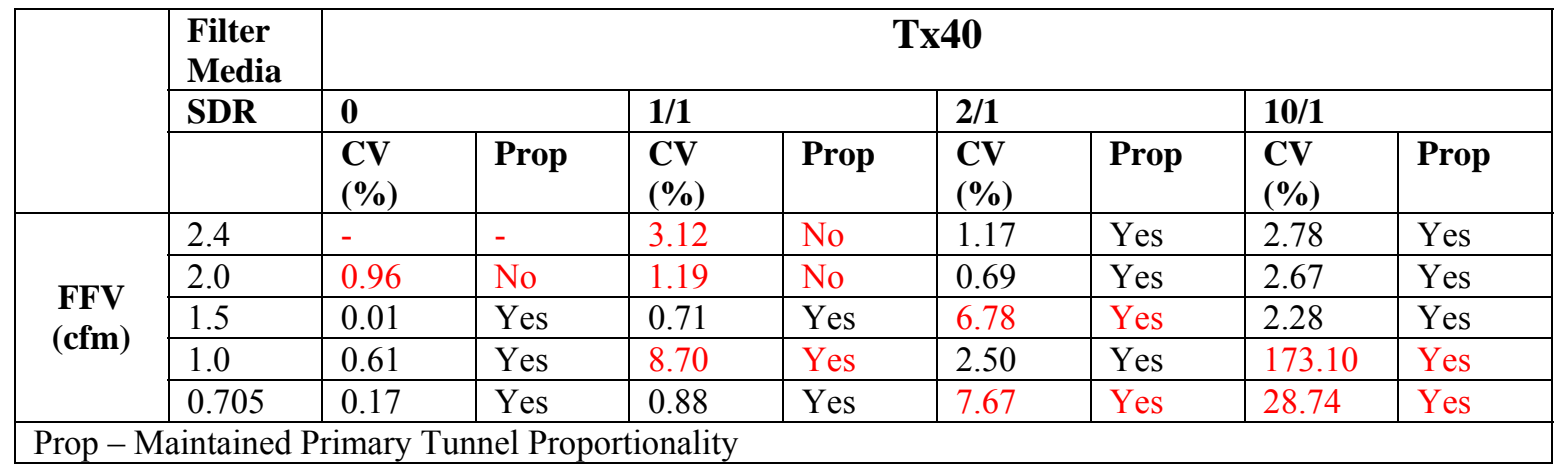

Table 5.19 Difference (\%) Between 70 mm T60A20 and 47 mm Tx40 Filters

\begin{tabular}{|l|l|l|l|l|l|}
\hline & Filter Media & \multicolumn{4}{|c|}{ Tx40 } \\
\cline { 2 - 6 } & SDR & \multicolumn{1}{|c|}{$\mathbf{0}$} & \multicolumn{1}{|c|}{$\mathbf{2 / 1}$} & \multicolumn{1}{|c|}{$\mathbf{1 0 / 1}$} \\
\hline \multirow{5}{*}{ FFV (cfm) } & $\mathbf{2 . 4}$ & - & -4.45 & -4.65 & -6.02 \\
\cline { 2 - 6 } & $\mathbf{2 . 0}$ & 6.18 & 0.98 & -4.16 & -10.42 \\
\cline { 2 - 6 } & $\mathbf{1 . 5}$ & 2.29 & -0.24 & -5.99 & -20.05 \\
\cline { 2 - 6 } & $\mathbf{1 . 0}$ & 0.76 & -10.63 & -8.37 & -69.54 \\
\cline { 2 - 6 } & $\mathbf{0 . 7 0 5}$ & -4.36 & -11.23 & -14.46 & -69.91 \\
\hline
\end{tabular}


Tables 5.20 through 5.23 represent the unfilled matrix of test results for the filter media types Teflo and T60A20. While all the test conditions were not represented, the trends seem to be continuous across all media types.

Table 5.20 Tabulated Results for Teflo 47 mm Filters.

\begin{tabular}{|l|l|l|l|l|l|l|l|}
\hline & $\begin{array}{l}\text { Filter } \\
\text { Media }\end{array}$ & \multicolumn{6}{|c|}{ Teflo } \\
\cline { 2 - 9 } & SDR & $\mathbf{0}$ & $\mathbf{1 / 1}$ & $\mathbf{2 / 1}$ \\
\cline { 2 - 9 } & & $\begin{array}{l}\text { CV } \\
\text { (\%) }\end{array}$ & Prop & $\begin{array}{l}\text { CV } \\
(\%)\end{array}$ & Prop & $\begin{array}{l}\text { CV } \\
(\%)\end{array}$ & Prop \\
\hline \multirow{4}{*}{$\begin{array}{l}\text { FFV } \\
(\mathbf{c f m})\end{array}$} & 2.4 & - & No & - & No & - & No \\
\cline { 2 - 9 } & 2.0 & - & No & - & No & - & - \\
\cline { 2 - 9 } & 1.5 & 13.46 & No & 2.32 & No & 2.19 & Yes \\
\cline { 2 - 9 } & 1.0 & 1.24 & Yes & - & - & - & - \\
\cline { 2 - 9 } & 0.705 & 1.36 & Yes & 3.02 & Yes & 4.64 & Yes \\
\hline
\end{tabular}

Table 5.21 Difference (\%) Between 70 mm T60A20 and 47 mm Teflo Filters

\begin{tabular}{|l|l|l|l|l|}
\hline & Filter Media & & & \\
\cline { 2 - 5 } & SDR & \multicolumn{1}{|c|}{$\mathbf{0}$} & $\mathbf{1}$ & $\mathbf{1}$ \\
\hline \multirow{5}{*}{ FFV (cfm) } & $\mathbf{2 . 4}$ & - & - & - \\
\cline { 2 - 5 } & $\mathbf{2 . 0}$ & - & - & - \\
\cline { 2 - 5 } & $\mathbf{1 . 5}$ & -38.95 & -33.44 & -29.32 \\
\cline { 2 - 5 } & $\mathbf{1 . 0}$ & -0.52 & - & - \\
\cline { 2 - 5 } & $\mathbf{0 . 7 0 5}$ & -8.93 & -29.09 & -38.86 \\
\hline
\end{tabular}

Table 5.22 Tabulated Results for T60A20 47 mm Filters.

\begin{tabular}{|c|c|c|c|c|c|c|c|c|c|}
\hline & \multirow{3}{*}{$\begin{array}{l}\begin{array}{l}\text { Filter } \\
\text { Media }\end{array} \\
\text { SDR } \\
\end{array}$} & \multicolumn{8}{|c|}{ T60A20 } \\
\hline & & \multicolumn{2}{|l|}{0} & \multicolumn{2}{|l|}{$1 / 1$} & \multicolumn{2}{|l|}{$2 / 1$} & \multicolumn{2}{|l|}{$10 / 1$} \\
\hline & & $\begin{array}{l}\text { CV } \\
\text { (\%) }\end{array}$ & Prop & $\begin{array}{l}\text { CV } \\
\text { (\%) }\end{array}$ & Prop & $\begin{array}{l}\text { CV } \\
\text { (\%) }\end{array}$ & Prop & $\begin{array}{l}\text { CV } \\
(\%)\end{array}$ & Prop \\
\hline \multirow{5}{*}{$\begin{array}{l}\text { FFV } \\
\text { (cfm) }\end{array}$} & 2.4 & - & No & 2.19 & No & - & - & 1.21 & Yes \\
\hline & 2.0 & 0.36 & No & 1.82 & Yes & - & - & - & - \\
\hline & 1.5 & 1.11 & Yes & 0.45 & Yes & 0.70 & Yes & 0.84 & Yes \\
\hline & 1.0 & - & - & 0.56 & Yes & 2.59 & Yes & - & - \\
\hline & 0.705 & 0.93 & Yes & - & - & - & - & - & - \\
\hline
\end{tabular}


Table 5.23 Difference (\%) Between $70 \mathrm{~mm}$ T60A20 and $47 \mathrm{~mm}$ T60A20 Filters

\begin{tabular}{|l|l|l|l|l|l|}
\hline & Filter Media & \multicolumn{5}{|c|}{ T60A20 } \\
\cline { 2 - 7 } & SDR & \multicolumn{1}{|c|}{$\mathbf{0}$} & $\mathbf{1 / 1}$ & $\mathbf{2} / \mathbf{1}$ & $\mathbf{1 0 / \mathbf { 1 }}$ \\
\hline \multirow{5}{*}{ FFV (cfm) } & $\mathbf{2 . 4}$ & - & 0.77 & - & -14.49 \\
\cline { 2 - 7 } & $\mathbf{2 . 0}$ & -0.69 & -2.97 & - & - \\
\cline { 2 - 7 } & $\mathbf{1 . 5}$ & 2.95 & -3.32 & -8.76 & -43.68 \\
\cline { 2 - 7 } & $\mathbf{1 . 0}$ & - & -6.49 & -15.15 & - \\
\cline { 2 - 7 } & $\mathbf{0 . 7 0 5}$ & -6.03 & - & - & - \\
\hline
\end{tabular}

\subsection{Filter Efficiencies}

\subsubsection{Introduction}

After evaluating the performance of the three filter media types at different SDRs and FFVs, it was necessary to determine which media was the most efficient. As stated in the CFR, the efficiency of the $47 \mathrm{~mm}$ filters must have a minimum value of $99 \%$ as specified by the manufacturer [31]. While all three media types chosen for this testing has been specified as having high enough efficiencies, the relationship between the specific filters and WVU's 2007 PM collection system needed to be outlined. It should be noted that these experiments were performed using only a single primary Teflo and Tx40 filters, and both primary and secondary T60A20 filters.

As mentioned before, the TSI 3007 handheld CPC was installed in line with the 2007 PM collection system. A number of FTPs were collected with the CPC upstream of the filter face in order to determine the number of particles existing before the specific media as well as downstream in order to represent the number of particles which were not collected onto the filter face. These tests were performed at a FFV of $1.5 \mathrm{cfm}$, which previously led to acceptable filter variations, at three different SDRs: 10/1, 2/1, and 1/1.

\subsubsection{Discussion}

As can be seen below in Figure 5.25, the SDR does seem to have an effect on the resulting filter efficiency. At the lower SDRs of $1 / 1$ and $2 / 1$, Tx40 is the most efficient media, followed by Teflo and T60A20 respectfully. All of the media types show an increase in efficiency between the SDRs of $1 / 1$ and 2/1. It is between the SDRs of 2/1 and 10/1 where there is an obvious change between media types. While both the Tx40 
and T60A20 show a decrease in efficiency, the single Teflo filter shows a rather drastic increase to over $99.8 \%$.

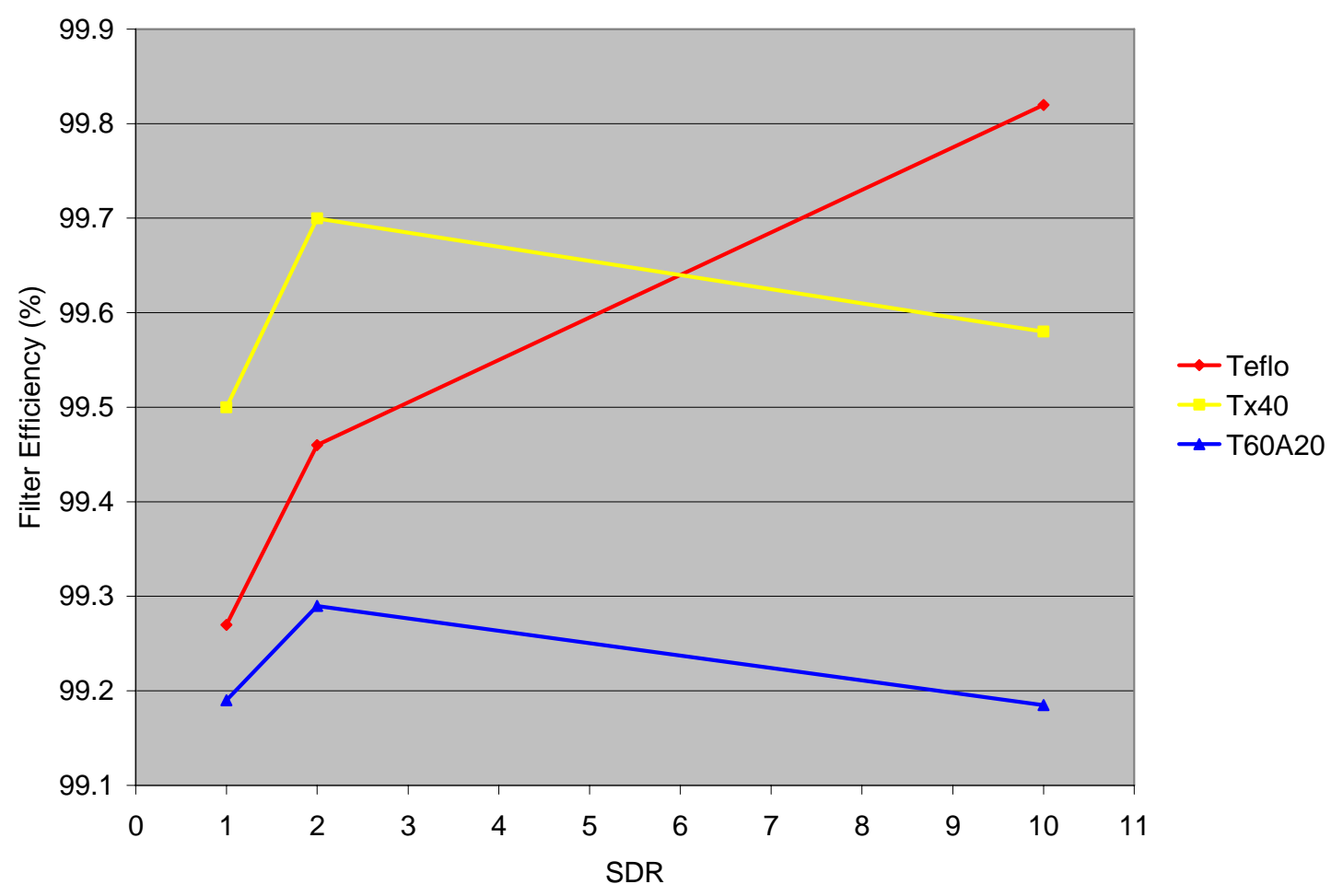

Figure 5.25 Secondary Dilution Ratio's Effect on Filter Efficiency

\subsubsection{Summary}

The increase in filter efficiency with increasing SDR, especially with the single Teflo filter, leads to the observation that by increasing the amount of secondary air within the sampled mixture, the filter media is able to deposit higher percentages of the available PM. The variation in filter efficiency is minimal however, with all efficiencies between $99.8 \%$ and $99.2 \%$, so any of the reported values are acceptable.

It should also be noted that in order to obtain the downstream particle count, it was necessary to install a low pressure pump in line with the CPC. It is very likely that running the post-filtered air through the pump added to the downstream particle count, and in turn decreasing the filter efficiency calculations. 


\section{Conclusions and Recommendations}

Due to the high variability in testing parameters involved with this analysis, it was difficult to draw concrete conclusions. There are however, some obvious relationships, allowing for a number of recommendations on how to operate the $200747 \mathrm{~mm}$ PM sampling system, as well as how to establish further PM research aimed at producing more viable results.

As expected, the SDR, FFV and filter media across which the exhaust sample is exposed have an impact on the amount of PM collected by this gravimetric measurement approach. The flow conditions which produced the most reliable results, and are therefore recommended for future use of the 2007 system, include a SDR of 1/1 to 2/1 with a FFV of $1.0 \mathrm{cfm}$ to $1.5 \mathrm{cfm}$ (about $40 \mathrm{~cm} / \mathrm{s}$ to $60 \mathrm{~cm} / \mathrm{s}$ for $47 \mathrm{~mm}$ filters) across a single Teflo filter.

\subsection{SDR}

As shown in the completed matrix of results for the Tx 40 media type, repeatable results follow a trendline of low SDR and low FFV towards increasingly higher SDR and FFV. In fact some of the most repeatable tests appeared with a SDR between levels of 0 to 2/1. Kittleson had recommended a SDR between 5/1 and 50/1, but these levels may be too high for WVU's particular system. Ranges of SDR should remain between 1/1 and $2 / 1$.

\subsection{FFV}

The flow rate which produced the most consistent and repeatable results was between $1.0 \mathrm{cfm}$ and $1.5 \mathrm{cfm}$, approximately $40 \mathrm{~cm} / \mathrm{s}$ to $60 \mathrm{~cm} / \mathrm{s}$ across the $47 \mathrm{~mm}$ filter. This moderate level of PM reduced extreme pressure drops across the filter face for all media types and showed lower variations then higher velocities. It is also much lower then the $90 \mathrm{~cm} / \mathrm{s}$ recommended by Khalek in the E-66 report.

\subsection{Filter Media}

The Teflo and Tx40 filters manufactured by Pall are both capable of producing highly repeatable results. The T60A20 filters however, do not meet the manufacturer efficiency rating and therefore should not be used with the 2007 WVU PM collection 
system. After the efficiency calculations, it was determined that single Teflo and Tx40 filters are efficient enough to be used in a setup consisting only of a single primary filter. The Teflo filters not only produced the lowest PM mass accumulation, but also the lowest variation. This finding was also reported by Khalek in the E-66 study.

\subsection{Recommendations}

This study would have been much more effective if the PM research had been conducted as the primary reason for engine testing. The setup with ongoing collaborative research provided too much variation between test cycles for major comparisons to be conducted. By changing fuels, throttles, and engines on a daily basis, it was impossible to establish a baseline PM standard for day-to-day repeatability. Also, by establishing a more standardized test matrix, it would be possible to choose the most acceptable filter media for WVU's PM collection system. In other words, what level of PM each type of filter consistently collects and at what level of repeatability collection occurs.

The results were drawn from an average of only three test cycles. A more extensive study, consisting of at least twice as many tests for each average would provide a much more acceptable range of data for which to compute PM variation. The corresponding confidence level would improve, if the Test Set truly represented the relationships, with more FTPs included within the Test Set.

An SMPS used both upstream and downstream of each different media filter would allow for a comparison of which types of particles are allowed to pass through the corresponding filter face. This could assist in explaining possible mass differences for each filter media in WVU's PM collection system. It could also relate to the changing filter efficiencies at different SDRs. 


\section{References}

1. Code of Federal Regulations, Part 86, Section 86.1310-1990.

2. Burtscher, H. and Majewski, W.A., "Particulate Matter Measurements," www.dieselnet.com, Ecopoint, Inc., 2004.

3. “PM Research, OTAQ, EPA,” www.epa.gov/pmresearch/, United States Environmental Protection Agency-Office of Transportation and Air Quality, 2007.

4. "Review of the National Ambient Air Quality Standards for Particulate Matter," OAQPS Staff Paper, US EPA, 2005.

5. Khalek, I.A., Stewart, D.W., and Ullman, T.L., "2007 Diesel Particle Measurement Research," Southwest Research Institute, San Antonio, Texas, May 2005.

6. Khalek, I.A., "The Particulars of Diesel Particle Emissions," Technology Today, Spring 2006.

7. Walsh, M.P., "Global Trends in Diesel Emissions Regulation - A 2001 Update," Warrendale, PA, SAE Paper No. 2001-01-0183, 2001.

8. HEI Program Summary, "Research on Diesel Exhaust and Other Particles" Health Effects Institute, Charleston Navy Shipyard, Boston, MA, 2003.

9. "Proposed Identification of Diesel Exhaust as a Toxic Air Contaminant Appendix III Part A: Exposure Assessment," California Environmental Protection Agency, California Air Resources Board, April 22, 1998. 
10. Witze, P.O., "Diagnostics for the Measurement of Particulate Matter Emissions from Reciprocating Engines," Combustion Research Facility, Sandia National Laboratories, Livermore, CA, 2001.

11. Kittelson, D.B., "Review of Diesel Particulate Matter Sampling Methods," University of Minnesota Center for Diesel Research, 1999.

12. Snelling, D.R., Smallwood, G.J., Sawchuk, R.A., et al, "Particulate Matter Measurements in a Diesel Engine Exhaust by Laser-Induced Incandescence and the Standard Gravimetric Procedure," Warrendale, PA, SAE Paper No. 1999-01$3653,1999$.

13. Bockhorn, H. (ed.), "Soot Formation in Combustion, Round Table Discussion," Springer Verlag, Heidelberg, 1991.

14. Mansurov, Z.A., "Soot Formation in Combustion Processes (Review)," Translated from Fizika Goreniya I Vzryva, Vol. 41, No. 6, pp. 137-156, November-December, 2005.

15. Haynes, B.S. and Wagner, H.G., "Soot Formation," Prog. Energy Combust. Sci., 7, pp. 229-273, 1981.

16. Frenklach, M., Clary, D.W., Gardiner, W.C., and Stein, S.E., "Effect of Fuel Structure on Pathways to Soot," $21^{\text {st }}$ Symp. (Int.) on Combustion, Combustion Inst., Pittsburgh, 1986.

17. Khan, I.M., "Formation and Combustion of Carbon in a Diesel Engine," Inst. Mech. Eng. Proc., 184, Part 35, pp. 36-43, 1969. 
18. Khalek, I.A., Kittleson, D.B., Graskow, B.R., Wei, Q., and Brear, F., “Diesel Exhaust Particle Size: Measurement Issues and Trends," Warrendale, PA, SAE Paper No. 980525, 1998.

19. "Model 3007 Condensation Particle Counter," Operation and Service Manual, http://www.tsi.com/documents/1930035e-3007.pdf, TSI Inc., 2006.

20. Wang, S.C. and Flagan, R.C., "Scanning Electrical Mobility Spectrometer," California Institute of Technology. Pasadena, CA, Division of Engineering and Applied Science, 138-78, 1990.

21. Shah, S.D. and Cocker, D.R., "A Fast Scanning Mobility Particle Spectrometer for Monitoring Transient Particle Size Distributions," Aerosol Science and Technology, 39:519-526, 2005.

22. Pus, D.Y.H. and Swift, D.L., "Direct-Reading Instruments for Airborne Particles," Ch. 16 in Air Sampling Instruments for Evaluation of Atmospheric Contaminants. ACGIH, Cincinnati, OH, 8 ${ }^{\text {th }}$ Edition, pp. 337-338, 1995.

23. Podsiadlik, D. H., Chase, R. E., Lewis, D; and Spears, M., "Phase-based TEOM Measurements Compared with Traditional Filters for Diesel PM," Warrendale, PA, SAE Paper No. 2003-01-0783, 2003.

24. Proposed Diesel Vehicle Emissions "In-Service Emissions Performance - Phase 2: Vehicle Testing - Appendices," NEPC, November 2000.

25. Kelly, N.A. and Morgan, C. "An Evaluation of the Tapered Element Oscillating Microbalance Method for Measuring Diesel Particulate Emissions," ISSN 10473289 J. Air \& Waste Manage. Assoc. 52:1362-1377, 2002. 
26. Shuhong, X., Clark, N., Gautam, M., and Wayne, W.S., "Comparison of HeavyDuty Truck Diesel Particulate Matter Measurement: TEOM and Traditional Filter," Warrendale, PA, SAE Paper No. 2005-01-2153, 2005.

27. Gautam, M. Carder, D. Booker, D. Gautam, S., "Real-time Measurement of Particulate Matter Emissions from On-Highway and Off-road Vehicles, $12^{\text {th }} \mathrm{CRC}$ On-road Emissions Workshop, 2002.

28. Khalek, I. A., "2007 Diesel Particle Measurement Research,” Southwest Research Institute, San Antonio, Texas, March 2006.

29. Shimpi, S.A., "EPA Protocols for Sampling 2007 Level Diesel Exhaust Particulate Matter and Expected Concentrations," ACES Workshop, Cummins Inc, 2003.

30. "Exhaust Aftertreatment System Testing Produces Lowest Diesel Emissions Ever Measured in CRT Facility," http://www.transportation.anl.gov/transtech/v1n6/aftertreatment.html, Vehicle Systems, Argonne Transportation Research, 2002.

31. Code of Federal Regulations, Part 86, Section 86.1310-2007.

32. Maricq, M., “2007 Exhaust Composition and Sampling Artifacts," ACES Workshop, Ford Motor Company, 2003.

33. "Pallflex Filters," http://labfilters.pall.com/catalog/924 20056.asp, Pallflex Filters Specifications, Pall Corporation, 2007.

34. Shade, B.C., "A Performance of MEMS - An On-Road Emissions Measurement System Study." M.S. Thesis, Department of Mechanical and Aerospace Engineering, West Virginia University, Morgantown, WV, 2000. 
35. Shade, B.C., "A Work-Based Window Method for Calculating In-Use BrakeSpecific Oxides of Nitrogen Emissions of Heavy-Duty Diesel Engines." Ph.D. Dissertation, Department of Mechanical and Aerospace Engineering, West Virginia University, Morgantown, WV, 2006.

36. “Compressed Air Dryers,” http://www.domnickhunter.com/tech_Centre.asp, Technical Centre, Compressed Air Dryers, Domnick Hunter Inc., 2007.

37. Taylor, E., "Filter Weighing Procedures for 2007 and Newer Heavy Duty Diesel Engines," M.S. Thesis, Department of Mechanical and Aerospace Engineering, West Virginia University, Morgantown, WV, 2006. 


\section{Appendixes}

\subsection{DDC}

The following sections will present the tabulated PM filter mass data as well as show samples of the test-by-test flow proportionality as well as filter face temperature relationships for each system.

\subsubsection{January 9, 2007}

Table 8.1 January 9, PM Filter Mass Data

\begin{tabular}{|c|c|c|}
\hline Test Set & \multicolumn{2}{|c|}{1} \\
\hline PM System & $47 \mathrm{~mm}$ & $70 \mathrm{~mm}$ \\
\hline Filter Media & T60A20 & T60A20 \\
\hline SDR & 0 & - \\
\hline FFV (cfm) & 0.705 & 0.705 \\
\hline HS FTP Mass 1 (g) & 5.5300 & 5.8473 \\
\hline HS FTP Mass 2 (g) & 5.4581 & 5.8102 \\
\hline HS FTP Mass 3 (g) & 5.4310 & 5.8160 \\
\hline Average (g) & 5.4731 & 5.8245 \\
\hline CV (\%) & 0.93 & 0.34 \\
\hline Difference (\%) & \multicolumn{2}{|c|}{-6.03} \\
\hline
\end{tabular}

The flow proportionality illustration for this test day can be seen in the Results section 5.1.2.1.1. 


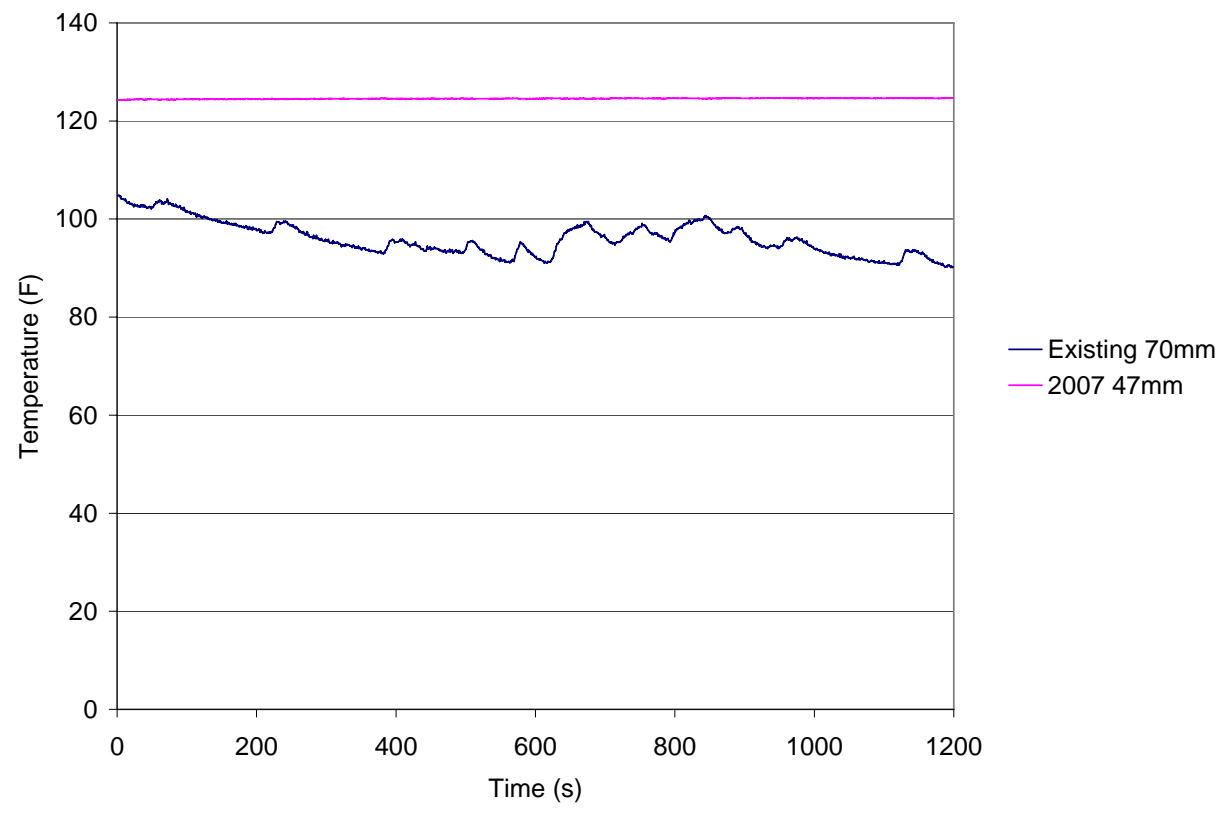

Figure 8.1 January 9, Filter Face Temperature

8.1.2 January 10, 2007

Table 8.2 January 10, PM Filter Mass Data

\begin{tabular}{|c|c|c|c|c|}
\hline Test Set & \multicolumn{2}{|c|}{2.1} & \multicolumn{2}{c|}{2.2} \\
\hline PM System & $47 \mathrm{~mm}$ & $47 \mathrm{~mm}$ & $70 \mathrm{~mm}$ & $70 \mathrm{~mm}$ \\
\hline Filter Media & Teflo & T60A20 & Tx40 & T60A20 \\
\hline SDR & 0 & - & 0 & - \\
\hline FFV (cfm) & 0.705 & 0.705 & 0.705 & 0.705 \\
\hline HS FTP Mass 1 (g) & 5.3385 & 5.8475 & 5.4485 & 5.7002 \\
\hline HS FTP Mass 2 (g) & 5.2248 & 5.7590 & 5.4521 & 5.7476 \\
\hline HS FTP Mass 3 (g) & 5.2062 & 5.7092 & 5.4661 & 5.6642 \\
\hline Average (g) & 5.2565 & 5.7719 & 5.4555 & 5.7040 \\
\hline CV (\%) & 1.36 & 1.21 & 0.17 & 0.73 \\
\hline Difference (\%) & \multicolumn{2}{|c|}{-8.93} & \multicolumn{2}{c}{-4.36} \\
\hline
\end{tabular}




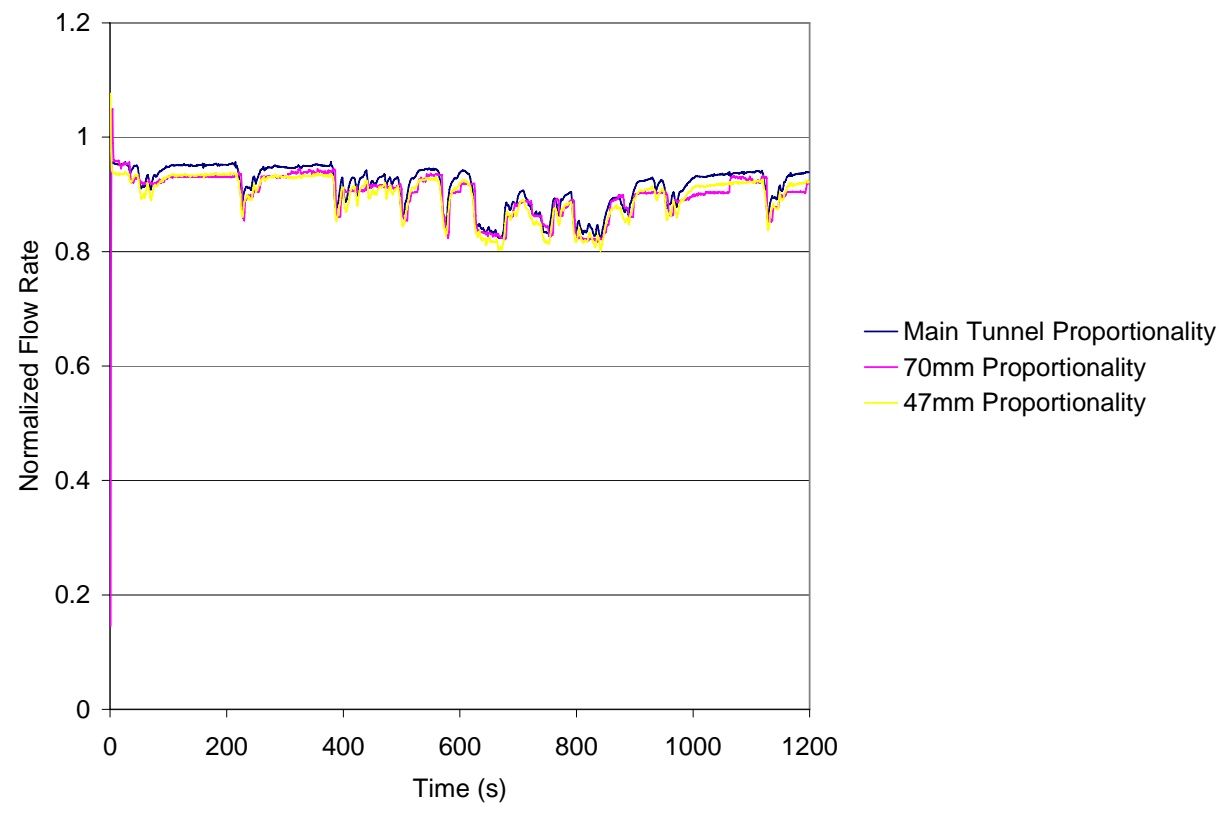

Figure 8.2 January 10, Proportionality for Teflo media at 0 SDR and 0.705 cfm FFV

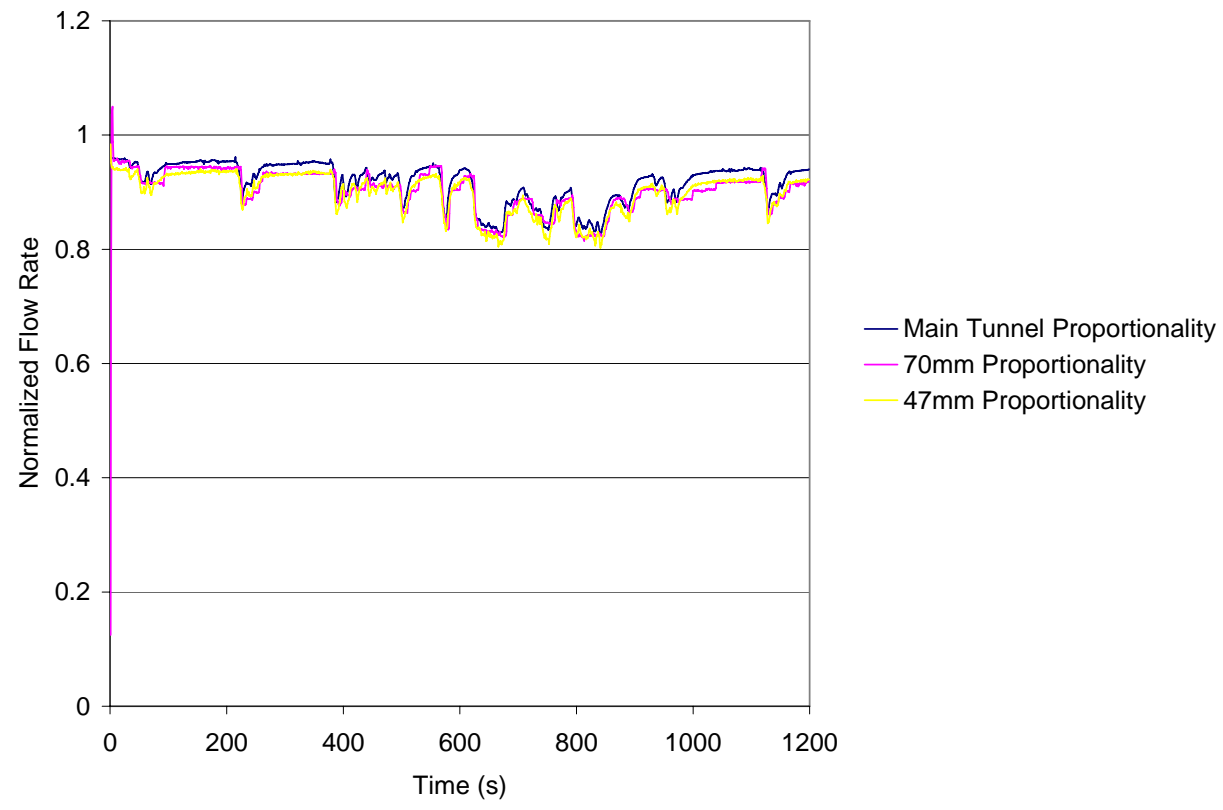

Figure 8.3 January 10, Proportionality for Tx40 media at 0 SDR and $0.705 \mathrm{cfm}$ FFV 


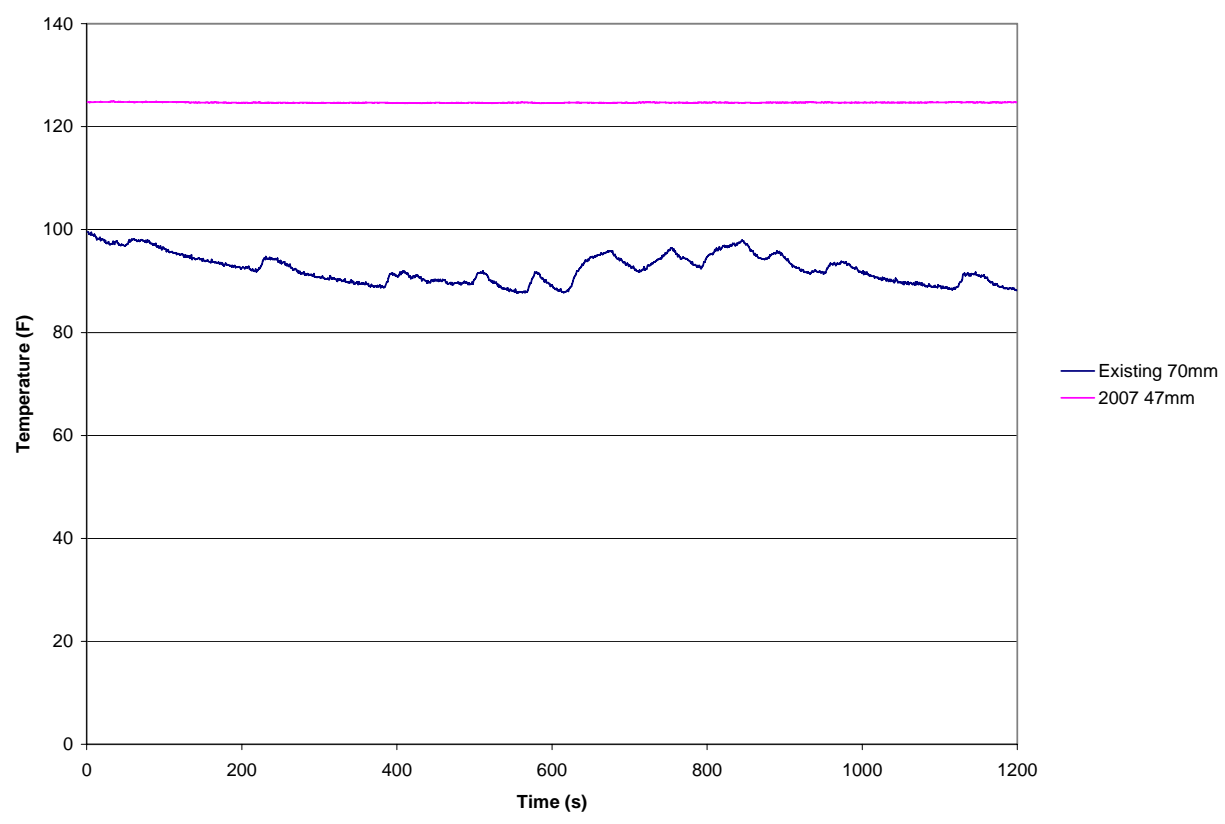

Figure 8.4 January 10, Filter Face Temperature

\subsubsection{January 11, 2007}

Table 8.3 January 11, PM Filter Mass Data

\begin{tabular}{|c|c|c|}
\hline Test Set & \multicolumn{2}{|c|}{3} \\
\hline PM System & $47 \mathrm{~mm}$ & $47 \mathrm{~mm}$ \\
\hline Filter Media & T60A20 & T60A20 \\
\hline SDR & 0 & - \\
\hline FFV (cfm) & 2.0 & 0.705 \\
\hline HS FTP Mass 1 (g) & 5.9530 & 5.9847 \\
\hline HS FTP Mass 2 (g) & 5.9957 & 6.0160 \\
\hline HS FTP Mass 3 (g) & 5.9686 & 6.0407 \\
\hline Average (g) & 5.9724 & 6.0138 \\
\hline CV (\%) & 0.36 & 0.47 \\
\hline Difference (\%) & \multicolumn{2}{|c|}{-0.69} \\
\hline
\end{tabular}

The example of failure to maintain flow proportionality was previously shown in the Results section, 5.1.2.1.3. 


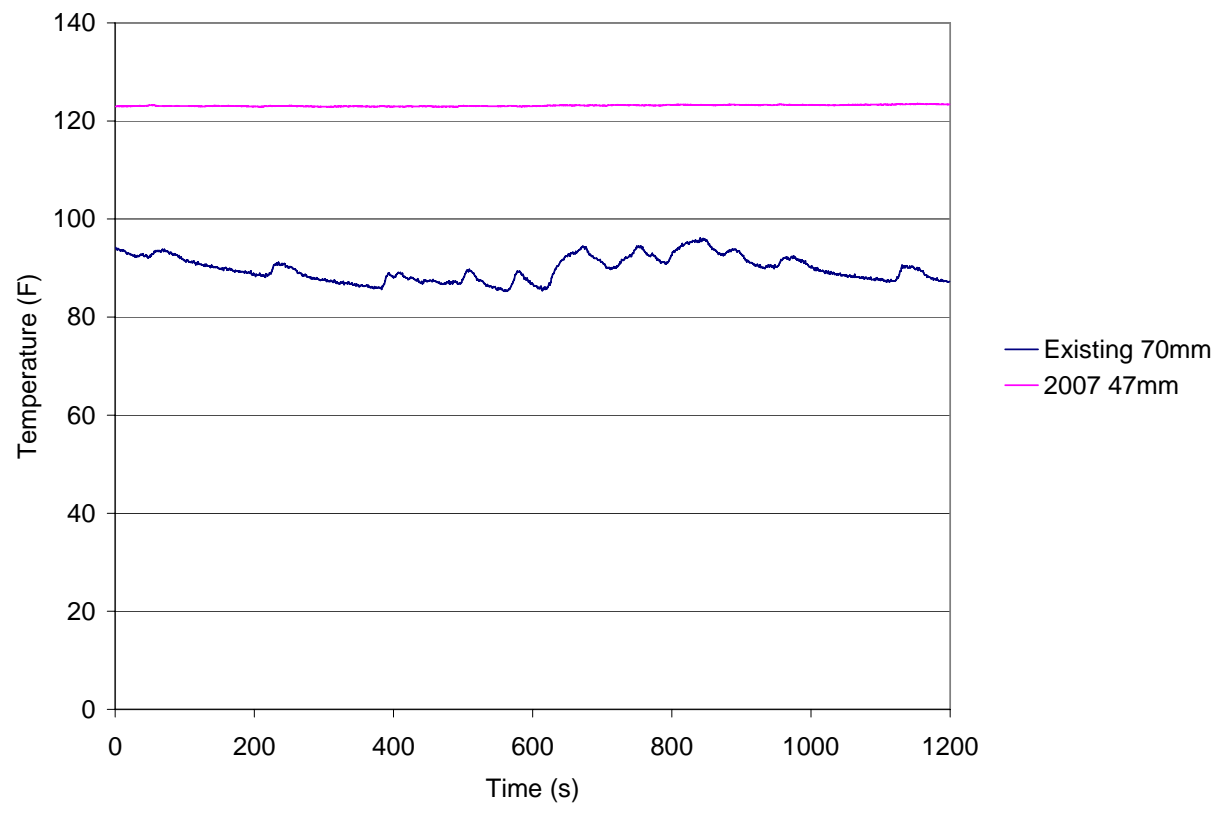

Figure 8.5 January 11, Filter Face Temperature

\subsubsection{January 17, 2007}

Table 8.4 January 17, PM Filter Mass Data

\begin{tabular}{|c|c|c|}
\hline Test Set & \multicolumn{2}{|c|}{4} \\
\hline PM System & $47 \mathrm{~mm}$ & $47 \mathrm{~mm}$ \\
\hline Filter Media & Tx40 & T60A20 \\
\hline SDR & 0 & - \\
\hline FFV (cfm) & 1.0 & 0.705 \\
\hline HS FTP Mass 1 (g) & 2.9356 & 2.8941 \\
\hline HS FTP Mass 2 (g) & 2.9598 & 2.9552 \\
\hline HS FTP Mass 3 (g) & 2.9245 & 2.9041 \\
\hline Average (g) & 2.9400 & 2.9178 \\
\hline CV (\%) & 0.61 & 1.12 \\
\hline Difference (\%) & \multicolumn{2}{|c|}{0.76} \\
\hline
\end{tabular}




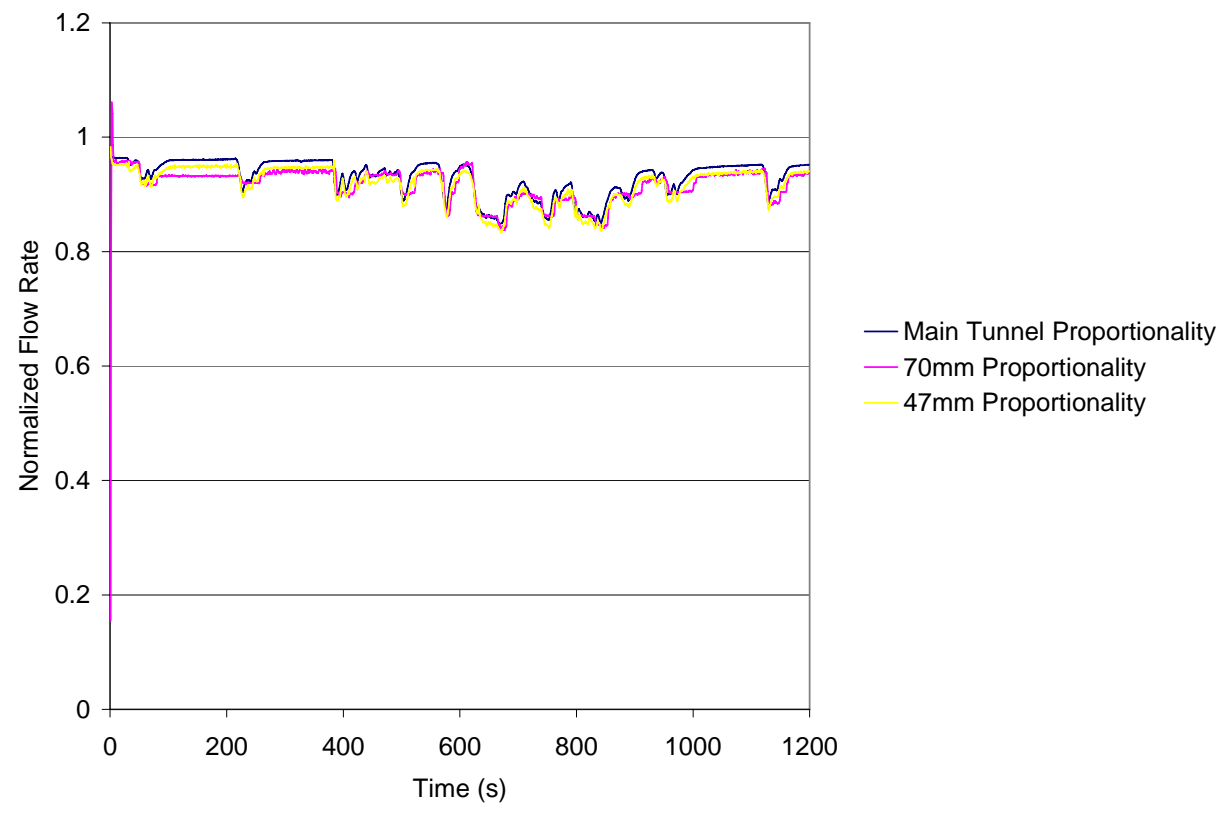

Figure 8.6 January 17, Proportionality for Tx40 Media at 0 SDR and $1 \mathrm{cfm}$ FFV

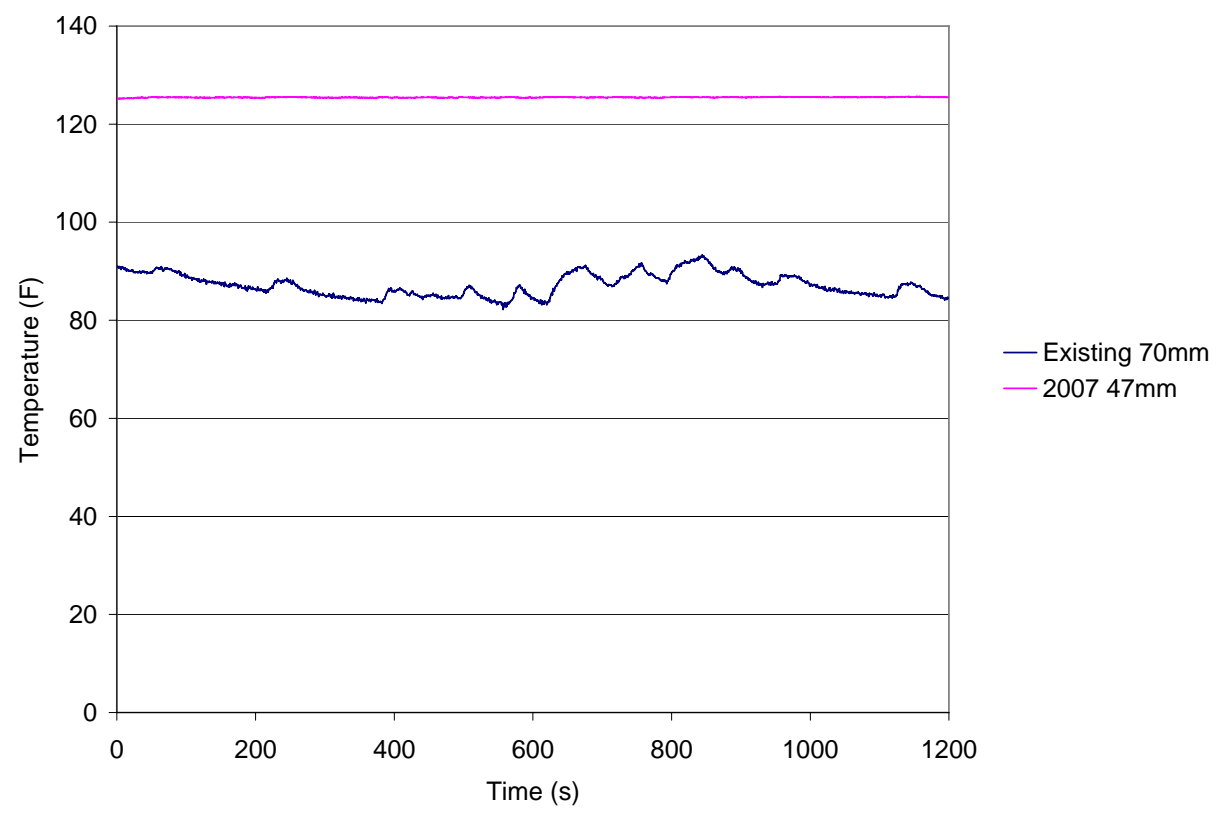

Figure 8.7 January 17, Filter Face Temperature 
8.1.5 January 18, 2007

Table 8.5 January 18, PM Filter Mass Data

\begin{tabular}{|c|c|c|c|c|}
\hline Test Set & \multicolumn{2}{|c|}{5.1} & \multicolumn{2}{c|}{5.2} \\
\hline PM System & $47 \mathrm{~mm}$ & $47 \mathrm{~mm}$ & $70 \mathrm{~mm}$ & $70 \mathrm{~mm}$ \\
\hline Filter Media & Tx40 & T60A20 & Tx40 & T60A20 \\
\hline SDR & 0 & - & $1 / 1$ & - \\
\hline FFV (cfm) & 1.5 & 0.705 & 0.705 & 0.705 \\
\hline HS FTP Mass 1 (g) & 3.0205 & 2.9450 & 2.6187 & 2.9627 \\
\hline HS FTP Mass 2 (g) & 3.0504 & 2.9901 & 2.6474 & 2.9551 \\
\hline HS FTP Mass 3 (g) & - & - & 2.6647 & 3.0163 \\
\hline Average (g) & 3.0354 & 2.9676 & 2.6436 & 2.9780 \\
\hline CV (\%) & 0.01 & 0.01 & 0.88 & 1.12 \\
\hline Difference (\%) & \multicolumn{2}{|c|}{-11.23} \\
\hline
\end{tabular}

Table 8.5 cont.

\begin{tabular}{|c|c|c|c|c|}
\hline Test Set & \multicolumn{2}{|c|}{5.3} & \multicolumn{2}{c|}{5.4} \\
\hline PM System & $47 \mathrm{~mm}$ & $47 \mathrm{~mm}$ & $70 \mathrm{~mm}$ & $70 \mathrm{~mm}$ \\
\hline Filter Media & Tx40 & T60A20 & Tx40 & T60A20 \\
\hline SDR & 0 & - & $1 / 1$ & - \\
\hline FFV (cfm) & 2.0 & 0.705 & 1.5 & 0.705 \\
\hline HS FTP Mass 1 (g) & 4.0100 & 3.7796 & 3.6442 & 3.6481 \\
\hline HS FTP Mass 2 (g) & 3.9558 & 3.7225 & 3.5935 & 3.6148 \\
\hline HS FTP Mass 3 (g) & - & - & 3.6256 & 3.6267 \\
\hline Average (g) & 3.9829 & 3.7510 & 3.6211 & 3.6299 \\
\hline CV (\%) & 0.88 & 1.08 & 0.71 & 0.46 \\
\hline Difference (\%) & \multicolumn{2}{|c|}{6.18} & \multicolumn{2}{c|}{-0.24} \\
\hline
\end{tabular}




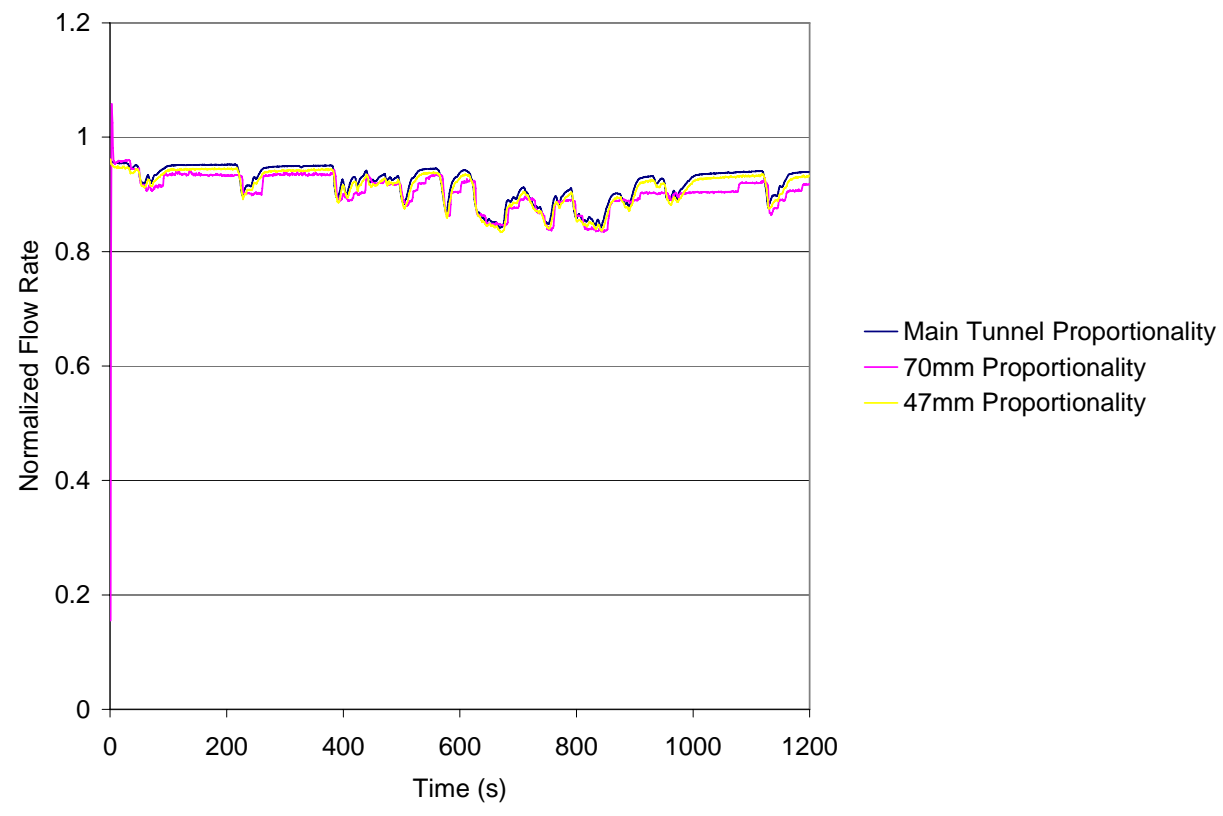

Figure 8.8 January 18, Proportionality for Tx40 Media at 0 SDR and $1.5 \mathrm{cfm}$ FFV

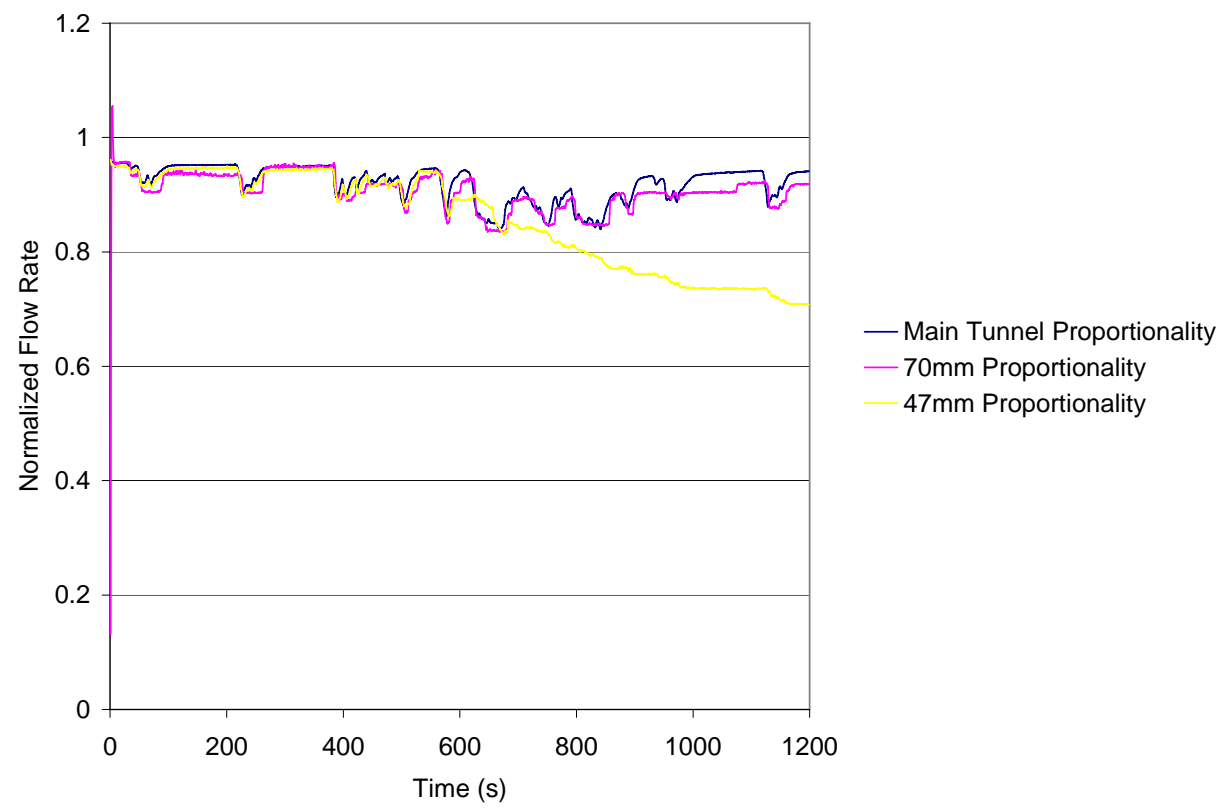

Figure 8.9 January 18, Proportionality for Tx40 Media at 0 SDR and 2 cfm FFV 


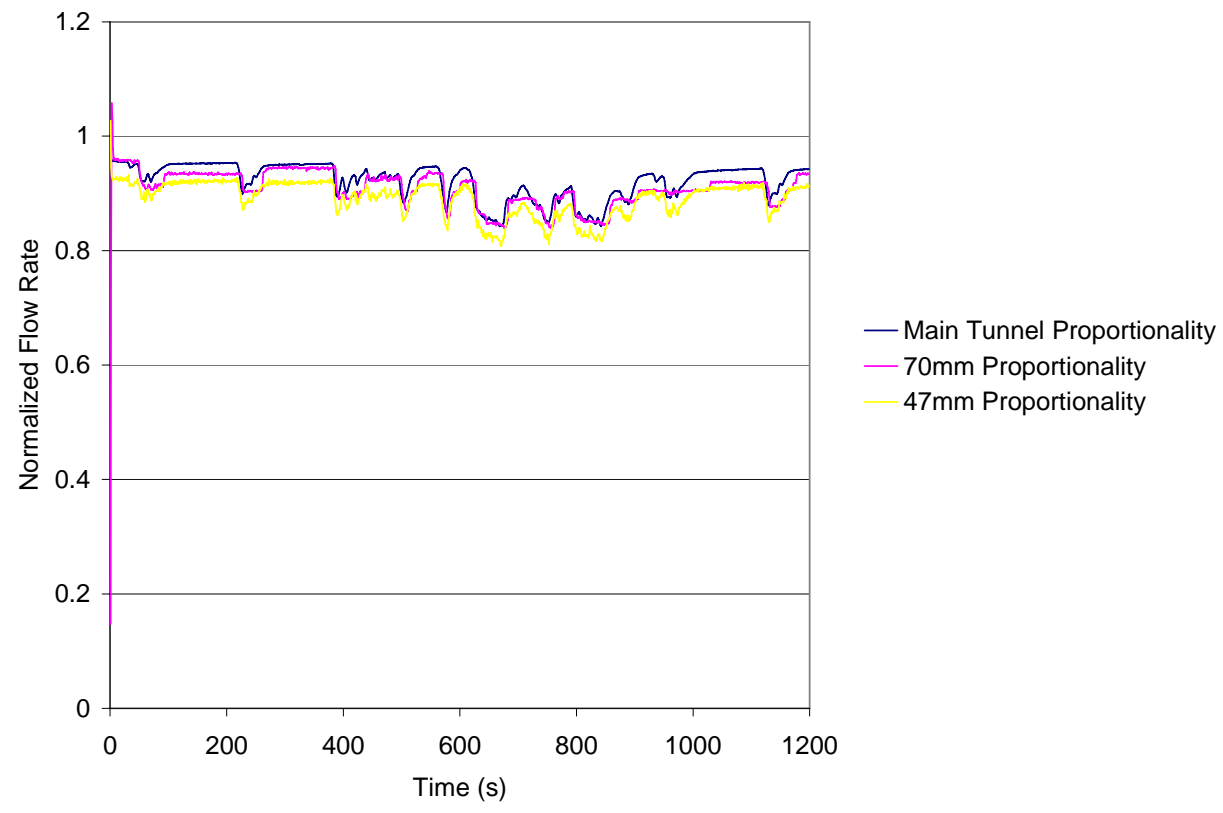

Figure 8.10 January 18, Proportionality for Tx40 Media at $1 / 1$ SDR and $0.705 \mathrm{cfm}$ FFV

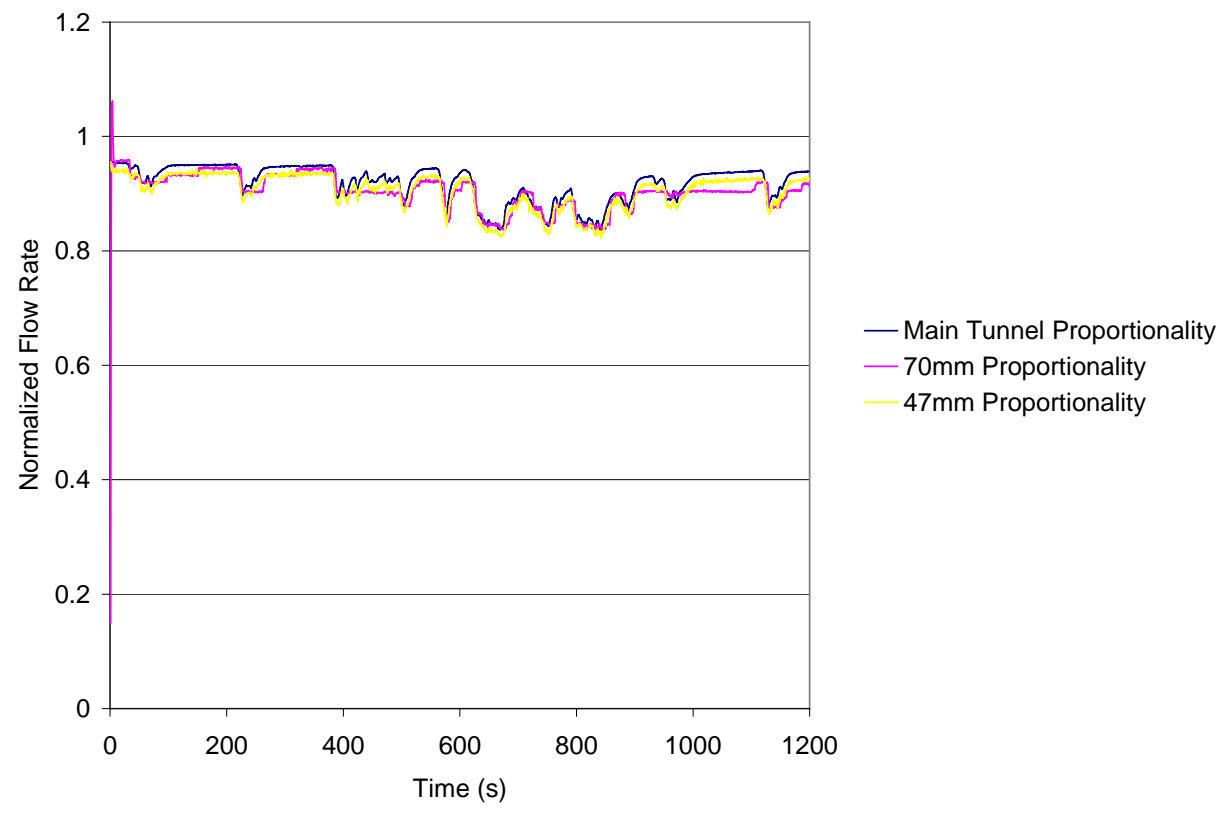

Figure 8.11 January 18, Proportionality for Tx40 Media at 1/1 SDR and $1.5 \mathrm{cfm}$ FFV 


\subsubsection{January 19, 2007}

The highly diluted flow conditions, 10/1 SDR, with 1.5 and $0.705 \mathrm{cfm}$, Test Set 6.2 and 6.4, showed noise from the mass flow controllers in the proportionality plots. This noise could have influenced the results.

Table 8.6 January 19, PM Filter Mass Data

\begin{tabular}{|c|c|c|c|c|}
\hline Test Set & \multicolumn{2}{|c|}{6.1} & \multicolumn{2}{c|}{6.2} \\
\hline PM System & $47 \mathrm{~mm}$ & $47 \mathrm{~mm}$ & $70 \mathrm{~mm}$ & $70 \mathrm{~mm}$ \\
\hline Filter Media & Tx40 & T60A20 & Tx40 & T60A20 \\
\hline SDR & $1 / 1$ & - & $10 / 1$ & - \\
\hline FFV (cfm) & 2.0 & 0.705 & 1.5 & 0.705 \\
\hline HS FTP Mass 1 (g) & 2.9717 & 2.9332 & 2.3276 & 2.8852 \\
\hline HS FTP Mass 2 (g) & 2.9313 & 2.8912 & 2.2588 & 2.8313 \\
\hline HS FTP Mass 3 (g) & 2.9019 & 2.8953 & 2.2262 & 2.8044 \\
\hline Average (g) & 2.9350 & 2.9066 & 2.2708 & 2.8403 \\
\hline CV (\%) & 1.19 & 0.80 & 2.28 & 1.45 \\
\hline Difference (\%) & \multicolumn{2}{|c|}{-20.98} \\
\hline
\end{tabular}

Table 8.6 cont.

\begin{tabular}{|c|c|c|c|c|}
\hline Test Set & \multicolumn{2}{|c|}{6.3} & \multicolumn{2}{c|}{6.4} \\
\hline PM System & $47 \mathrm{~mm}$ & $47 \mathrm{~mm}$ & $70 \mathrm{~mm}$ & $70 \mathrm{~mm}$ \\
\hline Filter Media & Tx40 & T60A20 & Tx40 & T60A20 \\
\hline SDR & $10 / 1$ & - & $10 / 1$ & - \\
\hline FFV (cfm) & 2.4 & 0.705 & 0.705 & 0.705 \\
\hline HS FTP Mass 1 (g) & 3.4076 & 3.4945 & 0.7017 & 3.4514 \\
\hline HS FTP Mass 2 (g) & 3.3073 & 3.5408 & 1.1373 & 3.4307 \\
\hline HS FTP Mass 3 (g) & 3.2234 & 3.5391 & 1.2718 & 3.4549 \\
\hline Average (g) & 3.3128 & 3.5248 & 1.0369 & 3.4457 \\
\hline CV (\%) & 2.78 & 0.74 & 28.74 & 0.38 \\
\hline Difference (\%) & -6.02 & \multicolumn{3}{c}{-69.91} \\
\hline
\end{tabular}




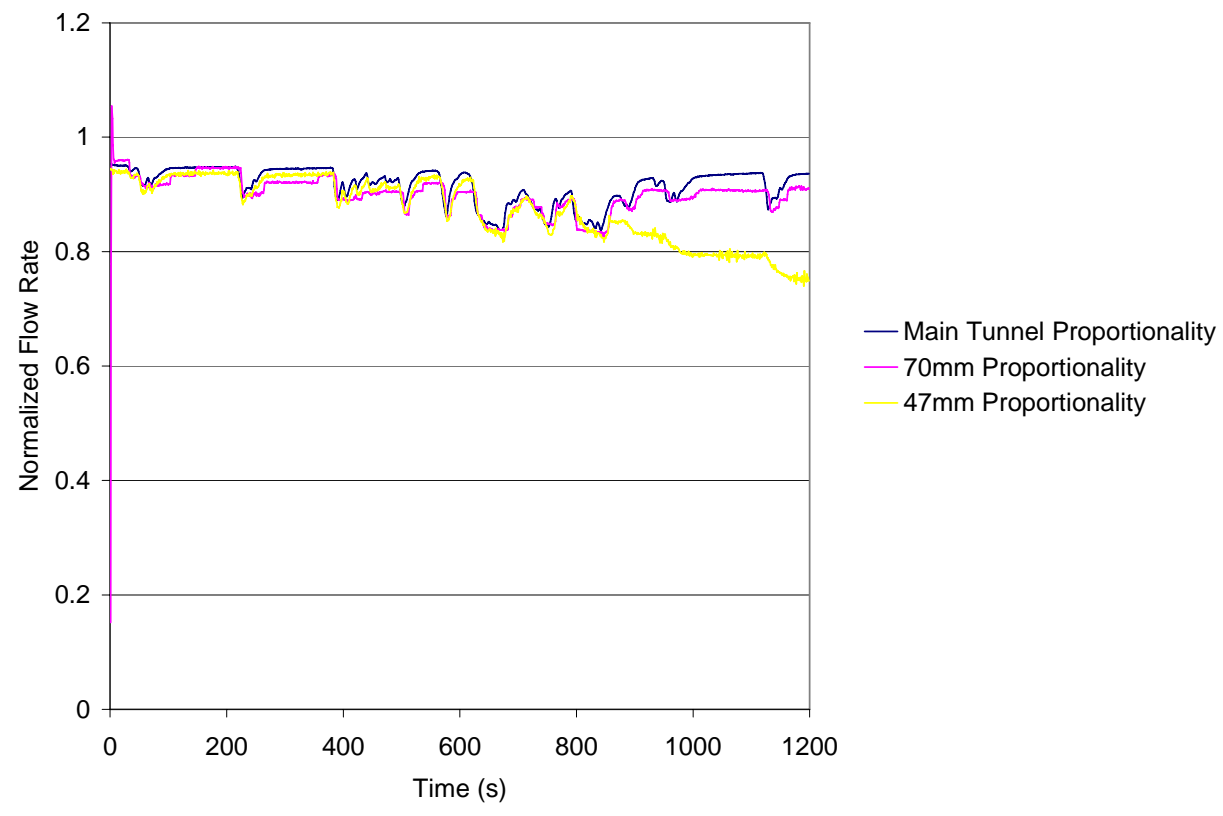

Figure 8.12 January 19, Proportionality for Tx40 Media at 1/1 SDR and $2.0 \mathrm{cfm}$ FFV

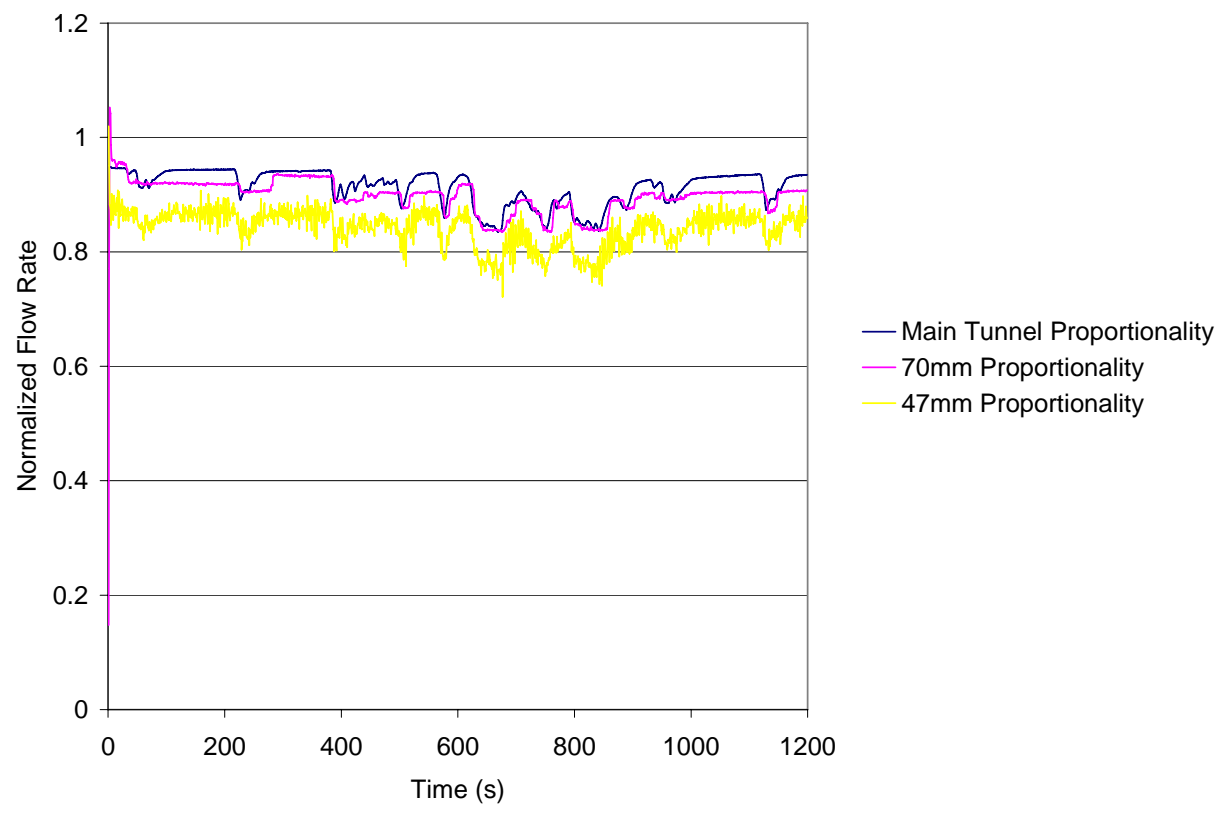

Figure 8.13 January 19, Proportionality for Tx40 Media at 10/1 SDR and $1.5 \mathrm{cfm}$ FFV 


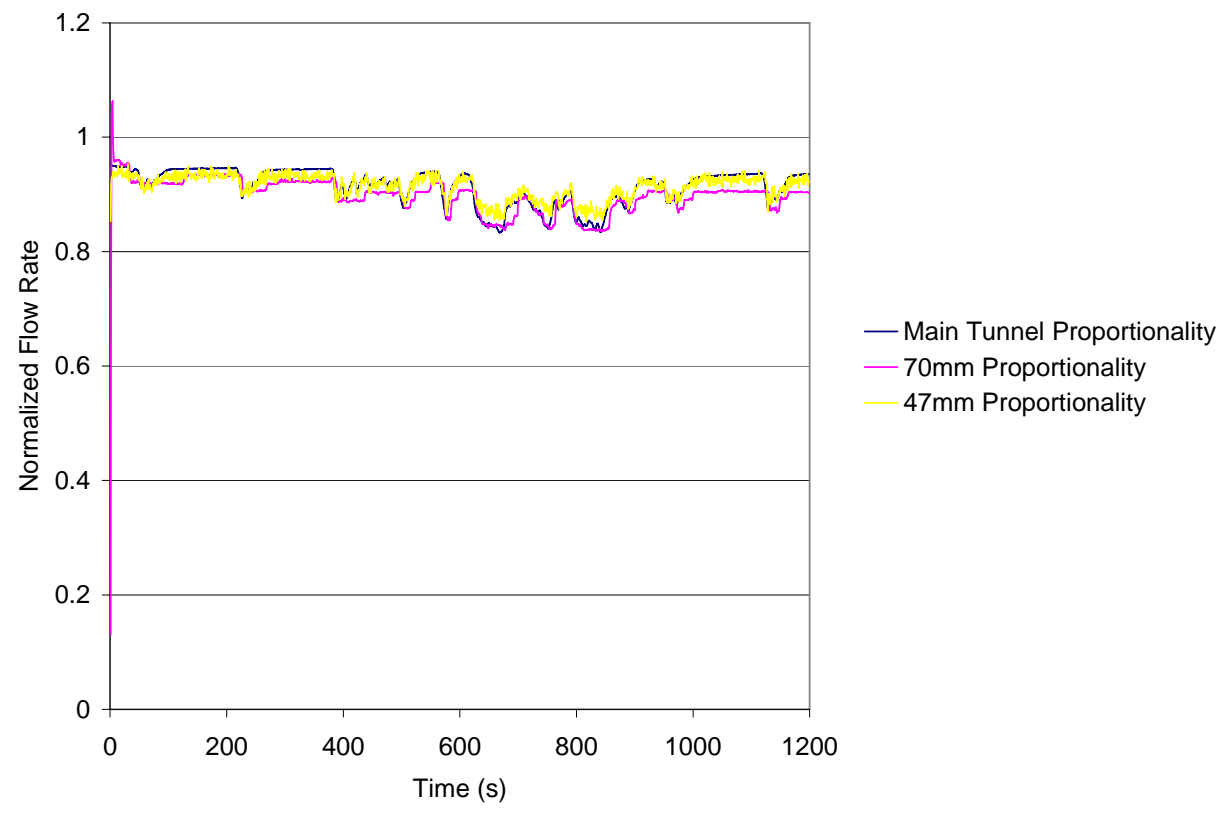

Figure 8.14 January 19, Proportionality for Tx40 Media at 10/1 SDR and $2.4 \mathrm{cfm}$ FFV

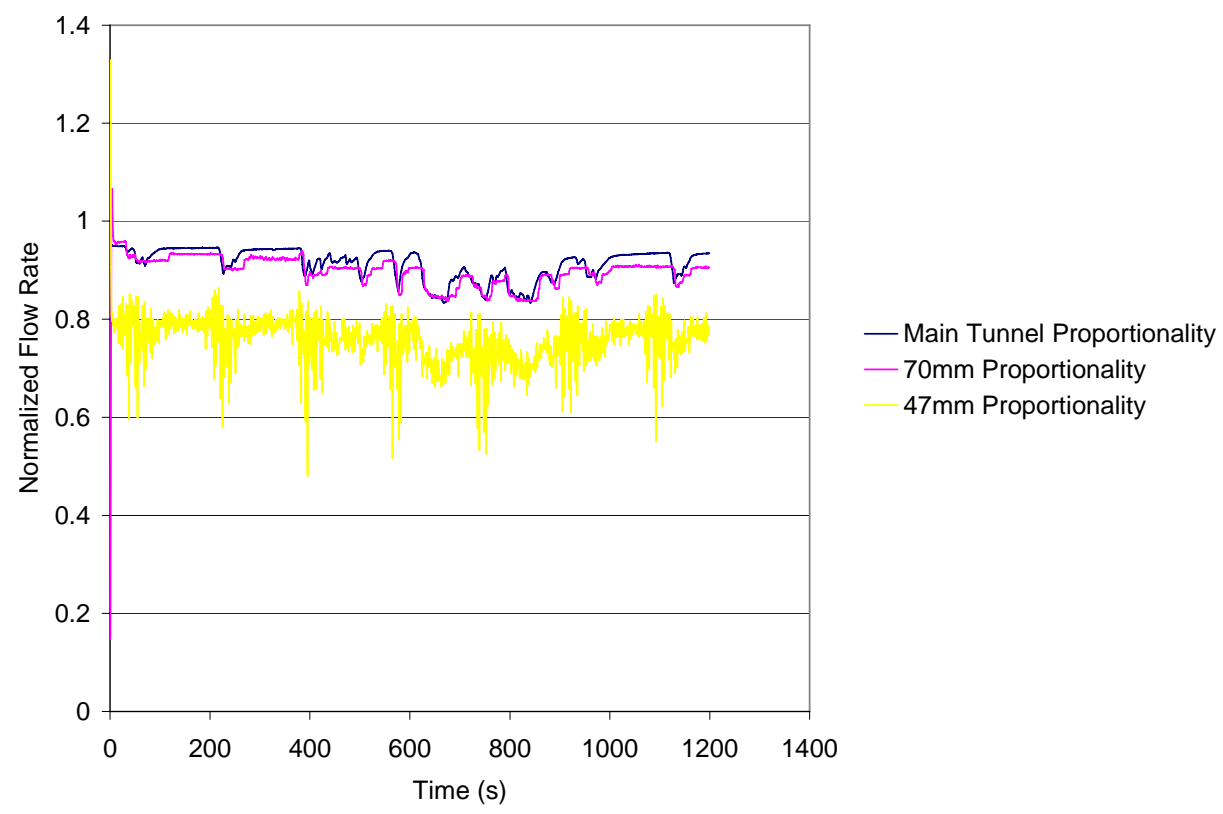

Figure 8.15 January 19, Proportionality for Tx40 Media at 10/1 SDR and $0.705 \mathrm{cfm}$ FFV 
8.1.7 January 24, 2007

Table 8.7 January 24, PM Filter Mass Data

\begin{tabular}{|c|c|c|c|c|}
\hline Test Set & \multicolumn{2}{|c|}{7.1} & \multicolumn{2}{c|}{7.2} \\
\hline PM System & $47 \mathrm{~mm}$ & $47 \mathrm{~mm}$ & $70 \mathrm{~mm}$ & $70 \mathrm{~mm}$ \\
\hline Filter Media & T60A20 & T60A20 & T60A20 & T60A20 \\
\hline SDR & $1 / 1$ & - & $1 / 1$ & - \\
\hline FFV (cfm) & 1.5 & 0.705 & 2.0 & 0.705 \\
\hline HS FTP Mass 1 (g) & 6.6285 & 6.8447 & 6.2514 & 6.4117 \\
\hline HS FTP Mass 2 (g) & 6.6873 & 6.9301 & 6.2948 & 6.5781 \\
\hline HS FTP Mass 3 (g) & 6.6457 & 6.8728 & 6.1386 & 6.3304 \\
\hline HS FTP Mass 4 (g) & - & - & 6.0464 & 6.1680 \\
\hline Average (g) & 6.6538 & 6.8825 & 6.1828 & 6.3721 \\
\hline CV (\%) & 0.45 & 0.63 & 1.82 & 2.68 \\
\hline Difference (\%) & \multicolumn{2}{|c|}{-2.97} \\
\hline
\end{tabular}

Table 8.7 cont.

\begin{tabular}{|c|c|c|}
\hline Test Set & \multicolumn{2}{|c|}{7.3} \\
\hline PM System & $47 \mathrm{~mm}$ & $47 \mathrm{~mm}$ \\
\hline Filter Media & T60A20 & T60A20 \\
\hline SDR & $1 / 1$ & - \\
\hline FFV (cfm) & 2.4 & 0.705 \\
\hline HS FTP Mass 1 (g) & 6.2526 & 6.1995 \\
\hline HS FTP Mass 2 (g) & 6.4495 & 6.4060 \\
\hline HS FTP Mass 3 (g) & - & - \\
\hline Average (g) & 6.3511 & 6.3027 \\
\hline CV (\%) & 2.19 & 2.32 \\
\hline Difference (\%) & \multicolumn{2}{|c|}{0.77} \\
\hline
\end{tabular}




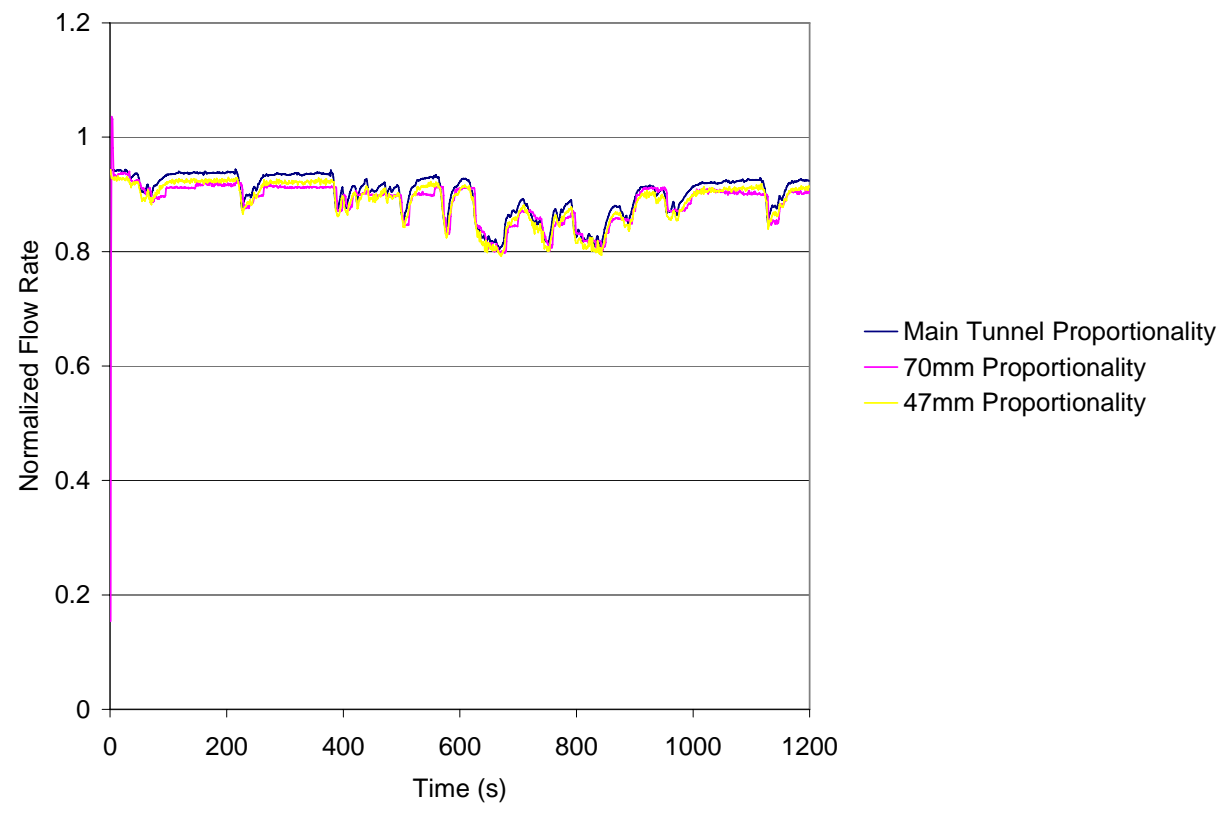

Figure 8.16 January 24, Proportionality for T60A20 Media at 1/1 SDR and $1.5 \mathrm{cfm}$ FFV

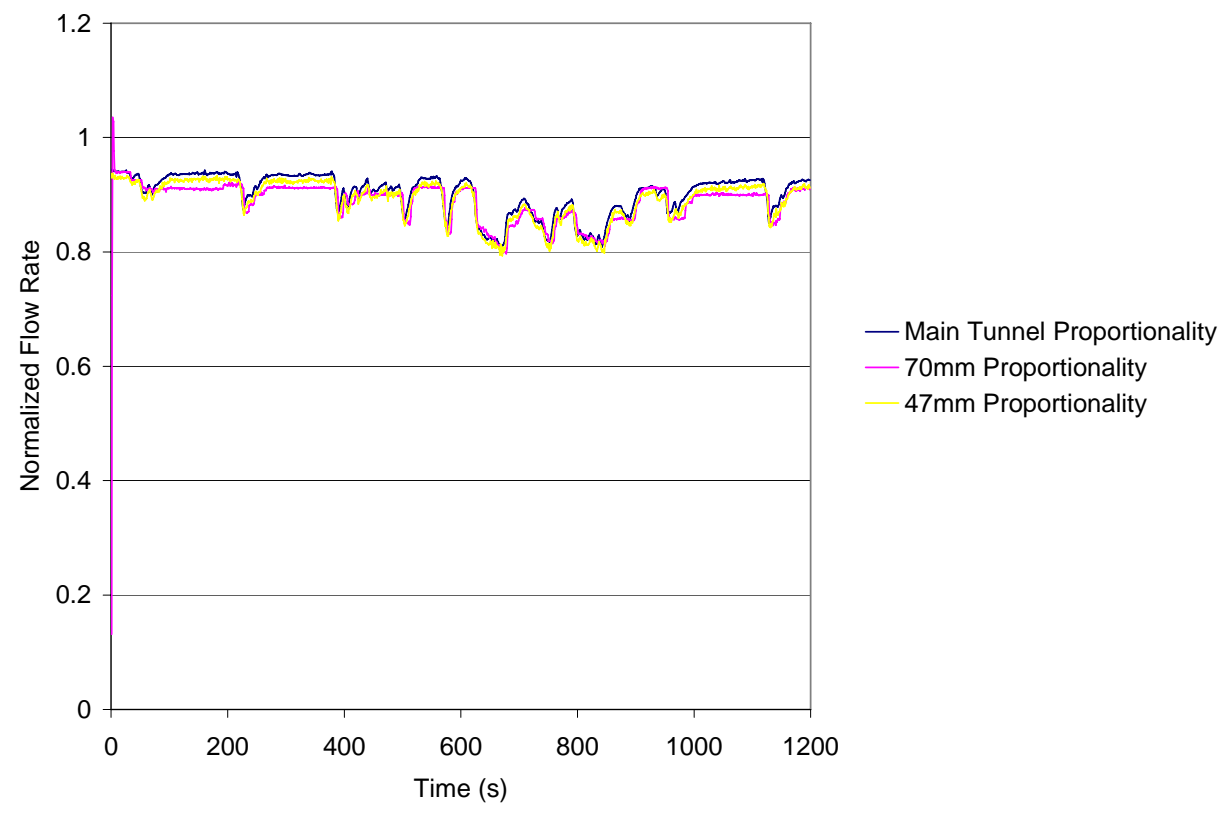

Figure 8.17 January 24, Proportionality for T60A20 Media at 1/1 SDR and $2.0 \mathrm{cfm}$ FFV 


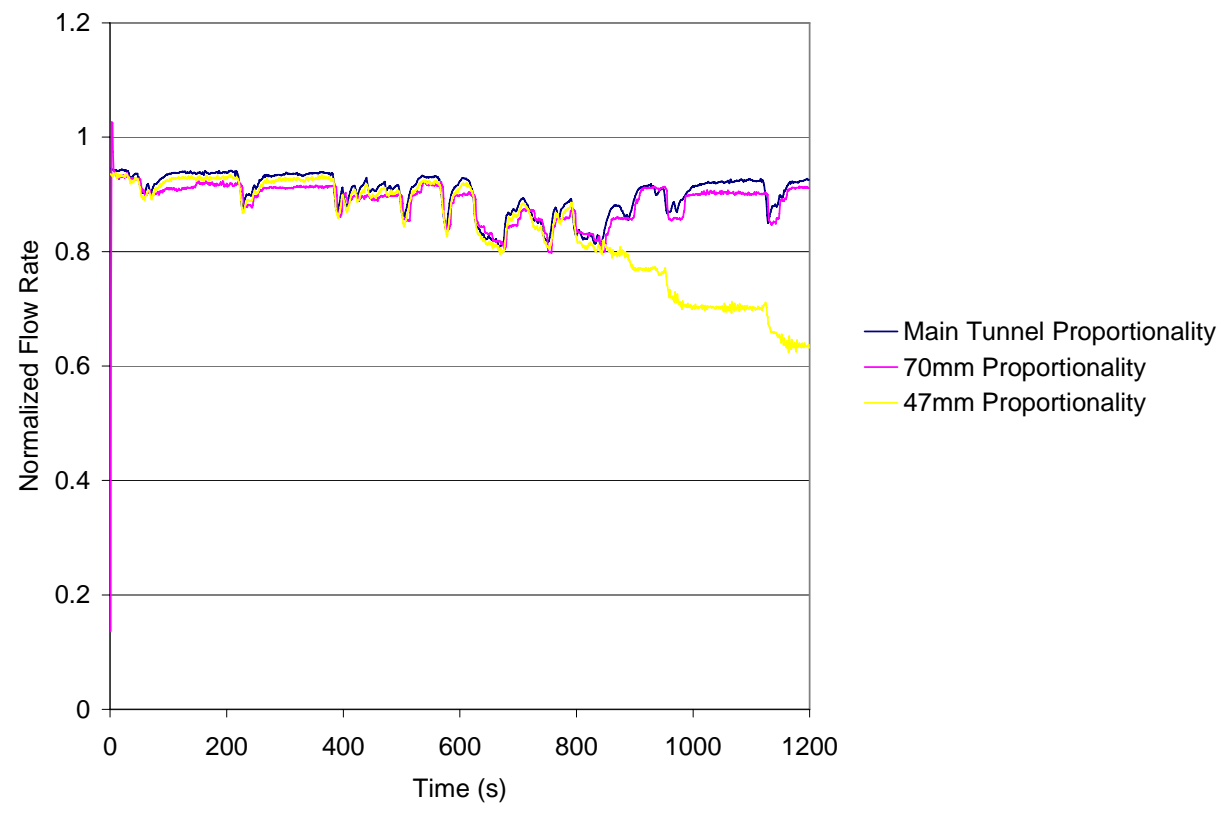

Figure 8.18 January 24, Proportionality for T60A20 Media at 1/1 SDR and $2.4 \mathrm{cfm}$ FFV

\subsubsection{January 25, 2007}

Figure 8.21 displays noise for the $47 \mathrm{~mm}$ flow proportionality. Once again, this mass flow controller noise may influence results.

Table 8.8 January 25, PM Filter Mass Data

\begin{tabular}{|c|c|c|c|c|}
\hline Test Set & \multicolumn{2}{|c|}{8.1} & \multicolumn{2}{c|}{8.2} \\
\hline PM System & $47 \mathrm{~mm}$ & $47 \mathrm{~mm}$ & $70 \mathrm{~mm}$ & $70 \mathrm{~mm}$ \\
\hline Filter Media & T60A20 & T60A20 & T60A20 & T60A20 \\
\hline SDR & $10 / 1$ & - & $2 / 1$ & - \\
\hline FFV (cfm) & 2.4 & 0.705 & 1.0 & 0.705 \\
\hline HS FTP Mass 1 (g) & 5.1181 & 6.0434 & 5.0014 & 5.8451 \\
\hline HS FTP Mass 2 (g) & 4.9973 & 5.8195 & 4.8554 & 5.7337 \\
\hline HS FTP Mass 3 (g) & 5.0434 & 5.8650 & 4.7501 & 5.6364 \\
\hline Average (g) & 5.0529 & 5.9093 & 4.8690 & 5.7384 \\
\hline CV (\%) & 1.21 & 2.00 & 0.84 & 2.58 \\
\hline Difference (\%) & \multicolumn{2}{|c|}{-15.15} \\
\hline
\end{tabular}


Table 8.8 cont.

\begin{tabular}{|c|c|c|c|c|}
\hline Test Set & \multicolumn{2}{|c|}{8.3} & \multicolumn{2}{c|}{8.4} \\
\hline PM System & $47 \mathrm{~mm}$ & $47 \mathrm{~mm}$ & $70 \mathrm{~mm}$ & $70 \mathrm{~mm}$ \\
\hline Filter Media & T60A20 & T60A20 & T60A20 & T60A20 \\
\hline SDR & $10 / 1$ & - & $2 / 1$ & - \\
\hline FFV (cfm) & 1.5 & 0.705 & 1.5 & 0.705 \\
\hline HS FTP Mass 1 (g) & 3.8336 & 6.7231 & 5.7393 & 6.2695 \\
\hline HS FTP Mass 2 (g) & 3.8796 & 6.9729 & 5.7756 & 6.3299 \\
\hline HS FTP Mass 3 (g) & - & - & 5.6953 & 6.2634 \\
\hline Average (g) & 3.8566 & 6.8480 & 5.7367 & 6.2876 \\
\hline CV (\%) & 0.84 & 2.58 & 0.70 & 0.58 \\
\hline Difference (\%) & \multicolumn{2}{|c|}{-43.68} & \multicolumn{2}{c}{-8.76} \\
\hline
\end{tabular}

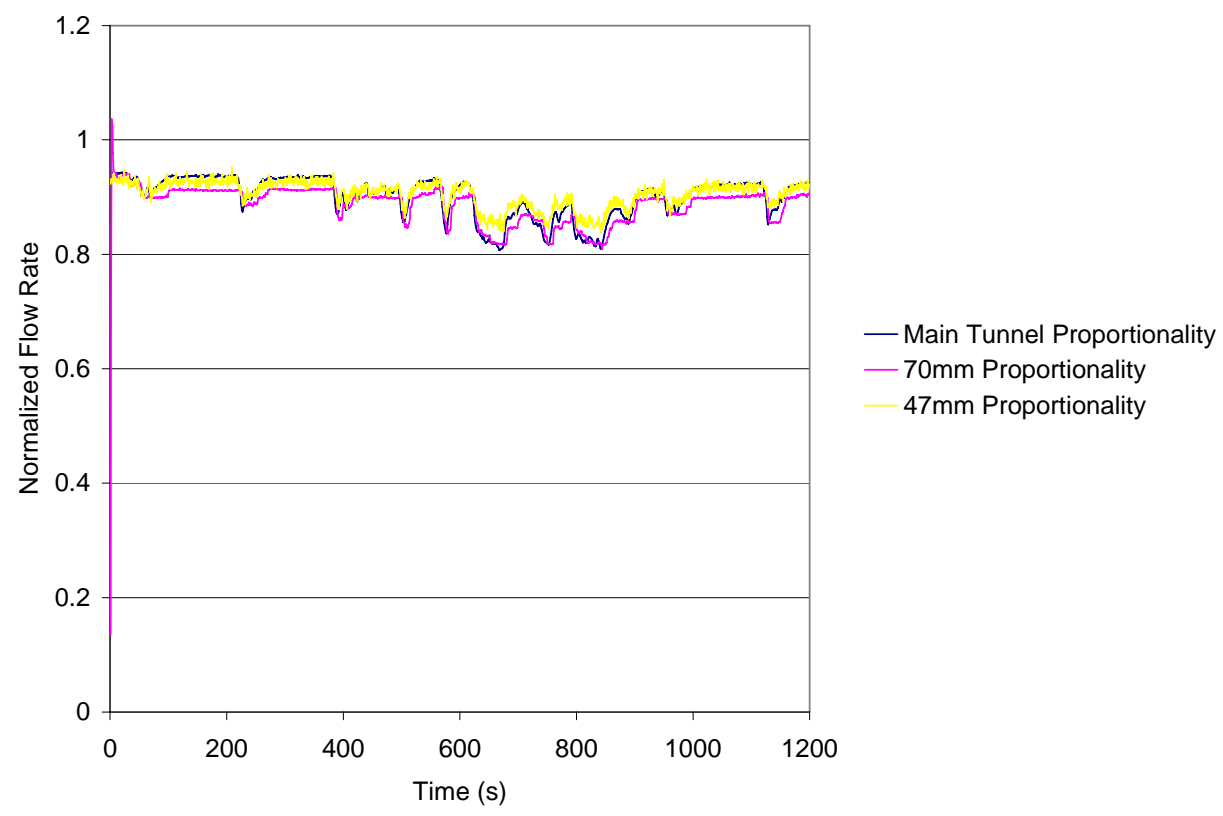

Figure 8.19 January 25, Proportionality for T60A20 Media at 10/1 SDR and $2.4 \mathrm{cfm}$ FFV 


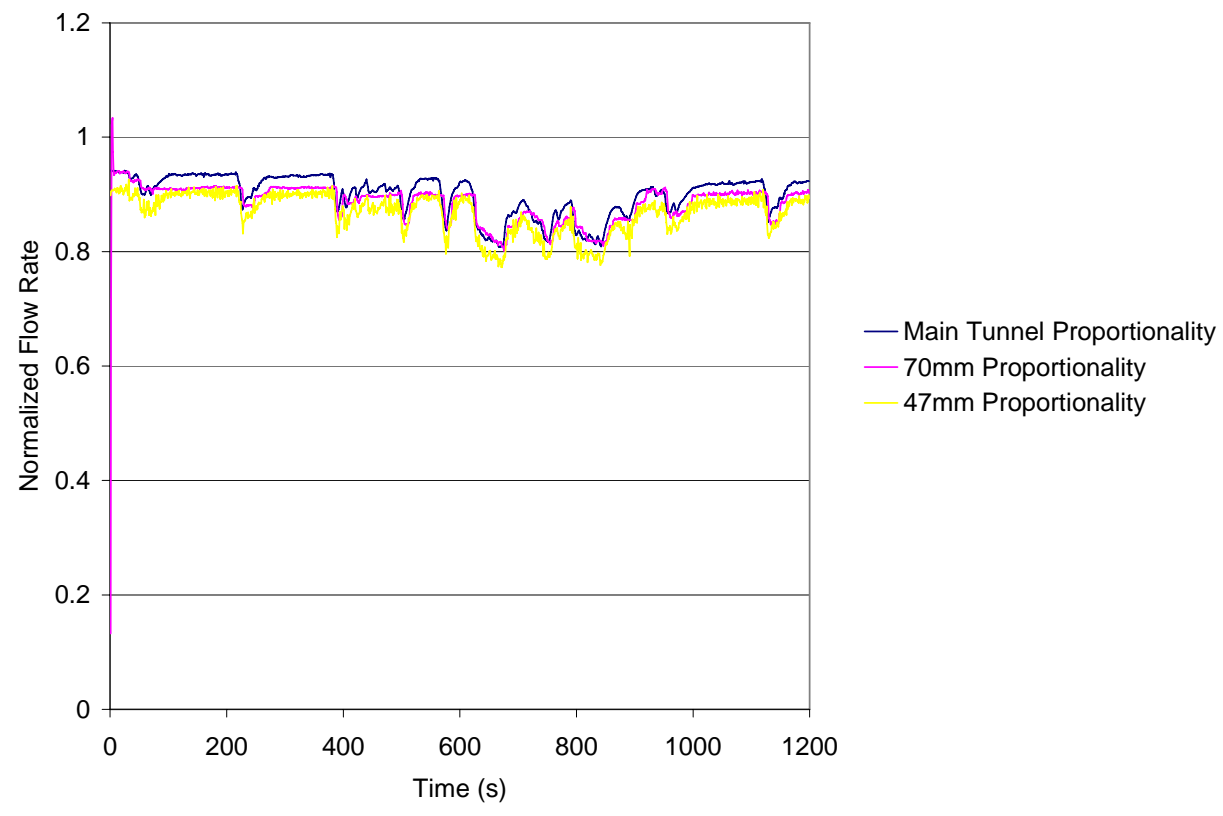

Figure 8.20 January 25, Proportionality for T60A20 Media at 2/1 SDR and $1.0 \mathrm{cfm}$ FFV

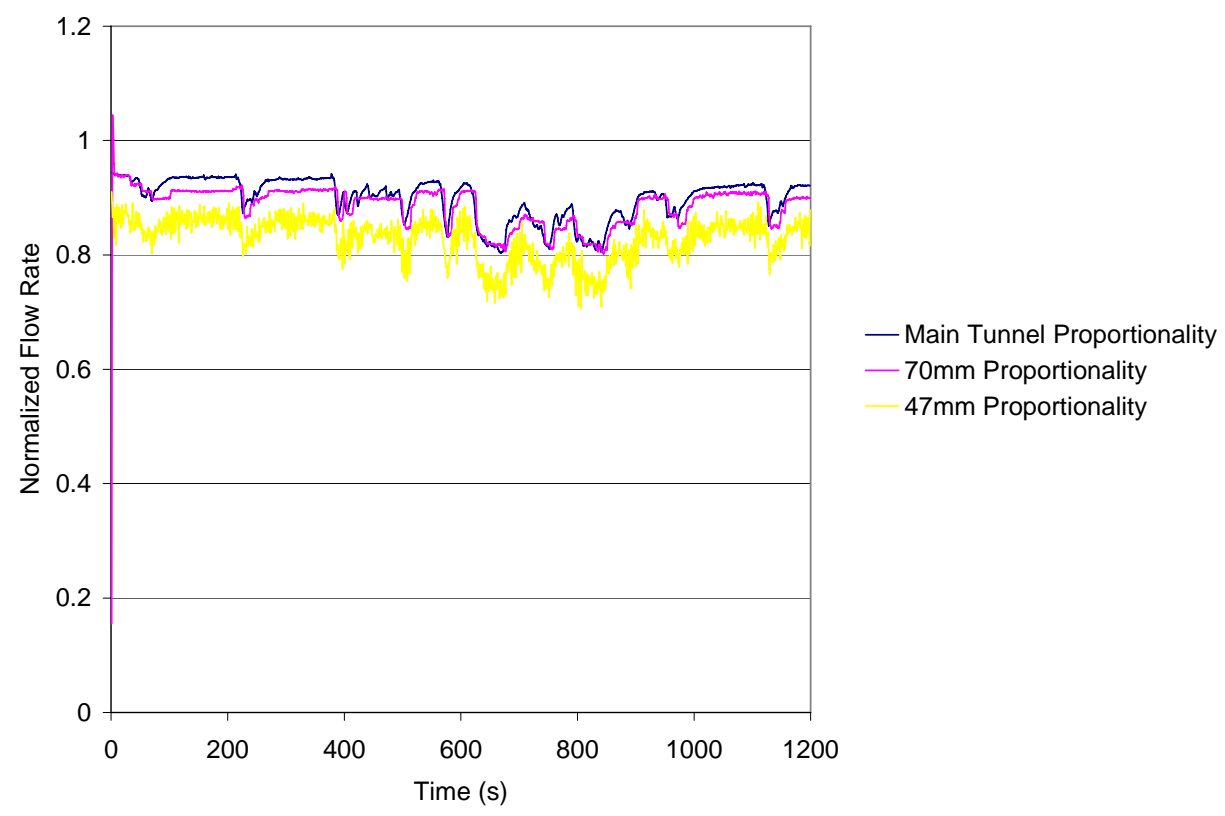

Figure 8.21 January 25, Proportionality for T60A20 Media at 10/1 SDR and $1.5 \mathrm{cfm}$ FFV 


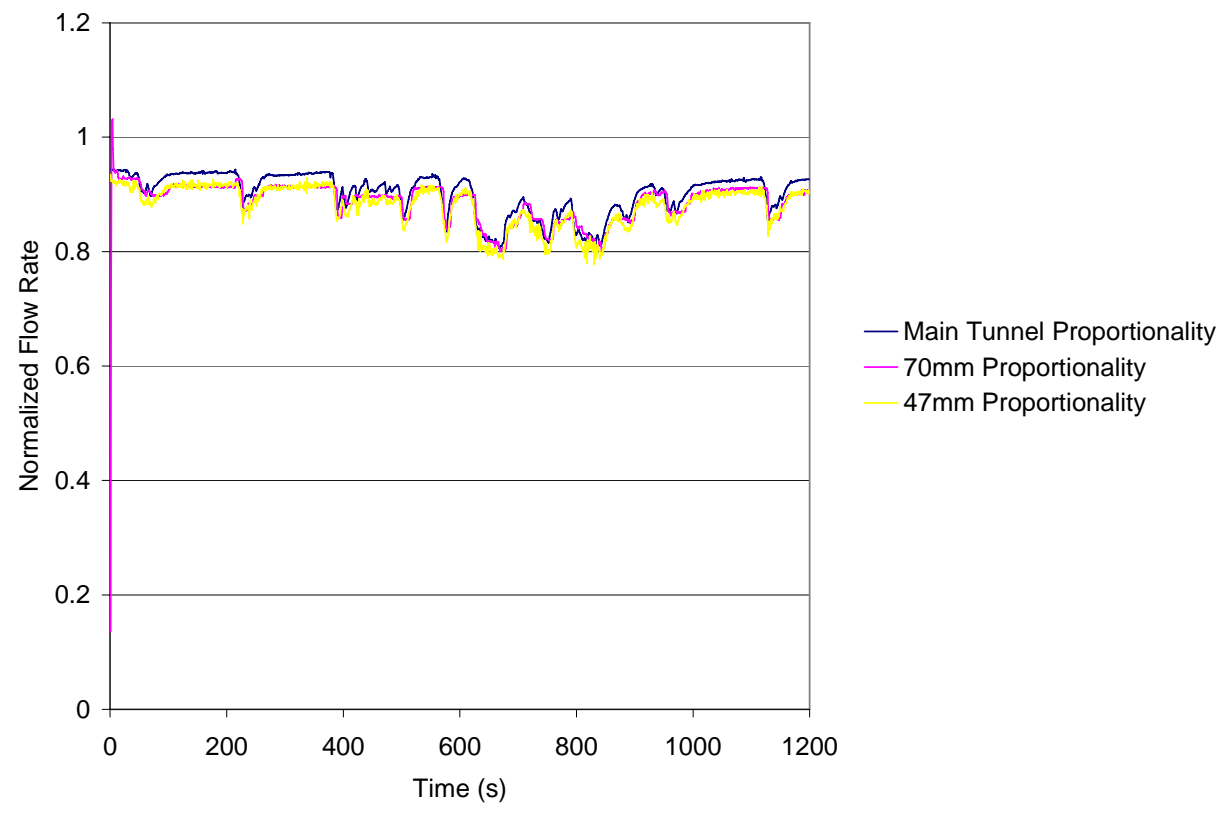

Figure 8.22 January 25, Proportionality for T60A20 Media at 2/1 SDR and $1.5 \mathrm{cfm}$ FFV

\subsubsection{January 26, 2007}

Table 8.9 January 26, PM Filter Mass Data

\begin{tabular}{|c|c|c|c|c|}
\hline Test Set & \multicolumn{2}{|c|}{9.1} & \multicolumn{2}{c|}{9.2} \\
\hline PM System & $47 \mathrm{~mm}$ & $47 \mathrm{~mm}$ & $70 \mathrm{~mm}$ & $70 \mathrm{~mm}$ \\
\hline Filter Media & T60A20 & T60A20 & Teflo & T60A20 \\
\hline SDR & $1 / 1$ & - & 0 & - \\
\hline FFV (cfm) & 1.0 & 0.705 & 1.0 & 0.705 \\
\hline HS FTP Mass 1 (g) & 5.3275 & 5.7835 & 6.4755 & 6.1967 \\
\hline HS FTP Mass 2 (g) & 5.3795 & 5.7244 & 6.5597 & 6.4143 \\
\hline HS FTP Mass 3 (g) & 5.3800 & 5.6955 & 6.6200 & 6.4806 \\
\hline Average (g) & 5.3623 & 5.7344 & 5.7805 & 6.3639 \\
\hline CV (\%) & 0.56 & 0.78 & 1.24 & 3.28 \\
\hline Difference (\%) & \multicolumn{2}{|c|}{-6.49} & \multicolumn{2}{c|}{-0.52} \\
\hline
\end{tabular}


Table 8.9 cont.

\begin{tabular}{|c|c|c|}
\hline Test Set & \multicolumn{2}{|c|}{9.3} \\
\hline PM System & $47 \mathrm{~mm}$ & $47 \mathrm{~mm}$ \\
\hline Filter Media & T60A20 & T60A20 \\
\hline SDR & $10 / 1$ & - \\
\hline FFV (cfm) & 1.5 & 0.705 \\
\hline HS FTP Mass 1 (g) & 5.8247 & 6.0036 \\
\hline HS FTP Mass 2 (g) & 5.6976 & 5.6228 \\
\hline HS FTP Mass 3 (g) & 5.8191 & 5.8058 \\
\hline Average (g) & 6.5517 & 6.3639 \\
\hline CV (\%) & 1.11 & 2.33 \\
\hline Difference (\%) & \multicolumn{2}{|c|}{2.95} \\
\hline
\end{tabular}

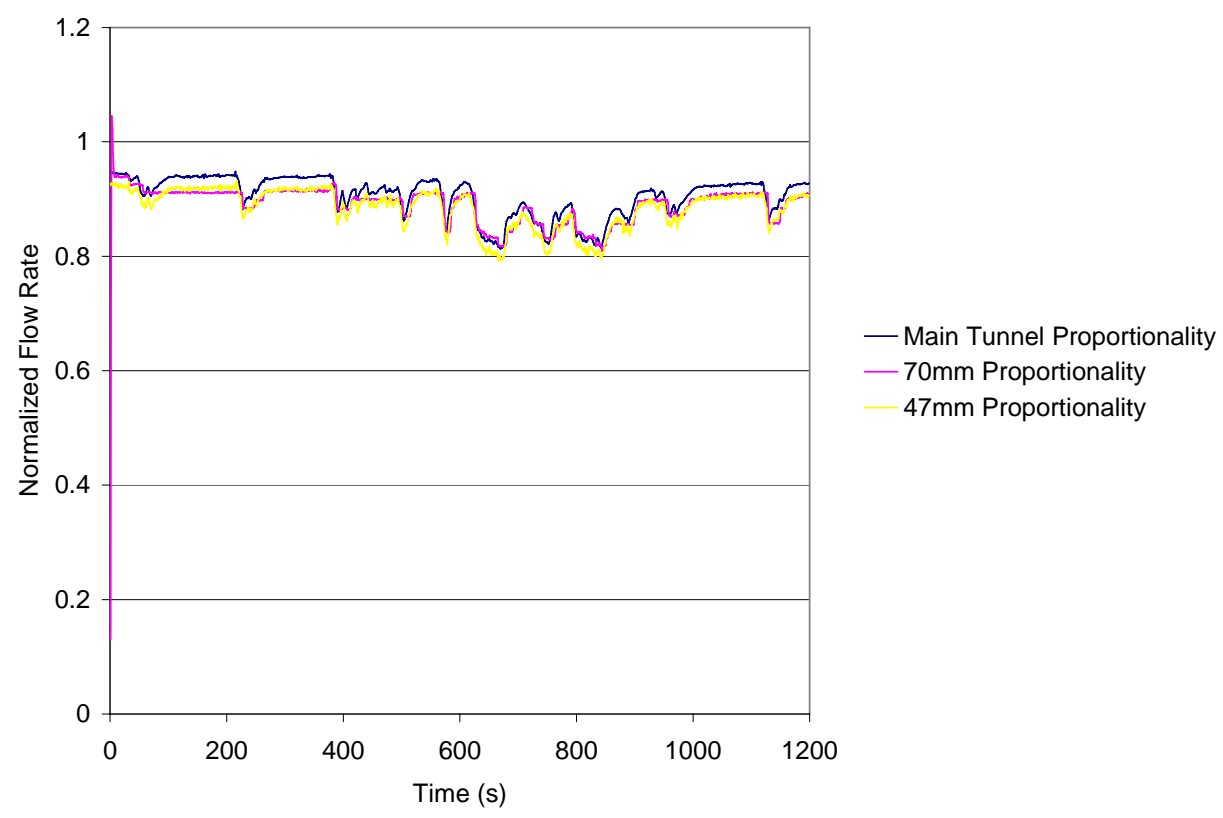

Figure 8.23 January 26, Proportionality for T60A20 Media at 1/1 SDR and $1.0 \mathrm{cfm}$ FFV 


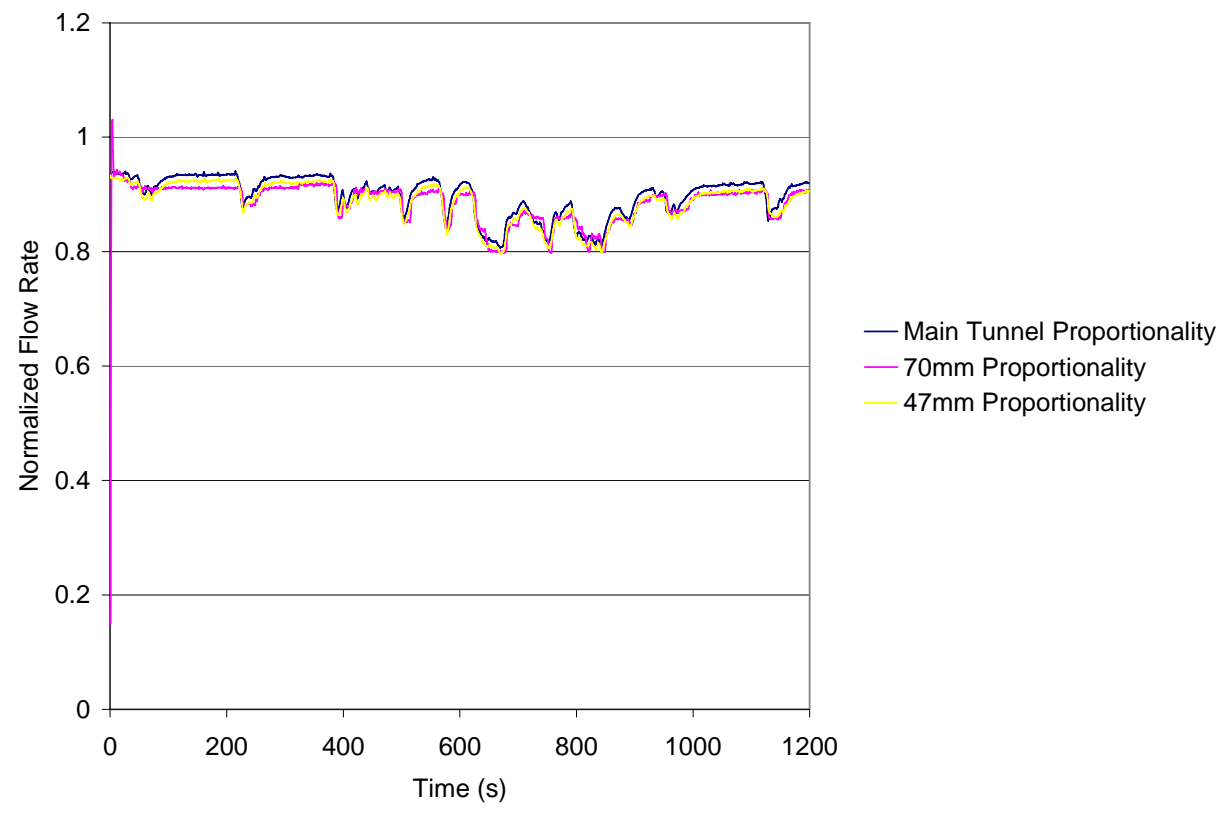

Figure 8.24 January 26, Proportionality for Teflo Media at 0 SDR and $1.0 \mathrm{cfm}$ FFV

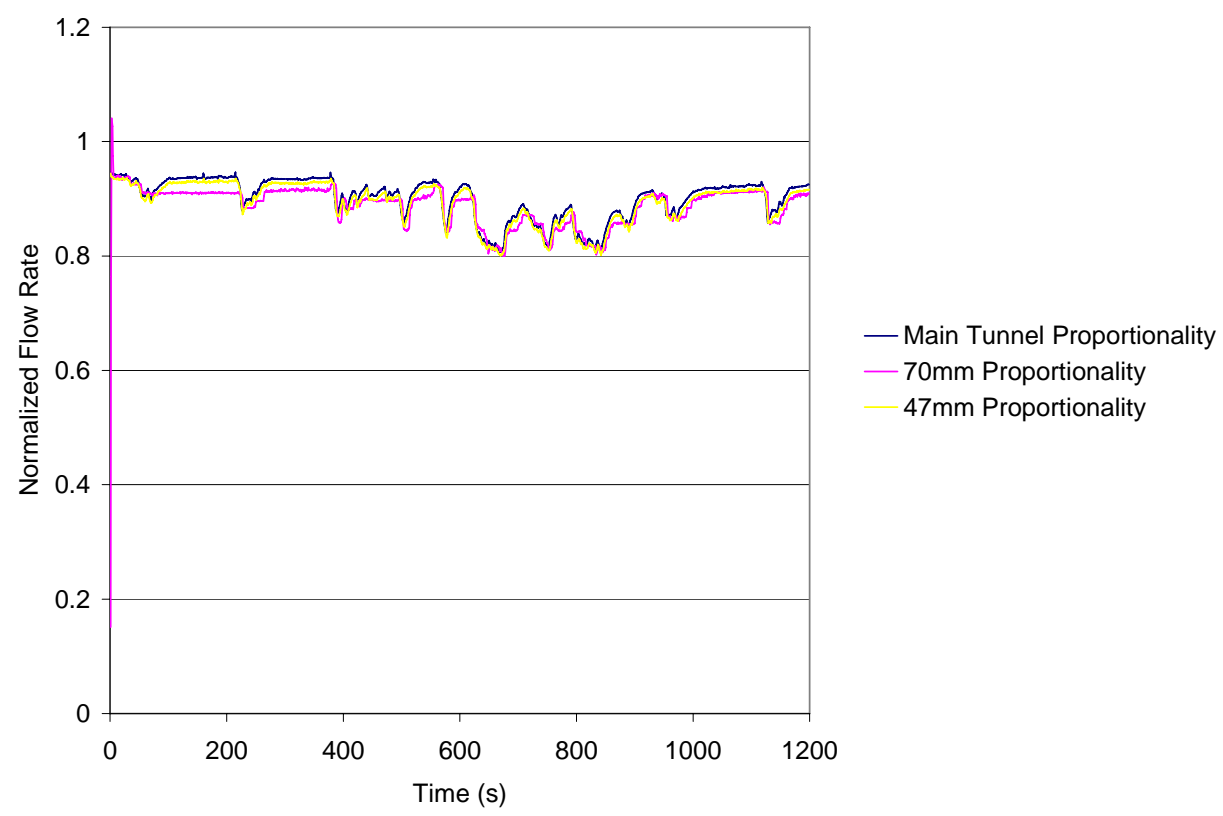

Figure 8.25 January 26, Proportionality for T60A20 Media at 0 SDR and $1.5 \mathrm{cfm}$ FFV 


\subsection{Cummins ISM}

8.2.1 February 7, 2007

Table 8.10 February 7, PM Filter Mass Data

\begin{tabular}{|c|c|c|c|c|}
\hline Test Set & \multicolumn{2}{|c|}{10.1} & \multicolumn{2}{c|}{10.2} \\
\hline PM System & $47 \mathrm{~mm}$ & $47 \mathrm{~mm}$ & $70 \mathrm{~mm}$ & $70 \mathrm{~mm}$ \\
\hline Filter Media & Teflo & T60A20 & Teflo & T60A20 \\
\hline SDR & 0 & - & $1 / 1$ & - \\
\hline FFV (cfm) & 1.5 & 0.705 & 1.5 & 0.705 \\
\hline HS FTP Mass 1 (g) & 1.9841 & 3.0343 & 2.3776 & 3.5989 \\
\hline HS FTP Mass 2 (g) & 2.0482 & 3.1115 & 2.3266 & 3.5546 \\
\hline HS FTP Mass 3 (g) & 1.5834 & 3.0529 & 2.2591 & 3.3089 \\
\hline Average (g) & 1.8719 & 3.0662 & 2.3211 & 3.4875 \\
\hline CV (\%) & 13.46 & 1.31 & 2.32 & 3.49 \\
\hline Difference (\%) & \multicolumn{3}{|c|}{-38.95} & \multicolumn{2}{c}{} \\
\hline
\end{tabular}

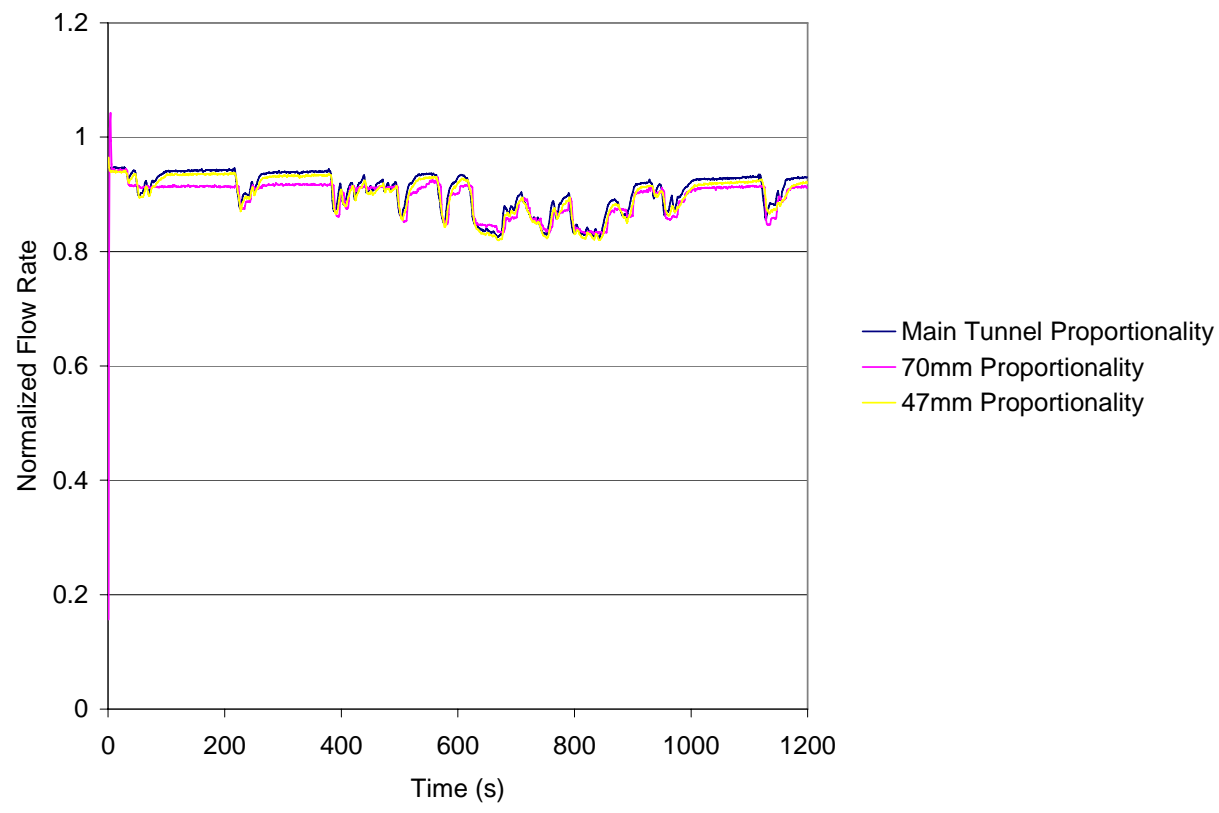

Figure 8.26 February 7, Proportionality for Teflo Media at 0 SDR and $1.5 \mathrm{cfm}$ FFV 


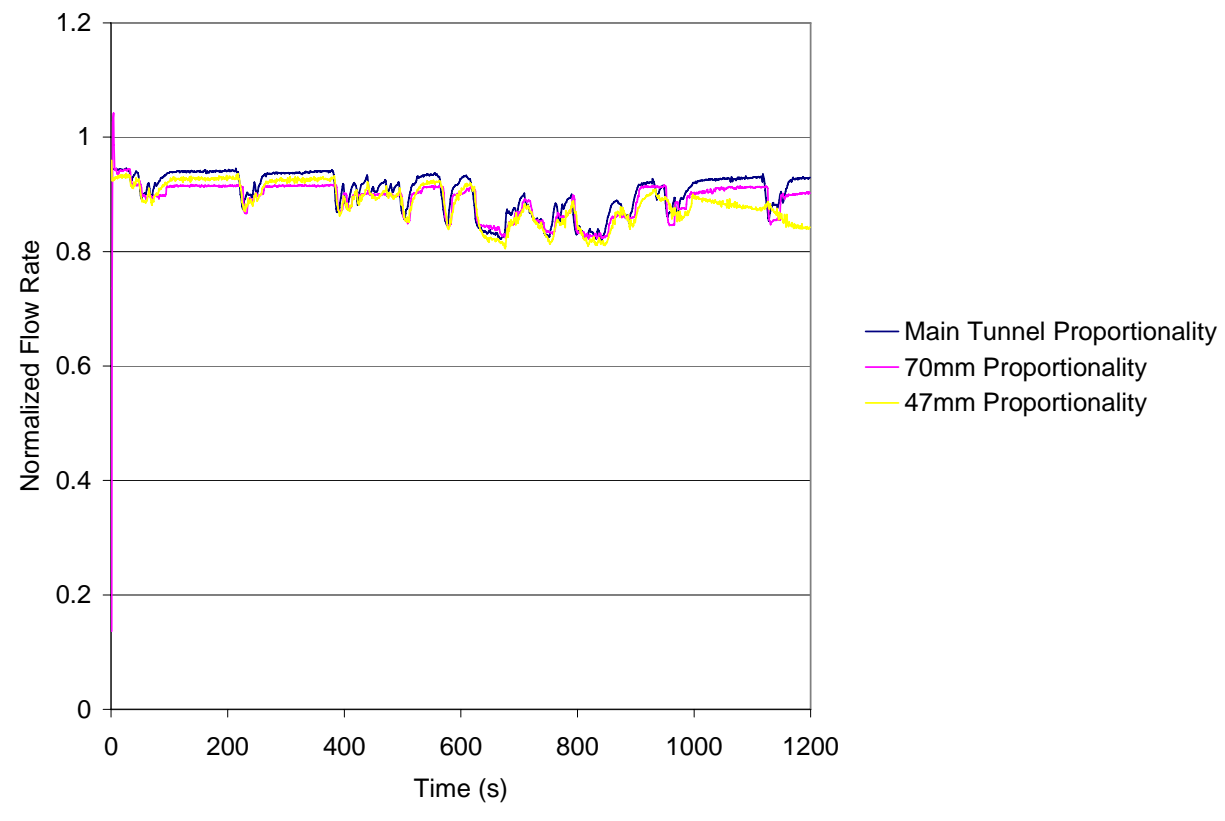

Figure 8.27 February 7, Proportionality for Teflo Media at 1/1 SDR and $1.5 \mathrm{cfm}$ FFV 
Table 8.11 February 9, PM Filter Mass Data

\begin{tabular}{|c|c|c|}
\hline Test Set & \multicolumn{2}{|c|}{11} \\
\hline PM System & $47 \mathrm{~mm}$ & $47 \mathrm{~mm}$ \\
\hline Filter Media & Teflo & T60A20 \\
\hline SDR & $2 / 1$ & - \\
\hline FFV (cfm) & 1.5 & 0.705 \\
\hline HS FTP Mass 1 (g) & 1.8577 & 2.6889 \\
\hline HS FTP Mass 2 (g) & 1.7994 & 2.4895 \\
\hline HS FTP Mass 3 (g) & 1.7820 & 2.5169 \\
\hline Average (g) & 1.8130 & 2.5651 \\
\hline CV (\%) & 2.19 & 4.21 \\
\hline Difference (\%) & \multicolumn{2}{|c|}{-29.32} \\
\hline
\end{tabular}

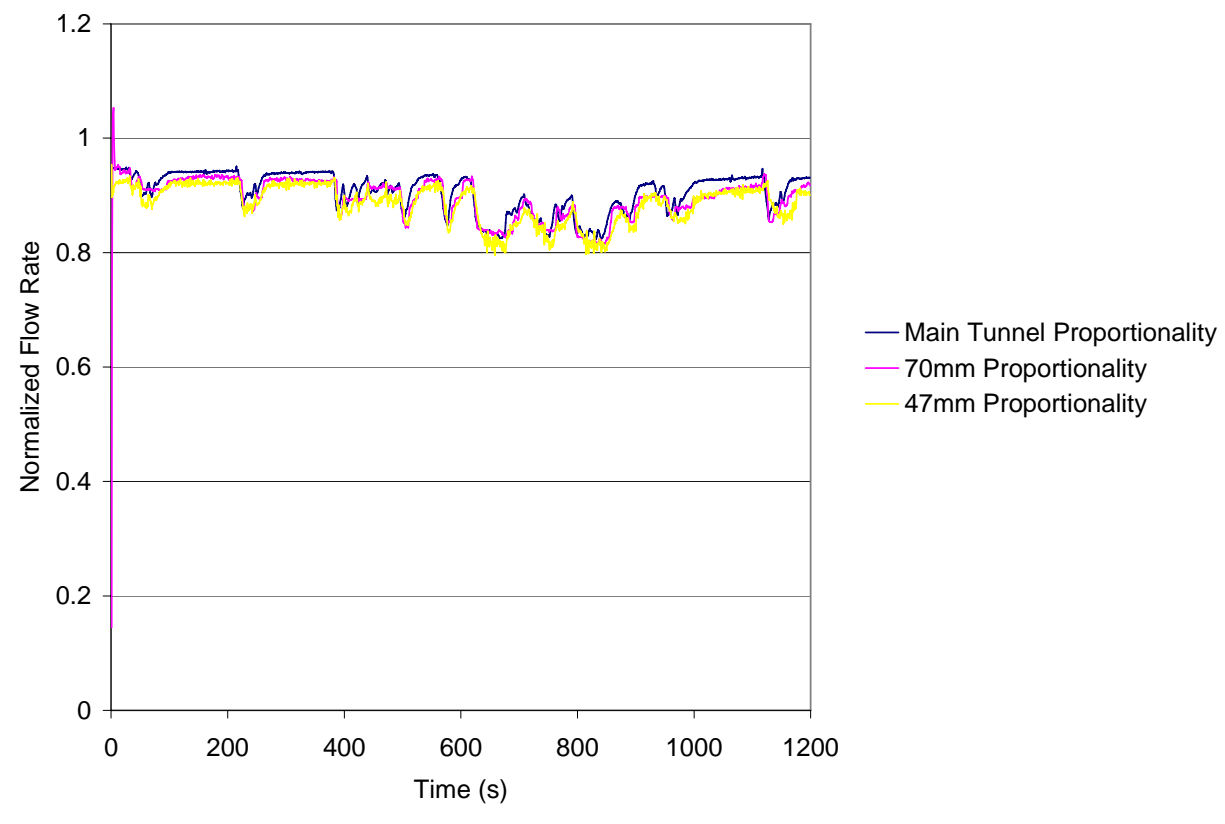

Figure 8.28 February 9, Proportionality for Teflo Media at 2/1 SDR and $1.5 \mathrm{cfm}$ FFV 
Table 8.12 February 13, PM Filter Mass Data

\begin{tabular}{|c|c|c|}
\hline Test Set & \multicolumn{2}{|c|}{12} \\
\hline PM System & $47 \mathrm{~mm}$ & $47 \mathrm{~mm}$ \\
\hline Filter Media & Tx40 & T60A20 \\
\hline SDR & $10 / 1$ & - \\
\hline FFV (cfm) & 2.0 & 0.705 \\
\hline HS FTP Mass 1 (g) & 1.9453 & 2.1784 \\
\hline HS FTP Mass 2 (g) & 2.0358 & 2.1991 \\
\hline HS FTP Mass 3 (g) & 1.9435 & 2.2362 \\
\hline Average (g) & 1.9749 & 2.2046 \\
\hline CV (\%) & 2.67 & 1.33 \\
\hline Difference (\%) & \multicolumn{3}{|c|}{-10.42} \\
\hline
\end{tabular}

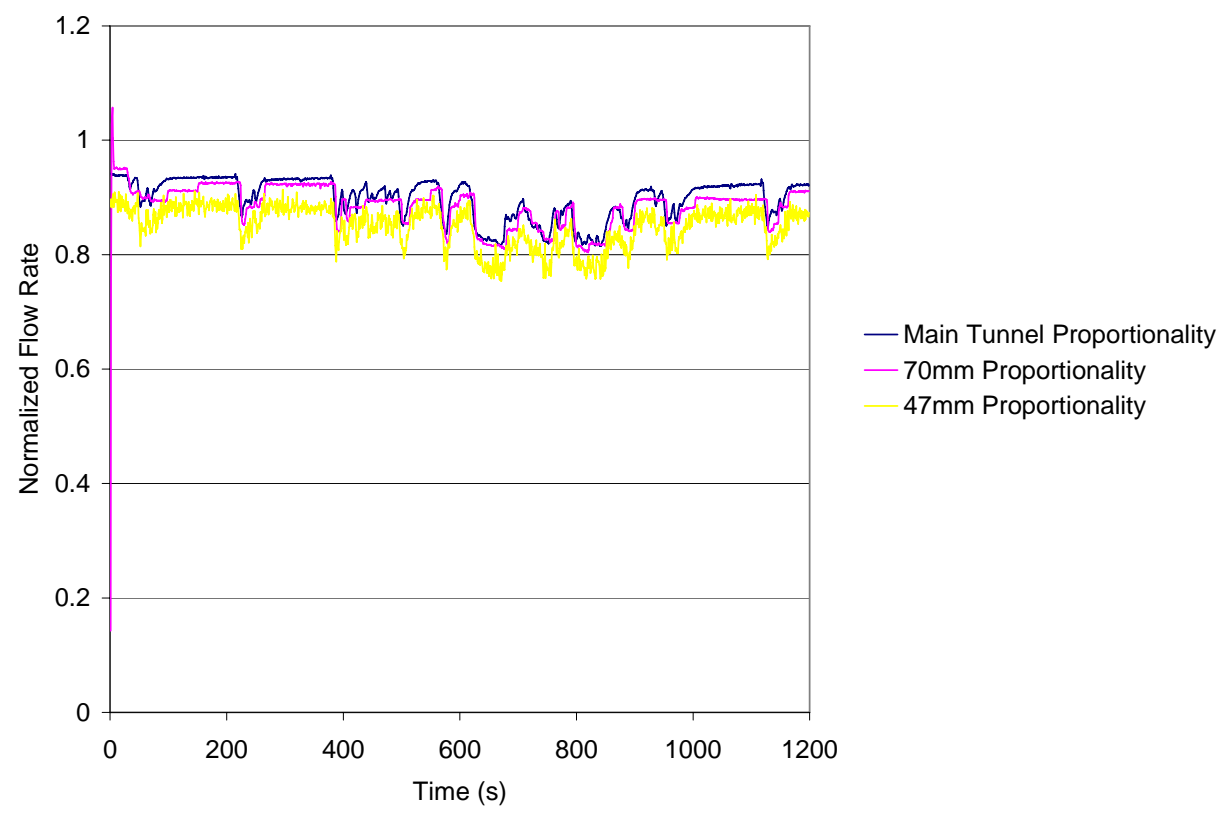

Figure 8.29 February 13, Proportionality for Teflo Media at 2/1 SDR and $1.5 \mathrm{cfm}$ FFV 


\subsection{Cummins ISM}

8.3.1 February 20, 2007

Table 8.13 February 20, PM Filter Mass Data

\begin{tabular}{|c|c|c|c|c|}
\hline Test Set & \multicolumn{2}{|c|}{13.1} & \multicolumn{2}{c|}{13.2} \\
\hline PM System & $47 \mathrm{~mm}$ & $47 \mathrm{~mm}$ & $70 \mathrm{~mm}$ & $70 \mathrm{~mm}$ \\
\hline Filter Media & Tx40 & T60A20 & Tx40 & T60A20 \\
\hline SDR & $10 / 1$ & - & $1 / 1$ & - \\
\hline FFV (cfm) & 1.0 & 0.705 & 1.0 & 0.705 \\
\hline HS FTP Mass 1 (g) & 1.3895 & 1.5636 & 1.7698 & 1.9142 \\
\hline HS FTP Mass 2 (g) & 0.0986 & 1.4948 & 1.9763 & 2.1862 \\
\hline HS FTP Mass 3 (g) & - & - & 1.6683 & 1.9581 \\
\hline Average (g) & 0.7440 & 1.5292 & 1.8048 & 2.0195 \\
\hline CV (\%) & 122.68 & 3.18 & 8.70 & 7.23 \\
\hline Difference (\%) & \multicolumn{2}{|c|}{-51.34} & \multicolumn{2}{c|}{-10.63} \\
\hline
\end{tabular}

Table 8.13 cont.

\begin{tabular}{|c|c|c|}
\hline Test Set & \multicolumn{2}{|c|}{13.3} \\
\hline PM System & $47 \mathrm{~mm}$ & $47 \mathrm{~mm}$ \\
\hline Filter Media & Tx40 & T60A20 \\
\hline SDR & $1 / 1$ & - \\
\hline FFV (cfm) & 2.4 & 0.705 \\
\hline HS FTP Mass 1 (g) & 1.8382 & 1.8896 \\
\hline HS FTP Mass 2 (g) & 1.7303 & 1.8616 \\
\hline HS FTP Mass 3 (g) & 1.8101 & 1.8779 \\
\hline Average (g) & 1.7929 & 1.8764 \\
\hline CV (\%) & 3.12 & 0.75 \\
\hline Difference (\%) & \multicolumn{2}{|c|}{-4.45} \\
\hline
\end{tabular}




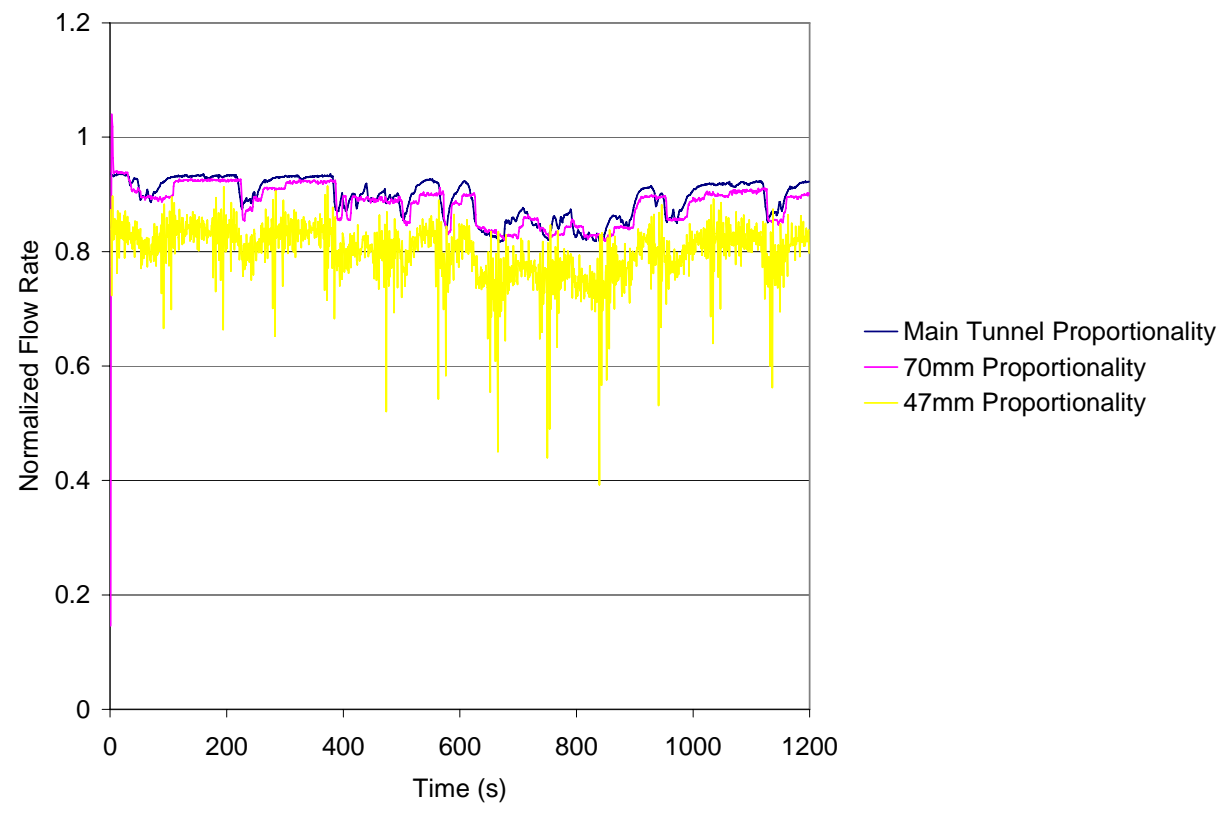

Figure 8.30 February 20, Proportionality for Tx40 Media at 10/1 SDR and 1.0 cfm FFV

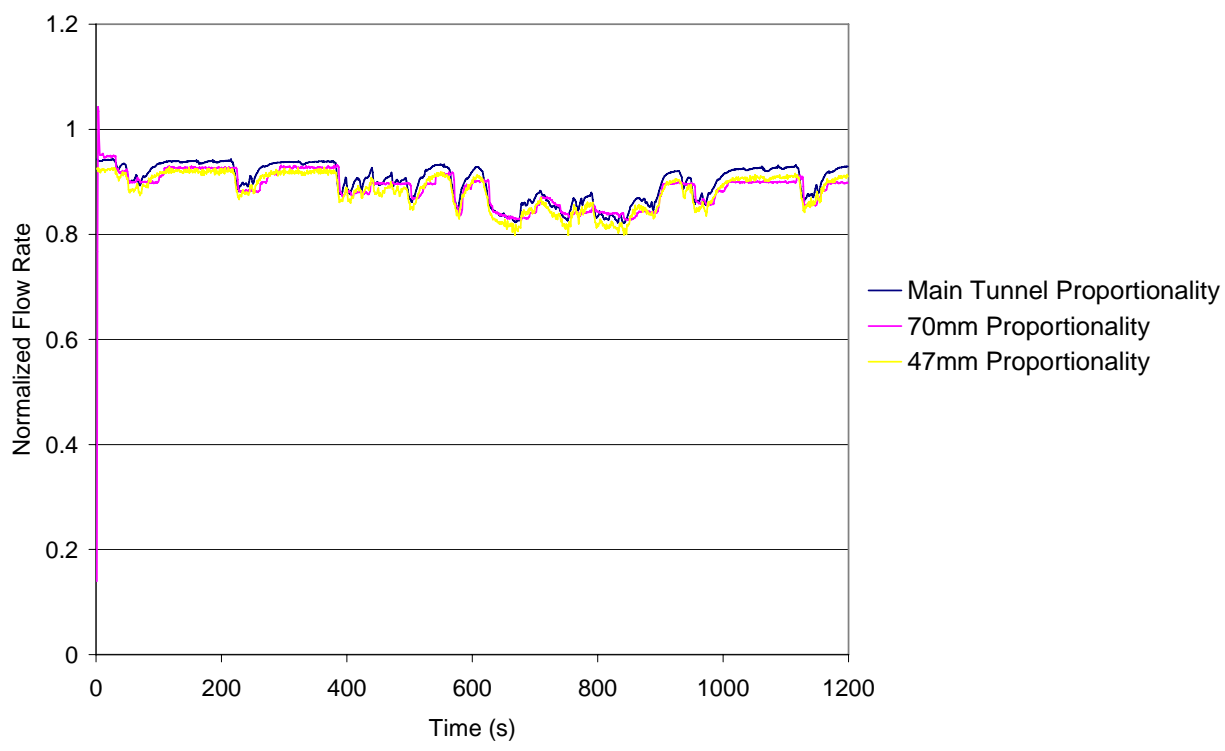

Figure 8.31 February 20, Proportionality for Tx40 Media at 1/1 SDR and $1.0 \mathrm{cfm}$ FFV 


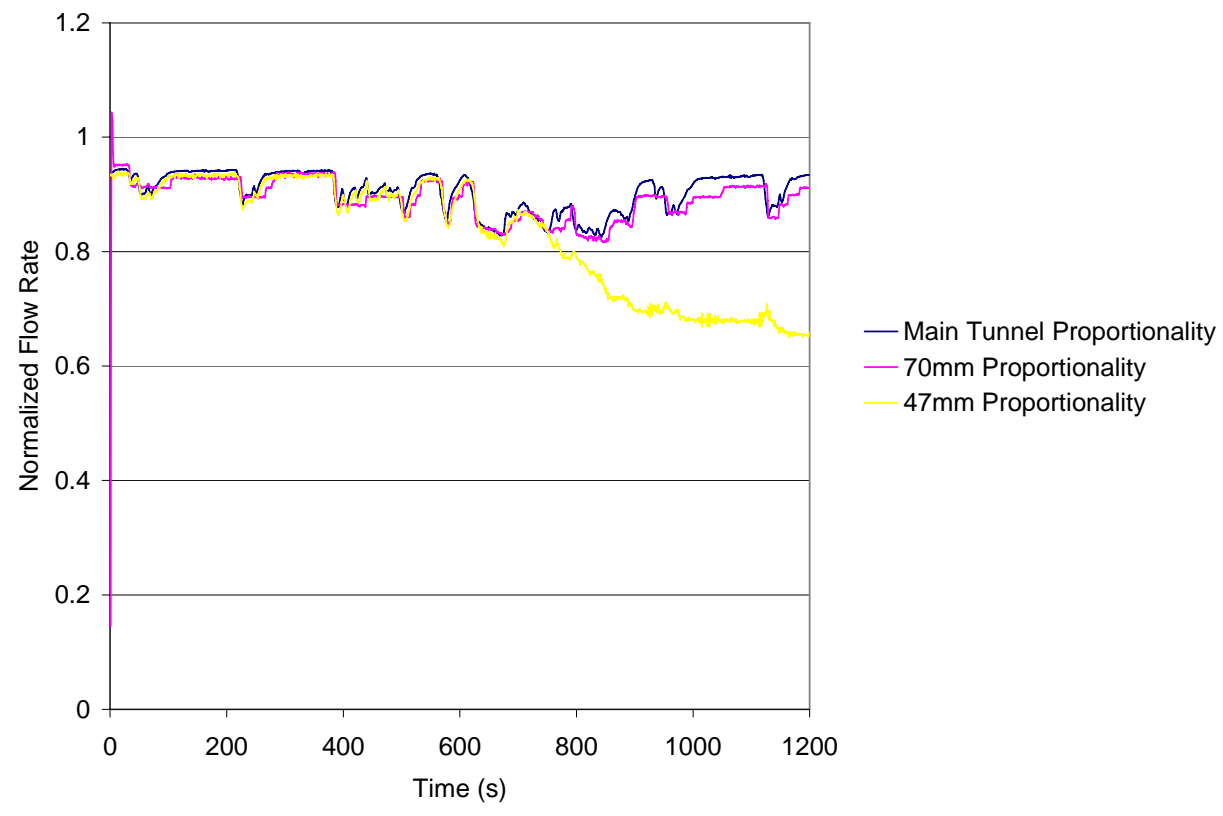

Figure 8.32 February 20, Proportionality for Tx40 Media at 1/1 SDR and $2.4 \mathrm{cfm}$ FFV

8.3.2 February 21, 2007

Table 8.14 February 21, PM Filter Mass Data

\begin{tabular}{|c|c|c|c|c|}
\hline Test Set & \multicolumn{2}{|c|}{14.1} & \multicolumn{2}{c|}{14.2} \\
\hline PM System & $47 \mathrm{~mm}$ & $47 \mathrm{~mm}$ & $70 \mathrm{~mm}$ & $70 \mathrm{~mm}$ \\
\hline Filter Media & Tx40 & T60A20 & Tx40 & T60A20 \\
\hline SDR & $2 / 1$ & - & $2 / 1$ & - \\
\hline FFV (cfm) & 1.5 & 0.705 & 1.0 & 0.705 \\
\hline HS FTP Mass 1 (g) & 1.8542 & 1.9111 & 1.6549 & 1.9662 \\
\hline HS FTP Mass 2 (g) & 2.0379 & 2.1673 & 1.6916 & 1.7684 \\
\hline HS FTP Mass 3 (g) & 1.7905 & 1.9661 & 1.7394 & 1.8161 \\
\hline Average (g) & 1.8942 & 2.0148 & 1.6953 & 1.8502 \\
\hline CV (\%) & 6.78 & 6.69 & 2.50 & 5.58 \\
\hline Difference (\%) & \multicolumn{2}{|c|}{-5.99} \\
\hline
\end{tabular}




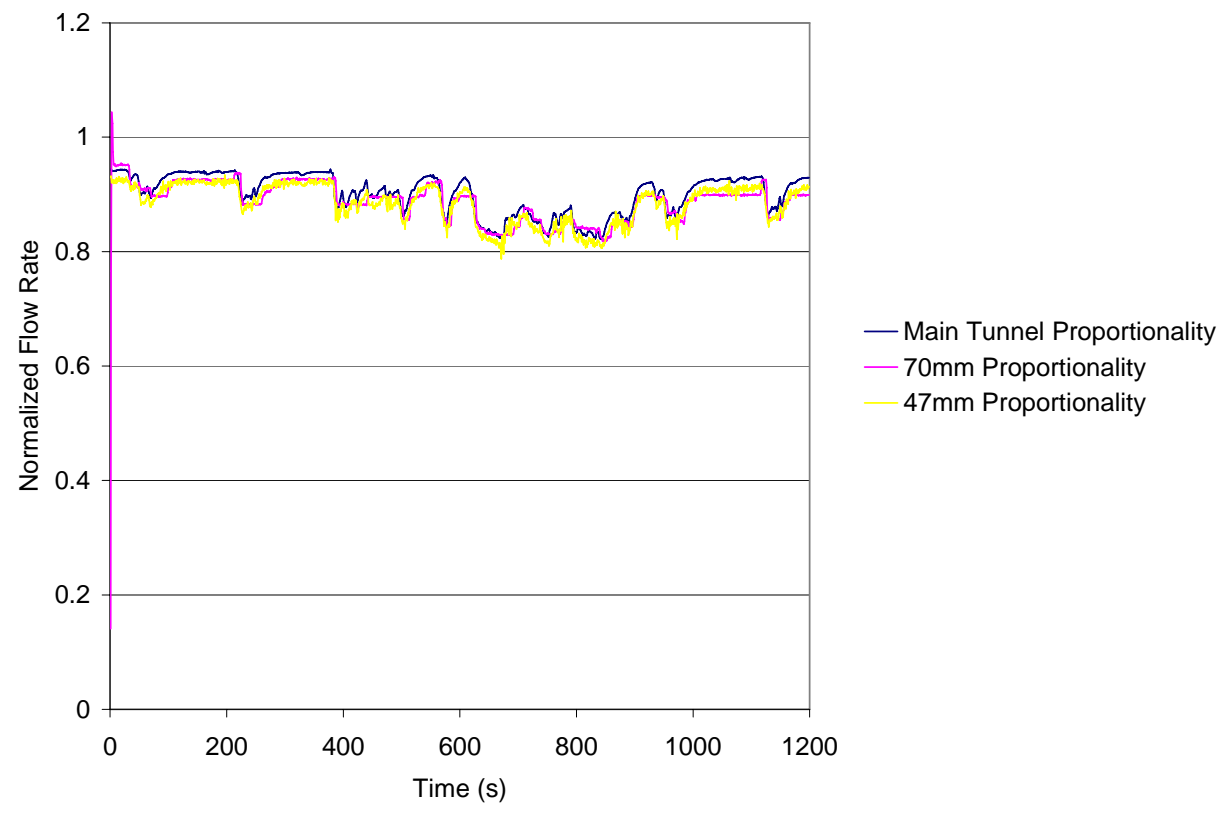

Figure 8.33 February 21, Proportionality for Tx40 Media at 2/1 SDR and 1.5m cfm FFV

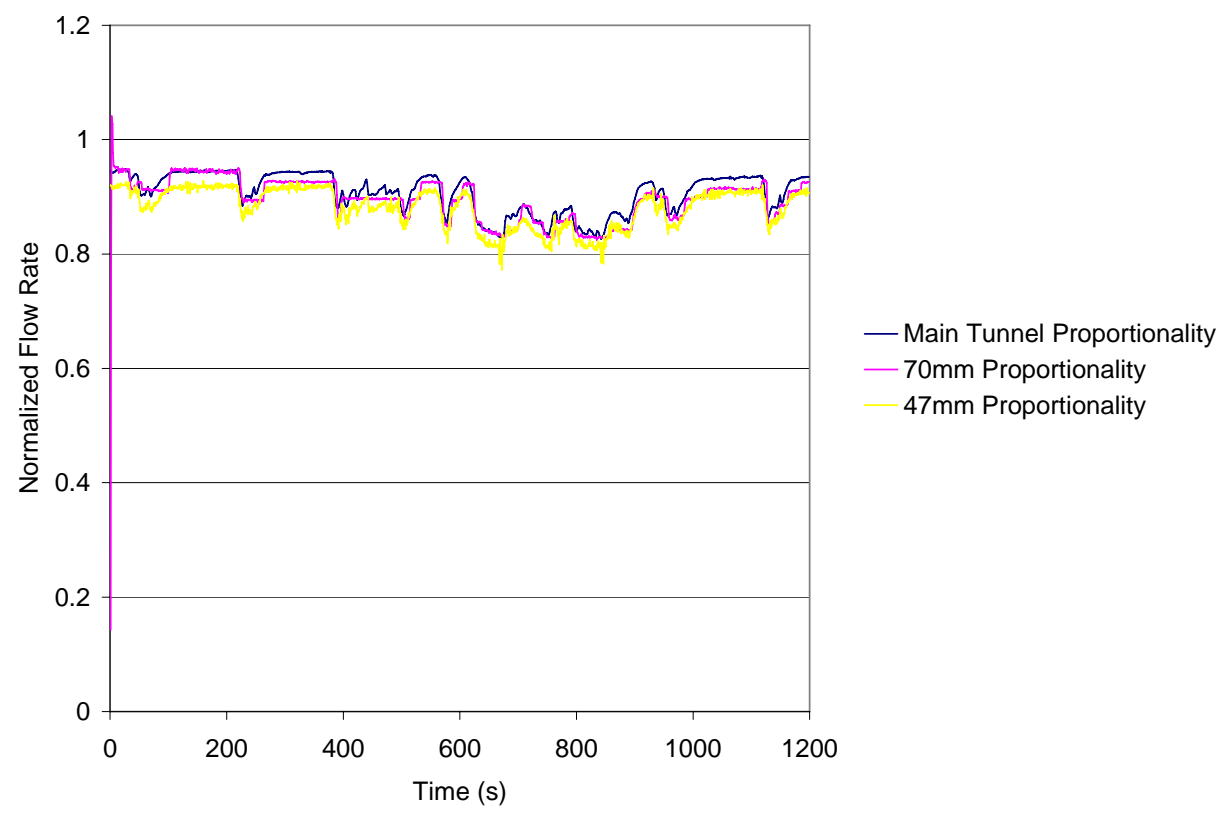

Figure 8.34 February 21, Proportionality for Tx40 Media at 2/1 SDR and $1.0 \mathrm{cfm}$ FFV 
Table 8.15 February 22, PM Filter Mass Data

\begin{tabular}{|c|c|c|}
\hline Test Set & \multicolumn{2}{|c|}{15.1} \\
\hline PM System & $47 \mathrm{~mm}$ & $47 \mathrm{~mm}$ \\
\hline Filter Media & Tx40 & T60A20 \\
\hline SDR & $2 / 1$ & - \\
\hline FFV (cfm) & 0.705 & 0.705 \\
\hline HS FTP Mass 1 (g) & 1.4706 & 1.8631 \\
\hline HS FTP Mass 2 (g) & 1.7005 & 1.8857 \\
\hline HS FTP Mass 3 (g) & 1.6641 & 1.9039 \\
\hline Average (g) & 1.6117 & 1.8842 \\
\hline CV (\%) & 7.67 & 1.08 \\
\hline Difference (\%) & \multicolumn{2}{|c|}{-14.46} \\
\hline
\end{tabular}

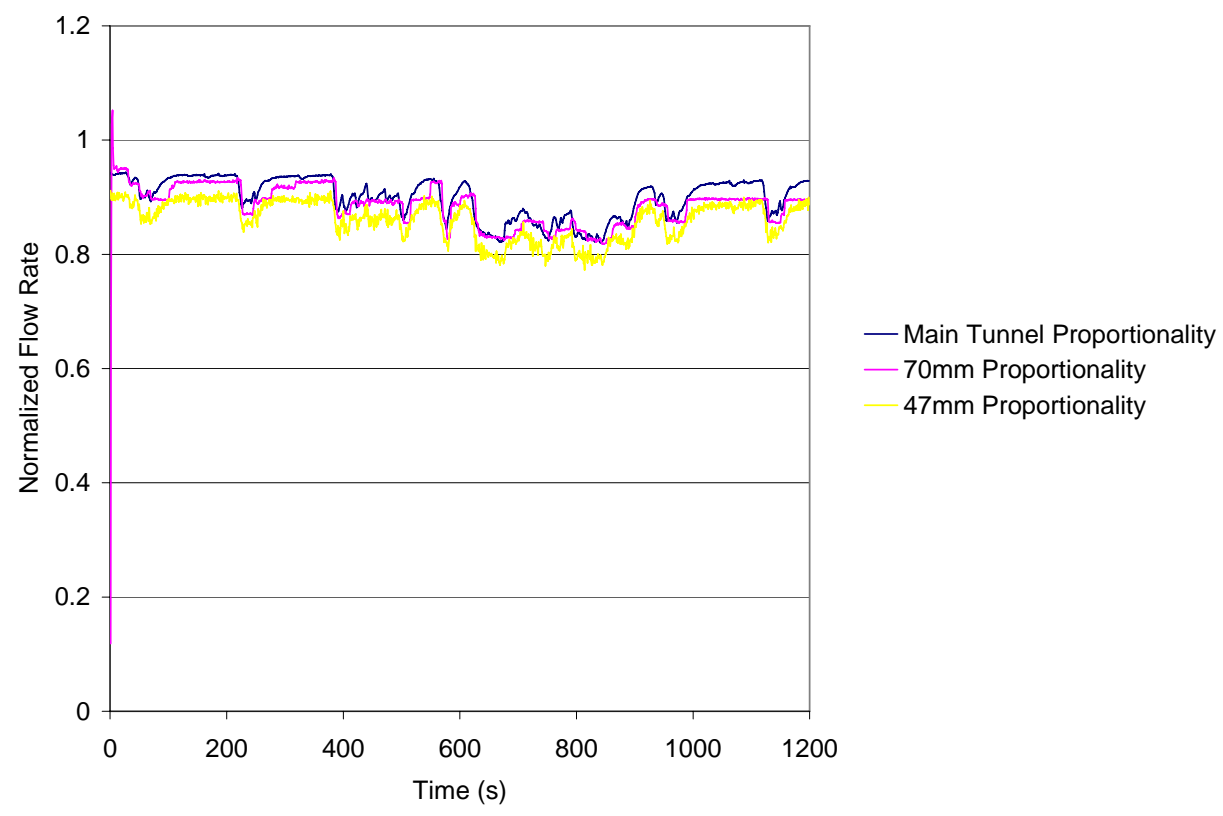

Figure 8.35 February 21, Proportionality for Tx40 Media at 2/1 SDR and $0.705 \mathrm{cfm}$ FFV 
8.3.4 February 26, 2007

Table 8.16 February 26, PM Filter Mass Data

\begin{tabular}{|c|c|c|c|c|}
\hline Test Set & \multicolumn{2}{|c|}{16.1} & \multicolumn{2}{c|}{16.2} \\
\hline PM System & $47 \mathrm{~mm}$ & $47 \mathrm{~mm}$ & $70 \mathrm{~mm}$ & $70 \mathrm{~mm}$ \\
\hline Filter Media & Tx40 & T60A20 & Tx40 & T60A20 \\
\hline SDR & $2 / 1$ & - & $10 / 1$ & - \\
\hline FFV (cfm) & 2.0 & 0.705 & 2.4 & 0.705 \\
\hline HS FTP Mass 1 (g) & 1.7619 & 1.8217 & 1.7767 & 1.7990 \\
\hline HS FTP Mass 2 (g) & 1.7856 & 1.8430 & 1.7524 & 1.8793 \\
\hline HS FTP Mass 3 (g) & 1.7680 & 1.8818 & 1.7936 & 1.9039 \\
\hline Average (g) & 1.7718 & 1.8488 & 1.7742 & 1.8607 \\
\hline CV (\%) & 0.69 & 1.65 & 1.17 & 2.95 \\
\hline Difference (\%) & \multicolumn{3}{|l}{-4.16} & \multicolumn{3}{c}{-4.65} \\
\hline
\end{tabular}

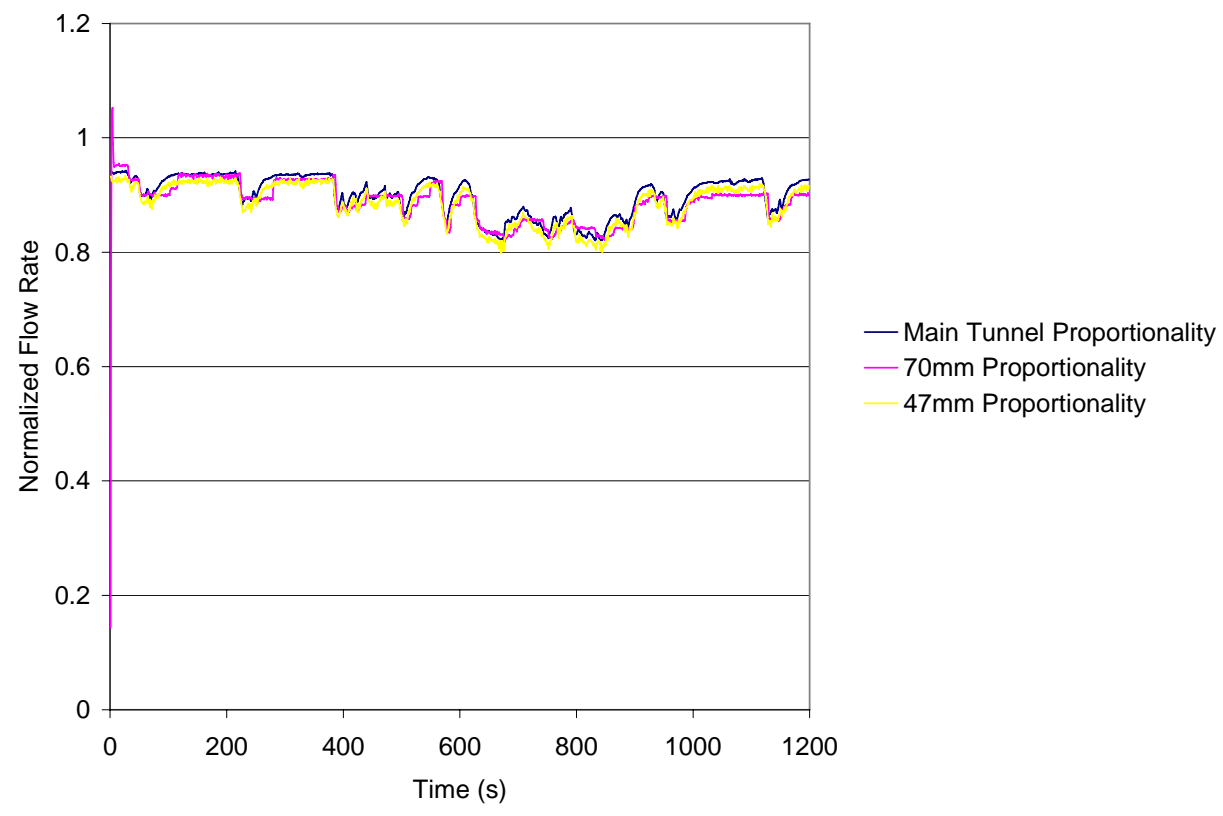

Figure 8.36 February 26, Proportionality for Tx40 Media at 2/1 SDR and $2.0 \mathrm{cfm}$ FFV 


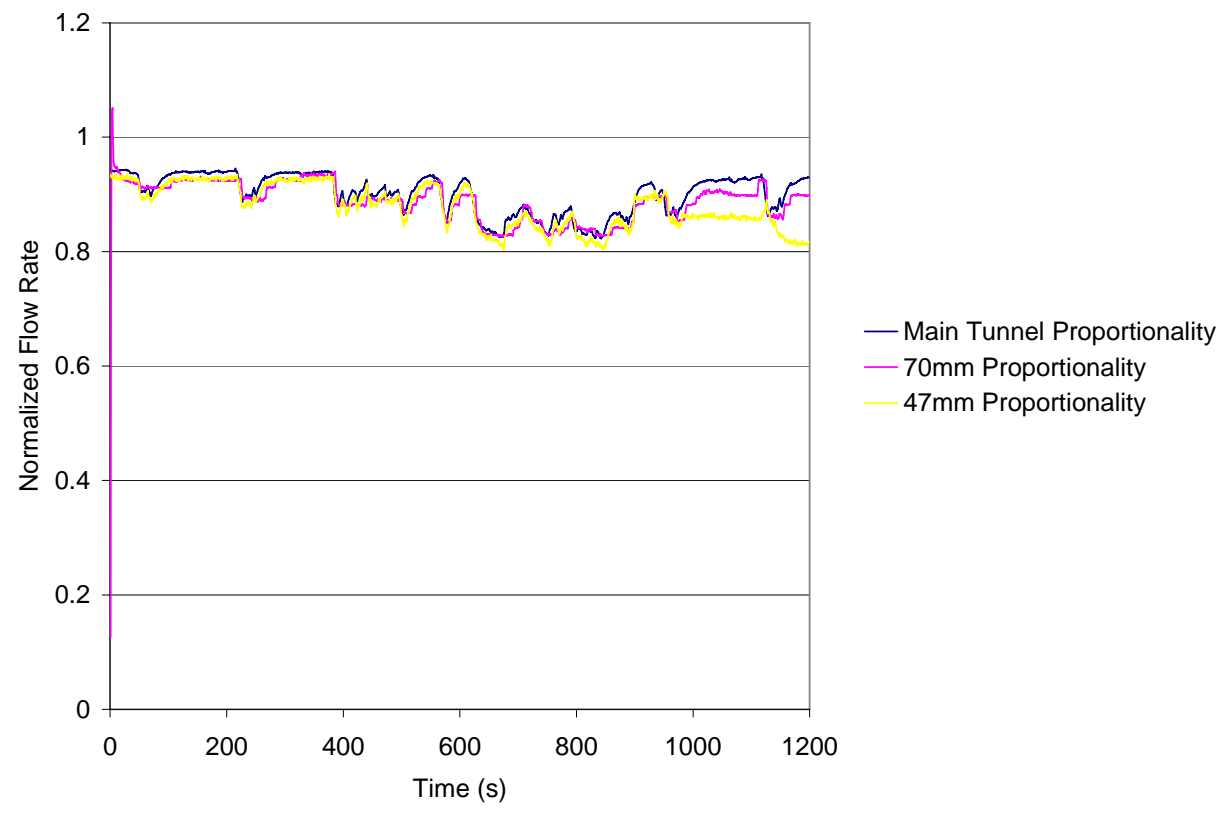

Figure 8.37 February 26, Proportionality for Tx40 Media at 10/1 SDR and $2.4 \mathrm{cfm}$ FFV

8.3.5 February 28, 2007

Table 8.17 February 28, PM Filter Mass Data

\begin{tabular}{|c|c|c|c|c|}
\hline Test Set & \multicolumn{2}{|c|}{17.1} & \multicolumn{2}{c|}{17.2} \\
\hline PM System & $47 \mathrm{~mm}$ & $47 \mathrm{~mm}$ & $70 \mathrm{~mm}$ & $70 \mathrm{~mm}$ \\
\hline Filter Media & Teflo & T60A20 & Teflo & T60A20 \\
\hline SDR & $1 / 1$ & - & $2 / 1$ & - \\
\hline FFV (cfm) & 0.705 & 0.705 & 0.705 & 0.705 \\
\hline HS FTP Mass 1 (g) & 0.9965 & 1.3867 & 1.0375 & 1.7164 \\
\hline HS FTP Mass 2 (g) & 1.0563 & 1.4832 & 0.9512 & 1.6700 \\
\hline HS FTP Mass 3 (g) & 1.0134 & 1.4541 & 1.0248 & 1.5423 \\
\hline Average (g) & 1.0220 & 1.4413 & 1.0045 & 1.6429 \\
\hline CV (\%) & 3.02 & 3.43 & 4.64 & 5.49 \\
\hline Difference (\%) & -29.09 & \multicolumn{2}{c|}{-38.86} \\
\hline
\end{tabular}




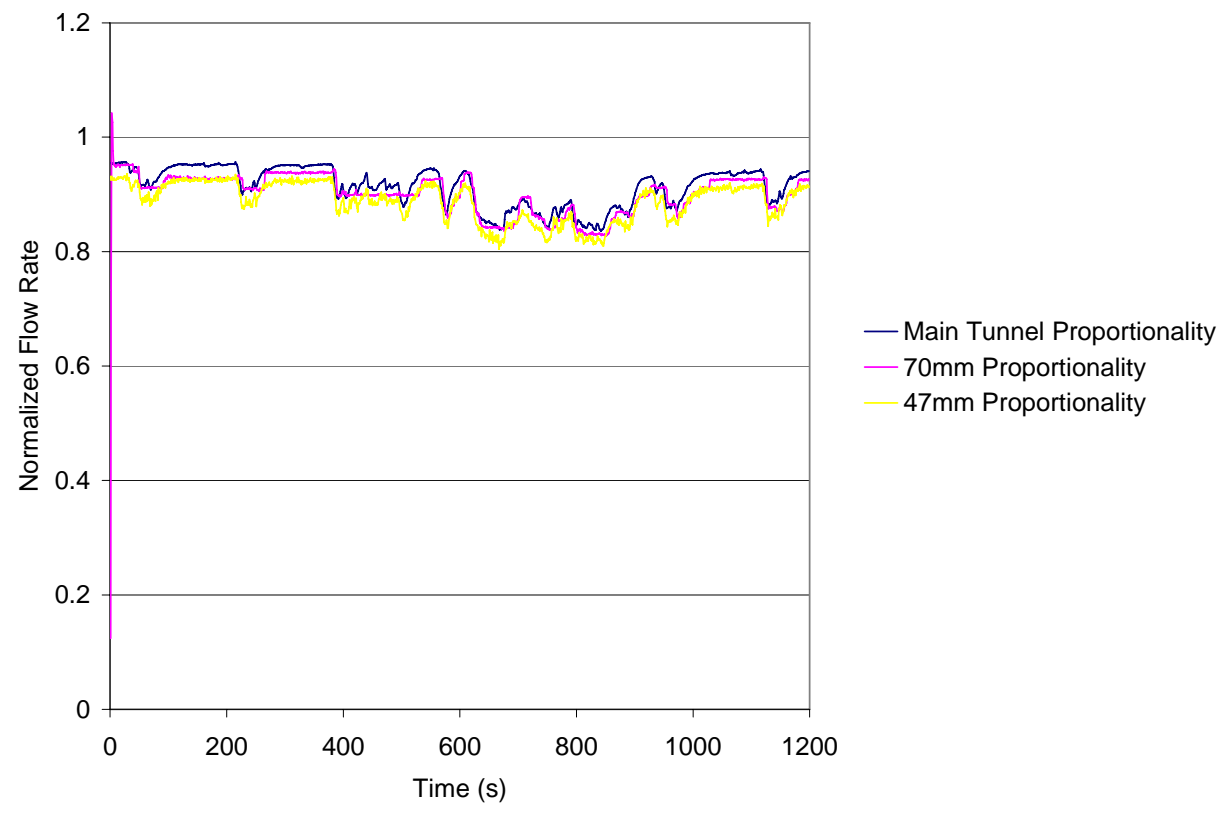

Figure 8.38 February 28, Proportionality for Teflo Media at 1/1 SDR and $0.705 \mathrm{cfm}$ FFV

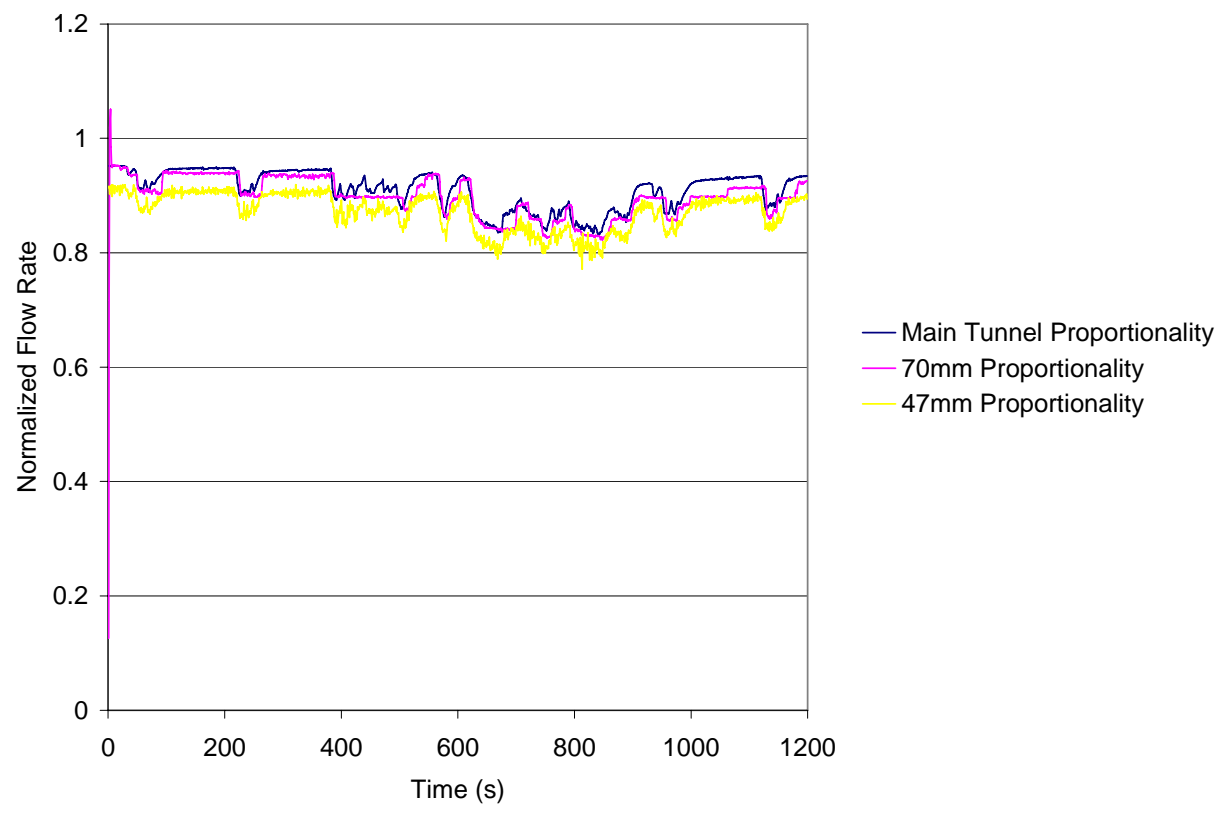

Figure 8.39 February 28, Proportionality for Teflo Media at 2/1 SDR and $0.705 \mathrm{cfm}$ FFV 


\subsection{Efficiency Testing}

Continuous particle counts from the CPC are shown for each SDR and filter media. Each continuous count shown represents an average count of three FTPs.

\subsubsection{SDR 1/1}

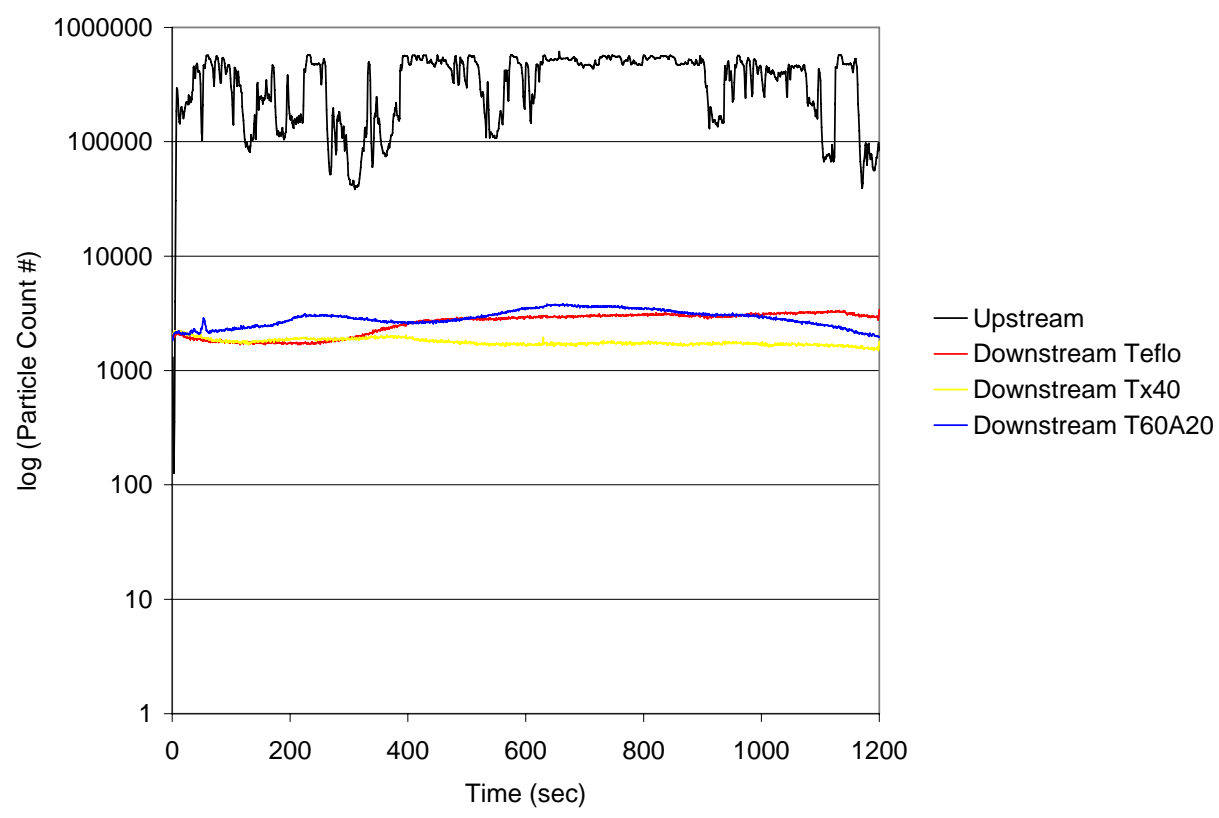

Figure 8.40 Particle Counts across Pall Filters at 1/1 SDR and $1.5 \mathrm{cfm}$ FFV 


\subsubsection{SDR 2/1}

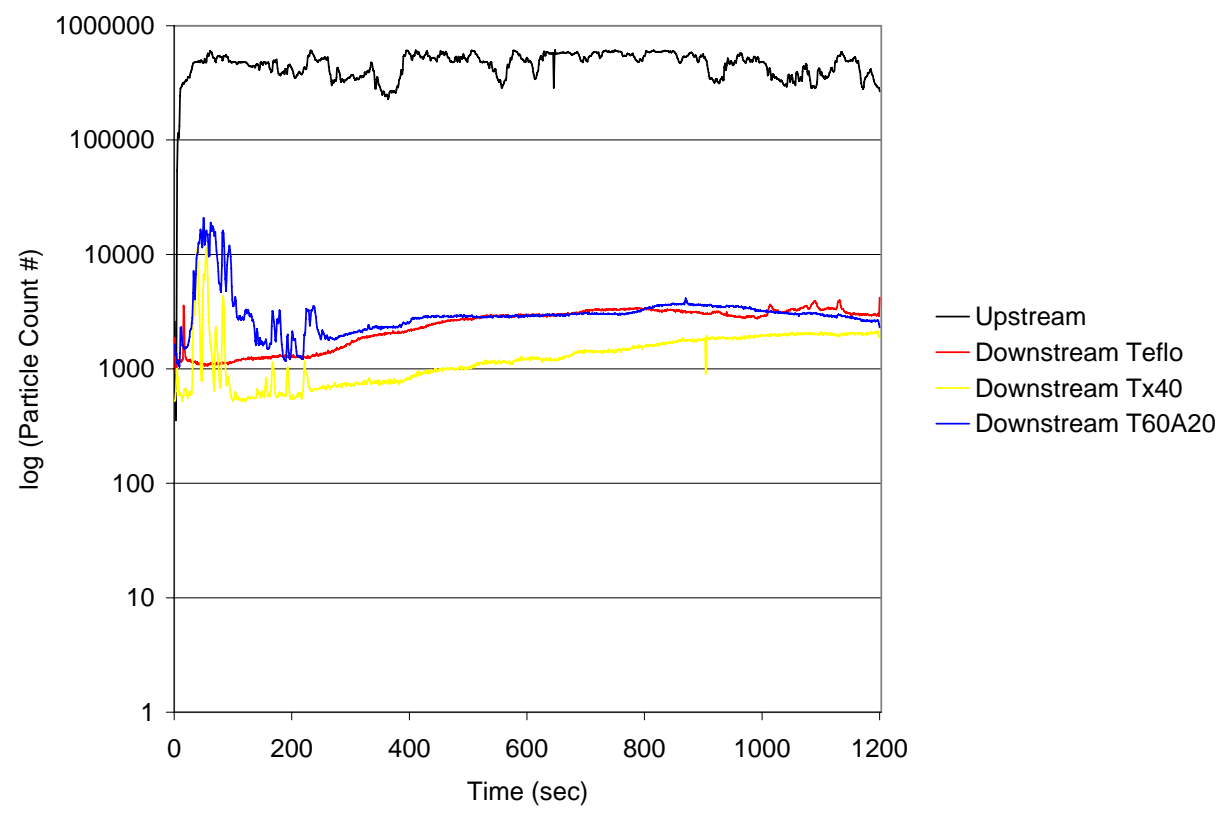

Figure 8.41 Particle Counts across Pall Filters at 2/1 SDR and $1.5 \mathrm{cfm}$ FFV

\subsubsection{SDR 10/1}

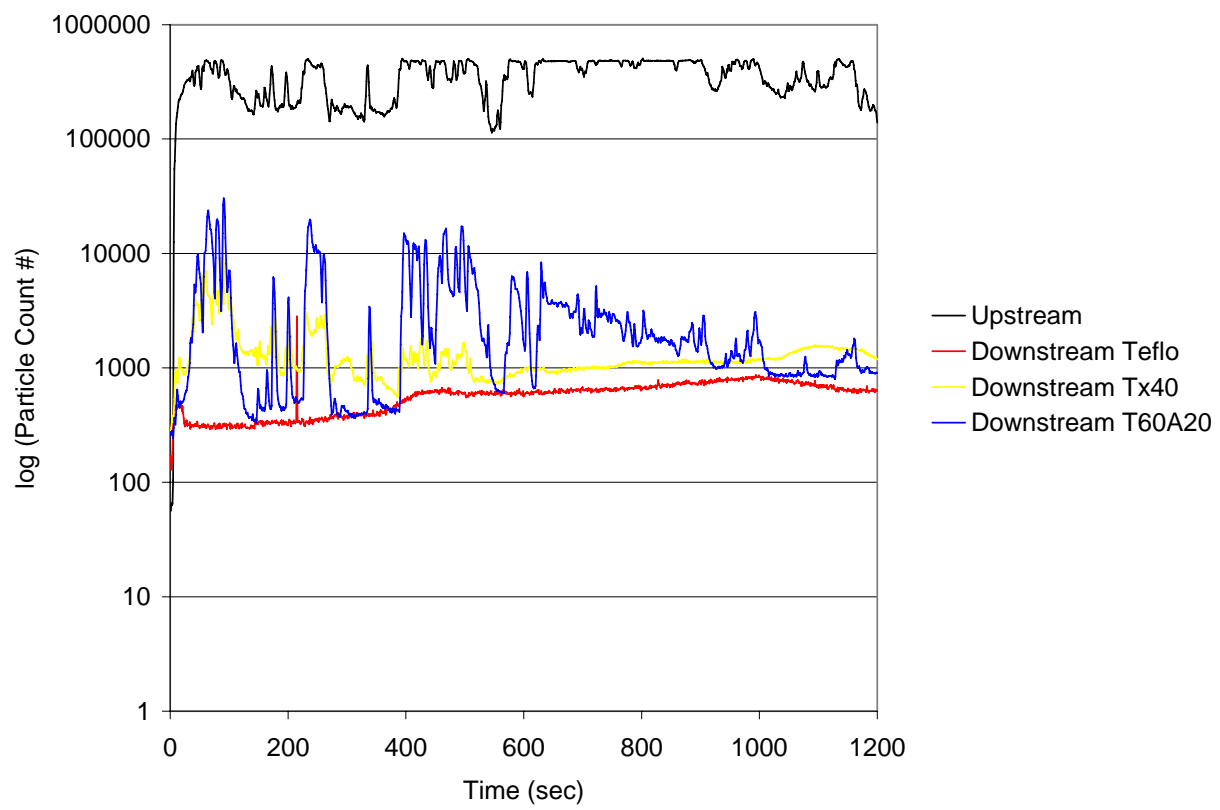

Figure 8.42 Particle Counts across Pall Filters at 10/1 SDR and 1.5 cfm FFV 


\subsection{WVU EERL Clean Room Procedures}

WVU's procedures for preparing, weighing, and recording 2007 compliant PM data is shown in great detail.

\section{TPM Filter Weighing - 2007 and Later Model Year Engines [37].}

\section{Overview}

A precision microbalance, with readability of $0.1 \mu \mathrm{g}$ and a precision of $0.25 \mu \mathrm{g}$, is used to measure filter weights. Environment, calibration and weighing information is recorded by software on the cleanroom computer. Many precautions need to be taken to prevent contamination of sample filters due to the small mass of collected PM.

\section{References}

40 CFR Parts 86.1312-2007

\section{Conditions}

Ensure that the conditions of the weighing and storage area are within the following specifications.

- Each filter must be placed in a partially open Petri dish and exposed to the conditioning environment for a minimum of 30 minutes prior to pre or post test weighing.

- Filters must be stored in covered Petri dishes or sealed filter holders in the conditioned storage area when not being pre or post test conditioned.

- Used filter pairs being conditioned for post use must be stored face-to-face in covered Petri dishes. Otherwise, single filters must be stored face up.

- If the sample on the filters contacts the Petri dish or any other surface, the associated test is void and must be re-run.

- At least two unused reference filters must be stored next to the microbalance at any given time. If the average weight of the reference filter pairs changes between sample filter measurements by more than $10 \mu \mathrm{g}$, then all the associated sample and 
background filters being stabilized are void and their respective emissions tests must be re-run.

- A filter post weight must be determined within 60 hours of the start of the stabilization period.

- Test filters must be weighed within 2 hours of reference filters but preferably during the same session.

- The reference filters should be changed once a month. A minimum of two reference filters must be associated with a test filter pre and post weight.

- The zero/tare drift of the scale must not exceed $\pm 1 \mu \mathrm{g}$ during any drift check. The zero/tare drift must be checked after weighing for 10 minutes and at the conclusion of a weighing session.

The filter weighing room must be maintained at the following conditions

- Temperature: $22^{\circ} \pm 1^{\circ} \mathrm{C}$

- Dew Point: $9.5^{\circ} \pm 1{ }^{\circ} \mathrm{C}$ where the temperature and dew point are averaged over 5 minutes intervals. If these conditions are not met the room conditions must be brought to within the above specifications and allowed to remain in that state for 30 minutes prior to performing filter weighing operations. If the room exceeds the environmental specifications, then the filters will be required to condition in the room for 30 minutes after the environmental conditions have been corrected.

\section{Procedures}

1. Ensure that balance is level.

2. Place the anti-static wristband on your wrist to minimize static charge buildup on filters.

3. Start the filter weighing software.

4. Log on to begin the weighing session.

5. Observe any discrepancies in the room conditions from those listed 
above. If problems exist, contact the laboratory supervisor.

6. Follow the weighing program prompts through the initial calibration and reference filter weighing steps.

a. Complete the onscreen instructions to complete the internal calibration and internal linearization functions.

b. The program will check that the zero/tare reading is within \pm 1 $\mu \mathrm{g}$. The program will record the zero/tare reading from the scale and will re-zero the scale if required and record the new zero value.

c. Place the reference weight onto the weighing pan and record the reading. The program will ensure that the weight will be within \pm $1 \mu \mathrm{g}$. The program will not allow the weighing process to progress if the reference weight is out of the previous specification. d. Remove the reference weight and allow the program to check that the zero/tare reading is $\pm 1 \mu \mathrm{g}$. The user will need to complete steps 6 to 7 if the zero/tare reading exceeds specifications. Contact a laboratory supervisor if, after a third attempt, the zero cannot meet the specifications.

e. Pass each side of the reference filter over the Polonium spot before placing the reference filter onto the weighing pan.

f. Measure and record the weight of the reference filter.

g. Continue to measure additional reference filter, ensure step 6e is followed for each filter.

h. After 10 minutes or at the completion of the reference filter weighing, the program will check that the zero/tare reading is within $\pm 1 \mu \mathrm{g}$. The program will record the zero/tare reading from the scale and will re-zero the scale if required and record the new zero value. If the zero/tare is outside the allowable range, the reference filters weighed between the last valid zero/tare check and invalid zero/tare check will be re-weighed.

7. Follow the weighing program prompts through the test filter weighing 
steps.

a. For post-test filter weighing, the program will check that the difference in the average change in weight of the reference filters is less than $10 \mu \mathrm{g}$ between the pre and post test weighing sessions. If the average change is greater than $10 \mu \mathrm{g}$ then all tests associated with those reference filters are invalid and must be re-run.

b. Pass each side of the sample filter over the Polonium spot before placing the sample filter onto the weighing pan.

c. Measure and record the weight of each sample filter.

d. Continue to measure additional test filter, insure step $7 \mathrm{~b}$ is followed for each filter.

e. After 10 minutes or at the completion of the filter weighing, the program will check that the zero/tare reading is within is within \pm $1 \mu \mathrm{g}$. The program will record the zero/tare reading from the scale and will re-zero the scale if required and record the new zero value. If the zero/tare is outside the allowable range, the filters weighed between the last valid zero/tare check and invalid zero/tare check will be re-weighed.

f. All filters will be reweighed to determine an average of the filter weight, in which the program will ensure that the filter weight is within $\pm 2.5 \mu \mathrm{g}$. A third weighing will be taken if the program finds that the filter is outside the $\pm 2.5 \mu \mathrm{g}$.

\section{Corrective Actions}

If the room conditions are not met, wait until the room conditions are within specifications. If the scale is unable to meet the zero, spans, or reference filter requirements, ensure that the room conditions are stable. If problems persist, contact the laboratory supervisor. 